TE WHARE WĀNANGA O TE ŪPOKO O TE IKA A MĀUI

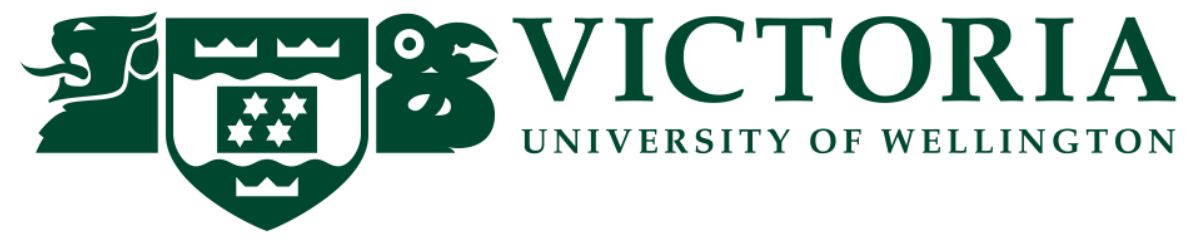

\title{
High-Resolution Water Stable Isotope Ice-Core Record: Roosevelt Island, Antarctica
}

\author{
PhD Thesis
}

\section{B. Daniel Emanuelsson}

A thesis submitted to the Victoria University of Wellington in fulfilment of the requirements of the degree of Doctor of Philosophy (Geology)

Victoria University of Wellington, 2016 



\section{Abstract}

This thesis presents a water-isotope $(\delta \mathrm{D})$ record from 1900 to 2009 for the Roosevelt Island Climate Evolution (RICE) ice core, Antarctica. Examination of the RICE isotope record with observation data (using global reanalysis and SST datasets) revealed details of the climate signal that is preserved within the full $763 \mathrm{~m}$ isotope record. RICE $\delta \mathrm{D}$ provides a proxy record, which captures the central tropical Pacific ENSO variability, the significant $(p<0.01)$ central Pacific $\delta$ D-SST correlation pattern contain the Niño-4 SST region. Central tropical Pacific ENSO variability projects upon the Amundsen Sea region via a Pacific-South American pattern (PSA)like teleconnection. RICE $\delta \mathrm{D}$ is primarily influenced by Amundsen Sea circulation, which coincides with the leading PSA pattern's (PSA1) circulation focal point in the Amundsen Sea. Additionally, RICE regional physical setting (sheltered from direct impact from Amundsen Sea cyclones by WA orography) offers a unique setting, where enriched isotopes only are associated with one PSA1 polarity (El Niño, PSA1+, Amundsen Sea anticyclones). In contrast, during La Niña and Amundsen Sea cyclones, $\delta \mathrm{D}$ is depleted. Combined these settings, provides a compelling explanation to why RICE $\delta$ D preserves PSA1 and ENSO variability. On interannual and seasonal time scales, the RICE $\delta \mathrm{D}$ variability is well-explained by the PSA teleconnections and their interactions over the Pacific sector. The influence from PSA2 on $\delta \mathrm{D}$ is strong during the beginning of the year (December-February, DJF). In contrast, the PSA1 influence is strong during the latter part of the year, peaking in spring (September-November, SON). The isotope record appears to preserve tropical Pacific El Niño-like interdecadal variability, particularly a decadal-signal from the central-Pacific (Niño-4 SST region) and from the Pacific-wide Interdecadal Pacific Oscillation (IPO). On decadal-scales RICE $\delta \mathrm{D}$ is modulated by ENSO and Southern Annular Mode (SAM); when the correlation with SAM is active (during IPO+) $\delta \mathrm{D}$ appears to be in a depleted state and when the correlation with SAM breaks down (during IPO-) $\delta \mathrm{D}$ appears to be in a relatively enriched state. A RICE $\delta \mathrm{D}$ SST proxy reconstruction can potentially provide a record longer than the currently available observational datasets, allowing for examination of intrinsic decadal-scale tropical Pacific climate variability and its extratropical impact. 


\section{Acknowledgement}

First, I would like to thank my primary supervisor Nancy Bertler (Victoria University and GNS Science), who always has been very supportive for the RICE $\mathrm{PhD}$ students and whose enthusiasm and good work ethics have been central for the success for the RICE project. I am very thankful for all the opportunities that I have got to do a variety of different interesting work, all the connections I made along the way, and for getting the chance to work with a very interesting ice core record. I am thankful for the help and great ideas I got from my co-supervisor Troy Baisden (National Isotope Center (NIC), GNS Science), while I was working on developing the water isotope CFA setup and comments on my manuscripts. Thank you Elizabeth Keller for working with me to develop a rigorous calibration code for the RICE isotope record. Other employees at NIC GNS Science who also provided invaluable help to the project are: Ed Hutchinson and Bruce Crothers who assisted with electrical work on the water isotope CFA setup. Steve Mawdesley, Grant Kellett and Ryan Davidson at the GNS workshop helped with numerous tasks and lent me their tools. Cedric Douence and Andy Philips helped by analyzing part of the discrete ice core measurements that were used in the Emanuelsson et al. [2015] publication. Silvia Canessa helped with the RICE database. Franck Ganachauad, who helped with Linux programing on the LGR analyzer. I would like to thank everybody at the Antarctic Research Center (ARC) at Victoria University of Wellington for all the support throughout my PhD project. A special thanks goes out to Warren Dickinson, Lionel Carter, Michelle Dow, Alex Pyne, Peter Barrett, and Tim Naish. Input from Vasileios Gkinis and Valerie Claymore during the development stages of the RICE isotope CFA setup were essential for the success of the project, and I am extremely thankful for their contributions. I am also grateful to Stefanie Semper for work with LabVIEW programing. Thanks also to: Manish Gupta and Robert Provencal at LGR; Paul Vallelonga and Bo Vinther for providing isotope data for the 1974/75 Danish ice core from the Roosevelt Island summit; to Andy Schauer for providing the ITASE water standard; and to Harmonie Akers.

I am also grateful to all the international collaborators who contributed to the success of the RICE field and lab processing campaigns. Thanks to everybody that I worked with during the RICE ice core processing and field campaigns. Darcy Mandeno, Howard Conway, Sepp Kipfstuhl, Paul Vallelonga, Ross Edwards, Thomas Beers, Skyler Haines, Hedley Berge, 
Rebecca Pyne and Stefanie Semper. Thanks also to fellow RICE PhD students and office mates Peter Neff and Andrea Tuohy who have been great to work with and good company both in New Zealand and during field work in Antarctica. After I realized the key role that blocking plays for RICE isotope signal, it came to my attention that one of the well renowned scientists who's name kept showing up in the literature that I was reading, James Renwick, was working from the same building. I managed to convince James to work with me and I have learned a great deal about Southern Hemisphere climate from him. I am also extremely grateful to Bradley Markle for constructive feedback on manuscripts and for input on MATLAB coding. Thanks to Ian Goodwin and Eric Steig, with whom I had early discussions that greatly benefited the project. I would like to thank Eric Steig and his team at University of Washington for giving me the opportunity to work with them for three months during the spring of 2014. I also like to thank my family for being supportive. Finally, I like to express my deep appreciation to my external examiners Nerilie Abram (Australian National University) and Adrian McDonald (University of Canterbury). Their critiques and comments have greatly improved the thesis.

This work was supported by the New Zealand Government through GNS Science (Global Change through Time Programme, GNS-540GCT12 and GNS-540GCT32) and Victoria University of Wellington (RDF-VUW-1103). This work is a contribution to the Roosevelt Island Climate Evolution (RICE) Program, funded by national contributions from New Zealand, Australia, Denmark, Germany, Italy, the People's Republic of China, Sweden, United Kingdom, and the United States of America. The main logistic support was provided by Antarctica New Zealand (K049) and the US Antarctic Program.

\section{Foreword}

This section outlines my work and contribution to the success of the RICE project.

\section{Field work}

I was part of the RICE team that went to Roosevelt Island during the 2011/12 and 2012/13 field seasons. During my first season at RICE, we dug out the drill trench, set up the camp infrastructure and ice core drill, and drilled the top $130 \mathrm{~m}$ of the core. During 2011/12 season field seasons, I assisted in drilling several firn cores using a hand-auger drill and dug out a snow 
pit. I also collected daily snow samples during both seasons. During my second season (2012/13) most of the $763 \mathrm{~m}$ core was drilled (130-763 m) in just a little over a month. I worked as part of a four-man crew during the "night shift." My main duty was as a core-handler during this shift, but I also assisted with the ice core drilling.

\section{CFA development}

After the 2011/12 field season, the first pending goal of my $\mathrm{PhD}$ was to develop CFA setup to facilitate water stable isotopic measurements on the RICE core. I led this effort under supervision of Troy Baisden. The modifications that I made to a commercially-available water standard evaporation unit (the WVISS from LGR) to enable continuous sample introduction from an ice core melt stream is described in Emanuelsson et al. [2015]. The 2013 setup that I built was part of the 2013 ice core processing campaign, when the upper $500 \mathrm{~m}$ of the RICE ice core was processed. Prior to the 2013 RICE ice core processing campaign, I also worked with staff at GNS Science to get accurate ice core depth registration, order equipment, automate the isotope calibration process between core stacks (using LabVIEW and multi-port valves), put in a filtered dry air line to the ice core lab, and to automatically backup data and time sync the LGR analyzer. Additional work included preparing and determining the values for the in-house water standards and analyzing discrete isotope samples from water standards and RICE ice core sections. I also organized for the LGR analyzer to be shipped to California to add the $\mathrm{H}_{2} \mathrm{O}^{17}$ measurement capability.

\section{Ice core processing}

I was part of the first two RICE ice core CFA processing campaigns (2012 and 2013), both lasting for two months. During the 2013 ice core processing campaign I led the "night shift", one of two 12-hour processing shifts. During this shift, we measured water isotopes, black carbon, methane, $\mathrm{pH}$ and dust continuously and collected discrete measurements for IC and ICP-MS for later analysis. The isotope CFA data from 0 to $500 \mathrm{~m}$ of the RICE core was measured using the custom isotope setup, and the isotope record was either measured by me or under my direct supervision. This is a major achievement, as the isotope record is one of the fundamental data sets from the RICE ice core. I also assisted during 2014 processing campaign by setting up the isotope CFA equipment and by helping with problem solving throughout the campaign. 


\section{Data processing}

I worked closely with Elizabeth Keller and Troy Baisden to generate a semi-automatic MATLAB code for importing, depth register and calibrate the isotope CFA data. The RICE isotope CFA calibration process is described and evaluated in Emanuelsson et al. [2015]. Elizabeth Keller has since improved the coding and developed a GUI-based import and calibration script to handle the isotope CFA-data.

RICE age scale

The updated age scale (v.1.1 March 2015) for the top $40 \mathrm{~m}$ of the RICE core was mainly an effort conducted by the author, (with QA/QC steps by Nancy Bertler, Peter Neff and Andrea Touhy), while the earlier version was a collaborative effort. With the main difference that in the updated version non-sea-salt sulfate $\left(\mathrm{nssSO}_{4}\right)$ was used as the primary age layer identifier.

\section{Data analysis using reanalysis datasets}

I developed MATLAB code to determine mean frequencies of anticyclonic events and PPA (persistent positive anomalies) events congregant with precipitation for WA ice core sites. With the specific aim to establish, dynamical conditions associated with snowfall for WA sites, to investigate potential precipitation prevalence for climate polarity phases and thus preservation of climate signals.

\section{Conference presentations}

Emanuelsson B. D., N. A. N. Bertler, W. T. Baisden, and E. D. Keller. A 100-year Reconstruction of Regional Sea Ice Extent in the Ross and Amundsen-Bellingshausen Seas as Derived from the RICE Ice Core, Coastal West Antarctica. (Poster) American Geophysical Union Fall 2014 Meeting, San Francisco, USA, December 15-19, 2014.

Emanuelsson B. D., N. A. N. Bertler, W. T. Baisden, and E. D. Keller. Interpretation of a 2,000 year, high resolution stable isotope record from the RICE ice core Roosevelt Island, Antarctica. (Talk) Scientific Committee on Antarctic Research 2014 Open Science Conference, Auckland, NZ, August 25-28, 2014. 


\section{Table of Contents}

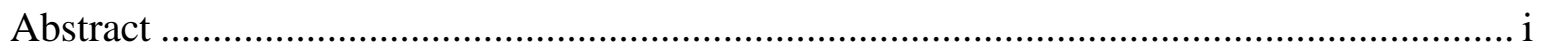

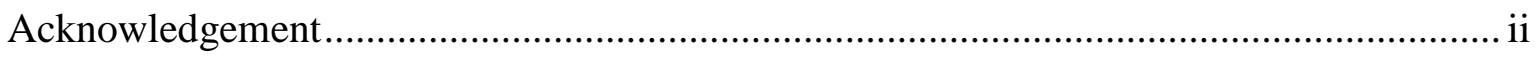

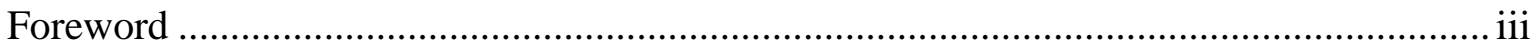

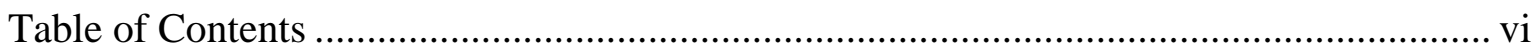

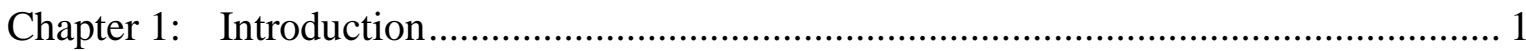

1.1 Roosevelt Island Climate Evolution (RICE) Ice Core Site ....................................... 3

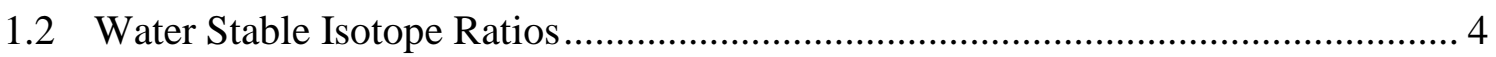

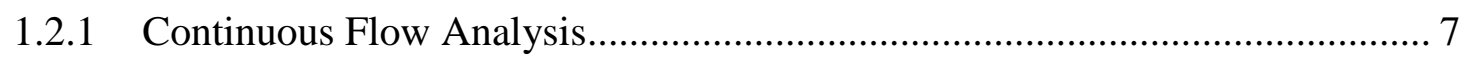

1.3 Large-Scale Atmospheric Circulation................................................................ 9

1.4 Relationship between RICE $\delta \mathrm{D}$ and Surface Air Temperatures ............................. 17

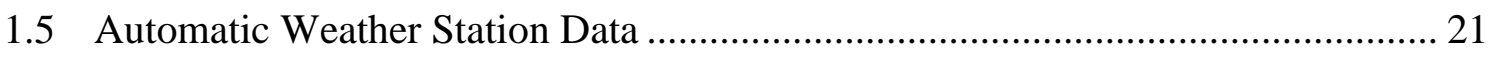

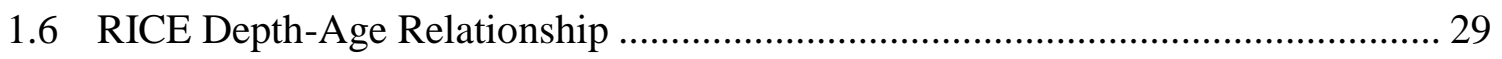

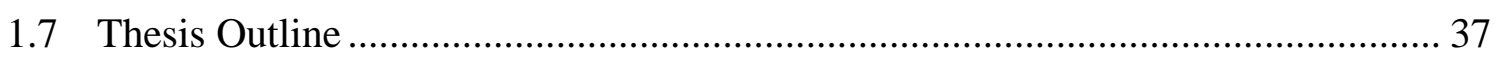

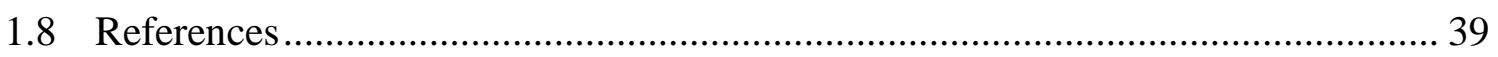

Chapter 2: High-Resolution Continuous Flow Analysis Setup for Water Isotopic Measurement from Ice Cores using Laser Spectroscopy ............................................................ 51

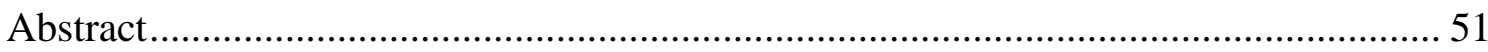

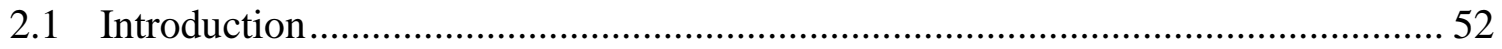

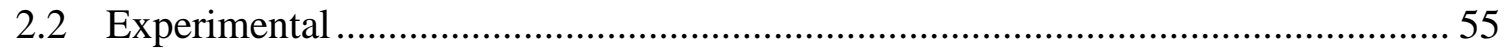

2.2.1 Isotope Water Analyzer (IWA-35EP)/Triple Isotope Water Analyzer (TIWA45EP) Laser Spectroscopy System .................................................................................. 55

2.2.2 Evaporation/Vapor Introduction Systems ………….................................... 56

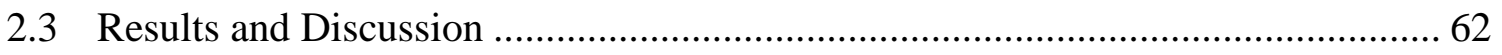

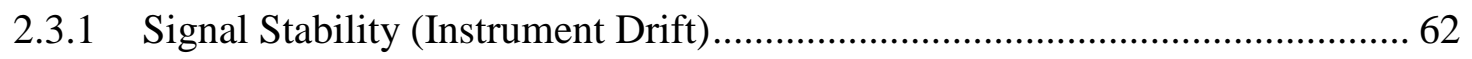

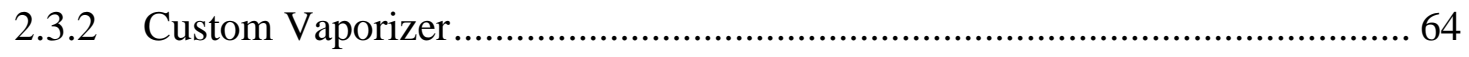

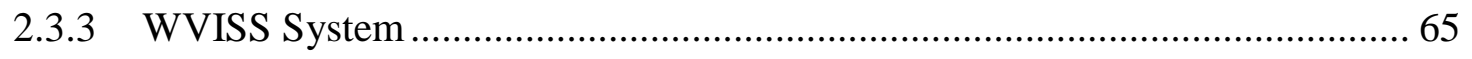

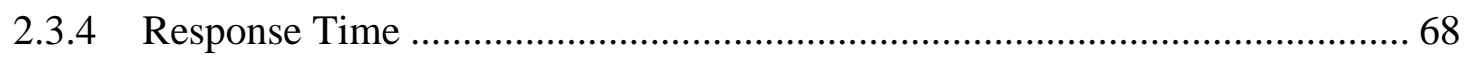

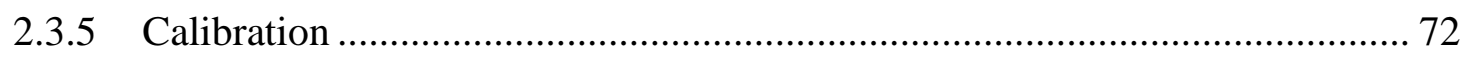

2.3.6 Long-Term Precision and Accuracy ........................................................... 76

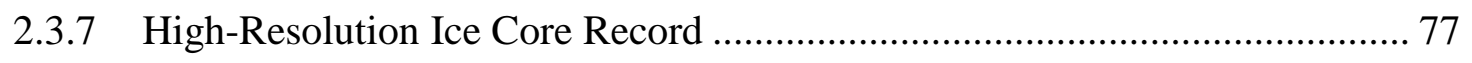

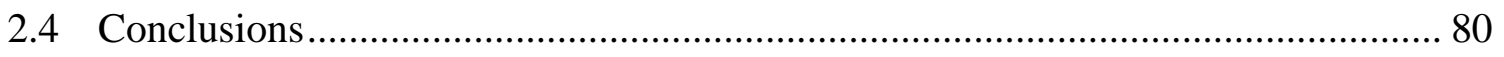

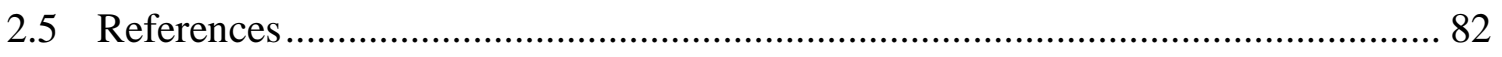

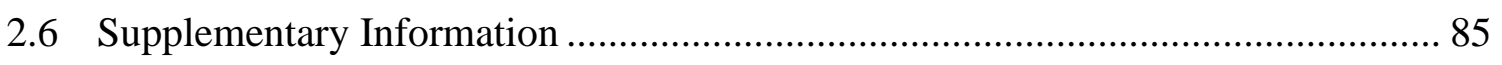


Chapter 3: The role of the Amundsen-Bellingshausen Sea anticyclonic circulation for

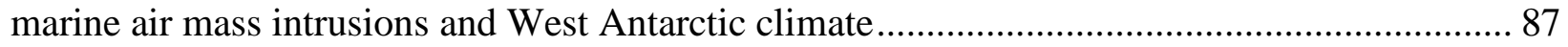

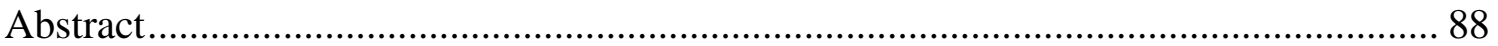

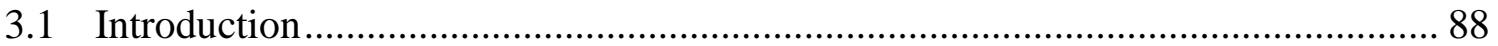

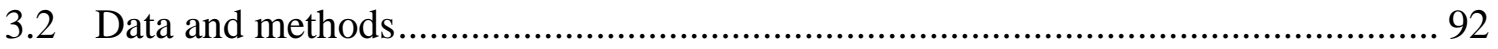

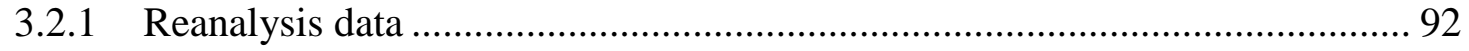

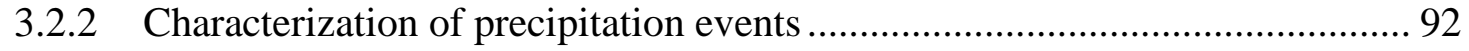

3.2.3 Characterization of ABS anticyclonic and cyclone events.......................... 93

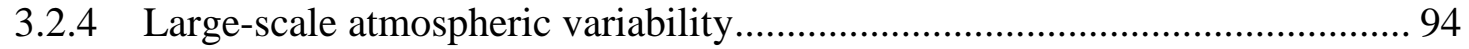

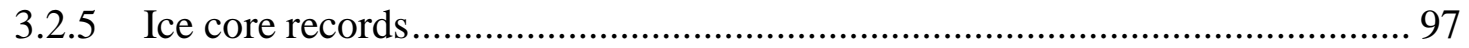

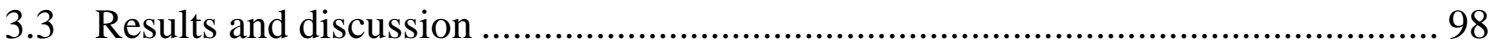

3.3.1 The ASL and anticyclonic events influence on RICE ................................ 99

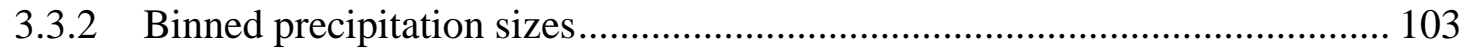

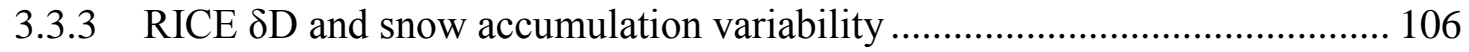

3.3.4 Low-frequency anticyclonic and cyclonic events influence on West Antarctica 107

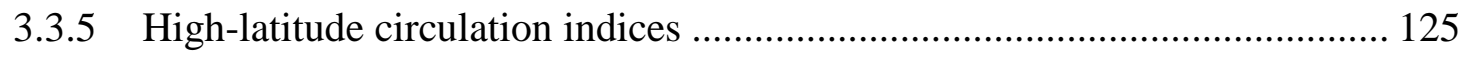

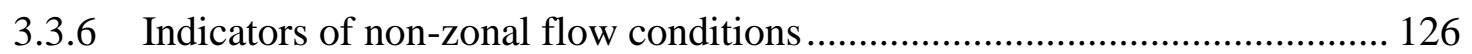

3.3.7 SH trends in high-latitude anticyclone occurrences ............................... 128

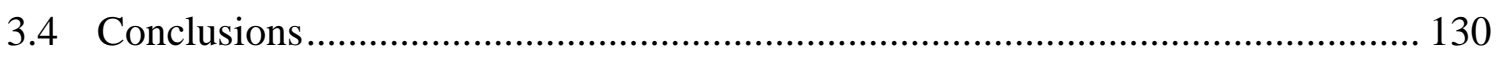

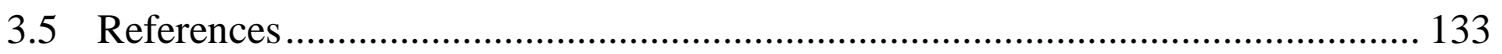

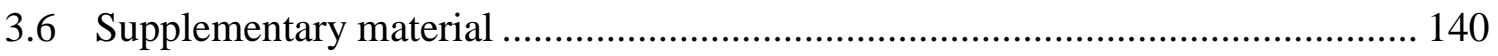

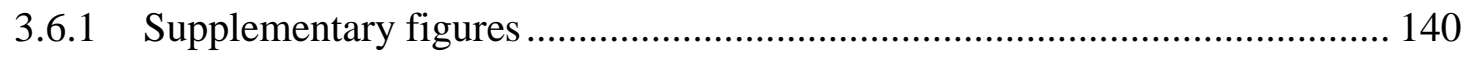

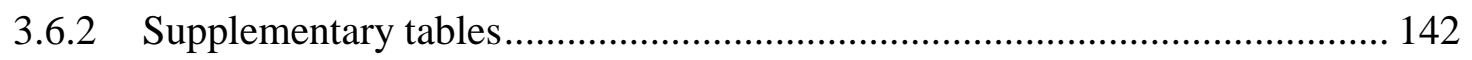

Chapter 4: Central tropical Pacific ENSO variability preserved in water stable isotopes from the Roosevelt Island Climate Evolution (RICE) ice core, Antarctica............................ 143

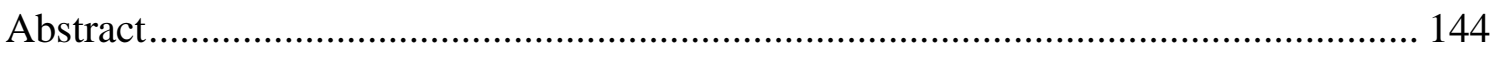

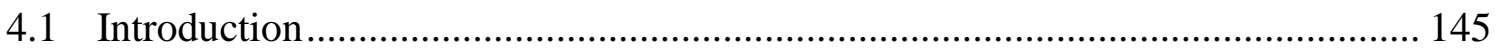

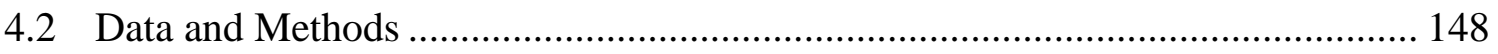

4.2.1 Reanalysis and Observational Data ....................................................... 148

4.2.2 RICE Accumulation Record ........................................................... 149

4.2.3 RICE Water Stable Isotope Record ......................................................... 150

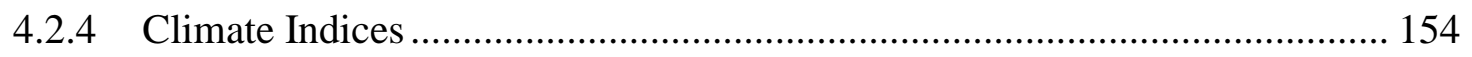

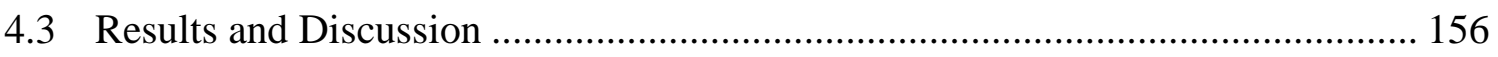

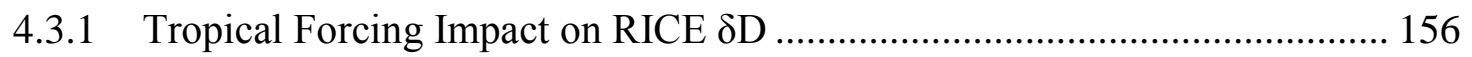




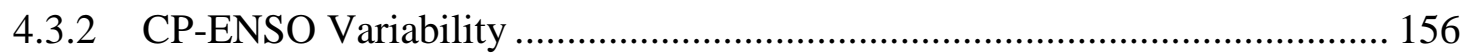

4.3.3 Drivers of Marine Air Mass Intrusions into RICE ....................................... 162

4.3.4 Influence from the Southern Annular Mode................................................ 163

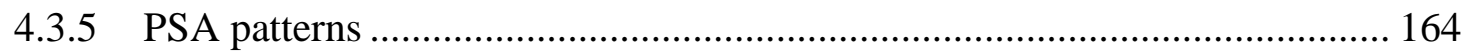

4.3.6 West Antarctic Ice Cores ........................................................................... 168

4.3.7 Seasonality of SH Extratropical Teleconnections ......................................... 170

4.3.8 Pacific Decadal-Scale Variability............................................................. 183

4.3.9 Modern RICE Snow Accumulation and 8D Trends ..................................... 193

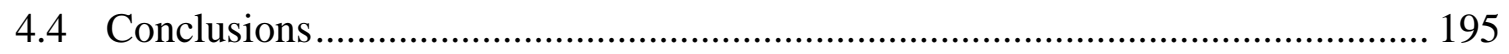

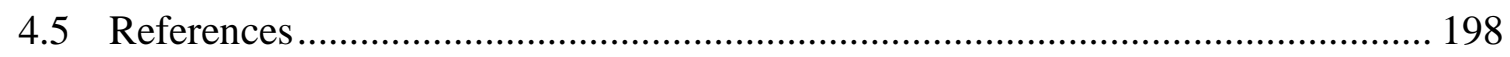

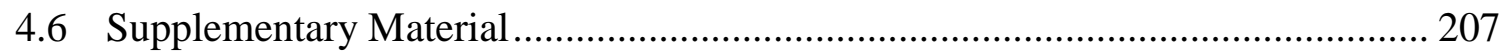

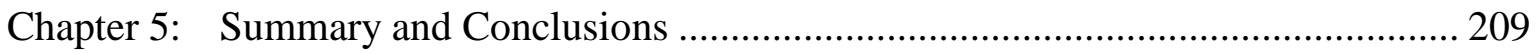

5.1.1 Continuous-Flow Analysis Water Stable Isotope Setup............................... 209

5.1.2 The Role of Anticyclonic Activity for WA Air Mass Intrusions .................. 210

5.1.3 Tropical Pacific Forcings Impact on RICE Isotopic Signature ..................... 210

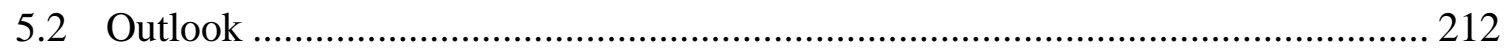

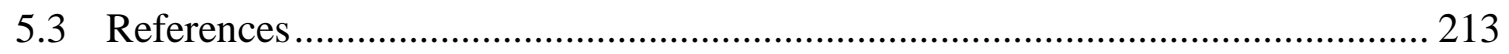




\section{Chapter 1: Introduction}

The longest semi-continuous WA temperature record is from Byrd Station in the interior of WA, reaching back to 1957 [Bromwich et al., 2013]. More recently, additional weather station data have become available, in particular from coastal regions (University of Wisconsin Madison, AMRC [Lazzara et al., 2012]). Since 1979, satellite data provide high spatial and temporal coverage, which are processed along with in-situ metrological data in reanalysis datasets to provide global gridded data sets of metrological parameters. Examples of readily available reanalysis products are the ERA-Interim Re-Analysis data sets from European Centre for Medium-Range Weather Forecasts (ECMWF, [Dee et al., 2011]) and the National Centers for Environmental Prediction/National Center for Atmospheric Research (NCEP/NCAR) data sets [Kanamitsu et al., 2002]. Numerous studies have employed reanalysis datasets in combination with station observational data for studying the variability of SH high-latitude atmospheric circulation and its impact on WA surface climate [e.g., Thomas and Bracegirdle, 2009; Ding et al., 2011, 2012; Marshall and Thompson, 2016].

In this study, we use the Interim Re-Analysis (ERA-Interim; [Dee et al., 2011]) datasets from the ECMWF. The ERA-Interim datasets are chosen because it provide the most reliable reanalysis product for high SH latitudes [Bracegirdle and Marshall, 2012; Bracegirdle, 2013; Jones et al., 2016]. The ERA-Interim datasets are superior in capturing SH high-latitude circulation features and are consistent with research station-based climate indices [Bracegirdle and Marshall, 2012; Bracegirdle, 2013]. However, it must be stressed that the reanalysis datasets are still short records (36-years) and SH climate is associated with large variability, which acts at different time scales [Schneider et al., 2011; Okumura et al., 2012]. Therefore, it is important to not base our understanding solely on these relatively short datasets. For example, the reliable reanalysis data (post 1979) only span one full Pacific Decadal Oscillation (PDO)-cycle [England et al., 2014; Trenberth et al., 2014; Schneider et al., 2015]. To provide natural baselines, assess trends, and understand and predict low-frequency variability, proxy records provide the sole information of high-latitude SH environmental conditions prior to 1950 s [Schneider and Noone, 2007; Mulvaney et al., 2012; Okumura et al., 2012; Schneider et al., 2012; Steig et al., 2013; Thomas et al., 2013]. It is increasingly important to ascertain reliable long (thousands of years) past proxy records; to identify and separate the roles of intrinsic from anthropogenically-induced 
variability, to understand the nature of the low-frequency variability of the tropical Pacific forcings effect on high-latitudes, and to constrain general circulation models (GCMs)

projections. In particular, WA ice cores provide records with high-temporal resolution because of high accumulation rates. WA cores and coastal East Antarctic cores have been able to provide valuable high-resolution records, which have been used to extend the short Antarctic observational records [e.g., Schneider and Noone, 2007; Sinclair et al., 2012] and to create proxy based climate indices [e.g., Kreutz et al., 2000; Abram et al., 2014]. In contrast, East Antarctic plateau sites are characterized by low snow accumulation [Bromwich, 1988], and by comparison, therefore lower temporal resolution. However, due to the thickness of the East Antarctic Ice Sheet (at places $>4,000 \mathrm{~m}$ thick) and the low precipitation rate, records from the East Antarctic plateau provides climate archives that go farther back in time. For example, records from the Dome C drill site in Eastern Antarctic cover the past 800,000 years [EPICA Community Members, 2004].

The overarching motivation behind this study are as follows:

\section{- Experimental Design}

○ To modify a commercially-available laser spectroscopy instrument to facilitate high-resolution water stable isotope measurements and to seamlessly integrate the customized setup with other on-line analytical instruments during a major ice core processing campaign.

\section{- The role of anticyclones and cyclones at SH high-latitudes}

○ Establish high-latitude anticyclone indices to assess, anticyclones role in controlling non-zonal transport, and thus its dynamical role for WA surface climate and subsequent precipitation.

- Assess why ENSO and SAM-variability only is well preserved in water stable isotopes and precipitation for certain WA region.

\section{- RICE water stable isotope record}

○ Determine global drivers and regional high-latitude influences for the RICE isotope record. Assess whether ENSO and decadal-scale tropical Pacific variability is preserved in the isotope records. Global reanalysis and SST 
datasets and climate indices for ENSO, PDO, SAM, and the PSA patterns are employed to address these questions.

- Assess the effect of seasonality on the RICE isotope records by examining the influence from tropical SST anomalies and the strength of teleconnections during different seasons.

\subsection{Roosevelt Island Climate Evolution (RICE) Ice Core Site}

This research is part of the RICE project. A $763 \mathrm{~m}$ ice core was drilled to bedrock at Roosevelt Island, Antarctica over two field seasons (2011/12 and 2012/13). Roosevelt Island, an independent ice rise, located at the north-eastern margin of the Ross Ice Shelf (Figure 1.1). At the RICE drill site $\left(79.36^{\circ} \mathrm{S}, 161.70^{\circ} \mathrm{W}, 560 \mathrm{~m}\right.$ a.s.1.), the ice is grounded $200 \mathrm{~m}$ below sea level with the Ross Ice Shelf ice flowing around the rise [Conway, 1999]. A "Raymond Bump" [Raymond, 1983; Nereson and Waddington, 2002] is observed under the divide of the ice rise, suggestive of a stable position of the ice divide. The ice cores described in this study were retrieved within close proximity $1 \mathrm{~km}$ distance of the topographic and Raymond bump divide. The RICE ice core was drilled with the Victoria University of Wellington intermediate depth ice core drill. The design of this drill is based on the Danish Hans Tausen drill, with a hydraulically extendable tower addition to facilitate gentle core breaks [Darcy Mandeno personal communication]. The top $130 \mathrm{~m}$ of the ice core was drilled in a dry hole during the 2011/12 austral summer field season. The majority of the core (130 to $763 \mathrm{~m}$ ) was drilled during the 2012/13 field season. An Estisol/Coasol drill fluid mix was used during the 2012/13 season to remove ice cuttings from the borehole and to keep the hole open.

In addition to the RICE deep core, a number of shallow firn cores and snow pits were also collected (firn cores: 10/11 A, 10/11 B, 11/12 A, 12/13 B, 10/11 4 m snow pit [Cohen, 2013], 11/12 $3 \mathrm{~m}$ snow pit [Tuohy et al., 2015], these include processed core, there are still unprocessed firn cores which are not listed). Moreover, a $11 \mathrm{~m}$ firn core was retrieved from the Roosevelt Island summit in 1974/75 using a hand auger drill [Clausen et al., 1979]. This core was dated using water isotopes and beta-activity [Clausen et al., 1979]. A deeper core $51 \mathrm{~m}$ core was also drilled at the summit $\left(79.3667^{\circ} \mathrm{S}, 161.667^{\circ} \mathrm{W}\right)$ in $1974 / 75$ [Paul Vallelonga and Bo Vinther personal communication]. 


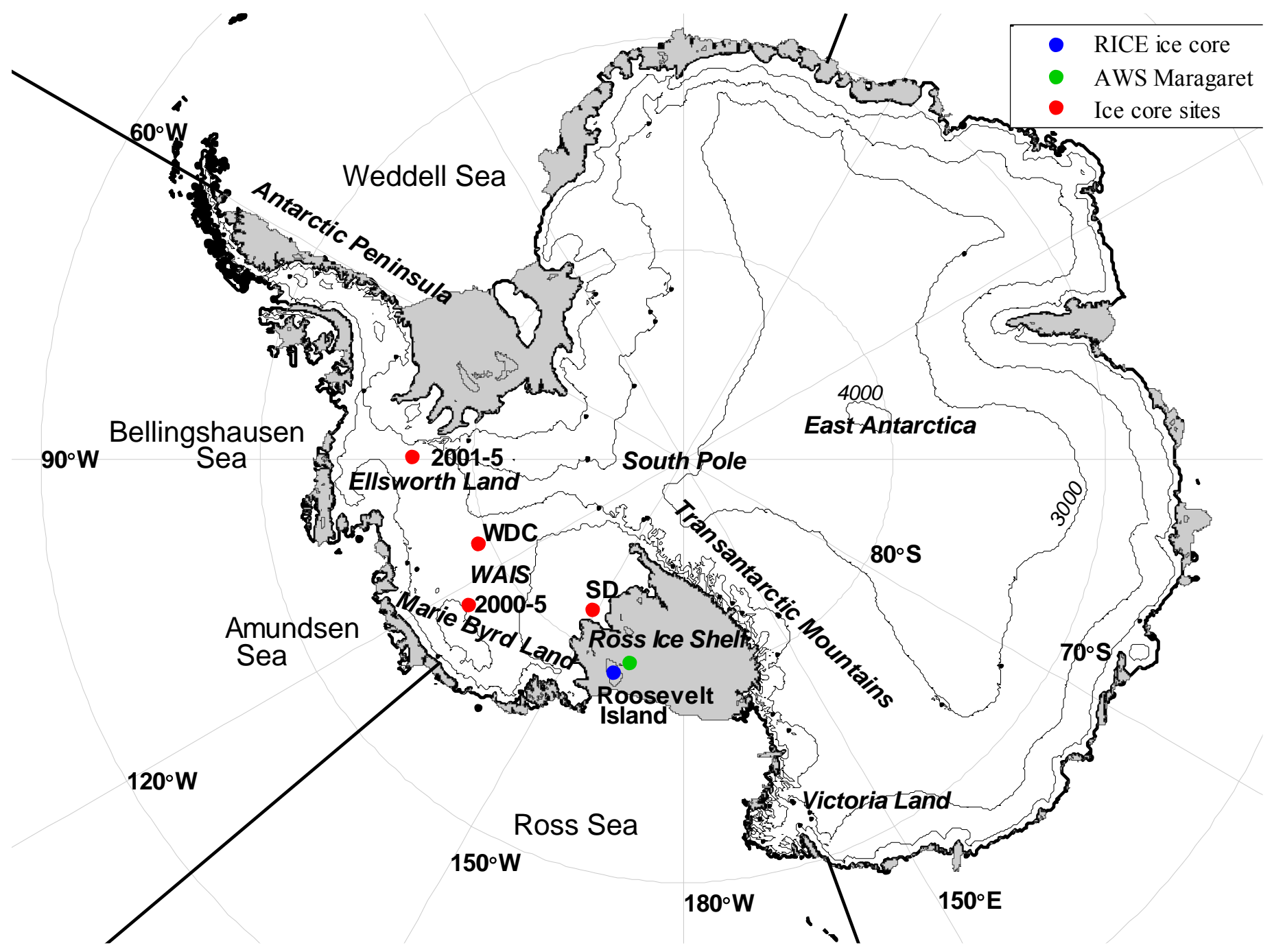

Figure 1.1. Map of Antarctica showing the location of Roosevelt Island, the RICE ice core site (blue dot) and several other WA ice core sites (red dots): e.g. the WAIS Divide ice core (WDC) and Siple Dome (SD). Contours (black thin lines) with 1,000 m spacing indicate the elevation above sea level. Black thick lines depicts the boundaries for the main Antarctic seas.

\subsection{Water Stable Isotope Ratios}

The measurement and interpretation of water isotope ratios (ratios of hydrogen and oxygen atoms which are different forms of the same element that contain equal numbers of protons but different numbers of neutrons in their nuclei; atoms display the same chemical behavior, but have different masses) has been central for our understanding of current and past climate. Pioneering work by Craig [1961], Epstein and Goddard [1963], and Dansgaard [1964] examined meteoric water and spatial variations of deuterium and oxygen stable isotopes; the effect of equilibrium and kinetic processes in the hydrological cycle. These studies related the 
isotopic composition of water to latitude, elevation, precipitation amount, surface air temperature and distance to the coast. Water isotopes $\left(\delta^{18} \mathrm{O}\right.$ and $\left.\delta \mathrm{D}\right)$ and deuterium excess (d-excess) have provided us with quantitative measures of changes in air temperature, ocean surface temperature, sea level and global ice volume through time. Water stable isotope records from ice cores provide fundamental data sets from which changes and variability of climate can be obtained on different time scales; millennial-scale [e.g., Petit et al., 1999; Steig and Alley, 2002; Wolff et al., 2010], abrupt changes [e.g., Masson-Delmotte et al., 2010] and an important observational dataset to assess recent trends and climate variability for areas with a paucity of metrological observations [e.g., Schneider et al., 2006; Mulvaney et al., 2012; Steig et al., 2013; Thomas et al., 2013].

Fractionation in water stable isotopes occur due to differences in mass of the water molecules (different number of neutrons). Isotopically heavier (enriched $\delta^{2} \mathrm{H}(\delta \mathrm{D})$ and $\left.\delta^{18} \mathrm{O}\right)$ molecules are preferentially left in the liquid phase during evaporation and in the fallout during condensation, while the remaining air parcel becomes isotopically lighter. Consider the water molecules with the speciation of $\mathrm{H}_{2} \mathrm{O}^{16}, \mathrm{H}_{2} \mathrm{O}^{18}$ and $\mathrm{HDO}^{16}$, where $\mathrm{H}_{2} \mathrm{O}^{16}$ is the most abundant ('light') isotopic species and $\mathrm{H}_{2} \mathrm{O}^{18}$ and $\mathrm{HDO}^{16}$ are the rare ('heavy') isotopic species of water. The abundance of the rare isotopes can be presented as $\mathrm{D} / \mathrm{H}$ and ${ }^{18} \mathrm{O} /{ }^{16} \mathrm{O}$ ratios respectively. The common way to represent the abundance of heavy isotopes is by $\delta \mathrm{D}$ and $\delta^{18} \mathrm{O}$, using the $\delta$ notation:

$$
\delta^{18} O(\text { or } \delta D)=1000\left[\frac{\left(R_{\text {sample }}-R_{\text {SMOW }}\right)}{R_{\text {SMOW }}}\right] \%
$$

where $R \equiv \frac{\left[{ }^{18} \mathrm{O}\right]}{\left[{ }^{16} \mathrm{O}\right]}$ or $R \equiv \frac{\left[{ }^{2} \mathrm{H}\right]}{\left[{ }^{1} \mathrm{H}\right]}$ and $R_{\text {SMOW }}$ is the corresponding ratio in Standard Mean Ocean Water [Gonfiantini, 1978].

Slightly different vapor pressures for the heavy and light isotopic species of water cause an isotopic effect or "fractionation", i.e. an enrichment of the heavy isotopes in the water phase and a depletion in the vapor phase. The differences in vapor pressure for the isotopic species is dependent upon temperature. For water vapor equilibrated with liquid water at $25^{\circ} \mathrm{C}$, the $\delta^{18} \mathrm{O}$ 
and $\delta \mathrm{D}$ of the vapor is $-9.3 \%$ and $-76 \%$, respectively, depleted relative to liquid ocean water [e.g., Clark and Fritz, 1997]. The kinetic isotope effect is a non-equilibrium process that occurs during evaporation. It causes a depletion of $\delta^{18} \mathrm{O}$ and $\delta \mathrm{D}$ in the water vapor added to air. The kinetic effect is caused by the difference in molecular diffusion rates for the isotopic species of water (Clark and Fritz 1999). The kinetic isotope effect during evaporation causes a larger fractionation to occur for $\mathrm{H}_{2} \mathrm{O}^{18}$ than for $\mathrm{HDO}^{16}$ [Clark and Fritz, 1997].

Deuterium excess (d-excess $\left.=\delta \mathrm{D}-8 \delta^{18} \mathrm{O}\right)$ is a second-order parameter, which is sensitive to kinetic fractionation, and captures differences in fractionation between the $\delta^{18} \mathrm{O}$ and $\delta \mathrm{D}$ isotopes during evaporation at the ocean surface, and is often used as a proxy for moisture source area [Merlivat and Jouzel, 1979]. The slower diffusion during evaporation of the $\mathrm{H}_{2}{ }^{18} \mathrm{O}$ molecule leads to a relative enrichment of the HDO in the gas phase, which causes a deviation of the theoretical slope of 8 between the $\delta^{18} \mathrm{O}$ and $\delta \mathrm{D}$. In the global hydrological cycle, water is predominantly evaporated at mid-latitudes and transported towards the poles. As an air parcel is transported poleward it cools, the water molecules with heavier isotopes of hydrogen and oxygen precipitate preferentially because their lower vapor pressure causes them to condense more readily. This explains the low isotopic ratios that is found in the Polar Regions, most depleted ratios can be found on the East Antarctic plateau [e.g., Bowen and Revenaugh, 2003], which can be attributed to its isolation, high elevation, dry and cold conditions. The water isotope proxies provide an integrated measure of the hydrologic activity along the transport path from the evaporation source. As such, the isotopic composition of Antarctic snow records reflects a combination of the degree to which water mass is removed from the air during the transport poleward, the additive contribution of local water mixed into the transported mass, and the temperature dependence of isotopic fractionation [Noone, 2008]. Rayleigh distillation is a conceptual model that simulates the hydrological poleward advection of air of an isolated air parcel and the isotopic composition changes as the air mass pathway reaches colder temperature and loses moisture through condensation [Dansgaard, 1964; Jouzel and Merlivat, 1984; Fisher and Alt, 1985], slightly more complex Rayleigh type models incorporate eddy transport [Hendricks et al., 2000] and local resupply of vapor [Noone, 2008]. Isotopic concentration has also been modeled with Rayleigh type models combined with airmass trajectories in polar regions [e.g., Helsen et al., 2006; Sinclair and Marshall, 2009] or using GCMs equipped with isotope tracers [e.g., Delaygue et al., 2000; Werner et al., 2001; Noone and Simmonds, 2002]. 
Post-depositional effects can significantly alter the water stable isotope signature [e.g., Masson-Delmotte et al., 2008]. Site-specific knowledge about post-depositional effects are crucial to enable quantitative description of ice core records. Diffusive processes in firn, through exchange between granulates and vapor phase in pore spaces in the firn, attenuate the amplitude of the isotopic signal with depth [van Ommen and Morgan, 1997; Cuffey and Steig, 1998; Johnsen et al., 2000]. For WA ice cores diffusion can typically be neglected on interannual timescales, as accumulation rates generally are high [Cuffey and Steig, 1998]. Several methods exist to restore the amplitude of the original deposited isotopic signal (back-diffuse) [Cuffey and Steig, 1998; Johnsen et al., 2000]. Seasonal bias in precipitation amount can also skew the isotopic signature towards certain seasons [e.g., Krinner et al., 1997]. Furthermore, precipitation can be biased towards certain environmental conditions, such as warm air temperatures, due to seasonal a seasonal precipitation bias and/or a bias towards a synoptically condition [Sime et al., 2009]. To reduce the effect of depositional noise, stacks of $\delta$-records have been generated [Fisher, 1985; Vinther et al., 2010] both from several local cores [e.g., van Ommen and Morgan, 1997; Van Ommen et al., 2004] or regionally [e.g., Küttel et al., 2012]. Schneider and Noone [Schneider and Noone, 2007] discusses the advantage of core stacks in reducing noise but also highlights the risk of canceling out climate signals if the isotope records in the cores stack are driven by different forcings.

\subsubsection{Continuous Flow Analysis}

As a first practical step of the research, a continuous flow setup (CFA) for isotopes measurements was developed. The setup enabled real time measurement of water isotopes using laser absorption spectroscopy from a continuous ice core sample stream (Chapter 2). The isotope CFA system was integrated with other simultaneous measurements e.g. discreet samples for chemical impurities, and continuous analysis of black carbon and methane. Laser spectroscopy in the infrared region was first proven as a viable alternative to isotope-ratio mass spectrometry (IRMS) by Kerstel et al. [1999]. The improvements within the field of commercially available laser absorption spectroscopy analyzers [Baer et al., 2002; Crosson, 2008; Berman et al., 2013; Steig et al., 2014] makes them suitable to analyze water vapor continuously to achieve high frequency in-situ simultaneous measurements of $\delta^{18} \mathrm{O}$ and $\delta \mathrm{D}$, within a range of research areas including atmospheric sciences [e.g., Johnson et al., 2011; Aemisegger et al., 2012], 
paleoclimate ice cores records [Gkinis et al., 2011; Maselli et al., 2013; Emanuelsson et al., 2015], ecology and hydrology.

The two main commercially available laser spectroscopic systems are based on off-axis integrated cavity output spectroscopy (Los Gatos Research) and cavity ring-down spectroscopy (Picarro). The OA-ICOS system uses a semiconductor diode laser to scan over nearby absorption lines with similar line strengths around a wave length of about $1.39 \mu \mathrm{m}$, near infrared part of the spectrum [Baer et al., 2002]. The "ring-down" measurement is made by quickly turning off the laser and measuring the light intensity in the cavity as the light decays exponentially in time [Crosson, 2008]. Gkinis et al. [2011] demonstrated that a customized evaporation unit can provide both a continuous sample stream and facilitate reliable calibrations for cavity ring-down spectroscopy (CRDS) instruments analysis of water vapor. The water stable isotope CFA system can provide simultaneous measurements of $\delta^{18} \mathrm{O}$ and $\delta \mathrm{D}$ with accuracy and precision equivalent to or superseding traditional single speciation discrete IRMS measurements [Gkinis et al., 2011; Maselli et al., 2013]. Additionally, with the laser spectroscopy measurements, the automated high-resolution measurements can be achieved in a fraction of the time, compared to the time required for IRMS and discrete laser spectroscopy measurements, and with only minimal sample preparation [Gkinis et al., 2011; Maselli et al., 2013; Emanuelsson et al., 2015]. There have been improvements in accuracy and precision between the latest generations of CRDS and OA-ICOS and their predecessors [Aemisegger et al., 2012; Maselli et al., 2013; Steig et al., 2014]. Comparison studies of CRDS and OA-ICOS setups have shown that $\delta^{18} \mathrm{O}$ measurements from OA-ICOS based systems are associated with uncertainty due to instrumental drift [Aemisegger et al., 2012; Emanuelsson et al., 2015]. This is particularly important when the measurements are used for calculations of secondary parameters such as d-excess (Chapter 2) [Aemisegger et al., 2012; Emanuelsson et al., 2015].

Even though the CRDS and OA-ICOS CFA based system are similar, there are some important differences in terms of their physical requirements, e.g. OA-ICOS systems require greater volumes of dry air [Aemisegger et al., 2012]. The higher carrier gas throughput rates for OA-ICOS systems can be an advantage in terms of responsiveness of the systems, but can compromise the system stability (mainly as the conditions in the cavity can be difficult to keep constant, due to the high turn-over rate). Differences in requirements for the two systems is also 
important to consider for laboratory requirements and during field operation. Considering the differences between the systems, Chapter 2 provides an important addition to earlier ice-core CFA studies_-which has had a focus on CRDS [Gkinis et al., 2011; Maselli et al., 2013] —in the form of a detailed description and evaluation of an OA-ICOS based CFA system. Chapter 2 also offers a framework for integration of laser spectroscopy setups with other analytical equipment, with sometimes competing requirements. Additionally, a comparison of two continuous ice core water stable isotope systems (using the latest generation of spectroscopy analyzers) was performed.

\subsection{Large-Scale Atmospheric Circulation}

Large-scale atmospheric circulation is the main driver of the WA isotopic signature [Bromwich et al., 2000; Küttel et al., 2012] and recent variability/changes in circulation patterns has been linked to WA trends in water stable isotopes [Steig et al., 2013] and temperature [Orsi et al., 2012; Bromwich et al., 2013]. Recent research efforts have emphasized the role of the Amundsen Sea Low (ASL) [Hosking et al., 2013; Turner et al., 2013; Raphael et al., 2015] and the Amundsen Sea circulation in particular [Thoma et al., 2008; Ding et al., 2011, 2012; Bracegirdle, 2013; Burgener et al., 2013] for WA climate. The ASL is a quasi-stationary lowpressure cell with large geopotential height variability located in the Amundsen-Bellingshausen Sea (ABS) and Ross Sea region (Figure 1.2a) [Cullather et al., 1996; Turner et al., 2013; Raphael et al., 2015]. The ASL is an area characterized by a high density of synoptic and subsynoptic scale cyclonic low pressure systems [Hosking et al., 2013] and is a favored region for blocking [e.g., Renwick, 2005]. Furthermore, the ASL is the deepest of three sea level pressure cells that are present around Antarctica, in a wave number 3 pattern [Raphael, 2004]. A wave number three pattern is clearly discernable in Figure 1.2a, with three low pressures centers over the Southern Ocean at $20^{\circ} \mathrm{E}, 105^{\circ} \mathrm{E}$ and $120^{\circ}-160^{\circ} \mathrm{W}$ (for the ASL). Cyclones in the ASL region are associated with meridional flow conditions [Hosking et al., 2013; Raphael et al., 2015] that impact Antarctic surface climate in the form of heat and moisture transport, precipitation and sea ice distribution [e.g., Hosking et al., 2013; Turner et al., 2015]. In this study, it is demonstrated that ABS meridional flow is enhanced by blocking conditions, by diverting the dominant zonal flow, resulting in WA air-mass intrusions and associated precipitation. Air mass instructions and 
subsequent precipitation occur along the longitudinal band where anticyclones and cyclones interact and generate non-zonal flow conditions.
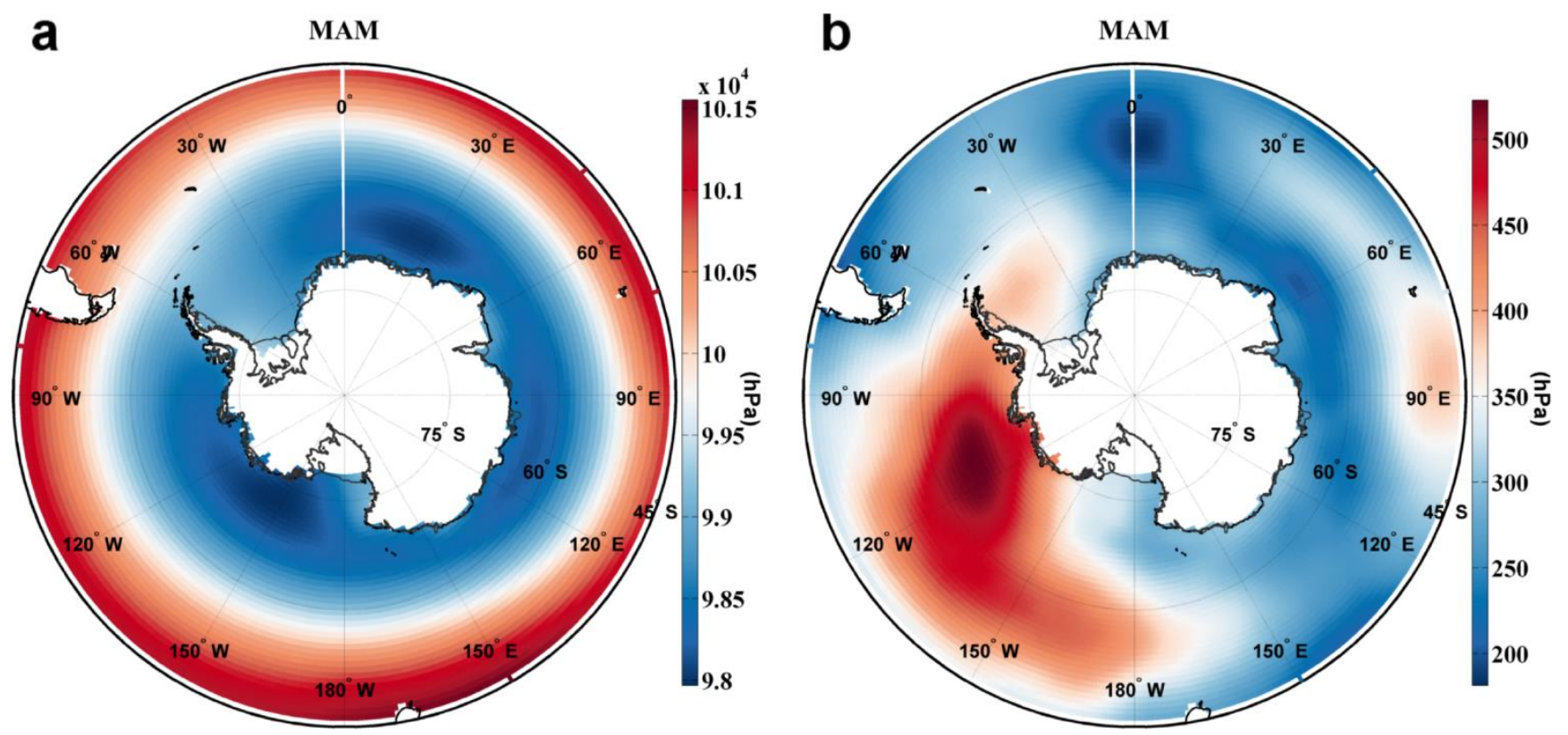

Figure 1.2. (a) Mean sea level pressure (MSLP) for the austral fall season (March-May, MAM) and (b) the standard deviation of MSLP for MAM (1979-2014). MSLP values over the Antarctic continent are not valid and are masked.

The depth and seasonal migration of the location ASL (between Ross Sea and Bellingshausen Sea) generates an anti-phase meridional winds/temperature/sea ice pattern between the Ross Sea and the Bellingshausen Sea/Antarctic Peninsula/Weddell Sea region. This pattern of variability is known as the Antarctic Dipole [Yuan and Martinson, 2000; Liu, 2004; Hobbs and Raphael, 2010; Turner et al., 2013]. The ABS region is characterized by the largest geopotential height variability in SH high-latitudes [Connolley, 1997; Renwick, 2002; LachlanCope and Connolley, 2006; Ding et al., 2012], with a standard deviation maximum located over the Amundsen Sea (Figure 1.2b) [Ding et al., 2012]. The large variation of the circulation in the Amundsen Sea was observed by Connolley [1997], who described it as the "pole of variability." Regions of large overall geopotential height variability are likely to be associated with larger positive geopotential height anomalies with longer duration [Renwick, 2005]. Indeed, the Amundsen Sea region is known to be a favored location for blocking [e.g., Renwick, 2005]. The large geopotential height variability in the ABS has been attributed to a combination of zonal 
asymmetry of the Antarctic orography [Lachlan-Cope et al., 2001] and tropical Pacific SH highlatitude influence via Rossby waves [Lachlan-Cope and Connolley, 2006; Ding et al., 2012].

Changes in Amundsen Sea atmospheric circulation have been linked to increased upwelling of circumpolar deep water in the Amundsen Sea Embayment [Payne et al., 2004; Thoma et al., 2008; Pritchard et al., 2012; Steig et al., 2012], which contribute to basal melting and affect the stability of the West Antarctic Ice Sheet (WAIS). An increased freshening (reduced salinity) of the Amundsen Sea's waters from melting of the ice sheet may in turn impact Antarctic Bottom Water formation and the global thermohaline circulation [Weaver et al., 2003; Rintoul, 2007]. Thus, the Amundsen Sea atmospheric circulation appears to have a global role both in regards to WA tropical Pacific connections and potential impact on WAIS stability. An improved understanding of Amundsen Sea circulation and its variability is therefore not just of regional interest, but a global matter. Yet, our understanding of recent trends and its drivers in this important region and the overall sensitivity of WAIS is hampered by the scarcity of observational records prior to the satellite-era which commenced in 1979 (and reliable SH extratropical SST records prior to 1950), and due to the climates long intrinsic centennial- and decadal-scale variability [Connolley, 1997; Schneider et al., 2011; Okumura et al., 2012].

The state of the ASL is primarily modulated by the three dominating modes of SH largescale atmospheric variability: the Southern Annular Mode (SAM) and the two Pacific-South American patterns (PSA1 and PSA2). The SAM is the primary mode of large-scale atmospheric variability in the SH [Mo, 2000; Thompson and Wallace, 2000; Ding et al., 2012]. SAM is often defined as the first empirical orthogonal function (EOF) of SH sea level pressures or geopotential height fields [Mo, 2000; Ding et al., 2012]. The SAM has also been called the Antarctic Oscillation (AAO, [Thompson and Wallace, 2000]). The SAM, the SH leading EOF of 500-hPa geopotential height variability is well separated from the second and third EOFs [Kidson, 1988; Mo and Higgins, 1998; Marshall and Thompson, 2016]. The PSA1 and PSA2 patterns are defined as the second and third mode of SH atmospheric variability [Kidson, 1988; Mo and Higgins, 1998]. The second and third EOFs, the PSA1 and PSA2 patterns, explain 10\% of the variance each, are not as distinct from one another [Kidson, 1988; Mo and Higgins, 1998; Marshall and Thompson, 2016]. Positive tropical SST anomaly patterns and large rainfall anomalies, can cause deep convention with resulting high-level atmospheric divergent flow that force Rossby wave initiation and propagation [Gill, 1980; Hoskins and Karoly, 1981; Lachlan- 
Cope and Connolley, 2006; Trenberth et al., 2014]. Both the SST anomaly pattern [LachlanCope and Connolley, 2006] and the magnitude of the anomalies [Su and Jiang, 2013] are important for the initiation of the PSA patterns Rossby wave train responses. The variability of the PSA wave train response is therefore dependent on the tropical SST anomaly pattern and the strength of the jet streams, but is also affected by the zonal winds in the extratropical Pacific, as variability are linked to other climate modes, such as the SAM [Turner, 2004; Lachlan-Cope and Connolley, 2006].

Conceptually, EOF analysis determines a spatio-temporal pattern of variability that accounts for the maximum covariance between the geopotential heights time series (for atmospheric circulation) for all pairs of grid points in the data sets [Storch and Zwiers, 1999; Deser et al., 2010]. The residual data set is subsequently subjected to the same analysis with the additional constraints that the second EOF pattern is uncorrelated to the first [Storch and Zwiers, 1999; Deser et al., 2010]. Recent studies have demonstrated the central tropical Pacific's far reaching teleconnections and their influence on ABS regional atmospheric circulation. The central Pacific appears to have a greater influence on WA climate than the traditional eastern equatorial tropical Pacific region [Ding et al., 2011, 2012; Schneider et al., 2011; Okumura et $a l ., 2012]$. The climatologically warmer SST in the western and central tropical Pacific, compared to the eastern equatorial Pacific, may explain why central Pacific El Niño-Southern Oscillation (ENSO) events generate strong teleconnections [Ciasto et al., 2014]. ENSO is the leading mode of oceanic-atmospheric variability over the tropical Pacific and is the dominant source of global climate variability on interannual to decadal time scales [Trenberth et al., 1998]. ENSO influence the SH extratropics and Antarctica, via far reaching teleconnections [Karoly, 1989; Turner, 2004]. The PSA teleconnections (particularly PSA1) are commonly regarded as being associated with ENSO variability [Karoly, 1989; Trenberth et al., 1998; Alexander et al., 2002; Schneider et al., 2011] and is in part also influencing the variability of SAM [Ding et al., 2012]. The PSA1 pattern stands out in El Niño and La Niña circulation composites and in dynamical (anticyclone and cyclone) composites of the SAM polarity phases (e.g. Chapter 3; [Deser et al., 2010]). PSA1 can therefore be thought of as an extension of ENSO into the SH [Mo, 2000]. 
The SAM is characterized by quasi-zonally symmetric circulation, with anti-phase wind belts centered at $\sim 40^{\circ} \mathrm{S}$ and $\sim 65^{\circ} \mathrm{S}$. The SAM provides measure of the strength of the mid to high-latitude meridional geopotential height gradient, which relates to the vapor mass flux and heat transport to high-latitudes. Prominent zonal features characteristic of a positive SAM include: a strong polar vortex, increased strength of the westerly jet stream, and a polar shift of the circumpolar trough [e.g., Kidson, 1988; Ding et al., 2012]. The SAM is mainly an intrinsic mode of atmospheric variability and can therefore largely vary independently of ENSO [Limpasuvan and Hartmann, 2000]. However, part of the variability in the SAM can be explained by a western and tropical Pacific ENSO-like influence [Fogt and Bromwich, 2006; L'Heureux and Thompson, 2006; Yuan and Li, 2008; Ding et al., 2012; Bromwich et al., 2013]. The ENSO influence on SAM can be described as a non-negligible, non-annular component [Yuan and Li, 2008; Ding et al., 2012]. This teleconnection feature is attributed to PSA-like wave train connection with the western and central tropical Pacific [Ding et al., 2012]. Positive eastern tropical SST (El Niño) have been shown to be linked to the negative phase of the SAM, i.e. a weaker polar vortex [Schneider and Noone, 2007; Ding et al., 2012]. In contrast, La Niña events (characterized by cold central tropical Pacific SST anomalies) enhance the westerlies in the $60^{\circ} \mathrm{S}$ wind belt and is therefore equivalent to an increase in the SAM index [e.g., Schneider et al., 2015]. There has been a positive trend in SAM since the early 1960s, characterized by strengthening of the circumpolar westerlies. The positive trend in SAM has been attributed to decrease in ozone and increase in greenhouse gases [Thompson and Solomon, 2002; Marshall et $a l ., 2004]$. The trend exists in summer, but also persists throughout the year and thus, it cannot exclusively be attributed to ozone depletion [Ding et al., 2012]. Part of the trend can be explained by changes in tropical SST forcings [Ding et al., 2012; Schneider et al., 2015]. Schneider et al. [2015] used general circulation models to quantify drivers behind recent circulation changes and found that both tropical SST forcing and ozone reduction is needed to explain the strengthening of the westerlies in the eastern subtropical Pacific in $\left(\sim 60^{\circ} \mathrm{S}\right.$; i.e. the positive trend in SAM). The increase in SAM causes a southward migration of the westerly wind belt, lower geopotential heights in the ABS region (a deepening of the ASL) and an increase in northerly poleward winds in the Bellingshausen Sea area and off-the-continent winds in the eastern Ross Sea/Amundsen Sea region. 
The PSA teleconnections between tropical/subtropical Pacific and SH high-latitudes have its strongest Southern Ocean impact in the Amundsen Sea (Ross Sea for PSA2; Figure 1.3c, d). Periods of an in-phase relationship between the SAM and PSA are associated with pronounced Rossby wave connection between mid and high-latitudes and large geopotential height variability in the ABS region [Fogt and Bromwich, 2006]. In simple terms, Rossby waves are evident as major lateral undulations of the subtropical jets stream [e.g., Altenhoff et al., 2008] and are associated with zonally asymmetric circulation patterns (anticyclonic and cyclonic circulation action centers) at middle and high latitudes. The wave trains (also called teleconnections or atmospheric bridges) are fueled by anomalous deep convection and latent heating in the tropics, and are the main pathway between the tropics and the high SH latitudes. The resulting upper-level divergence perturbations are a key requirement for the generation of Rossby waves [e.g., Ding et al., 2012; Ciasto et al., 2014].

The PSA teleconnections are known to be associated with ABS blocking [van Loon and Shea, 1987; Sinclair, 1996; Renwick, 1998]. Blocking events are high-pressure centers that are semi-stationary and can therefore be defined as stationary events that exceed a defined positive pressure anomaly and persist for at least 5 days or more [e.g., Renwick, 2005]. A characteristic feature of stationary Rossby wave responses to tropical SST forcing results in geopotential height levels which have a nearly barotropic structure in the Pacific sector high-latitudes and displays phase reversal between the upper troposphere and the surface in the tropical Pacific (baroclinic) [Gill, 1980; Mo and Higgins, 1998; Ding et al., 2012]. The PSA patterns are characterized by out-of-phase geopotential height anomalies that arch across the extratropical Pacific from the tropical Pacific, in a seesaw pattern. During ENSO's positive polarity phase, El Niño, SST anomalies are positive over the tropical Pacific. El Niño events are associated with an increase in Rossby wave train initiation and propagation in the $\mathrm{SH}$ extratropics. The wave train associated with the El Niño phase (PSA1+) is manifested by negative geopotential height anomalies off western New Zealand arcing across the subtropical Pacific towards South America, positive geopotential height anomalies over the Amundsen Sea, and negative anomalies off the eastern coast of South America (Figure 1.3c) [Mo and Ghil, 1987; Karoly, 1989; Mo and Higgins, 1998]. The opposing sign of the geopotential height anomalies are displayed during La Niña conditions. The PSA1 pattern is the broad-scale response in the SH to tropical Pacific ENSO variability [Mo and Higgins, 1998; Mo and Paegle, 2001; Schneider et 
al., 2012]. PSA1's anticyclonic center of action is located at $\sim 130^{\circ} \mathrm{W}$ in the Amundsen Sea (Figure 1.3c). The PSA2 pattern is characterized by west-east arch of geopotential anomaly reversal cells, however, spanning across the Pacific at higher latitudes compared to PSA1 (Figure $1.3 \mathrm{c}, \mathrm{d}$ ). PSA2's anticyclonic center of action is located at $\sim 160^{\circ} \mathrm{W}$ over the Ross Sea (Figure 1.3d). The PSA2 pattern has been linked to central Pacific SST anomalies and affects the dipole mode of ocean-atmosphere variability in the South Atlantic [Rodrigues et al., 2015].

Furthermore, PSA2 is associated with a zonal wave number three feature with action centers in the Pacific $\left(150^{\circ} \mathrm{W}\right)$, Indian Ocean $\left(60^{\circ} \mathrm{E}\right)$ and Atlantic Ocean $\left(30^{\circ} \mathrm{W}\right)$ Sectors. PSA2 has therefore been described has having a more wide ranging hemispheric impact than PSA1 [e.g., Marshall and Thompson, 2016].

Recent circulation trends appear to have had an impact on the climate of New Zealand, Australia [Thompson et al., 2011] and South America [Seager et al., 2010; Rodrigues et al., 2015]. The aforementioned regions and the Amundsen Sea are all impacted by the PSA connections. A PSA-like wave train feature has also been linked to intrinsic variability of SAM [Ding et al., 2012]. Changes in tropical Pacific SSTs are linked to the increase in warm air mass advection through the Amundsen Sea circulation [Steig et al., 2009, 2013; Ding et al., 2011, 2012; Schneider et al., 2011], which has been associated with: changes in distribution of sea ice [Stammerjohn et al., 2008; Turner et al., 2015; Meehl et al., 2016], an increase in air temperature over the Antarctic Peninsula [Vaughan et al., 2003] and WA Byrd station [Bromwich et al., 2013], in ice core bore hole temperatures [Orsi et al., 2012], and for WAIS Divide and Ellsworth Land water isotopic signature [Steig et al., 2013; Thomas et al., 2013]. The direct impact of the deepening is strongest for eastern WA and AP sites, whereas WA sites would see a decrease in warm northerly marine air mass intrusions as a consequence of the increased clockwise circulation associated with ASL cyclones (Figure 1.4). Figure 1.4 displays geopotential height composite anomaly fields associated with precipitation (z500p, >50\%, 1979-2014) for the following Antarctic ice core sites: RICE, ITASE 2000-5, WDC (ITASE 2000-1), ITASE 2001-5 and Gomez (Figure 1.4). Of the considered sites, RICE has the maximum high composite center and ITASE 2001-5 the deepest low. Progressively moving eastward from RICE, the westernmost site, the relative influence from Amundsen Sea cyclones and anticyclones appears to wax and wane as the location of the sites high and low composite centers intersects more with the focal 
area of the Amundsen Sea atmospheric circulation for the westernmost and easternmost sites, respectively (Figure 1.4).
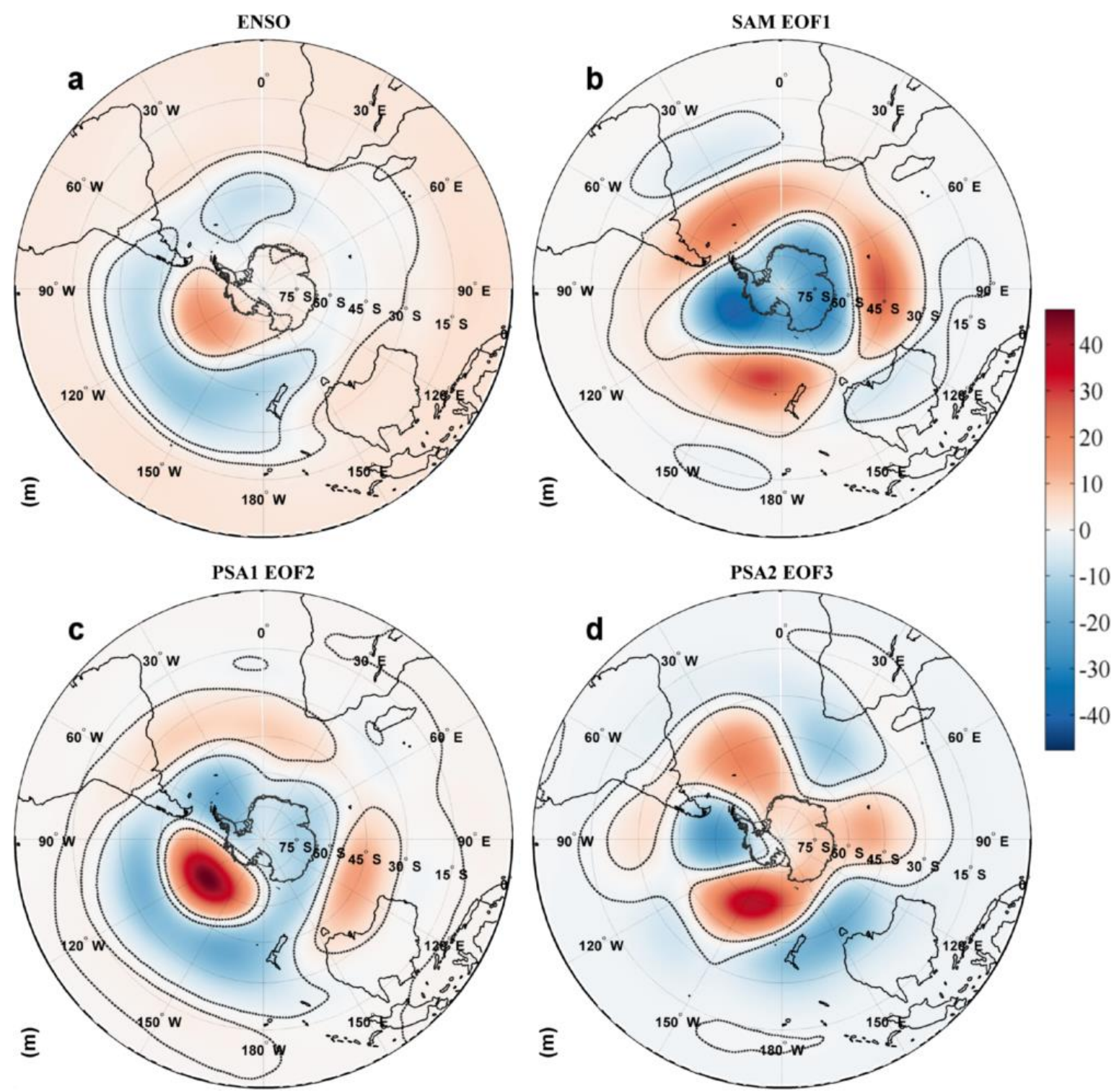

Figure 1.3. Regression maps showing spatial patterns of SH large-scale atmospheric circulation variability associated with (a) ENSO; (b) the leading EOF, the SAM; (c) the second EOF, the PSA1; and (d) third EOF, the PSA2. The EOFs were obtained using SH 500-hPa ERA-Interim geopotential heights field $\left(20^{\circ}-90^{\circ} \mathrm{S}\right)$ from all calendar months (January 1979-December 2015). The 500-hPa geopotential heights field is regressed upon standardized ENSO and PC time series. The ENSO regression map was generated using monthly Niño-3.4 SST. The climate-mode circulation patterns are all displayed for the modes positive polarities. The polarity for the PSA patterns are defined as in Kidson et al. (1988), their figure 4. Black contours enclose areas where regression coefficients are significant at the $p<0.05$ confidence level. 

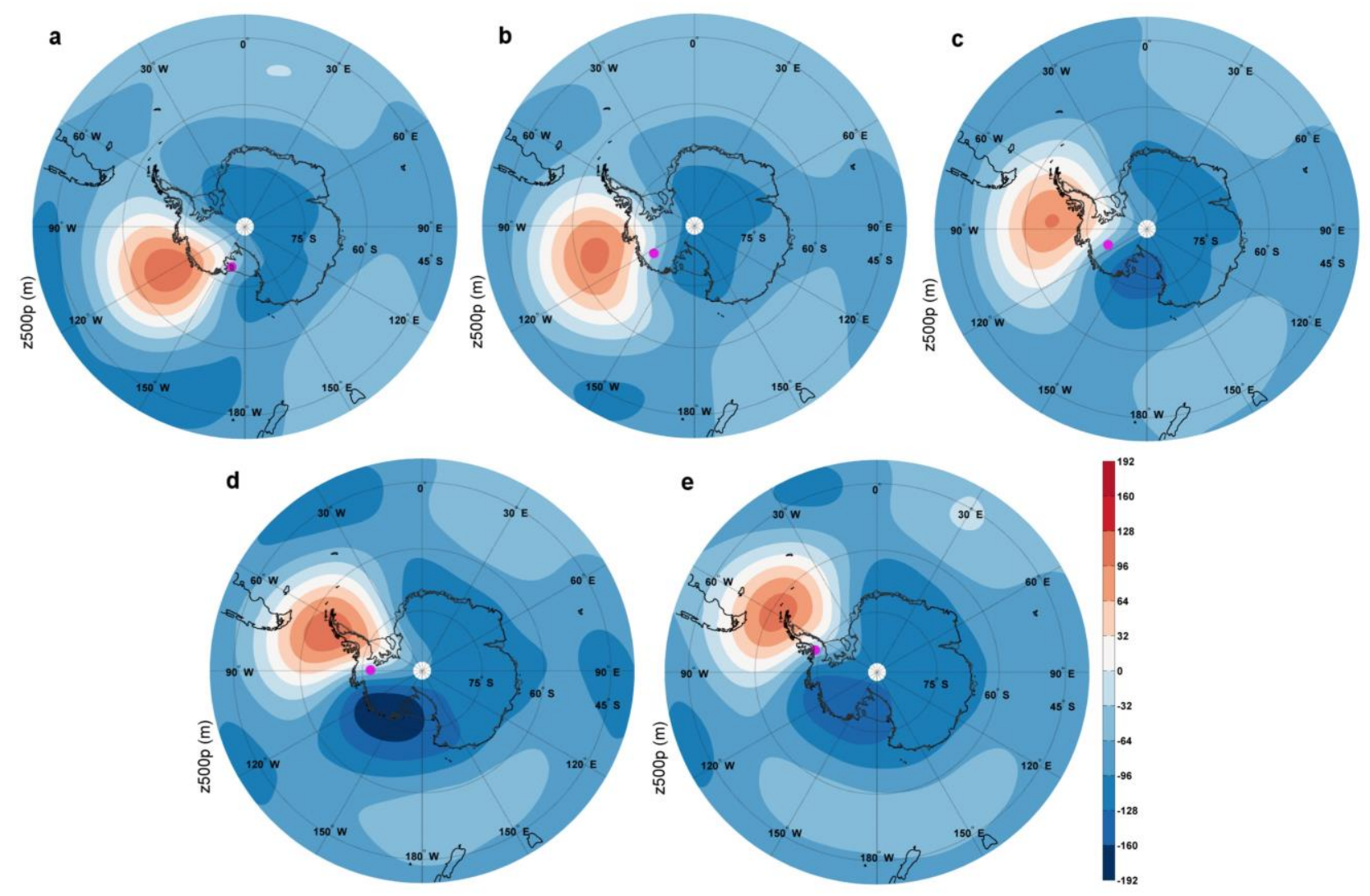

Figure 1.4. Geopotential height composite anomaly fields associated with precipitation (z500p, $>50 \%, 1979-2014$ ) for four WA sites (from west to east): (a) RICE, (b) ITASE 2000-5, (c) WDC, (d) ITASE 2001-5, and (e) Gomez. Locations are marked with magenta dots.

\subsection{Relationship between RICE $\delta D$ and Surface Air Temperatures}

The likelihood that accumulation variability biases the signal preserved in RICE $\delta \mathrm{D}$ was investigated using the method introduced by Sime et al. [2009]. This method determines synoptic conditions that are congruent with precipitation by annually averaging reanalysis parameters (e.g. ERA-Interim surface air temperature) that are concurrent with precipitation [Sime et al., 2009]. Here, high-resolution (latitude x longitude, $0.0125^{\circ} \times 0.0125^{\circ}$ ), 6-hourly ERA-Interim air temperature $(2 \mathrm{mT})$, and 3-hourly precipitation data from the closest grid point to RICE is used. First, daily temperature and precipitation data are generated. Then, a temperature record that only includes temperatures during precipitation events is generated using the daily ERA-Interim precipitation data. Both regular air temperature (including all time steps) and $\mathrm{Tp}$ are annually averaged (Figure 1.5a) and correlated with the RICE $\delta$ D record from firn core 12/13B. Additionally, the RICE and Margaret AWS air temperature records are annually averaged and 
displayed for comparison. The local RICE temperatures during precipitation (Tp) show that precipitation occurs during relatively warm temperatures. The mean difference between annual air temperatures congruent with precipitation (Tp) and annually averaged air temperature is $5.3^{\circ} \mathrm{C}$ (Figure 1.5a). Additionally, the results suggests that diffusion has a depleting effect on the isotopic signature, due to the existing warm bias during precipitation events. The snow pack is more exposed to diffusion during low accumulation than high years. There is a significant, but weak correlation between annually averaged air temperature (T) ERA-Interim at the RICE site and the $\delta \mathrm{D}$ record $(r=0.38, p<0.1,1979-2009$; Figure 1.5b). The correlation becomes significant, when $\delta \mathrm{D}$ is correlated with the Tp record $(r=0.47, p<0.05,1979-2009$, Figure 1.5b). These results show the event-driven nature of RICE precipitation and the synoptic conditions congruent with precipitations is preserved in the core. In other words, accumulation variability influence the air temperature signal that is preserved in the RICE $\delta \mathrm{D}$ record. Anomalously warm humid air masses are associated with RICE precipitation. Thus, causing a bias towards isotopically enriched $\delta \mathrm{D}$ values. 

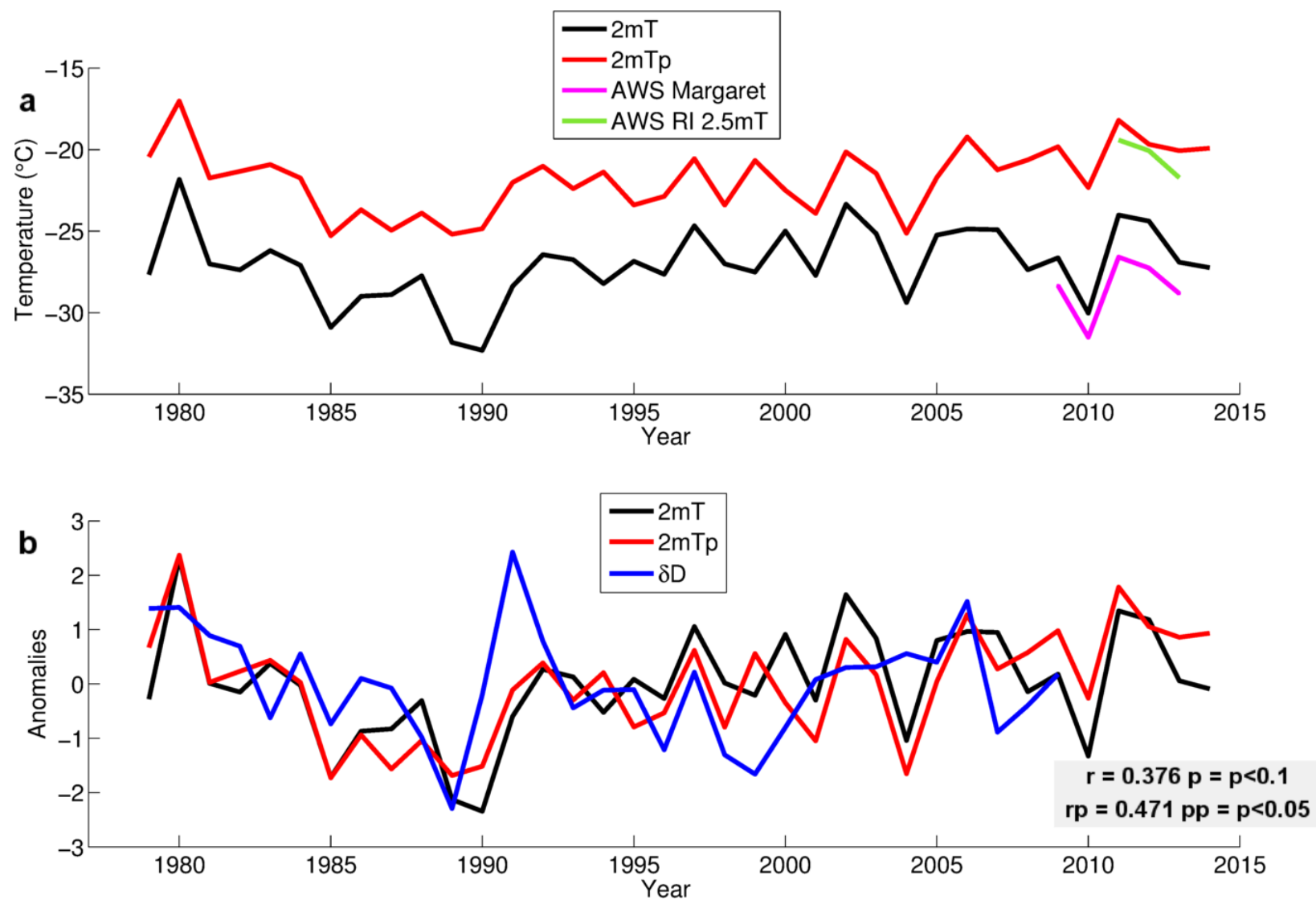

Figure 1.5. (a) Annual averages of ERA-Interim surface air temperature based on 6-hourly values from throughout the year ( $\mathrm{T}$, black line) and using temperatures congruent with RICE precipitation ( $\mathrm{Tp}$, red line). Also shown are annual means of temperature observations from the RICE (green line) and Margarete AWSs (magenta line). (b) Same as (a) but as anomalies and including $\delta \mathrm{D}$. Correlation coefficients $(\mathrm{r})$ for RICE $\delta \mathrm{D}$ with $\mathrm{T}$ and $\mathrm{Tp}$ is shown in the lower right corner.

The 500-hPa geopotential height field (z500) in the Amundsen Sea Low region $\left(60^{\circ}-75^{\circ} \mathrm{S}\right.$, $170^{\circ}-290^{\circ} \mathrm{E}$ ) is examined using the same approach (i.e. using daily averaged 6-hourly z500 ASL fields instead of RICE 3-hourly temperatures). The correlation between RICE $\delta \mathrm{D}$ and the annual average z500 in the ASL region is $(r=0.62, p<0.001,1979-2009)$. When RICE $\delta \mathrm{D}$ is correlated with annual z500averages that are congruent with RICE precipitation the strength of the correlation increases $(r=0.70, p<0.001,1979-2009)$. However, the strength of the correlation does not increase as much as for the air temperature and the regular z500 correlation (including all time steps) is already highly significant $(p<0.001)$. These results show that z500 (atmospheric circulation) in the ASL region, and not local air temperatures, is the main regional driver controlling RICE $\delta \mathrm{D}$. 
The interannual spatial correlation map between the ERA-Interim $2 \mathrm{mT}$ field and RICE $\delta \mathrm{D}$ record show significant positive correlation over the Amundsen Sea and over Victoria Land (Figure 1.6). The characteristic Antarctic dipole [Yuan and Martinson, 2000] pattern is clearly discernable in the correlation pattern, with an anti-phase in temperatures relationship between the Amundsen Sea/western Marie Byrd Land and the Antarctic Peninsula region. The RICE $\delta \mathrm{D} 2 \mathrm{mT}$ significant correlation pattern (shading inside the black contour in Figure 1.6) extends out over the Amundsen Sea Southern Ocean $\left(120^{\circ}-150^{\circ} \mathrm{W}\right)$ sector, an area that has been linked to blocking of westerly winds. The significance of the correlation pattern in the Amundsen Sea/Southern Ocean region is higher than the local temperature at RICE (Figure 1.6), indicating that $\delta \mathrm{D}$ is influenced by air mass advection associated with Amundsen Sea atmospheric circulation and conditions in the sea ice zone. The highly significant positive RICE $\delta \mathrm{D}$ and $2 \mathrm{mT}$ correlation pattern over Victoria Land is likely to be related to the PSA2 pattern, which is examined further in chapter 4. As Figure 1.6, mainly show weak correlation pattern over the Antarctic continent (with the exception of Victoria Land). The strong significant pattern is mainly associated with SATs over Southern Ocean. These results indicate that a temperature reconstruction using RICE $\delta \mathrm{D}$ would largely capture sea surface temperatures over the Amundsen Sea. An air temperature reconstruction would therefore be a proxy reconstruction of SST in the Pacific and in the western Southern Ocean Atlantic sectors. The results suggests that RICE $\delta \mathrm{D}$ is a highly skilled atmospheric circulation and SST proxy, but is not capturing Antarctic continental air temperature variability. Therefore, the focus of this thesis was placed on the preserved atmospheric-circulation and SST signal and not towards an air temperature reconstruction. 


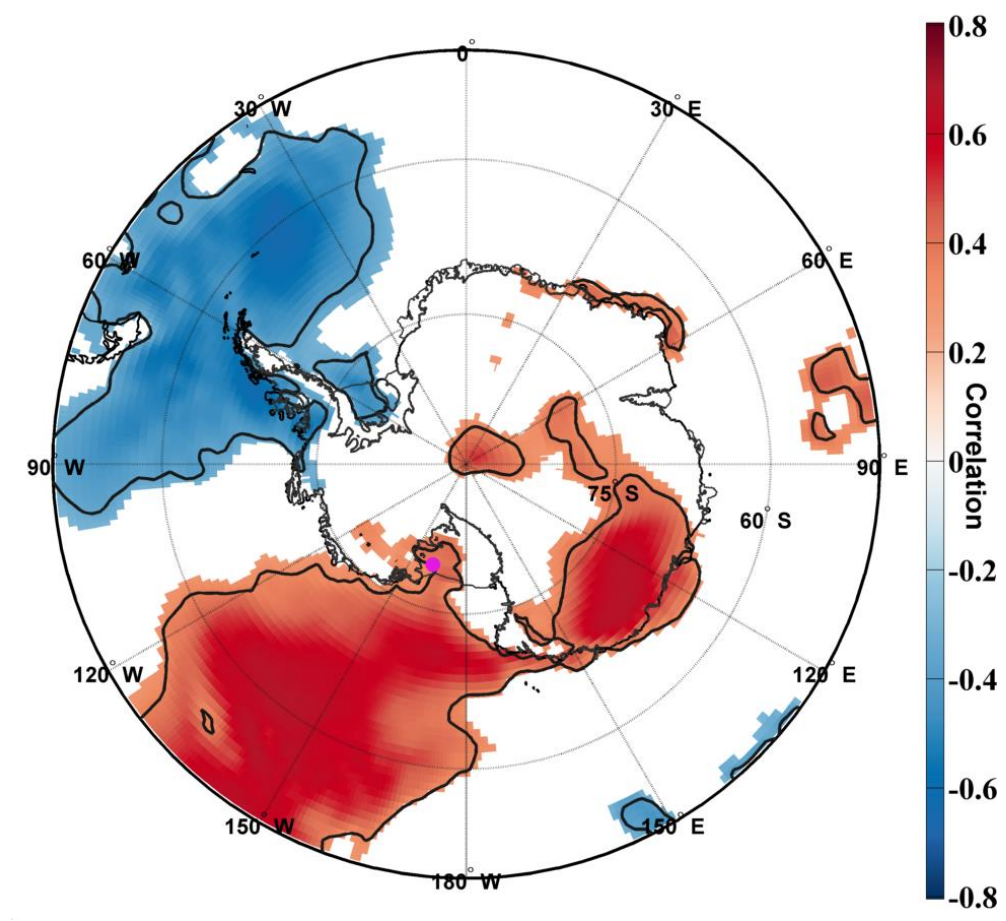

Figure 1.6. Interannual correlation map (1979-2009) of RICE $\delta D$ with annual average ERAInterim surface air temperatures. Spatial correlation coefficients $(r, p<0.1$, shading) and the $p<$ 0.05 confidence level (black contours). RICE location is indicated by a magenta dot.

\subsection{Automatic Weather Station Data}

An Automatic Weather Station (AWS) was deployed at Roosevelt Island from 14 November 2010 to 21 November 2013, which is the main evaluation period for this section. While this record is short, it is important (1) as the record is from a data sparse region and (2) the RICE AWS provides an observational data set that has not been assimilated in to the reanalysis data sets (i.e. it is independent of the ERA-Interim data). Additionally, this record provides an important opportunity to assess the sensitivity of the ice core record to local meteorological conditions. AWS locations are shown in Figure 1.7 and data availability is given in Table 1.1. Air temperatures from the RICE and Margaret AWS are provided in Figure 1.8. The Margaret AWS is located $100 \mathrm{~km}$ southwest of Roosevelt Island on the Ross Ice Shelf (Figure 1.7, 80.0 ${ }^{\circ} \mathrm{S}$, $165.0^{\circ} \mathrm{W}, 67 \mathrm{~m}$ a.s.1; University of Wisconsin Madison [Lazzara et al., 2012]). The Margaret AWS has been operational since 12 November 2008. 


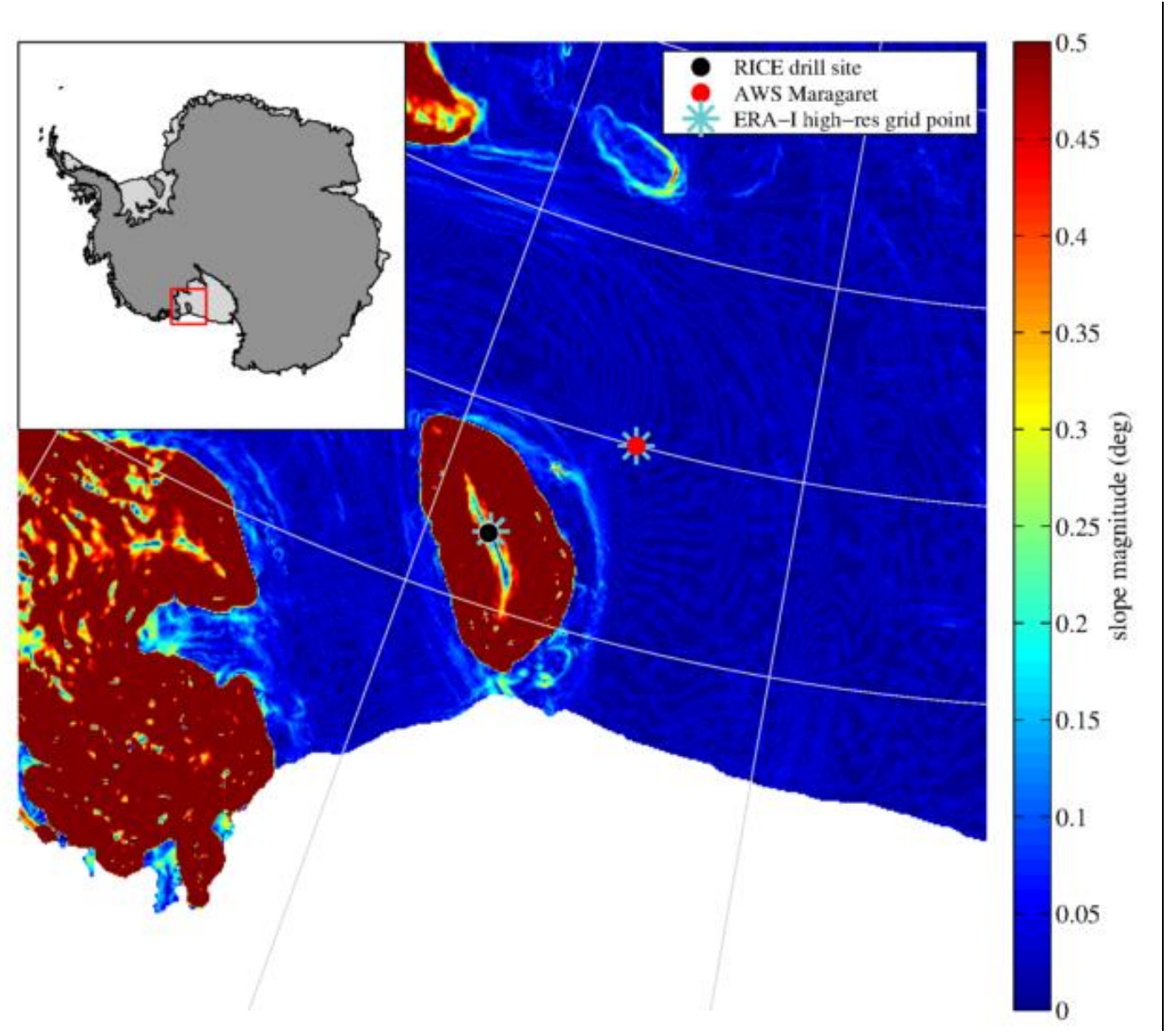

Figure 1.7. Location map of the Roosevelt Island region (eastern Ross Ice Shelf). The RICE drill site is indicated by a black dot and the Maragrete Automatic Weather Station (AWS) is depicted with a red dot. The location of high-resolution ERA-Interim grid points located close to the RICE and Margarete AWS are indicted with light-blue stars. 


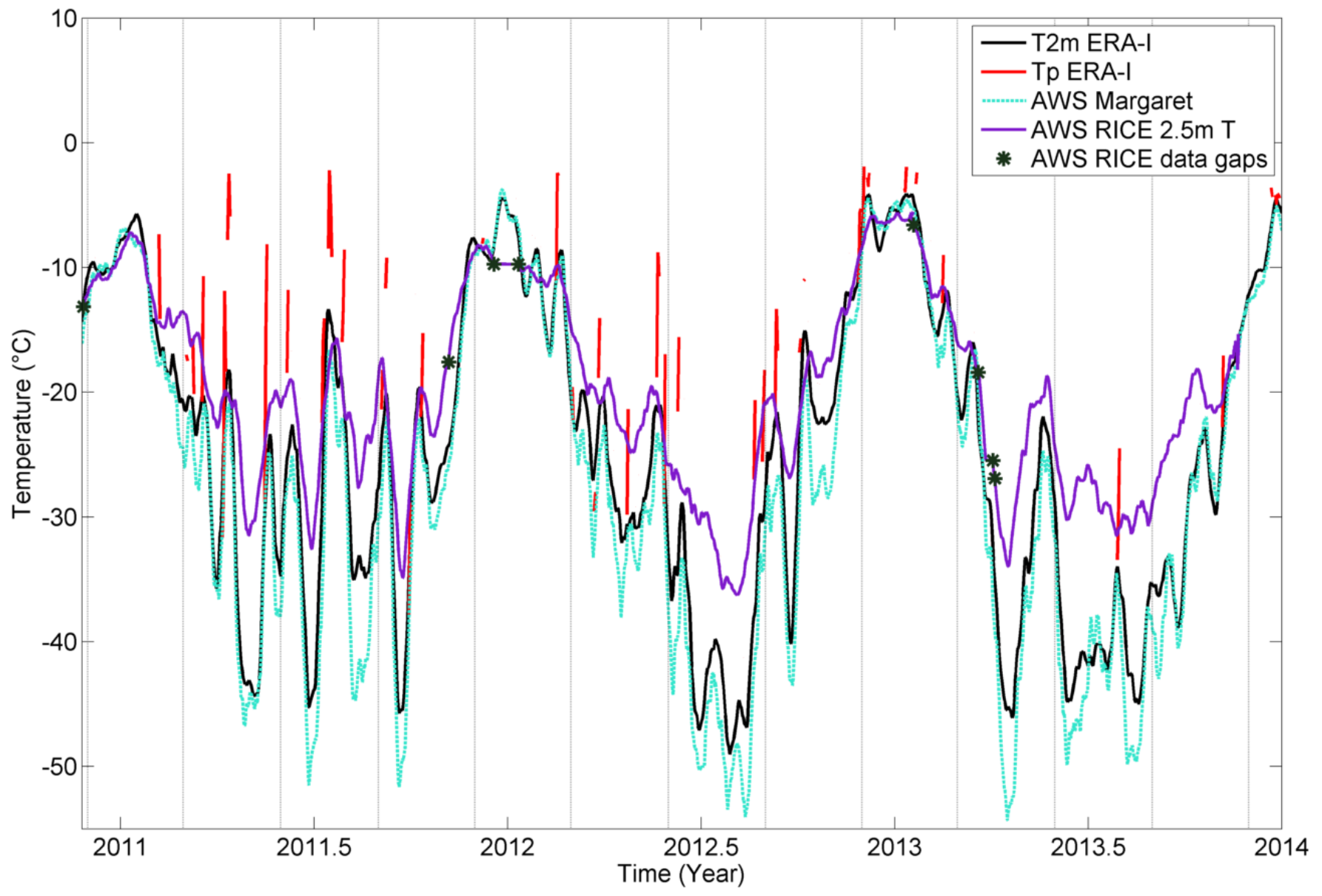

Figure 1.8. Surface air temperatures (SAT) from the RICE automatic weather station (AWS; $2.5 \mathrm{~m} \mathrm{~T}$; purple line), Margaret AWS (light-blue line) and ERA-Interim SAT ( $2 \mathrm{~m}$ T, black line). All SAT data are smoothed with a 10-day running mean. Except SAT values concurrent with precipitation, which are shown as unsmoothed data (red lines).

Evidence of winter warm spells are clearly discernable in the records, as in the 2011 winter when RICE and Margaret air temperatures increased from $-35^{\circ} \mathrm{C}$ to $-5^{\circ} \mathrm{C}$ within less than 5 days. These warm event can be indicative of blocking events that channel warm marine air in towards Antarctica. While RICE and Margaret summer temperatures are similar, RICE fall and winter temperatures are warmer compared to Margaret temperatures and RICE ERA-Interim temperatures (Figure 1.8). Lenaerts et al. [2014], who examined SAT records at Dronning Maud Land ice rises, suggested that higher temperatures, compared to the lower surrounding, can be found on ice rises during the winter season due to: (1) the presence of a semi-permanent surfacebased temperature inversion layer [Connolley, 1997] and (2) enhanced vertical mixing in the atmospheric surface layer during the cold season enhancing the downward entrainment of 
warmer and drier air and partly breaks down the stratified atmosphere near the surface, which is supported by higher wind speed over ice rises, and enhancing downward sensible heat flux.

Roosevelt Island and the Margarete AWS are located east of the main WA drainage flow from the Ross Air Stream over the Ross Ice Shelf [Parish and Bromwich, 1998; Parish et al., 2006; Knuth et al., 2010] in regions characterized by low wind speeds [Costanza et al., 2016]. Wind speeds at Margarete AWS are on average low and variable, but with a resultant southeasterly component (Figure 1.9b) [Costanza et al., 2016]. The wind distribution from the RICE AWS is variable with resultant southeasterly components. Moreover, the RICE AWS display higher winds speeds compared to the Margarete AWS located on the Ross Ice Shelf (Figure 1.9). Thus, the same arguments seem to be valid for the Roosevelt Island ice rise as for the Dronning Maud Land ice rises examined by Lenarearts et al. [2014]. The RICE AWS is affected by rime formation and while rime will have an influence on the wind speed record, the influence on the temperature records are considered negligible. Furthermore, rime formation will create a low wind speed biased record. Therefore, the argument made here with the relatively higher RICE wind speeds is conservative.

\section{Wind Speed [m/s] RICE AWS}

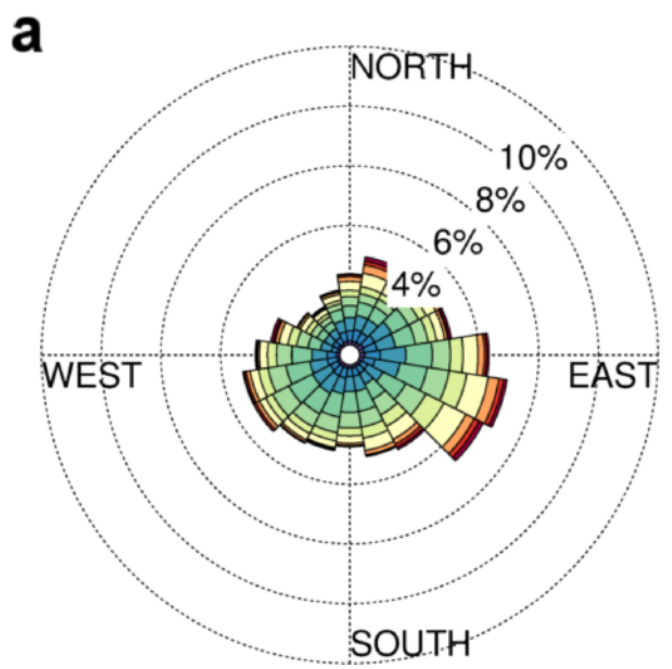

\section{Wind Speed [m/s] Margaret AWS}

b

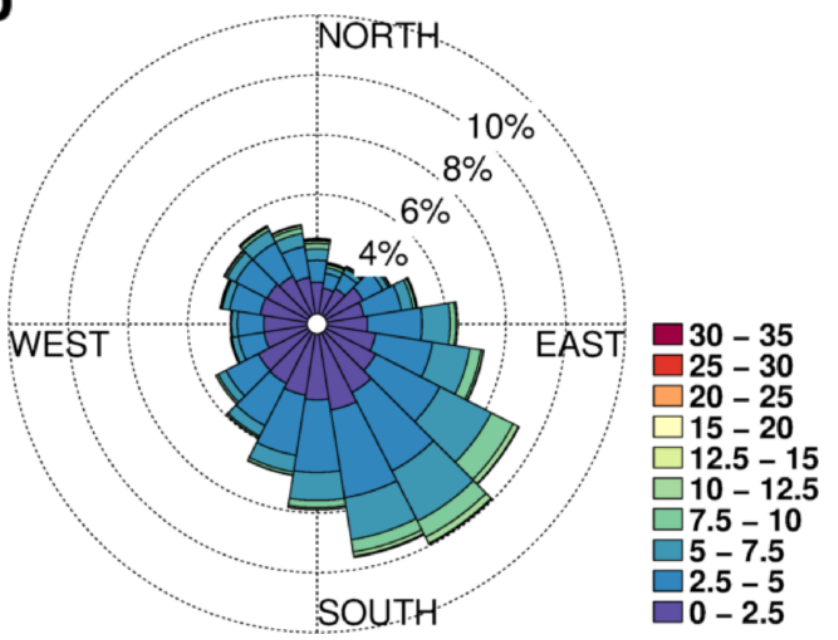

Figure 1.9. Winds speed and direction for (a) RICE AWS and (b) Margarete AWS. The RICE AWS was deployed from 14 November 2010 to 21 November 2013. Margarete wind data is show for the matching interval. 
The ERA-Interim temperature data is not adjusted for the height difference between the ERA-Interim grid point and the AWS (using the dry adiabatic lapse rate) because the height difference is governed to be minuscule, as we use the high-resolution ERA-Interim dataset (where the used grid point coincide with RICE, Figure 1.7). The ratio of standard deviations ( $\sigma$ ratio) between the ERA-Interim and RICE AWS surface air temperature (1.43) and between the Margarete ERA-Interim and Margarete AWS (0.83) reveals that the ERA-Interim data is more variable than RICE AWS surface air temperatures, and the ERA-Interim data is less variable than the Margarete SAT data (Table 1.1). A study by Jones et al. [2016] indicate that the ERAInterim SAT data tend have a cold bias in winter, show larger discrepancies in coastal areas and when atmospheric inversion is present. The RICE ERA-Interim SAT show closer resemblance with the Margarete SAT record, located on the Ross Ice Shelf, than with the RICE AWS SAT record (Figure 1.8), indicating that the ERA-Interim parametrization does not correctly capture the dynamics associated with the Roosevelt Island ice rise. There also appear to be discrepancies for the ERA-Interim SAT data over the ice shelf, however here the difference is not as large and in contrast the variance of the ERA-Interim SAT data appears to be too low. See comparison between the ERA-Interim SAT with the Margarete AWS SAT record (Figure 1.8 and Table 1.1).

Table 1.1. Comparison of daily averages of surface air temperatures from automatic weather station (AWS, observations) and ERA-Interim*

\begin{tabular}{ccccccccc}
\hline & \multicolumn{9}{c}{ Data } \\
& & Time start & Time end & availablity $(\%)$ & Mean T & Max T & Min T & $\sigma$ ratio \\
\hline RICE AWS & 2.5 m SAT & 2010.87 & 2013.89 & 97.22 & -19.98 & -1.63 & -41.73 & 1.43 \\
Margaret AWS & SAT & 2010.87 & 2013.89 & 99.97 & -27.54 & -1.46 & -60.34 & 0.83 \\
ERA-Interim RICE & 2 m SAT & 2010.87 & 2013.89 & 100.00 & -25.09 & -2.39 & -54.33 & - \\
Margaret AWS & SAT & 2009.00 & 2015.00 & 99.87 & -28.50 & -1.46 & -62.24 & 0.81 \\
ERA-Interim RICE & 2.5 m SAT & 1979.00 & 2015.00 & 100.00 & -27.04 & -0.60 & -61.90 & - \\
\hline
\end{tabular}

*To match the available RICE AWS SAT period, shorter records than the available Margarete and ERA-Interim SAT are used for the statistics on row two and three. Statistics based on the full extent of the Margarete and RICE ERA-Interim SAT data are show on the last two rows. ERA-Interim SAT high-resolution (0.125 x 0.125) data was extracted from the closest grid point to the RICE drill site. The ERA-Interim grid points are depicted as light-blue stars in Figure 1.7. 


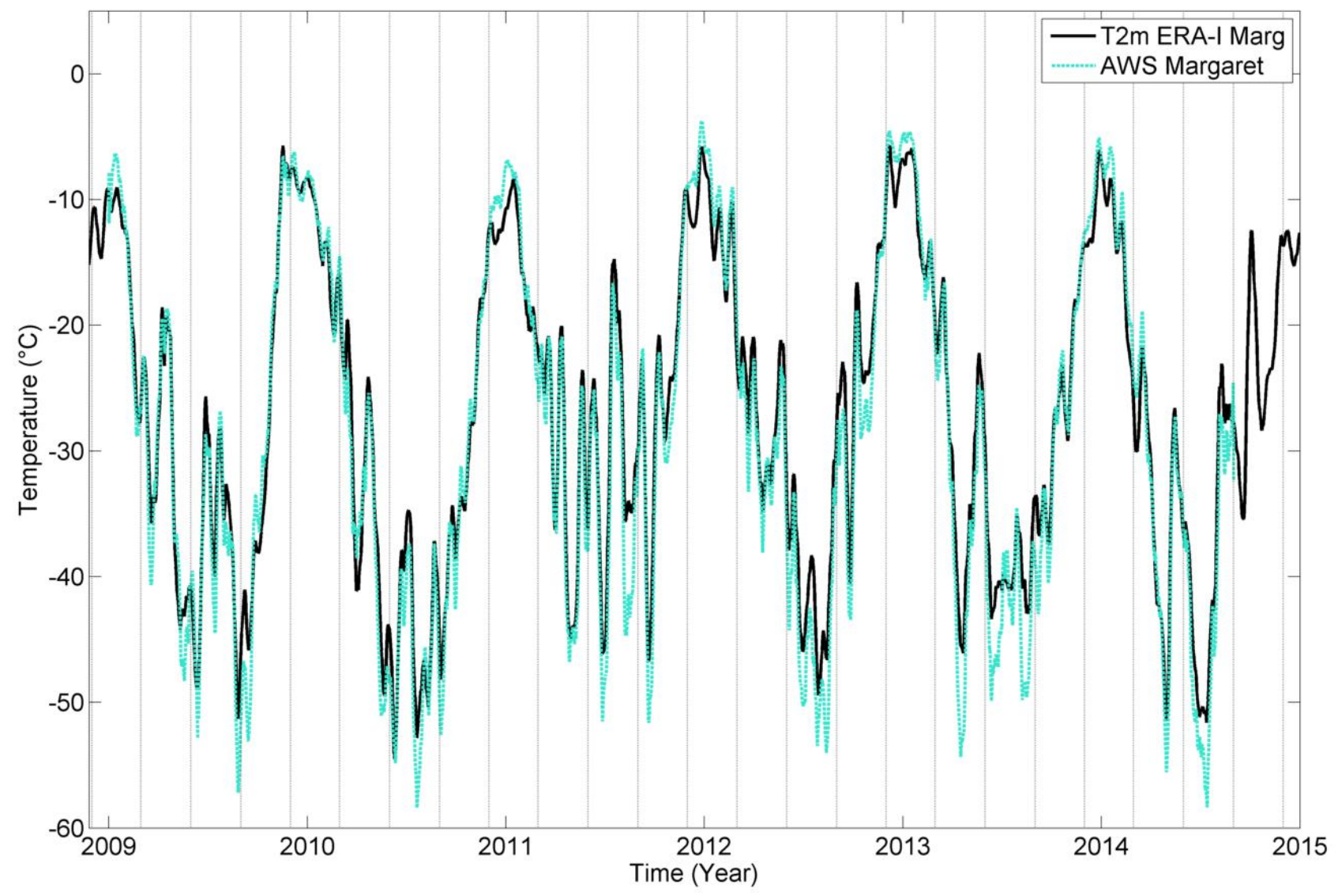

Figure 1.10. Surface air temperatures (SAT) from the Margarete Automatic Weather Station (AWS, light-blue line) and ERA-Interim SAT ( $2 \mathrm{~m}$ T, black line). All SAT data has been smoothed with a 10-day running mean.

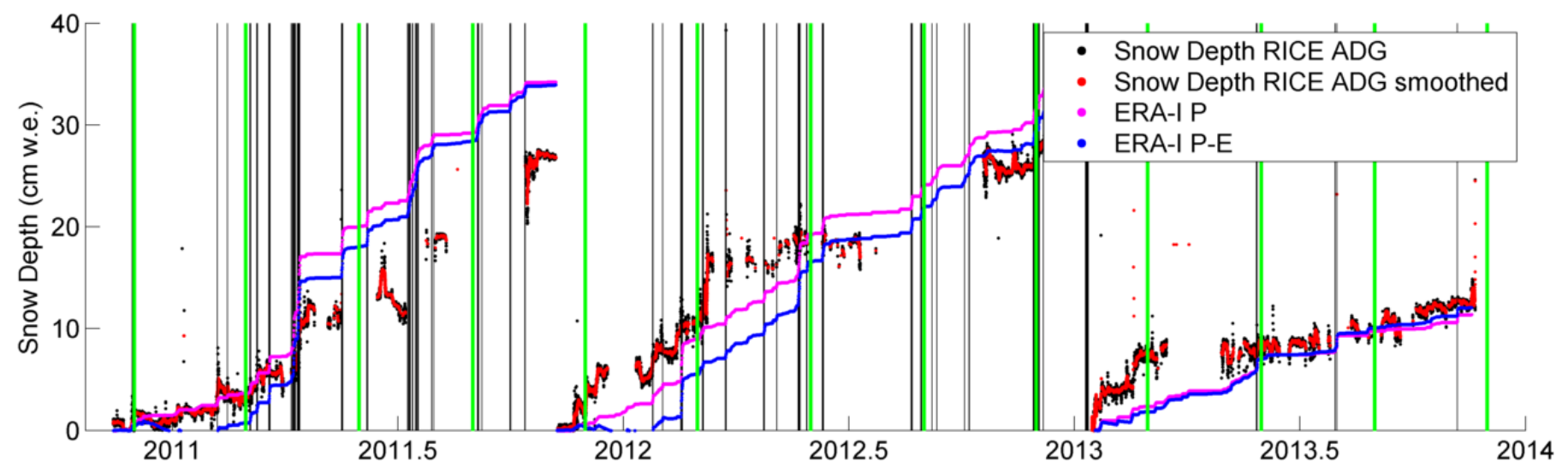

Figure 1.11. RICE Acoustic Depth Gauge (ADG) snow depth data (cm w.e.) from November 2010 to November 2013 (red line), ERA-Interim precipitation (magenta line) and precipitationevaporation (blue line) record. Precipitation events captured by the ERA-Interim precipitation data are marked with black vertical lines and green vertical lines indicate seasonal boundaries. 
Synoptic-type influence has been reported far into the interior of Antarctica (e.g. South Pole) [Sinclair, 1981], but is rare. The predominant type of precipitation on the East Antarctic plateau is from "clear-sky" precipitation formed from moisture advection under clear skies or from moisture generated from sublimation in summer [Bromwich, 1988]. WA lower elevation and closer proximity to Southern Ocean circulation centers results in synoptically driven precipitation and higher annual precipitation compared to the East Antarctic Ice Sheet (EAIS). The annual average accumulation was calculated using an array of ITASE cores is $21 \mathrm{~cm}$ w.e. year $^{-1}$ [Kaspari et al., 2004] and displays regional differences in WA accumulation. Western WA sites (north-western Marie Byrd Land) are characterized by lower accumulation rates compared to sites located east of WAIS divide [Bromwich et al., 2000; Kaspari et al., 2004] and the highest amounts of precipitation are received at the marginal ice slopes near the Amundsen Sea [Bromwich et al., 2000]. The RICE average accumulation rate $(21.54 \mathrm{~cm}$ w.e.) is close to the WA average, with higher accumulation than western WA sites, but with lower accumulation compared to eastern WA and Amundsen-Bellingshausen Sea (ABS) coastal sites. GCMs predicts an increase in Antarctic precipitation with increased temperatures [Manabe and Stouffer, 1980; Thompson and Pollard, 1997; Genthon et al., 2009] that potentially could mitigate sea-level rise [Oerlemans, 1982; Agosta et al., 2012], but this relationship has not been confirmed with observation over the WAIS. Reports of trends in WA snow accumulation have ranged from a decrease for cores located west of WAIS Divide and an increase for eastern cores [Kaspari et al., 2004], or a concurrent decrease west and east of the WAIS ice divide (though this current study used core that were all retrieved in the vicinity of the divide $<75 \mathrm{~km}$ ) [Burgener et al., 2013], to a report of no trends in WA accumulation from a study that used isochronous internal ice sheet layers to determine WA accumulation rates [Siegert and Payne, 2004].

Acoustic Depth Gauge (ADG) snow depths (cm w.e.) from the RICE AWS are shown in Figure 1.11. A clearly discernable event-driven nature of precipitation can be seen where a limited number of larger precipitation events provide the majority of the precipitation throughout any given year (Figure 1.11). The event-driven nature of the precipitation is common among WA and Antarctic coastal sites [e.g., Helsen et al., 2004; Kaspari et al., 2004; Sinclair et al., 2010]. The ERA-Interim precipitation data and the RICE ADG snow depth measurements are generally in agreement (Figure 1.11). Wind scour and snow pack redistribution are processes that are not captured in the ERA-Interim accumulation estimate, and can explain some of the discrepancies. 
The presence of wind scour at RICE can be seen from the negative RICE ADG snow depth changes (cm w.e.) during certain storms (e.g. 2001.5 and 2002.1 Figure 1.11). RICE annual accumulation record is compared with ERA-Interim precipitation to examine whether annual precipitation variability is preserved in the accumulation record. ERA-Interim 3-hourly precipitation $(\mathrm{P})$ and evaporation $(\mathrm{E})$ forecast data are used to estimate the annual accumulation history for RICE between 1979 and 2014. ERA-Interim P and E values (spatial resolution $\left.0.0125^{\circ} \times 0.0125^{\circ}\right)$ from the closest grid-point to the RICE drill site is extracted $\left(79.375^{\circ} \mathrm{S}\right.$, $161.750^{\circ} \mathrm{W}$, depicted as a star in Figure 1.7). The annual ERA-Interim P-E time series are compared to the annual RICE ice core accumulation record and RICE acoustic depth gauge (ADG) snow depth data. The ADG data are converted to $\mathrm{cm}$ w.e. using a snow density of $0.32 \mathrm{~kg}$ $\mathrm{m}^{2}$ (based on density of the top centimeters of the 2010-2011 [Cohen, 2013] and 2011-2012 snow pits).

Figure 1.12 presents the top part of the RICE annual accumulation record and the overlapping annual averaged ERA-Interim precipitation calculated from 3-hourly precipitation data (1979-2009). There is a significant positive correlation between RICE accumulation record and ERA-Interim precipitation $(r=0.75, p<0.001,1979-2009)$. The high correlation between ERA-Interim precipitation and the accumulation shows that precipitation is the most important component of the RICE annual accumulation record. However, the ERA-Interim precipitation time series consistently overestimates annual accumulation, on average $8.2 \mathrm{~cm}$ w.e. higher than the ice core accumulation values. Additionally, the ratio of standard deviation between the RICE ERA-Interim precipitation and snow accumulation (1.57), reveals that the ERA-Interim is more variable than the snow accumulation record. Bromwich [1988] found that snow accumulation in WA is predominantly driven by precipitation, with evaporation through sublimation and/or rime formation displaying a minor influence. This holds true also for RICE, where the ERA-Interim sublimation and rime component largely cancel-out over a year, resulting in a small net sublimation ( $-5 \mathrm{~mm}, 1979-2014)$. These results verify that precipitation explains most of the variability in RICE accumulation. These results also indicate that the ERA-Interim precipitation data captures RICE accumulation variability, but with a lower variance compared to the ERAInterim snowfall record. In addition to ERA-Interim model parametrization, snow scour, drift and reworking of the snow pack by wind are components that may explain some of the discrepancies between the records. 


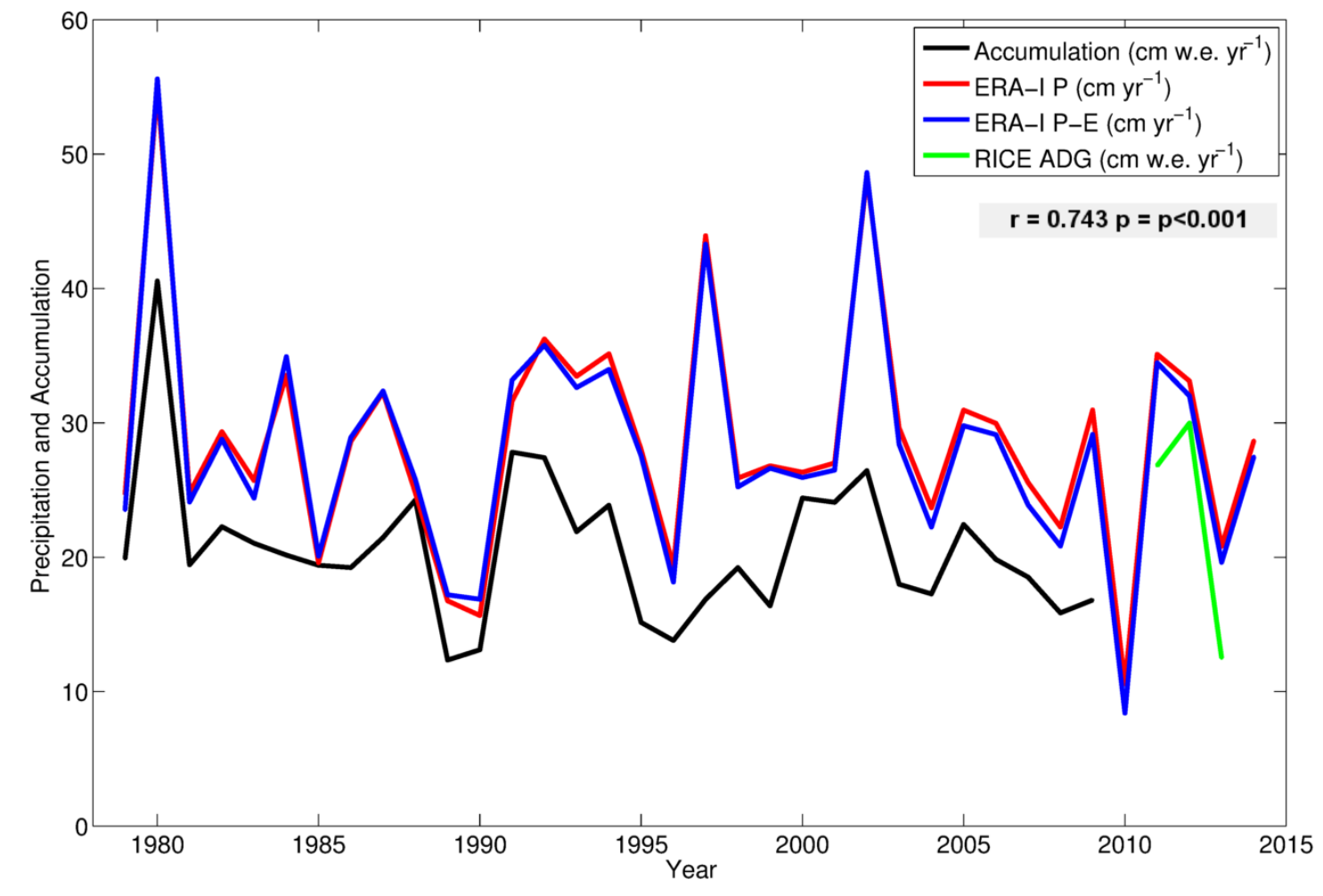

Figure 1.12. RICE annual accumulation record (black line), annually averaged ERA-Interim precipitation (red line) and ERA-Interim evaporation subtracted from precipitation ( $\mathrm{P}-\mathrm{E}$, blue line). Annual snow surface height records from the RICE acoustic depth gauge (ADG) is also provided (green line).

\subsection{RICE Depth-Age Relationship}

The top $38 \mathrm{~m}$ of the RICE ice core has been dated using annual-layer counting. For the annual-layer counting, we used records from several cores and snow pit data: the main deep RICE core, the recently drilled RICE 12/13 B, the RICE 11/12 firn cores, and the Danish-drilled firn core retrieved from Roosevelt Island in 1974-1975, and a snow pit completed during the 2011-2012 season. Characteristics of these cores and snow pit records are summarized in Table 1.2. Between 0 and $13.44 \mathrm{~m}$ the records are projected upon the depth scale of the 12/13 B and between 13.44 and $23.4 \mathrm{~m}$ the records are projected upon the depth scale of the deep RICE core. The only available records below $23.4 \mathrm{~m}$ are from the deep RICE core. 
Table 1.2. Overview of Roosevelt Island ice core and snow pit records*

\begin{tabular}{|c|c|c|c|c|c|c|}
\hline Site & Latitude $(\mathrm{N})$ & Longitude (E) & $\begin{array}{l}\text { Distance from main } \\
\text { RICE core }(\mathrm{m})\end{array}$ & $\begin{array}{l}\text { Depth from } \\
\text { surface }(\mathrm{m})\end{array}$ & $\begin{array}{c}\text { Composite } \\
\text { isotope record }\end{array}$ & $\begin{array}{l}\text { Density } \\
\text { profile }\end{array}$ \\
\hline RICE Deep & -79.3628 & -161.7011 & - & $763(1)$ & $\mathrm{x}$ & $\mathrm{x}$ \\
\hline $12 / 13 \mathrm{~B}$ & -79.3621 & -161.6984 & 93 & 19.3 & $\mathrm{x}$ & \\
\hline $11 / 12 \mathrm{~A}$ & -79.36344 & -161.70399 & 95 & 9.96 & & $\mathrm{x}(2)$ \\
\hline $11 / 12 \mathrm{~B}$ & -79.36344 & -161.70399 & 95 & 10.77 & & $x(2)$ \\
\hline $11 / 12 \mathrm{C}$ & -79.36331 & -161.70572 & 114 & 10.36 & & $\mathrm{x}(2)$ \\
\hline $10 / 11 \mathrm{~A}$ & -79.36396 & -161.70631 & 170 & 9.31 & & \\
\hline 10/11 B & -79.36272 & -161.7136 & 261 & 10.41 & & $\mathrm{x}(2)$ \\
\hline RI 74/75 $51 \mathrm{~m}$ & -79.3667 & -161.6667 & 825 & 51 & & \\
\hline RI 74/75 $11 \mathrm{~m}(3)$ & - & - & - & 10.68 & & \\
\hline $10 / 114 \mathrm{~m}$ snow pit (4) & - & - & - & 4 & & $\mathrm{x}$ \\
\hline $11 / 123 \mathrm{~m}$ snow pit & -79.36344 & -161.70399 & 95 & 3 & & \\
\hline
\end{tabular}

*Footnotes: 1. Isotope and snow accumulation data to $38 \mathrm{~m}$ depth below the surface are used in this study. 2 . Density measured using Dual Energy X-ray Absorptiometry (DEXA). 3. Retrieved from the Roosevelt Island summit [Clausen et al., 1979]. 4. Source Cohen, [2013].

For the annual-layer counting, we primarily use non-sea salt sulfate (nssSO 4 , using $\mathrm{Na}$ as the sea salt reference), a methodology that has been successfully applied for dating of several Antarctic ice cores [O'Brien et al., 1995; Pruett et al., 2004; Dixon et al., 2005; Abram et al., 2011], including the WA ITASE ice core network [Dixon et al., 2005; Steig et al., 2005]. WA $\mathrm{nssSO}_{4}$ concentrations generally peak in early summer [Whitlow et al., 1992; Wagenbach et al., 1998; Kreutz and Mayewski, 1999; Steig et al., 2005]. The $\mathrm{nssSO}_{4}$ is comprised of several components: a biogenic source from dimethyl sulfide (DMS) compounds produced by phytoplankton, as well as volcanic, anthropogenic, and extrapolar sources of the aforementioned parameters from the upper troposphere and lower stratosphere [Steig et al., 2005]. The biogenic and non-biogenic sources tend to peak in early summer due to phytoplankton blooms and the breakdown of the polar vortex, respectively [e.g., Steig et al., 2005]. A nssSO 4 peak can also be an indication of a proximity to an open water source [Abram et al., 2013]. The RICE nssSO 4 peaks coincides with the austral summer season (Figure 1.13). It therefore appears that the $\mathrm{nssSO}_{4}$ at RICE is controlled by an open water source. RICE $\delta \mathrm{D}$ does not always show clear annual cyclcity. RICE d-excess more consistently retain an annual cycle (Figure 1.13b). In contrast, the RICE nssSO4 signal display a consistent clear annual cyclcity (Figure 1.13a). Nonsea-salt SO4 was therefore used as the main proxy for the annual-layer counts and, $\delta \mathrm{D}$ and d-excess were used for additional guidance. Figure 1.13 shows RICE high-resolution ice core data and ERA-Interim records (1995-2012). Three-month running averaged daily (similar to the 
diffusion length of the isotopes) ERA-Interim surface air temperatures (2mT RICE) and 500-hPa geopotential height fields from the ASL region are shown in Figure 1.13c. The three panels in Figure 1.13 demonstrate that $\mathrm{nssSO}_{4}$ peak during the summer season at Roosevelt Island, generally around the 1 January (Figure 1.13c). We therefore assign the annual nssSO 4 chronology markers to the 1 January for each year.

a

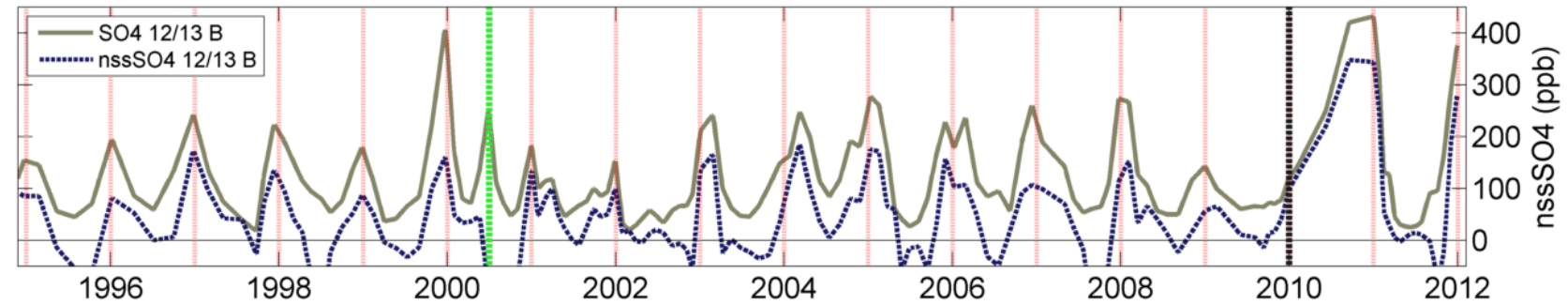

b
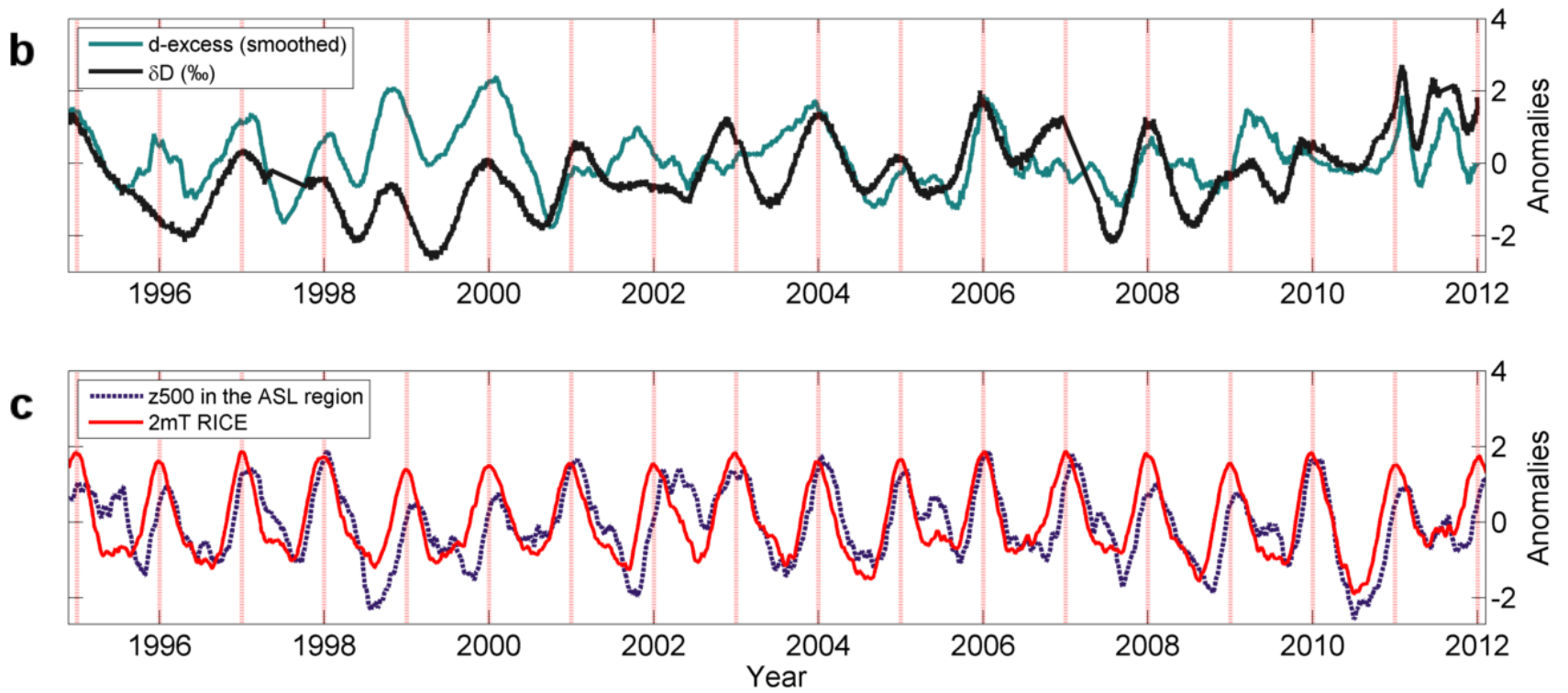

Figure 1.13. (a) Profiles of sulfate $\left(\mathrm{SO}_{4}\right.$, dark green line) and non-sea-salt sulfate (nssSO 4 , blue dashed line). (b) Anomaly plot of $\delta \mathrm{D}$ (black line) and d-excess (light-blue line) for the RICE 12/13 B firn core (c) Anomaly plot of surface air temperature (2m T ERA-Interim, red line) and 500-hPa geopotential height in the ASL region. (a) The green vertical dashed line ( 2000.5) indicate a year with a bi-annual $\mathrm{SO}_{4}$ peak and the dashed black line (2010) indicate an uncertain layer count. (c) Surface air temperatures and geopotential height has been smoothed with a 3 -month running average, which is similar to the time-scale that diffusion acts on the $\delta \mathrm{D}$ record, i.e. the diffusion length (in months). 
For interior WA ITASE sites, there is only a marginal difference between the $\mathrm{SO}_{4}$ and $\mathrm{nssSO}_{4}$ data. The width of the peaks becomes narrower when using nssSO $\mathrm{S}_{4}$, which results in improved consistency in timing between annual-layer counts [Steig et al., 2005]. This is also the case for RICE (Figure 1.13a), but here it is more critical to use $\mathrm{nssSO}_{4}$ for annual-layer counting, as some years show bi-annual $\mathrm{SO}_{4}$ peaks, i.e. some $\mathrm{SO}_{4}$ peaks have no corresponding $\mathrm{nssSO}_{4}$ peak (e.g. see $\mathrm{SO}_{4}$ peak at $\sim 1992.4$ and $\sim 2000.5$, indicated by green vertical lines in Figure 1.15a). If a nssSO ${ }_{4}$ peak is present, we count the $\mathrm{nsSO}_{4}$ peak, if absent (i.e. the calculated $\mathrm{nssSO}_{4}$ concentration is $<0$ ), the $\mathrm{SO}_{4}$ peak is considered sub-annual. There are 12 instances of bi-annual peaks in the top $38 \mathrm{~m}$ of the RICE core. The annual-layer counting (depth-age relationship) of the top $38 \mathrm{~m}$ of the RICE core is provided in Table 1.3.

The Roosevelt Island 1974/75 firn core drilled at Roosevelt Island summit was dated using beta counts [Clausen et al., 1979] and is used here to constrain the dating of the RICE cores. The isotope record of the Roosevelt Island 74/75 firn cores consists of Oxygen-18 water stable isotope $\left(\delta^{18} \mathrm{O}\right)$ measurements [Clausen et al., 1979], but is converted to Deuterium isotope equivalent $\left(\delta \mathrm{D}=\delta^{18} \mathrm{O} * 8.15\right)$ for display purposes using the slope of the meteoric water line (8.15) of the RICE $38 \mathrm{~m}$ composite record. The surface-age control marker and the depth-age relationship for the 74/75 $11 \mathrm{~m}$ core are considered to be known dates. The main deep RICE core has been matched to the 74/75 firn core using common feature in the isotope records (Figure 1.14b). The RICE depth-age relationship is considered to be robust, as the RICE nssSO ${ }_{4}$ layercount ages agrees with the Roosevelt Island 74/75 firn core at the firn core surface control marker (74/75) and through the period where the cores overlap (1951 to 1975). However, we cannot rule out that layers are off by one or two years for the intervals after the known age markers, because during the deeper part of the record, no known age markers are available for an extended period (1900-1954) that contain two ambiguous layers (Table 1.3). 

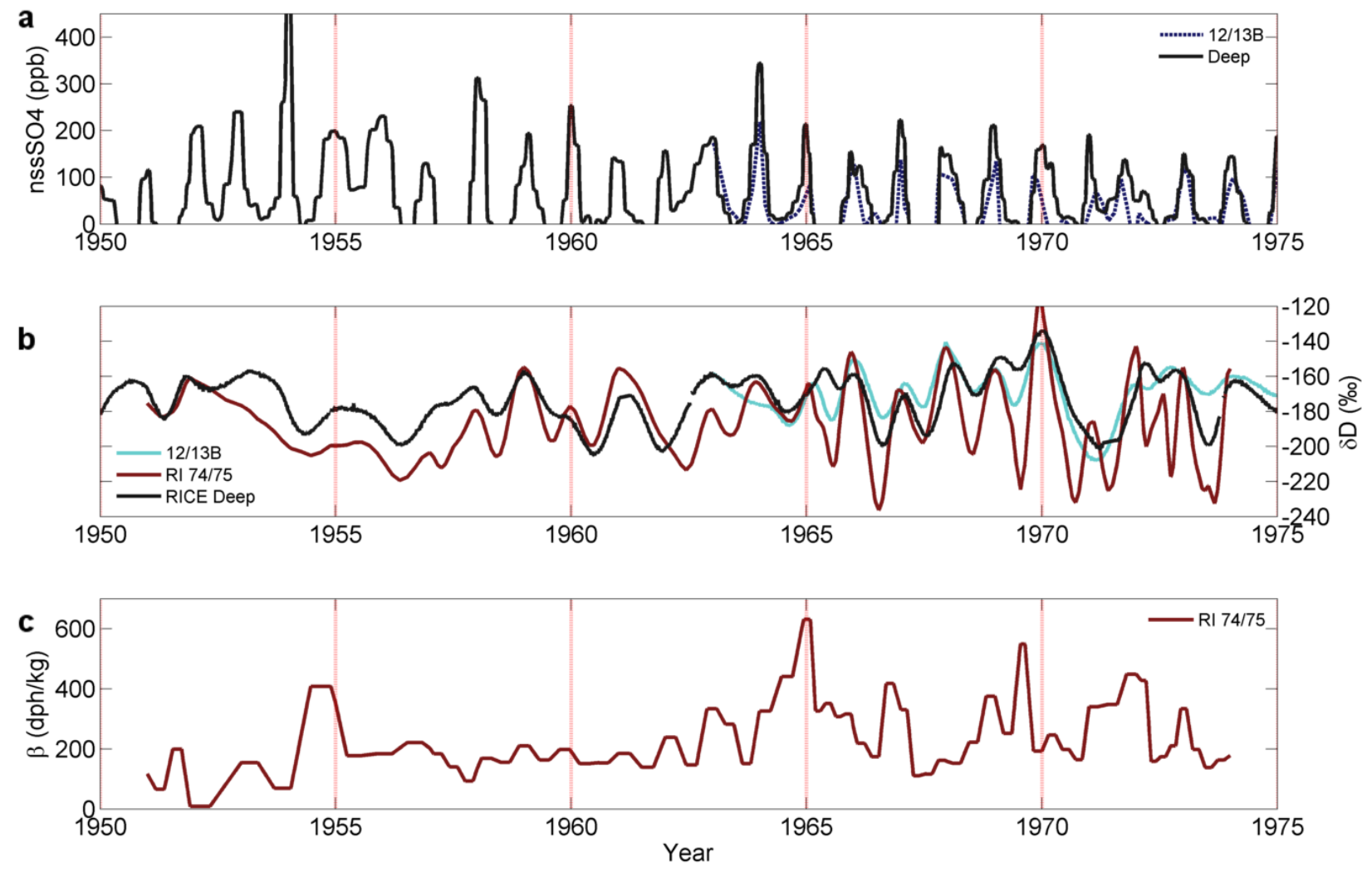

Figure 1.14. Profiles showing the years 1950 to 1975 for: (a) $\mathrm{nssSO}_{4}$ from the RICE 12/13 B core and the deep RICE core; (b) $\delta \mathrm{D}$ from the RICE 12/13 B firn core, the deep RICE core, and the Roosevelt Island 74/75 firn core; (c) and $\beta$-counts ( $\mathrm{dph} \mathrm{kg}{ }^{-1}, \mathrm{dph}$-disintegrations hour ${ }^{-1} \mathrm{~kg}^{-1}$ ) from the Roosevelt Island 74/75 firn core.

Commonly, assessment of the accuracy of ice core age-scales is by identification of signatures from volcanic eruptions in the $\mathrm{nssSO}_{4}$ record [e.g., Steig et al., 2005; Abram et al., 2011]. For the time span of the RICE record presented here (1900-2009), two volcanic eruptions are of interest; Pinatubo, Indonesia (1991.5) and Agung, Indonesia (1963.6), these events have been identified and dated at WAIS Divide [Sigl et al., 2013]. At coastal sites, the biogenic-source $\mathrm{SO}_{4}$ fractions may drown the volcanic signals [Steig et al., 2005], which appears to be the case for the Siple Dome site [Steig et al., 2005]. This also seems to be the case for RICE, where the $\mathrm{nssSO}_{4}$ concentration after these eruptions is not anomalously high. For this reason, it is currently not possible to assess the accuracy of the $38 \mathrm{~m}$ RICE age-scale using volcanic events. This might become a possibility in the future as micro tephra analyses are processed by the RICE tephra team [A. Kurbatov, personal communication 2015] and/or through identification of 
continuous flow $\mathrm{pH}$ peaks at specific wavelengths that are associated with volcanic sources [P. Vallelonga, personal communication 2015].

For the $38 \mathrm{~m}$ RICE record, three layers-counts are considered to be uncertain (at 1.47, 27.9 and $32.1 \mathrm{~m}$ ) due to ambiguous $\mathrm{nssSO}_{4}$ peaks (Table 1.3). To estimate the cumulative uncertainty, we count ambiguous layer as a year and add \pm 0.5 years of uncertainty for each ambiguous layer. Using this method, we estimate an age-uncertainty of \pm 1.5 years for the oldest part of the record (1900-1920). Reasons for assigning the \pm 0.5 age uncertainty vary. The $1.47 \mathrm{~m}$ layer displays a low local maxima that is present in two records, the 11/12 A firn core (64.26 ppb) and the 11/12 snow pit (36.56 ppb). The location of the $1.47 \mathrm{~m}$ layer is indicated by a black vertical line in Figure 1.15a. However, a broad high concentration peak starts prior to this depth in the 12/13 B core, and the $1.47 \mathrm{~m}$ signal seen in the other record is either not present in the 12/13 B record or not discernable due to a stronger influence from another source (Figures 1.15a and 1.13a). The $27.9 \mathrm{~m}$ layer is comprised of a wide peak, with two local maxima's, it is therefore ambiguous if this peak should be counted as one or two years (Figure 1.15b). The $32.1 \mathrm{~m}$ layer is considered to be uncertain as the $\mathrm{nsSSO}_{4}$ concentration is low with $65.9 \mathrm{ppb}$ (Figure 1.15c). 

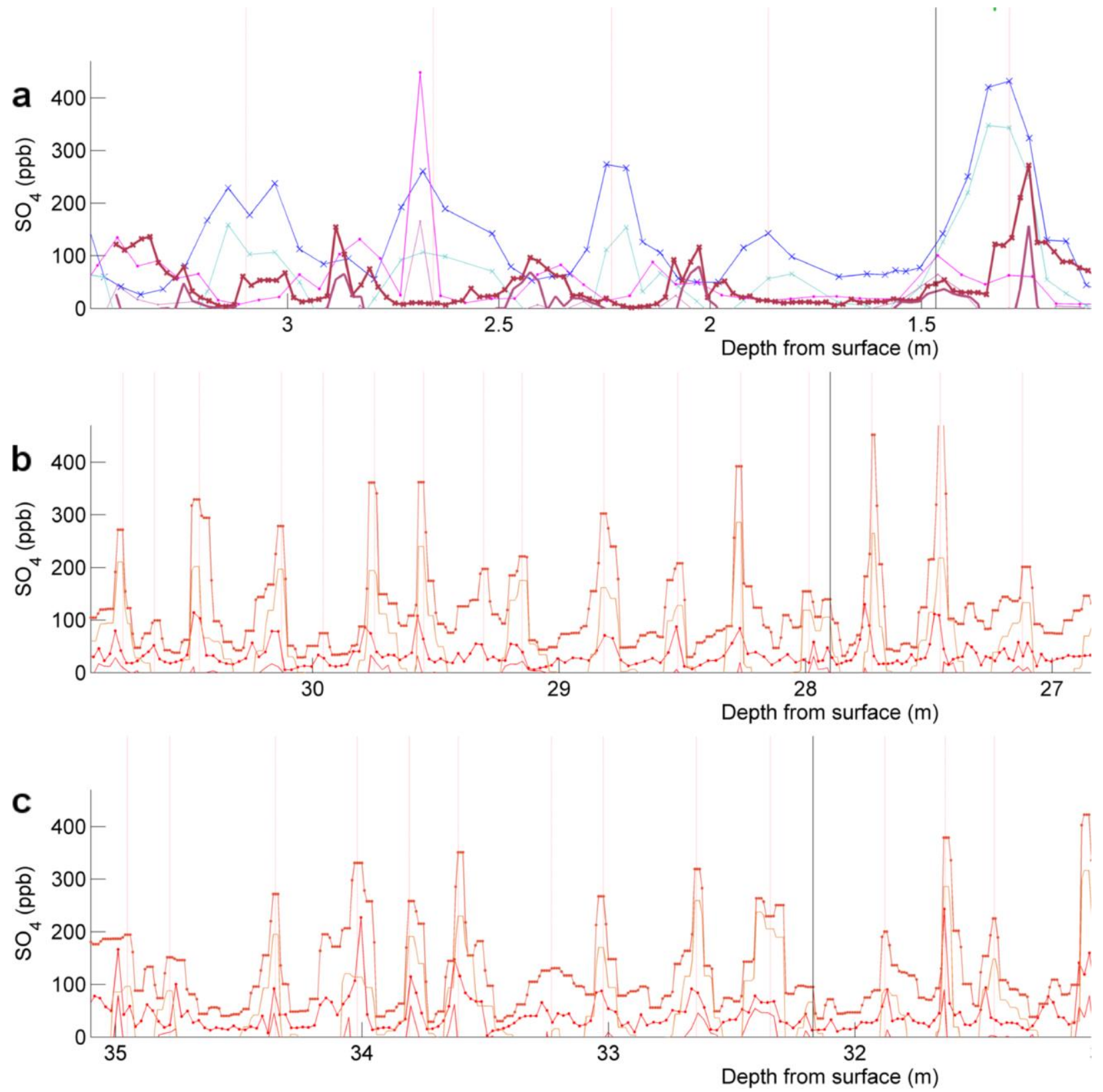

Figure 1.15. nssSO4 records around uncertain layer counts at (a) $1.47 \mathrm{~m}$, (b) $27.9 \mathrm{~m}$, and (c) $32.1 \mathrm{~m}$ depth from the surface. The projected proxy records are centered on the considered layer count (indicated by black vertical lines). 
Table 1.3. Depth-age relationship for the top $38 \mathrm{~m}$ of the RICE ice core.

\begin{tabular}{|c|c|c|c|c|c|c|c|c|}
\hline Year & Depth (m) & $\begin{array}{c}\begin{array}{c}\text { Uncertainty } \\
( \pm \mathrm{yrs})\end{array} \\
\end{array}$ & Year & Depth (m) & $\begin{array}{c}\text { Uncertainty } \\
( \pm \mathrm{yrs})\end{array}$ & Year & Depth (m) & \begin{tabular}{|c|}
$\begin{array}{c}\text { Uncertainty } \\
( \pm \mathrm{yrs})\end{array}$ \\
\end{tabular} \\
\hline 2012 & 0.570 & 0 & 1969 & 16.962 & 0.5 & 1926 & 30.459 & 1.0 \\
\hline 2011 & 1.292 & 0 & 1968 & 17.272 & 0.5 & 1925 & 30.769 & 1.0 \\
\hline 2010 & 1.466 & 0.5 & 1967 & 17.827 & 0.5 & 1924 & 31.035 & 1.0 \\
\hline 2009 & 1.862 & 0.5 & 1966 & 18.215 & 0.5 & 1923 & 31.435 & 1.0 \\
\hline 2008 & 2.234 & 0.5 & 1965 & 18.780 & 0.5 & 1922 & 31.633 & 1.0 \\
\hline 2007 & 2.655 & 0.5 & 1964 & 19.135 & 0.5 & 1921 & 31.878 & 1.0 \\
\hline 2006 & 3.099 & 0.5 & 1963 & 19.435 & 0.5 & 1920 & 32.170 & 1.5 \\
\hline 2005 & 3.587 & 0.5 & 1962 & 19.668 & 0.5 & 1919 & 32.344 & 1.5 \\
\hline 2004 & 3.949 & 0.5 & 1961 & 20.034 & 0.5 & 1918 & 32.643 & 1.5 \\
\hline 2003 & 4.319 & 0.5 & 1960 & 20.411 & 0.5 & 1917 & 33.021 & 1.5 \\
\hline 2002 & 4.851 & 0.5 & 1959 & 20.721 & 0.5 & 1916 & 33.608 & 1.5 \\
\hline 2001 & 5.324 & 0.5 & 1958 & 21.065 & 0.5 & 1915 & 33.808 & 1.5 \\
\hline 2000 & 5.794 & 0.5 & 1957 & 21.398 & 0.5 & 1914 & 34.019 & 1.5 \\
\hline 1999 & 6.104 & 0.5 & 1956 & 21.664 & 0.5 & 1913 & 34.351 & 1.5 \\
\hline 1998 & 6.466 & 0.5 & 1955 & 21.841 & 0.5 & 1912 & 34.780 & 1.5 \\
\hline 1997 & 6.781 & 0.5 & 1954 & 22.119 & 0.5 & 1911 & 34.952 & 1.5 \\
\hline 1996 & 7.036 & 0.5 & 1953 & 22.451 & 0.5 & 1910 & 35.150 & 1.5 \\
\hline 1995 & 7.313 & 0.5 & 1952 & 22.640 & 0.5 & 1909 & 35.350 & 1.5 \\
\hline 1994 & 7.745 & 0.5 & 1951 & 23.072 & 0.5 & 1908 & 35.549 & 1.5 \\
\hline 1993 & 8.137 & 0.5 & 1950 & 23.394 & 0.5 & 1907 & 35.815 & 1.5 \\
\hline 1992 & 8.622 & 0.5 & 1949 & 23.760 & 0.5 & 1906 & 36.215 & 1.5 \\
\hline 1991 & 9.110 & 0.5 & 1948 & 24.148 & 0.5 & 1905 & 36.392 & 1.5 \\
\hline 1990 & 9.343 & 0.5 & 1947 & 24.381 & 0.5 & 1904 & 36.825 & 1.5 \\
\hline 1989 & 9.563 & 0.5 & 1946 & 24.658 & 0.5 & 1903 & 36.990 & 1.5 \\
\hline 1988 & 9.997 & 0.5 & 1945 & 25.124 & 0.5 & 1902 & 37.435 & 1.5 \\
\hline 1987 & 10.374 & 0.5 & 1944 & 25.500 & 0.5 & 1901 & 37.712 & 1.5 \\
\hline 1986 & 10.707 & 0.5 & 1943 & 25.634 & 0.5 & 1900 & 37.967 & 1.5 \\
\hline 1985 & 11.039 & 0.5 & 1942 & 26.011 & 0.5 & & & \\
\hline 1984 & 11.383 & 0.5 & 1941 & 26.255 & 0.5 & & & \\
\hline 1983 & 11.740 & 0.5 & 1940 & 26.544 & 0.5 & & & \\
\hline 1982 & 12.115 & 0.5 & 1939 & 26.754 & 0.5 & & & \\
\hline 1981 & 12.440 & 0.5 & 1938 & 27.120 & 0.5 & & & \\
\hline 1980 & 13.113 & 0.5 & 1937 & 27.453 & 0.5 & & & \\
\hline 1979 & 13.440 & 0.5 & 1936 & 27.730 & 0.5 & & & \\
\hline 1978 & 13.756 & 0.5 & 1935 & 27.900 & 1.0 & & & \\
\hline 1977 & 14.034 & 0.5 & 1934 & 27.985 & 1.0 & & & \\
\hline 1976 & 14.244 & 0.5 & 1933 & 28.263 & 1.0 & & & \\
\hline 1975 & 14.644 & 0.5 & 1932 & 28.518 & 1.0 & & & \\
\hline 1974 & 14.910 & 0.5 & 1931 & 28.817 & 1.0 & & & \\
\hline 1973 & 15.387 & 0.5 & 1930 & 29.150 & 1.0 & & & \\
\hline 1972 & 15.800 & 0.5 & 1929 & 29.549 & 1.0 & & & \\
\hline 1971 & 16.130 & 0.5 & 1928 & 29.749 & 1.0 & & & \\
\hline 1970 & 16.562 & 0.5 & 1927 & 30.126 & 1.0 & & & \\
\hline
\end{tabular}




\subsection{Thesis Outline}

This report is structured as follows. Chapter 1 provides the introduction to the thesis; site characteristics for to the RICE ice core site and the age scale for the top $38 \mathrm{~m}$ of the RICE core. The body of this thesis, Chapters 2-4, are three separate manuscripts, which either have been (Chapter 2) or will be submitted for publication (Chapters 3 and 4).

Chapter 2: High-Resolution Continuous Flow Analysis Setup for Water Isotopic Measurement from Ice Cores using Laser Spectroscopy

Emanuelsson, B. D., W. T. Baisden, N. A. N. Bertler, E. D. Keller, and V. Gkinis, 2015: High-resolution continuous-flow analysis setup for water isotopic measurement from ice cores using laser spectroscopy. Atmos. Meas. Tech., 8, 2869-2883, doi:10.5194/amt-8-2869-2015. http://www.atmos-meas-tech.net/8/2869/2015/.

Chapter 2 presents results from the characterization of the laser spectroscopy setup that continuously measured water isotopes from the RICE ice core during the ice core processing campaigns. This chapter details how a commercially available water standard evaporation unit can be modified to facilitate sample introduction, improve temporal resolution, comply with a rigorous (two-point) calibration regime and be integrated with other simultaneous continuous flow analytical methods (e.g. methane).

The author built the 2013 customized setup, carried out the experiments, data analysis and prepared the manuscript. All co-authors have substantially contributed to this chapter by providing comments on several earlier draft versions of this chapter. Troy Baisden supervised the project and contributed with several central ideas for the experimental design. Elizabeth Keller carried out part of the programing for data handling and calibrations and oversees the RICE database.

Chapter 3: The Role of the Amundsen-Bellingshausen Sea Anticyclonic for Marine Air Mass Intrusions and West Antarctic Climate

Emanuelsson, B. D., N. A. N. Bertler, J. A. Renwick, B. R. Markle, W. T. Baisden, E. D. Keller and P. D. Neff (in prep.). This chapter has been prepared for submission to the international journal Climate Dynamics (Clim Dyn). 
In Chapter 3, the role of anticyclonic activity for marine air mass intrusions into WA and its effect on WA accumulation variability and water isotopic fractionation is quantitatively assessed. It is demonstrated that anticyclones have a key role in the ASL in providing enhanced non-zonal transport, associated with heat and moisture advection into WA. Anticyclonic circulation centers, defined as positive persistent anomalies (PPA) associated with precipitation, are determined for several WA ice core sites and regional differences are determined by investigating PPA frequencies during positive and negative SAM conditions.

The author developed the PPA processing code, carried out the data analysis and prepared the manuscript. All co-authors have substantially contributed to this chapter by providing comments on draft versions of this chapter.

Chapter 4: Central Tropical Pacific ENSO Climate Variability Preserved in Water Stable Isotopes from the Roosevelt Island Climate Evolution (RICE) Ice Core, Antarctica

Emanuelsson, B. D., N. A. N. Bertler, B. R. Markle, J. A. Renwick, W. T. Baisden, E. D. Keller and P.D Neff (in prep.). This chapter has been prepared for submission to Journal of Geophysical Research: Atmospheres.

In Chapter 4, we assess whether a climate signal is preserved in the RICE stable isotope record $(\delta \mathrm{D})$. There result shows that an ENSO signal is preserved on interannual time scale. The isotope record also appear to preserve decadal-scale tropical Pacific climate variability. The RICE SST- $\delta$ D correlation pattern is well explained by the PSA patterns and their interaction, where the influence from PSA2 is strong during the early part of the year (DJF), whereas PSA1 influence dominate during the latter part and peak in spring (SON).

The author carried out the data analysis and prepared the manuscript. All co-authors have substantially contributed to this chapter by providing comments on draft versions. Additionally, Brad Markle shared a version of his isotope-reanalysis correlation MATLAB code, which was modified by the author.

Chapter 5 summarizes the major finding of this $\mathrm{PhD}$ and provides suggestions for future work. 


\subsection{References}

Abram, N. J., R. Mulvaney, and C. Arrowsmith (2011), Environmental signals in a highly resolved ice core from James Ross Island, Antarctica, J. Geophys. Res. Atmos., 116(D20), 1-15, doi:10.1029/2011JD016147.

Abram, N. J., E. W. Wolff, and M. A. J. Curran (2013), A review of sea ice proxy information from polar ice cores, Quat. Sci. Rev., 79, 168-183, doi:http://dx.doi.org/10.1016/j.quascirev.2013.01.011.

Abram, N. J., R. Mulvaney, F. Vimeux, S. J. Phipps, J. Turner, and M. H. England (2014), Evolution of the Southern Annular Mode during the past millennium, Nat. Clim. Chang., 4(7), 564-569.

Aemisegger, F., P. Sturm, P. Graf, H. Sodemann, S. Pfahl, A. Knohl, and H. Wernli (2012), Measuring variations of $\delta 18 \mathrm{O}$ and $\delta 2 \mathrm{H}$ in atmospheric water vapour using two commercial laser-based spectrometers: An instrument characterisation study, Atmos. Meas. Tech., 5, 1491-1511, doi:10.5194/amt-5-1491-2012.

Agosta, C., V. Favier, C. Genthon, H. Gallée, G. Krinner, J. T. M. Lenaerts, and M. R. van den Broeke (2012), A 40-year accumulation dataset for Adelie Land, Antarctica and its application for model validation, Clim. Dyn., 38(1-2), 75-86, doi:10.1007/s00382-011$1103-4$.

Alexander, M. A., I. Bladé, M. Newman, J. R. Lanzante, N.-C. Lau, and J. D. Scott (2002), The Atmospheric Bridge: The Influence of ENSO Teleconnections on Air-Sea Interaction over the Global Oceans, J. Clim., 15(16), 2205-2231, doi:10.1175/15200442(2002)015<2205:TABTIO >2.0.CO;2.

Altenhoff, A. M., O. Martius, M. Croci-Maspoli, C. Schwierz, and H. U. W. C. Davies (2008), Linkage of atmospheric blocks and synoptic-scale Rossby waves: a climatological analysis, Tellus A, 60(5), 1053-1063, doi:10.1111/j.1600-0870.2008.00354.x.

Baer, D. S., J. B. Paul, M. Gupta, and a. O'Keefe (2002), Sensitive absorption measurements in the near-infrared region using off-axis integrated-cavity-output spectroscopy, Appl. Phys. $B$ Lasers Opt., 75, 261-265, doi:10.1007/s00340-002-0971-z.

Berman, E. S. F., N. E. Levin, a Landais, S. N. Li, and T. Owano (2013), Measurement of delta $\mathrm{O}-18$, delta O-17, and O-17-excess in Water by Off-Axis Integrated Cavity Output Spectroscopy and Isotope Ratio Mass Spectrometry, Anal. Chem., 85, 10392-10398, doi:Doi 10.1021/Ac402366t.

Bowen, G. J., and J. Revenaugh (2003), Interpolating the isotopic composition of modern meteoric precipitation, Water Resour. Res., 39(10), 1-13, doi:10.1029/2003WR002086.

Bracegirdle, T. J. (2013), Climatology and recent increase of westerly winds over the Amundsen Sea derived from six reanalyses, Int. J. Climatol., 33(4), 843-851, doi:10.1002/joc.3473.

Bracegirdle, T. J., and G. J. Marshall (2012), The Reliability of Antarctic Tropospheric Pressure and Temperature in the Latest Global Reanalyses, J. Clim., 25(20), 7138-7146, doi:10.1175/JCLI-D-11-00685.1.

Bromwich, D. H. (1988), Snowfall in high southern latitudes, Rev. Geophys., 26(1), 149-168, 
doi:10.1029/RG026i001p00149.

Bromwich, D. H., A. N. Rogers, P. Kållberg, R. I. Cullather, J. W. C. White, and K. J. Kreutz (2000), ECMWF Analyses and Reanalyses Depiction of ENSO Signal in Antarctic Precipitation*, J. Clim., 13(8), 1406-1420, doi:10.1175/15200442(2000)013<1406:EAARDO>2.0.CO;2.

Bromwich, D. H., J. P. Nicolas, A. J. Monaghan, M. A. Lazzara, L. M. Keller, G. A. Weidner, and A. B. Wilson (2013), Central West Antarctica among the most rapidly warming regions on Earth, Nat. Geosci, 6(2), 139-145.

Burgener, L. et al. (2013), An observed negative trend in West Antarctic accumulation rates from 1975 to 2010: Evidence from new observed and simulated records, J. Geophys. Res. Atmos., 118(10), 4205-4216, doi:10.1002/jgrd.50362.

Ciasto, L. M., G. R. Simpkins, and M. H. England (2014), Teleconnections between Tropical Pacific SST Anomalies and Extratropical Southern Hemisphere Climate, J. Clim., 28(1), 56-65, doi:10.1175/JCLI-D-14-00438.1.

Clark, I. D., and P. Fritz (1997), Environmental isotopes in hydrogeology, CRC Press/Lewis Publishers, Boca Raton, FL.

Clausen, H. B., W. Dansgaard, J. O. Nielsen, and J. W. Clough (1979), Surface accumulation on Ross Ice Shelf, Antarct. J. United States, 14(5), 68-74.

Cohen, L. (2013), Atmospheric variability and precipitation in the Ross Sea region, Victoria University of Wellington.

Connolley, W. M. (1997), Variability in annual mean circulation in southern high latitudes, Clim. Dyn., 13, 745-756, doi:10.1007/s003820050195.

Conway, H. (1999), Past and Future Grounding-Line Retreat of the West Antarctic Ice Sheet, Science (80-. )., 286(5438), 280-283, doi:10.1126/science.286.5438.280.

Costanza, C. A., M. A. Lazzara, L. M. Keller, and J. J. Cassano (2016), The surface climatology of the Ross Ice Shelf Antarctica, Int. J. Climatol., n/a-n/a, doi:10.1002/joc.4681.

Craig, H. (1961), Isotopic Variations in Meteoric Waters, Science (80-. )., 133(3465), 17021703.

Crosson, E. R. (2008), A cavity ring-down analyzer for measuring atmospheric levels of methane, carbon dioxide, and water vapor, Appl. Phys. B Lasers Opt., 92, 403-408, doi: 10.1007/s00340-008-3135-y.

Cuffey, K. M., and E. J. Steig (1998), Isotopic diffusion in polar firn: Implications for interpretation of seasonal climate parameters in ice-core records, with emphasis on central Greenland, J. Glaciol., 44(147), 273-284.

Cullather, R. I., D. H. Bromwich, and M. L. Van Woert (1996), Interannual variations in Antarctic precipitation related to El Niño-Southern Oscillation, J. Geophys. Res. Atmos., 101(D14), 19109-19118, doi:10.1029/96JD01769.

Dansgaard, W. (1964), Stable isotopes in precipitation, Tellus, 16(4), 436-468, doi:10.1111/j.2153-3490.1964.tb00181.x. 
Dee, D. P. et al. (2011), The ERA-Interim reanalysis: configuration and performance of the data assimilation system, Q. J. R. Meteorol. Soc., 137(656), 553-597, doi:10.1002/qj.828.

Delaygue, G., V. Masson, J. Jouzel, R. D. Koster, and R. J. Healy (2000), The origin of Antarctic precipitation: A modelling approach, Tellus, Ser. B Chem. Phys. Meteorol., 52(1), 19-36, doi:10.1034/j.1600-0889.2000.00951.x.

Deser, C., M. A. Alexander, S.-P. Xie, and A. S. Phillips (2010), Sea surface temperature variability: Patterns and mechanisms, Ann. Rev. Mar. Sci., 2, 115-143.

Ding, Q., E. J. Steig, D. S. Battisti, and M. Kuttel (2011), Winter warming in West Antarctica caused by central tropical Pacific warming, Nat. Geosci, 4(6), 398-403.

Ding, Q., E. J. Steig, D. S. Battisti, and J. M. Wallace (2012), Influence of the Tropics on the Southern Annular Mode, J. Clim., 25(18), 6330-6348, doi:10.1175/JCLI-D-11-00523.1.

Dixon, D., P. A. Mayewski, S. Kaspari, K. Kreutz, G. S. Hamilton, K. Maasch, S. B. Sneed, and M. J. Handley (2005), A 200-year sulfate record from sixteen antarctic ice cores and associations with southern ocean sea ice extent, Ann. Glaciol., 41(1), 155-166.

Emanuelsson, B. D., W. T. Baisden, N. A. N. Bertler, E. D. Keller, and V. Gkinis (2015), Highresolution continuous-flow analysis setup for water isotopic measurement from ice cores using laser spectroscopy, Atmos. Meas. Tech., 8(7), 2869-2883, doi:10.5194/amt-8-28692015.

England, M. H., S. McGregor, P. Spence, G. A. Meehl, A. Timmermann, W. Cai, A. Sen Gupta, M. J. McPhaden, A. Purich, and A. Santoso (2014), Recent intensification of wind-driven circulation in the Pacific and the ongoing warming hiatus, Nat. Clim. Chang., 4(3), 222227.

EPICA Community Members (2004), Eight glacial cycles from an Antarctic ice core, Nature, 429, 623-628, doi:http://www.nature.com/nature/journal/v429/n6992/suppinfo/nature02599_S1.html.

Epstein, S., and I. Goddard (1963), Oxygen-isotope ratios in Antarctic snow, firn, and ice, $J$ Geol, 71, 698-720.

Fisher, D. a (1985), Stratigraphic noise in time series derived from ice cores, Ann. Glaciol., 7 , 76-83.

Fisher, D. a, and B. T. Alt (1985), A global oxygen isotope model - semi-empirical, zonally averaged, Ann. Glaciol., 7, 117-124.

Fogt, R. L., and D. H. Bromwich (2006), Decadal variability of the ENSO teleconnection to the high-latitude south pacific governed by coupling with the Southern Annular mode, J. Clim., 19, 979-997, doi:10.1175/JCLI3671.1.

Genthon, C., C. Krinner, and H. Castebrunet (2009), Antarctic precipitation and climate-change predictions: Horizontal resolution and margin vs plateau issues, Ann. Glaciol., 50(50), 5560, doi:10.3189/172756409787769681.

Gill, A. E. (1980), Some simple solutions for heat-induced tropical circulation, Q. J. R. Meteorol. Soc., 106(449), 447-462, doi:10.1002/qj.49710644905. 
Gkinis, V., T. J. Popp, T. Blunier, M. Bigler, S. Schüpbach, E. Kettner, and S. J. Johnsen (2011), Water isotopic ratios from a continuously melted ice core sample, Atmos. Meas. Tech., 4, 2531-2542, doi:10.5194/amt-4-2531-2011.

Gonfiantini, R. (1978), Standards for stable isotope measurements in natural compounds, Nature, 271(5645), 534-536.

Helsen, M. M., R. S. W. van de Wal, M. R. van den Broeke, E. R. T. Kerstel, V. MassonDelmotte, H. a J. Meijer, C. H. Reijmer, and M. P. Scheele (2004), Modelling the isotopic composition of snow using backward trajectories: A particular precipitation event in Dronning Maud Land, Antarctica, Ann. Glaciol., 39, 293-299, doi:10.3189/172756404781814230.

Helsen, M. M., R. S. W. van de Wal, M. R. van den Broeke, V. Masson-Delmotte, H. a J. Meijer, M. P. Scheele, and M. Werner (2006), Modeling the isotopic composition of Antarctic snow using backward trajectories: Simulation of snow pit records, J. Geophys. Res. Atmos., 111, 1-19, doi:10.1029/2005JD006524.

Hendricks, M. B., D. J. DePaolo, and R. C. Cohen (2000), Space and time variation of $\delta 180$ and $\delta \mathrm{D}$ in precipitation: Can paleotemperature be estimated from ice cores?, Global Biogeochem. Cycles, 14(3), 851-861, doi:10.1029/1999GB001198.

Hobbs, W. R., and M. N. Raphael (2010), The Pacific zonal asymmetry and its influence on Southern Hemisphere sea ice variability, Antarct. Sci., 22(05), 559-571, doi:10.1017/S0954102010000283.

Hosking, J. S., A. Orr, G. J. Marshall, J. Turner, and T. Phillips (2013), The Influence of the Amundsen-Bellingshausen Seas Low on the Climate of West Antarctica and Its Representation in Coupled Climate Model Simulations, J. Clim., 26(17), 6633-6648, doi:10.1175/JCLI-D-12-00813.1.

Hoskins, B. J., and D. J. Karoly (1981), The Steady Linear Response of a Spherical Atmosphere to Thermal and Orographic Forcing, J. Atmos. Sci., 38(6), 1179-1196, doi:10.1175/15200469(1981)038<1179:TSLROA>2.0.CO;2.

Johnsen, S. J., H. B. Clausen, K. M. Cuffey, G. Hoffmann, J. Schwander, and T. Creyts (2000), Diffusion of stable isotopes in polar firn and ice: the isotope effect in firn diffusion, Phys. ice core Rec., 159, 121-140.

Johnson, L. R., Z. D. Sharp, J. Galewsky, M. Strong, A. D. Van Pelt, F. Dong, and D. Noone (2011), Hydrogen isotope correction for laser instrument measurement bias at low water vapor concentration using conventional isotope analyses: application to measurements from Mauna Loa Observatory, Hawaii, Rapid Commun. Mass Spectrom., 25(5), 608-616, doi:10.1002/rcm.4894.

Jones, R. W., I. A. Renfrew, A. Orr, B. G. M. Webber, D. M. Holland, and M. A. Lazzara (2016), Evaluation of four global reanalysis products using in-situ observations in the Amundsen Sea Embayment, Antarctica, J. Geophys. Res. Atmos., n/a-n/a, doi:10.1002/2015JD024680.

Jouzel, J., and L. Merlivat (1984), Deuterium and oxygen 18 in precipitation: Modeling of the isotopic effects during snow formation, J. Geophys. Res. Atmos., 89(D7), 11749-11757, 
doi:10.1029/JD089iD07p11749.

Kanamitsu, M., W. Ebisuzaki, J. Woollen, S.-K. Yang, J. J. Hnilo, M. Fiorino, and G. L. Potter (2002), NCEP-DOE AMIP-II Reanalysis (R-2), Bull. Am. Meteorol. Soc., 83(11), 16311643, doi:10.1175/BAMS-83-11-1631.

Karoly, D. J. (1989), Southern Hemisphere Circulation Features Associated with El NiñoSouthern Oscillation Events, J. Clim., 2(11), 1239-1252, doi:10.1175/15200442(1989)002<1239:SHCFAW>2.0.CO;2.

Kaspari, S., P. A. Mayewski, D. A. Dixon, V. B. Spikes, S. B. Sneed, M. J. Handley, and G. S. Hamilton (2004), Climate variability in West Antarctica derived from annual accumulationrate records from ITASE firn/ice cores, Ann. Glaciol., 39, 585-594, doi:10.3189/172756404781814447.

Kerstel, E., R. van Trigt, N. Dam, J. Reuss, and H. a J. Meijer (1999), Simultaneous determination of the $\mathrm{H}-2 / \mathrm{H}-1, \mathrm{O}-17 / \mathrm{O}-16$, and $\mathrm{O}-18 / \mathrm{O}-16$ isotope abundance ratios in water by means of laser spectrometry, Anal. Chem., 71(23), 5297-5303, doi:10.1021/ac990621e.

Kidson, J. W. (1988), Interannual Variations in the Southern Hemisphere Circulation, J. Clim., 1(12), 939-953, doi:10.1175/1520-0442(1988)001<1177:IVITSH>2.0.CO;2.

Knuth, S. L., G. J. Tripoli, J. E. Thom, and G. a. Weidner (2010), The influence of blowing snow and precipitation on snow depth change across the Ross Ice Shelf and Ross Sea regions of Antarctica, J. Appl. Meteorol. Climatol., 49(6), 1306-1321, doi:10.1175/2010JAMC2245.1.

Kreutz, K. J., and P. A. Mayewski (1999), Spatial variability of Antarctic surface snow glaciochemistry: implications for palaeoatmospheric circulation reconstructions, Antarct. Sci., 11(01), 105-118.

Kreutz, K. J., P. A. Mayewski, I. I. Pittalwala, L. D. Meeker, M. S. Twickler, and S. I. Whitlow (2000), Sea level pressure variability in the Amundsen Sea region inferred from a West Antarctic glaciochemical record, J. Geophys. Res. Atmos., 105(D3), 4047-4059, doi:10.1029/1999JD901069.

Krinner, G., C. Genthon, and J. Jouzel (1997), GCM analysis of local influences on ice core $\delta$ signals, Geophys. Res. Lett., 24(22), 2825-2828, doi:10.1029/97GL52891.

Küttel, M., E. J. Steig, Q. Ding, A. J. Monaghan, and D. S. Battisti (2012), Seasonal climate information preserved in West Antarctic ice core water isotopes: relationships to temperature, large-scale circulation, and sea ice, Clim. Dyn., 39(7), 1841-1857, doi:10.1007/s00382-012-1460-7.

L'Heureux, M. L., and D. W. J. Thompson (2006), Observed Relationships between the El Niño-Southern Oscillation and the Extratropical Zonal-Mean Circulation, J. Clim., 19(2), 276-287, doi:10.1175/JCLI3617.1.

Lachlan-Cope, T., and W. Connolley (2006), Teleconnections between the tropical Pacific and the Amundsen-Bellinghausens Sea: Role of the El Niño/Southern Oscillation, J. Geophys. Res. Atmos., 111(D23), n/a-n/a, doi:10.1029/2005JD006386.

Lachlan-Cope, T. A., W. M. Connolley, and J. Turner (2001), The role of the non-axisymmetric antarctic orography in forcing the observed pattern of variability of the Antarctic climate, 
Geophys. Res. Lett., 28(21), 4111-4114, doi:10.1029/2001GL013465.

Lazzara, M. A., G. A. Weidner, L. M. Keller, J. E. Thom, and J. J. Cassano (2012), Antarctic Automatic Weather Station Program: 30 Years of Polar Observation, Bull. Am. Meteorol. Soc., 93(10), 1519-1537, doi:10.1175/BAMS-D-11-00015.1.

Lenaerts, J. T. M., J. Brown, M. Van den Broeke, K. Matsuoka, R. Drews, D. Callens, I. Gorodetskaya, E. Van Meijgaard, F. Pattyn, and N. P.M. Van Lipzig (2014), High climate and surface mass balance variability induced by Antarctic ice rises, J. Glaciol., 60(224), 124, doi:10.3189/2014JoG14J040.

Limpasuvan, V., and D. L. Hartmann (2000), Wave-Maintained Annular Modes of Climate Variability, J. Clim., 13(24), 4414-4429, doi:10.1175/1520-

0442(2000)013<4414:WMAMOC>2.0.CO;2.

Liu, J. (2004), Interpretation of recent Antarctic sea ice variability, Geophys. Res. Lett., 31(2), 2000-2003, doi:10.1029/2003GL018732.

van Loon, H., and D. J. Shea (1987), The Southern Oscillation. Part VI: Anomalies of Sea Level Pressure on the Southern Hemisphere and of Pacific Sea Surface Temperature during the Development of a Warm Event, Mon. Weather Rev., 115(2), 370-379, doi:10.1175/15200493(1987)115<0370:TSOPVA>2.0.CO;2.

Manabe, S., and R. J. Stouffer (1980), Sensitivity of a global climate model to an increase of CO 2 concentration in the atmosphere, J. Geophys. Res., 85(80), 5529-5554, doi:10.1029/JC085iC10p05529.

Marshall, G. J., and D. W. J. Thompson (2016), The signatures of large-scale patterns of atmospheric variability in Antarctic surface temperatures, J. Geophys. Res. Atmos., 121(7), 3276-3289, doi:10.1002/2015JD024665.

Marshall, G. J., P. A. Stott, J. Turner, W. M. Connolley, J. C. King, and T. A. Lachlan-Cope (2004), Causes of exceptional atmospheric circulation changes in the Southern Hemisphere, Geophys. Res. Lett., 31(14), n/a-n/a, doi:10.1029/2004GL019952.

Maselli, O. J., D. Fritzsche, L. Layman, J. R. McConnell, and H. Meyer (2013), Comparison of water isotope-ratio determinations using two cavity ring-down instruments and classical mass spectrometry in continuous ice-core analysis., Isotopes Environ. Health Stud., 49, 387-398, doi:10.1080/10256016.2013.781598.

Masson-Delmotte, V. et al. (2008), A review of antarctic surface snow isotopic composition: Observations, atmospheric circulation, and isotopic modeling, J. Clim., 21(188), 33593387, doi:10.1175/2007JCLI2139.1.

Masson-Delmotte, V. et al. (2010), Abrupt change of Antarctic moisture origin at the end of Termination II., Proc. Natl. Acad. Sci. U. S. A., 107(27), 12091-12094, doi:10.1073/pnas.0914536107.

Meehl, G. A., J. M. Arblaster, C. M. Bitz, C. T. Y. Chung, and H. Teng (2016), Antarctic sea-ice expansion between 2000 and 2014 driven by tropical Pacific decadal climate variability, Nat. Geosci, advance on.

Merlivat, L., and J. Jouzel (1979), Global climatic interpretation of the deuterium-oxygen 18 
relationship for precipitation, J. Geophys. Res. Ocean., 84(C8), 5029-5033, doi:10.1029/JC084iC08p05029.

Mo, K. C. (2000), Relationships between Low-Frequency Variability in the Southern Hemisphere and Sea Surface Temperature Anomalies, J. Clim., 13(20), 3599-3610, doi:10.1175/1520-0442(2000)013<3599:RBLFVI>2.0.CO;2.

Mo, K. C., and M. Ghil (1987), Statistics and Dynamics of Persistent Anomalies, J. Atmos. Sci., 44(5), 877-902, doi:10.1175/1520-0469(1987)044<0877:SADOPA>2.0.CO;2.

Mo, K. C., and R. W. Higgins (1998), The Pacific-South American Modes and Tropical Convection during the Southern Hemisphere Winter, Mon. Weather Rev., 126(6), 15811596, doi:10.1175/1520-0493(1998)126<1581:TPSAMA>2.0.CO;2.

Mo, K. C., and J. N. Paegle (2001), The Pacific-South American modes and their downstream effects, Int. J. Climatol., 21(10), 1211-1229, doi:10.1002/joc.685.

Mulvaney, R., N. J. Abram, R. C. a. Hindmarsh, C. Arrowsmith, L. Fleet, J. Triest, L. Sime, O. Alemany, and S. Foord (2012), Recent Antarctic Peninsula warming relative to Holocene climate and ice shelf history, Nature, 488(7414), 141-144, doi:10.1038/nature11391.

Nereson, N. a., and E. D. Waddington (2002), Isochrones and isotherms beneath migrating ice divides, J. Glaciol., 48, 95-108, doi:10.3189/172756502781831647.

Noone, D. (2008), The influence of midlatitude and tropical overturning circulation on the isotopic composition of atmospheric water vapor and Antarctic precipitation, J. Geophys. Res. Atmos., 113(4), 1-13, doi:10.1029/2007JD008892.

Noone, D., and I. Simmonds (2002), Annular variations in moisture transport mechanisms and the abundance of $\delta 180$ in Antarctic snow, J. Geophys. Res. Atmos., 107(D24), ACL 3-1ACL 3-11, doi:10.1029/2002JD002262.

O’Brien, S. R., P. A. Mayewski, L. D. Meeker, D. A. Meese, M. S. Twickler, and S. I. Whitlow (1995), Complexity of Holocene Climate as Reconstructed from a Greenland Ice Core, Sci. , 270 (5244), 1962-1964.

Oerlemans, J. (1982), Response ' of the Antarctic Ice " Sheet To a Climatic Warming,: a Model Study, , 2(99), 1-11.

Okumura, Y. M., D. Schneider, C. Deser, and R. Wilson (2012), Decadal-Interdecadal Climate Variability over Antarctica and Linkages to the Tropics: Analysis of Ice Core, Instrumental, and Tropical Proxy Data, J. Clim., 25(21), 7421-7441, doi:10.1175/JCLI-D-12-00050.1.

van Ommen, T. D., and V. Morgan (1997), Calibrating the ice core paleothermometer using seasonality, J. Geophys., 102, 9351-9357, doi:10.1029/96JD04014.

Van Ommen, T. D., V. Morgan, and M. a J. Curran (2004), Deglacial and Holocene changes in accumulation at Law Dome, East Antarctica, Ann. Glaciol., 39(i), 359-365, doi:10.3189/172756404781814221.

Orsi, A. J., B. D. Cornuelle, and J. P. Severinghaus (2012), Little Ice Age cold interval in West Antarctica: Evidence from borehole temperature at the West Antarctic Ice Sheet (WAIS) Divide, Geophys. Res. Lett., 39(9), n/a-n/a, doi:10.1029/2012GL051260. 
Parish, T. R., and D. H. Bromwich (1998), A Case Study of Antarctic Katabatic Wind Interaction with Large-Scale Forcing*, Mon. Weather Rev., 126, 199-209, doi:10.1175/15200493(1998)126<0199:ACSOAK>2.0.CO;2.

Parish, T. R., J. J. Cassano, and M. W. Seefeldt (2006), Characteristics of the Ross Ice Shelf air stream as depicted Antarctic Mesoscale Prediction System simulations, J. Geophys. Res. Atmos., 111, 1-12, doi:10.1029/2005JD006185.

Payne, A. J., A. Vieli, A. P. Shepherd, D. J. Wingham, and E. Rignot (2004), Recent dramatic thinning of largest West Antarctic ice stream triggered by oceans, Geophys. Res. Lett., 31(23), 1-4, doi:10.1029/2004GL021284.

Petit, R. J., D. Raynaud, I. Basile, J. Chappellaz, C. Ritz, M. Delmotte, M. Legrand, C. Lorius, and L. Pe (1999), Climate and atmospheric history of the past 420,000 years from the Vostok ice core, Antarctica, Nature, 399, 429-413, doi:10.1038/20859.

Pritchard, H. D., S. R. M. Ligtenberg, H. A. Fricker, D. G. Vaughan, M. R. van den Broeke, and L. Padman (2012), Antarctic ice-sheet loss driven by basal melting of ice shelves, Nature, 484(7395), 502-505.

Pruett, L. E., K. J. Kreutz, M. Wadleigh, P. A. Mayewski, and A. Kurbatov (2004), Sulfur isotopic measurements from a West Antarctic ice core: Implications for sulfate source and transport, Ann. Glaciol., 39(1), 161-168, doi:10.3189/172756404781814339.

Raphael, M. N. (2004), A zonal wave 3 index for the Southern Hemisphere, Geophys. Res. Lett., 31(December), 1-4, doi:10.1029/2004GL020365.

Raphael, M. N., G. J. Marshall, J. Turner, R. Fogt, D. Schneider, D. a. Dixon, J. S. Hosking, J. M. Jones, and W. R. Hobbs (2015), The Amundsen Sea Low: Variability, Change and Impact on Antarctic Climate, Bull. Am. Meteorol. Soc., 150331122920005, doi:10.1175/BAMS-D-14-00018.1.

Raymond, C. F. (1983), Deformation in the vicinity of ice divides, J. Glaciol., (103), 357-373.

Renwick, J. A. (1998), ENSO-Related Variability in the Frequency of South Pacific Blocking, Mon. Weather Rev., 126(12), 3117-3123, doi:10.1175/15200493(1998)126<3117:ERVITF>2.0.CO;2.

Renwick, J. A. (2002), Southern Hemisphere Circulation and Relations with Sea Ice and Sea Surface Temperature, J. Clim., 15(21), 3058-3068, doi:10.1175/15200442(2002)015<3058:SHCARW>2.0.CO;2.

Renwick, J. A. (2005), Persistent Positive Anomalies in the Southern Hemisphere Circulation, Mon. Weather Rev., 133(4), 977-988, doi:10.1175/MWR2900.1.

Rintoul, S. R. (2007), Rapid freshening of Antarctic Bottom Water formed in the Indian and Pacific oceans, Geophys. Res. Lett., 34(6), 1-5, doi:10.1029/2006GL028550.

Rodrigues, R. R., E. J. D. Campos, and R. Haarsma (2015), The Impact of ENSO on the South Atlantic Subtropical Dipole Mode, J. Clim., 28(7), 2691-2705, doi:10.1175/JCLI-D-1400483.1.

Schneider, D. P., and D. C. Noone (2007), Spatial covariance of water isotope records in a global 
network of ice cores spanning twentieth-century climate change, J. Geophys. Res. Atmos., 112(D18), n/a-n/a, doi:10.1029/2007JD008652.

Schneider, D. P., E. J. Steig, T. D. van Ommen, D. A. Dixon, P. A. Mayewski, J. M. Jones, and C. M. Bitz (2006), Antarctic temperatures over the past two centuries from ice cores, Geophys. Res. Lett., 33(16), 1-5, doi:10.1029/2006GL027057.

Schneider, D. P., C. Deser, and Y. Okumura (2011), An assessment and interpretation of the observed warming of West Antarctica in the austral spring, Clim. Dyn., 38(1), 323-347, doi:10.1007/s00382-010-0985-x.

Schneider, D. P., Y. Okumura, and C. Deser (2012), Observed Antarctic Interannual Climate Variability and Tropical Linkages, J. Clim., 25(12), 4048-4066, doi:10.1175/JCLI-D-1100273.1.

Schneider, D. P., C. Deser, and T. Fan (2015), Comparing the Impacts of Tropical SST Variability and Polar Stratospheric Ozone Loss on the Southern Ocean Westerly Winds, $J$. Clim., 28(23), 9350-9372, doi:10.1175/JCLI-D-15-0090.1.

Seager, R., N. Naik, W. Baethgen, A. Robertson, Y. Kushnir, J. Nakamura, and S. Jurburg (2010), Tropical Oceanic Causes of Interannual to Multidecadal Precipitation Variability in Southeast South America over the Past Century, J. Clim., 23(20), 5517-5539, doi:10.1175/2010JCLI3578.1.

Siegert, M. J., and A. J. Payne (2004), Past rates of accumulation in central West Antarctica, Geophys. Res. Lett., 31(12), L12403, doi:10.1029/2004GL020290.

Sigl, M. et al. (2013), A new bipolar ice core record of volcanism from WAIS Divide and NEEM and implications for climate forcing of the last 2000 years, J. Geophys. Res. Atmos., 118(3), 1151-1169, doi:10.1029/2012JD018603.

Sime, L. C., G. J. Marshall, R. Mulvaney, and E. R. Thomas (2009), Interpreting temperature information from ice cores along the Antarctic Peninsula: ERA40 analysis, Geophys. Res. Lett., 36(June), 1-5, doi:10.1029/2009GL038982.

Sinclair, K. E., and S. J. Marshall (2009), Temperature and vapour-trajectory controls on the stable-isotope signal in Canadian Rocky Mountain snowpacks, J. Glaciol., 55(191), 485498, doi:10.3189/002214309788816687.

Sinclair, K. E., N. A. N. Bertler, and W. J. Trompetter (2010), Synoptic controls on precipitation pathways and snow delivery to high-accumulation ice core sites in the Ross Sea region, Antarctica, J. Geophys. Res. Atmos., 115(D22), 1-11, doi:10.1029/2010JD014383.

Sinclair, K. E., N. a N. Bertler, and T. D. Van Ommen (2012), Twentieth-century surface temperature trends in the western ross sea, antarctica: Evidence from a high-resolution ice core, J. Clim., 25, 3629-3636, doi:10.1175/JCLI-D-11-00496.1.

Sinclair, M. R. (1981), Record-high temperatures in the Antarctic- A synoptic case study, Mon. Weather Rev., 109, 2234-2242.

Sinclair, M. R. (1996), A climatology of anticyclones and blocking for the Southern Hemisphere, Mon. Weather Rev., 124(2), 245. 
Stammerjohn, S. E., D. G. Martinson, R. C. Smith, X. Yuan, and D. Rind (2008), Trends in Antarctic annual sea ice retreat and advance and their relation to El Niño-Southern Oscillation and Southern Annular Mode variability, J. Geophys. Res., 113, 1-20, doi:10.1029/2007JC004269.

Steig, E. J., and R. B. Alley (2002), Phase relationships between Antarctic and Greenland climate records, Ann. Glaciol., 35, 451-456, doi:10.3189/172756402781817211.

Steig, E. J. et al. (2005), High-resolution ice cores from USITASE (West Antarctica): development and validation of chronologies and determination of precision and accuracy, Ann. Glaciol. Vol 41, 2005, 41, 77-84.

Steig, E. J., D. P. Schneider, R. S. D, M. E. Mann, J. C. Comiso, and S. D. T. (2009), Warming of the Antarctic ice-sheet surface since the 1957 International Geophysical Year, Nature, 457(7228), 459-462, doi:10.1038/nature07669.

Steig, E. J., Q. Ding, D. S. Battisti, and A. Jenkins (2012), Tropical forcing of circumpolar deep water inflow and outlet glacier thinning in the amundsen sea embayment, west antarctica, Ann. Glaciol., 53(60), 19-28, doi:10.3189/2012AoG60A110.

Steig, E. J. et al. (2013), Recent climate and ice-sheet changes in West Antarctica compared with the past 2,000 years, Nat. Geosci, 6(5), 372-375.

Steig, E. J., V. Gkinis, a. J. Schauer, S. W. Schoenemann, K. Samek, J. Hoffnagle, K. J. Dennis, and S. M. Tan (2014), Calibrated high-precision ${ }^{17} \mathrm{O}$-excess measurements using cavity ring-down spectroscopy with laser-current-tuned cavity resonance, Atmos. Meas. Tech., 7, 2421-2435, doi:10.5194/amt-7-2421-2014.

Storch, H. Von, and F. W. Zwiers (1999), Statistical Analysis in Climate Research, J. Am. Stat. Assoc., 95, 1375, doi:10.1017/CBO9780511612336.

$\mathrm{Su}$, H., and J. H. Jiang (2013), Tropical Clouds and Circulation Changes during the 2006/07 and 2009/10 El Niños, J. Clim., 26(2), 399-413, doi:10.1175/JCLI-D-12-00152.1.

Thoma, M., A. Jenkins, D. Holland, and S. Jacobs (2008), Modelling Circumpolar Deep Water intrusions on the Amundsen Sea continental shelf, Antarctica, Geophys. Res. Lett., 35(18), 1-6, doi:10.1029/2008GL034939.

Thomas, E. R., and T. J. Bracegirdle (2009), Improving ice core interpretation using in situ and reanalysis data, J. Geophys. Res. Atmos., 114(D20), 1-8, doi:10.1029/2009JD012263.

Thomas, E. R., T. J. Bracegirdle, J. Turner, and E. W. Wolff (2013), A 308 year record of climate variability in West Antarctica, Geophys. Res. Lett., 40(20), 5492-5496, doi:10.1002/2013GL057782.

Thompson, D. W. J., and S. Solomon (2002), Interpretation of Recent Southern Hemisphere Climate Change, Science (80-. )., 296(5569), 895-899.

Thompson, D. W. J., and J. M. Wallace (2000), Annular Mode in the Extratropical Circulation. Part I : Month-to-Month Variability, , 13(1999), 1000-1016, doi:http://dx.doi.org/10.1175/1520-0442(2000)013<1000:AMITEC>2.0.CO;2.

Thompson, D. W. J., S. Solomon, P. J. Kushner, M. H. England, K. M. Grise, and D. J. Karoly 
(2011), Signatures of the Antarctic ozone hole in Southern Hemisphere surface climate change, Nat. Geosci, 4(11), 741-749.

Thompson, S. L., and D. Pollard (1997), Greenland and Antarctic mass balances for present and doubled atmospheric CO2 from the GENESIS version-2 global climate model, J. Clim., 10(5), 871-900, doi:http://dx.doi.org/10.1175/15200442(1997)010<0871:GAAMBF>2.0.CO;2.

Trenberth, K. E., G. W. Branstator, D. Karoly, A. Kumar, N.-C. Lau, and C. Ropelewski (1998), Progress during TOGA in understanding and modeling global teleconnections associated with tropical sea surface temperatures, J. Geophys. Res. Ocean., 103(C7), 14291-14324, doi:10.1029/97JC01444.

Trenberth, K. E., J. T. Fasullo, G. Branstator, and A. S. Phillips (2014), Seasonal aspects of the recent pause in surface warming, Nat. Clim. Chang., 4(10), 911-916.

Tuohy, A., N. Bertler, P. Neff, R. Edwards, D. Emanuelsson, T. Beers, and P. Mayewski (2015), Transport and deposition of heavy metals in the Ross Sea Region, Antarctica, J. Geophys. Res. Atmos., 120(20), 10,11,911-996, doi:10.1002/2015JD023293.

Turner, J. (2004), The El Niño-southern oscillation and Antarctica, Int. J. Climatol., 24(1), 1-31, doi:10.1002/joc.965.

Turner, J., T. Phillips, J. S. Hosking, G. J. Marshall, and A. Orr (2013), The Amundsen Sea low, Int. J. Climatol., 33(7), 1818-1829, doi:10.1002/joc.3558.

Turner, J., J. S. Hosking, G. J. Marshall, T. Phillips, and T. J. Bracegirdle (2015), Antarctic sea ice increase consistent with intrinsic variability of the Amundsen Sea Low, Clim. Dyn., 112, doi:10.1007/s00382-015-2708-9.

Vaughan, D., G. Marshall, W. Connolley, C. Parkinson, R. Mulvaney, D. Hodgson, J. King, C. Pudsey, and J. Turner (2003), Recent Rapid Regional Climate Warming on the Antarctic Peninsula, Clim. Change, 60(3), 243-274, doi:10.1023/A:1026021217991.

Vinther, B. M., P. D. Jones, K. R. Briffa, H. B. Clausen, K. K. Andersen, D. Dahl-Jensen, and S. J. Johnsen (2010), Climatic signals in multiple highly resolved stable isotope records from Greenland, Quat. Sci. Rev., 29(3-4), 522-538, doi:10.1016/j.quascirev.2009.11.002.

Wagenbach, D., F. Ducroz, R. Mulvaney, L. Keck, A. Minikin, M. Legrand, J. S. Hall, and E. W. Wolff (1998), Sea-salt aerosol in coastal Antarctic regions, J. Geophys. Res. Atmos., 103(D9), 10961-10974, doi:10.1029/97JD01804.

Weaver, A. J., O. a Saenko, P. U. Clark, and J. X. Mitrovica (2003), Meltwater pulse 1A from Antarctica as a trigger of the Bølling-Allerød warm interval., Science, 299(5613), 1709-13, doi:10.1126/science.1081002.

Werner, M., M. Heimann, and G. Hoffmann (2001), Isotopic composition and origin of polar precipitation in presentand glacial climate simulations, Tellus Ser. B Chem. Phys. Meteorol. B, 53, 53-+, doi:10.1034/j.1600-0889.2001.01154.x.

Whitlow, S., P. A. Mayewski, and J. E. Dibb (1992), A comparison of major chemical species seasonal concentration and accumulation at the South Pole and summit, Greenland, Atmos. Environ. Part A. Gen. Top., 26(11), 2045-2054, doi:http://dx.doi.org/10.1016/0960- 
1686(92)90089-4.

Wolff, E. W. et al. (2010), Changes in environment over the last 800,000 years from chemical analysis of the EPICA Dome C ice core, Quat. Sci. Rev., 29, 285-295, doi:10.1016/j.quascirev.2009.06.013.

Yuan, X., and C. Li (2008), Climate modes in southern high latitudes and their impacts on Antarctic sea ice, J. Geophys. Res. Ocean., 113(C6), 1-13, doi:10.1029/2006JC004067.

Yuan, X., and D. G. Martinson (2000), Antarctic Sea Ice Extent Variability and Its Global Connectivity, J. Clim., 13(10), 1697-1717, doi:10.1175/15200442(2000)013<1697:ASIEVA>2.0.CO;2. 


\title{
Chapter 2: High-Resolution Continuous Flow Analysis Setup for Water Isotopic Measurement from Ice Cores using Laser Spectroscopy
}

This chapter has been published in Atmospheric Measurement Techniques [Emanuelsson et al., 2015]. Co-authors on this paper are Troy Baisden, Nancy Bertler, Elizabeth Keller, and Vasileios Gkinis.

\begin{abstract}
Here we present an experimental setup for water stable isotope $\left(\delta^{18} \mathrm{O}\right.$ and $\left.\delta \mathrm{D}\right)$ continuous-flow measurements and provide metrics defining the performance of the setup during a major ice core measurement campaign (Roosevelt Island Climate Evolution; RICE). We also use the metrics to compare alternate systems. Our setup is the first continuous-flow laser spectroscopy system that uses off-axis integrated cavity output spectroscopy (OA-ICOS; analyzer manufactured by Los Gatos Research, LGR) in combination with an evaporation unit to continuously analyze water samples from an ice core. A Water Vapor Isotope Standard Source (WVISS) calibration unit, manufactured by LGR, was modified to (1) enable measurements on several water standards, (2) increase the temporal resolution by reducing the response time and (3) reduce the influence from memory effects. While this setup was designed for the continuous-flow analysis (CFA) of ice cores, it can also continuously analyze other liquid or vapor sources. The custom setups provide a shorter response time ( 54 and $18 \mathrm{~s}$ for 2013 and 2014 setup, respectively) compared to the original WVISS unit ( $62 \mathrm{~s})$, which results in an improvement in measurement resolution. Another improvement compared to the original WVISS is that the custom setups have a reduced memory effect. Stability tests comparing the custom and WVISS setups were performed and Allan deviations $\left(\sigma_{\text {Allan }}\right)$ were calculated to determine precision at different averaging times. For the custom 2013 setup the precision after integration times of $10^{3} \mathrm{~s}$ is 0.060 and $0.070 \%$ for $\delta^{18} \mathrm{O}$ and $\delta \mathrm{D}$, respectively. The corresponding $\sigma_{\text {Allan }}$ values for the custom 2014 setup are 0.030 , 0.060 and $0.043 \%$ for $\delta^{18} \mathrm{O}, \delta \mathrm{D}$ and $\delta^{17} \mathrm{O}$, respectively. For the WVISS setup the precision is $0.035,0.070$ and $0.042 \%$ after $10^{3} \mathrm{~s}$ for $\delta^{18} \mathrm{O}, \delta \mathrm{D}$ and $\delta^{17} \mathrm{O}$, respectively. Both the custom setups and WVISS setup are influenced by instrumental drift with $\delta^{18} \mathrm{O}$ being more drift sensitive than $\delta \mathrm{D}$. The $\sigma_{\text {Allan }}$ values for $\delta^{18} \mathrm{O}$ are 0.30 and $0.18 \%$ for the custom 2013 and WVISS setup,
\end{abstract}


respectively, after averaging times of $10^{4} \mathrm{~s}(2.78 \mathrm{~h})$. Using response time tests and stability tests, we show that the custom setups are more responsive (shorter response time), whereas the University of Copenhagen (UC) setup is more stable. More broadly, comparisons of different setups address the challenge of integrating vaporizer/spectrometer isotope measurement systems into a CFA campaign with many other analytical instruments.

\subsection{Introduction}

Ice cores are valuable archives from which we can gain knowledge of past atmospheric processes and climate by investigating records that are preserved in the ice or in entrapped gas bubbles, e.g. from water molecules, chemical impurities, particulates and methane gas e.g. [Petit et al., 1999; EPICA Community Members, 2004; WAIS Divide Project Members, 2013]. Water stable isotopes $\left(\delta^{18} \mathrm{O}\right.$ and $\delta \mathrm{D}$, hereafter referred to as $\delta$ ) preserved in ice are among the most powerful proxy records of past climate and atmospheric processes, which greatly extend the limited instrumental and observational records from Antarctica that are available only over the last century e.g. [Steig et al., 2013; Thomas et al., 2013].

$\delta$ records in ice cores have most frequently been used as a site temperature proxy [Epstein and Mayeda, 1953; Dansgaard, 1964], but sea ice extent, atmospheric circulation, transportation pathways, changes in source region as well as post-depositional effects (wind scour, diffusion, etc.) also influence the $\delta$ signal [Jouzel et al., 1997; Masson-Delmotte et al., 2008; Küttel et al., 2012; Sinclair et al., 2012]. Deuterium excess (d-excess) is a second-order proxy $\left(\mathrm{d}\right.$-excess $\left.=\delta \mathrm{D}-8 \cdot \delta^{18} \mathrm{O}\right) \quad[$ Craig et al., 1963; Dansgaard, 1964$]$ commonly interpreted as describing relative humidity and temperature at the moisture source region, as a result of the kinetic isotope effect during evaporation [Merlivat and Jouzel, 1979]. Laser spectrometry has made continuous-flow analysis (CFA) of $\delta$ in ice core melt streams possible [Gkinis et al., 2010; Maselli et al., 2013], replacing measurement of discrete samples e.g., [Rhodes et al., 2012; Sinclair et al., 2012].

Following the first measurements of $\delta$ from laser absorption spectrometry [Kerstel et al., 1999], improvements in commercially available analyzers [Baer et al., 2002; Crosson, 2008; Berman et al., 2013; Steig et al., 2014] have made them increasingly suitable to analyze water vapor continuously. High temporal resolution measurement applications have included atmospheric sciences e.g., [Johnson et al., 2011; Aemisegger et al., 2012; Steen-Larsen et al., 
2013], ice core records [Gkinis et al., 2010; Maselli et al., 2013; Steig et al., 2013], ecology e.g., [Lee et al., 2007] and hydrology e.g., [Goebel and Lascano, 2012]. Successful measurement of a liquid water stream using laser spectrometry requires that the liquid sample stream is converted to vapor and compared to water standards of known isotopic composition to achieve calibration. Reliable calibration vaporizing units have been developed for research [Gkinis et al., 2010; Schmidt et al., 2010; Sturm and Knohl, 2010; Steig et al., 2014], and calibration units are available commercially: the Water Vapor Isotope Standard Source (WVISS) manufactured by Los Gatos Research (LGR) and Standards Delivery Module (SDM) by Picarro. The WVISS system vaporizes one standard using a self-aspirating nebulizer into a heated $\left(75^{\circ} \mathrm{C}\right)$ evaporation jar, whereas the SDM uses a syringe-pump-based system that can switch between two standards. For $\delta$-CFA of ice cores, a range of criteria including the stability and response time of the vaporizer/spectrometer system must be understood and matched to practical requirements, including the operation of other CFA analyzers and the collection of discrete samples.

Here, we present new experimental setups and identify the following aims for the characterization of new and previously reported systems: (1) enable accurate calibration to several water standards, (2) increase the temporal resolution by reducing the response time and (3) reduce memory effects. With regard to the first aim, calibration to two standards allows us to properly normalize our results on the Vienna Standard Mean Ocean Water/Standard Light Antarctic Precipitation (VSMOW/SLAP) scale [Gonfiantini, 1978; Coplen, 1996]. In addition, we are able to characterize the instrumental response time using the step changes between standards. We define the response time as the time from the first 5 to the last $5 \%$ of the response to a step change in $\delta$. A short response time is desirable to minimize the time required for completing calibration cycles and to maximize the resolution with which the $\delta$ signal that is preserved in the ice is captured. Alongside the response time, we define a memory effect as causing an asymmetric tail in the last 5\% of the step in $\delta$ values, with an extended tail compared to our empirical fit. Avoiding memory effects is desirable given the large range of $\delta$ in ice cores and in the standards required for normalization.

A key challenge we address is the integration of vaporizer/spectrometer isotope measurement systems into a CFA campaign with many other instruments. In the case of a multiinstrument CFA campaign, the competing demands of different instrumentation and associated 
logistics of extended continuous operation may require the CFA isotope measurement system to be constructed so that the entire multi-instrument CFA system can be optimized. For example, CFA methane measurements require long uninterrupted periods of melting due to large memory effects, whereas $\delta$ measurements for the custom and WVISS setups will benefit from more frequent calibration. Therefore, the number of consecutive core sections that are stacked on top of one another and melted continuously without interruption for calibration can necessitate a compromise between the ideal time intervals of continuous melting for each analysis type.

Here, we describe the design and performance characterization of two custom vaporizer/spectrometer $\delta$ CFA employed for analysis of an ice core - the Roosevelt Island Climate Evolution (RICE) Antarctic ice core, retrieved from $79.36^{\circ} \mathrm{S}, 161.70^{\circ} \mathrm{W}$ (560 $\mathrm{m}$ a.s.l.) on an ice rise [Conway, 1999] situated at the northeastern edge of the Ross Ice Shelf. The $\delta$-CFA systems were required to yield maximum response resolutions for relating ice core $\delta$ to sea ice extent, atmospheric circulation modes and local temperature using reanalysis data (1979 to 2012) and in response to past climate events while maintaining stable and accurate $\delta$ CFA throughout the analyzed depths of the $763 \mathrm{~m}$ ice core. Our $\delta$-CFA setups are compared in response times and stability to a similar $\delta$-CFA ice core setup, the University of Copenhagen (UC) setup and the commercially available WVISS (Table 2.1). This is the first study within the field of ice core science that provides a detailed characterization and comparison between $\delta$-CFA setups that are using the new generation of off-axis integrated cavity output spectroscopy (OA-ICOS) and cavity ring-down spectroscopy (CRDS) techniques. The performance of the $\delta$-CFA systems is described and evaluated in the context of the RICE project, with a focus on the characterization to aid the selection and potential customization of $\delta$-CFA systems for future CFA campaigns. 
Table 2.1. Technical detail and properties for the different setups.

\begin{tabular}{cccccc}
\hline Setup name & Analyzer & Manufacturer & Technology & Vaporizer & Reference \\
\hline Custom 2013 & IWA-EP35 & LGR & OA-ICOS & modified WVISS & This study \\
$\begin{array}{c}\text { Custom 2014 } \\
\text { TIWA-EP45 }\end{array}$ & LGR & OA-ICOS & modified WVISS & This study \\
WVISS & TIWA-EP45 & LGR & OA-ICOS & WVISS & \\
UC & L2130-i & Picarro & CRDS & $\begin{array}{c}\text { Capillary and a } \\
\text { furnace, see ref. }\end{array}$ & $\begin{array}{c}\text { Gkinis et al. (2010, 2011); } \\
\text { Steig et al. (2013) }\end{array}$ \\
\hline
\end{tabular}

\subsection{Experimental}

Results are reported in $\delta$ notation, representing the abundance of rare isotopes as a deviation from a reference ratio: $\delta=\mathrm{R} / \mathrm{R}_{\text {SMOw }}-1$, where $\mathrm{R}$ and Rsmow are the ratio between rare and abundant isotopes ${ }^{18} \mathrm{O} /{ }^{16} \mathrm{O}$, or D/H in the sample and in VSMOW (Vienna Standard Mean Ocean Water), respectively. Results are reported in per mil, \%o.

\subsubsection{Isotope Water Analyzer (IWA-35EP)/Triple Isotope Water Analyzer (TIWA-45EP) Laser Spectroscopy System}

In this study, we use an absorption spectroscopy instrument based on OA-ICOS technology in combination with an evaporation unit to continuously analyze sample from an ice core or water standards during calibration. The absorption spectroscopy instrument is an Isotope Water Analyzer (IWA) manufactured by LGR. The main system we describe (custom 2013) was developed and employed for the RICE CFA melting campaign (0 to $500 \mathrm{~m}$ ) in 2013. It consists of an IWA and a customized furnace and evaporation chamber, which was built and fitted inside a modified WVISS calibration unit. In addition to its function as a calibration unit, the custom 2013 setup (Table 2.1) was used as a sample introduction system, in which the ice core melt stream is continuously vaporized and introduced to the IWA. A similar system (custom 2014) incorporating improvements was assembled for the 2014 RICE CFA melting campaign (500 to $761 \mathrm{~m})$ and is described briefly.

The IWA-35EP analyzer uses a near-infrared, tunable diode laser that scans over three nearby absorption peaks, $\mathrm{H}_{2}{ }^{16} \mathrm{O}, \mathrm{H}_{2}{ }^{18} \mathrm{O}$, and $\mathrm{HDO}$, located near the $1.4 \mu \mathrm{m}$ wavelength. The instrument uses an OA-ICOS technique [Baer et al., 2002], in which the laser is directed off axis into an optical cavity. The semi-transparent cavity absorption cell has highly reflective mirrors, yielding an effective path length of several kilometers. The transmitted intensities are recorded 
by a photo detector. Laser spectroscopy analyzers are able to provide simultaneous measurements of $\delta^{18} \mathrm{O}, \delta \mathrm{D}$ and water vapor mixing ratios.

Aemisegger et al. [2012] characterized the response time characteristics of commercially available analyzers, finding that the L1115-i Picarro CRDS analyzer has a longer response time compared to the LGR IWA by $\sim 31$ and $22 \mathrm{~s}$ for $\delta \mathrm{D}$ and $\delta^{18} \mathrm{O}$, respectively. Additionally, the signal for the L1115-i is biased by isotope-specific time lags (henceforth called lag bias), with $\delta \mathrm{D}$ having a $\sim 10 \mathrm{~s}$ longer response time than $\delta^{18} \mathrm{O}$. A $\delta$ signal without lag bias is important when calculating high-frequency d-excess values. The faster response time and lack of lag bias of our custom setups allows us to explore the maximum extent to which the rapidly changing $\delta$ signal preserved in an ice core can be resolved. The pumping rate of the cavity is higher for the IWA (500 to $800 \mathrm{~mL} \mathrm{~min}^{-1}$ ) compared to the L1115-I (25 $\mathrm{mL} \mathrm{min}^{-1}$ ) setup, which increases the turnover rate of the cavity, a contributing factor to the short response time of the IWA [Aemisegger et al., 2012]. Sturm and Knohl [2010] reported on temperature sensitivity of the IWA. Recent IWA models have an enhanced performance (EP) feature, which improved the thermal control of the cavity by keeping the temperature of the cavity $\left(\sim 46.3^{\circ} \mathrm{C}\right)$ stable and

elevated above the ambient temperature. Recent models also have the capability to measure $\delta^{17} \mathrm{O}$, such as the TIWA-45EP from LGR [Berman et al., 2013] and L2140-i from Picarro [Steig et al., 2014]. Our IWA-35EP analyzer was updated in December 2013 to a TIWA-45EP analyzer, which added the capability of measuring $\delta^{17} \mathrm{O}$ using a second tunable diode laser. The update of the analyzer enabled us to include $\delta^{17} \mathrm{O}$ in our evaluation of the WVISS and the 2014 custom setup.

\subsubsection{Evaporation/Vapor Introduction Systems}

We evaluate the performance of two water evaporation units, the WVISS calibration unit and the custom 2013 setup. In addition to this we present preliminary data and results from the updated custom 2014 setup and new previously unpublished results from a CRDS L2140-i Picarro ice core setup (UC setup) with a custom-made vaporizer (vaporizer and setup described in [Gkinis et al., 2010; Steig et al., 2014]). The UC setup was optimized with stability in mind.

\subsubsection{WVISS System}

The original WVISS unit (WVISS v.2 evaporation unit; manufactured December 2013) was set up to run a single water standard. A stream of water standard is continuously evaporated 
by the WVISS during calibration events. The WVISS unit consists of a heated $\left(75^{\circ} \mathrm{C}\right) 1.1 \mathrm{~L}$ jar into which a nebulizer injects a constant stream of minuscule water droplets that rapidly evaporate. For incoming dry air, the WVISS incorporates a built-in compressor and drier, but we chose to plumb to an external compressed dry air source to maximize stability and minimize noise and vibration in the laboratory. The dry air is split up into two flows inside the WVISS: one constant flow that goes through the nebulizer and the second, constituting the majority of the dry air flow, that is regulated by a mass flow controller (MFC) and is introduced to the evaporation jar. Tests of the WVISS unit were performed using external compressed dry air (<20 ppm). When provided by the manufacturer, the nebulizer (Savillex, PFA C-flow 50 nebulizer) is set up to self-aspirate a flow of $50 \mu \mathrm{L} \mathrm{min}^{-1}$ from a $0.5 \mathrm{~L}$ glass water bottle. We use a multi-port valve (C25-3186EMH, VICI), which enables us to use more than one water standard. Additional flow resistance introduced by the multi-port valve necessitated the use of a peristaltic pump (P2; $\mathrm{MP}^{2}$, Elemental Scientific) to provide a more stable water flow to the evaporation chamber. The WVISS unit is described in detail in Rambo et al. [2011] and Kurita et al. [2012]. The performance of an unaltered WVISS evaporation unit was also evaluated, using the TIWA-45EP LGR analyzer.

\subsubsection{Experimental setup for water vapor isotope measurements}

Building on the design of the WVISS as a calibration unit supporting measurement of vapor samples, a key principle of our customized design was that both the ice core melt stream and isotopic standards passed through the same vaporization process. All changes to the WVISS involved readily available components that could easily be integrated within the WVISS shell and controlled with the IWA-WVISS system. In the custom setups, we modified the following aspects of the setup: (1) volume of the evaporation chamber, (2) materials, (3) evaporation temperature, (4) introduction of the sample into the carrier gas and (5) reduction of travel distances of the samples. We will explain the rationale and outcome of these changes in the following sections.

\section{Volume of the evaporation chamber}

We reduced the internal volume of the WVISS evaporation chamber from $1.1 \mathrm{~L}$ to $40 \mathrm{~mL}$ in the 2013 custom vaporizer. The substantially smaller volume increases the turnover rate and reduces the response time. This is particularly important when analyzing multiple standards 
and/or a rapidly changing continuous flow signal (e.g., from an ice core). The maximum resolution will be determined by the time it takes to replace the vapor volume in the evaporation chamber. The evaporation chamber volume is less important for one standard calibration setups (without the requirement of rapid volume exchange), as used for example to obtain real time measurements of atmospheric vapor for which the WVISS was designed [Rambo et al., 2011; Aemisegger et al., 2012].

\section{Material}

The WVISS setup has a Savilex sealed 1.1 L jar evaporation chamber. For the custom 2013 setup we use borosilicate glass for the evaporation chamber. A cavity was milled within an aluminum block to hold the glass evaporation chamber in place and to conduct heat from the furnace efficiently into the evaporation chamber. Glass was chosen as the material for the evaporation chamber because it can be molded when heated to form the desired shape of the chamber (Figure 2.1). 


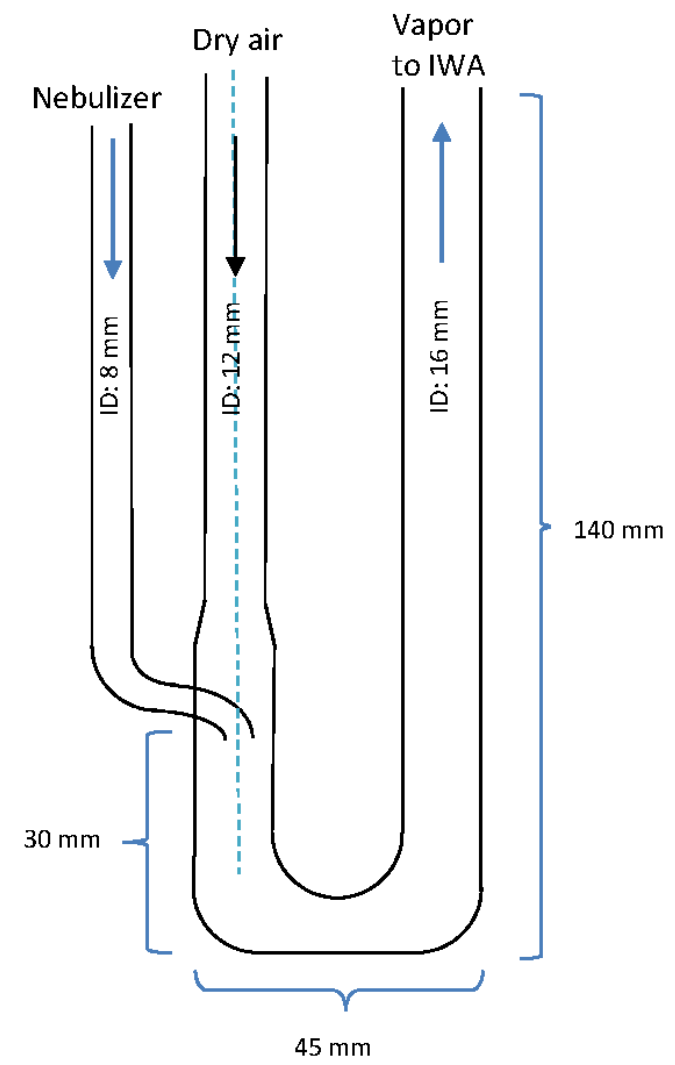

Figure 2.1. Diagram of glass evaporation chamber. A moist air stream is generated from the nebulizer, merged with the MFC regulated dry air, mixed at $170^{\circ} \mathrm{C}$ and subsequently flows out of the glass evaporation chamber to the IWA.

\section{Evaporation temperature}

To achieve complete evaporation at higher vapor throughput rates, we increased the temperature of our custom furnace to $\sim 170^{\circ} \mathrm{C}$ compared to the WVISS, which operates at $75^{\circ} \mathrm{C}$. The temperature of the custom furnace and WVISS evaporation jar is regulated using a PID regulated Omega temperature controller (CN7500).

\section{Introduction of the sample into the carrier gas}

Filtered compressed dry air $(<20 \mathrm{ppm})$ was used for evaporation of water sample flow and to transport the vapor to the IWA. Only a small portion of the total dry air flow goes through the nebulizer. The nebulizer injects a mixture of water and dry air into a glass evaporation chamber inside a customized furnace, where the sample water is instantaneously evaporated. In the 2013 evaporation chamber, the moist air stream generated by the nebulizer (Figure 2.1) and a line with dry air flow passes through the furnace parallel to each other in separate lines. These two gas 
streams are later merged, with the vapor line from the nebulizer being centered inside the dry air stream at the merger. Separating the two lines has the advantage that it provides a longer residence time in the furnace for the sample that is injected by the nebulizer. This ensures complete evaporation; if all of the dry air were to be introduced directly adjacent to the nebulizer, the throughput rate of moist air could exceed the rate at which the dry air can be heated, causing inefficient and incomplete evaporation at a high vapor throughput rate. The dry air line represents the majority of the total air flow $\left(0\right.$ to $\left.10 \mathrm{~L} \mathrm{~min}^{-1}\right)$ and the dry air flow is controlled by an Omega MFC. After the vapor has left the furnace the internal plumbing of the WVISS was used to transport the sample vapor to the analyzer. The water vapor concentration introduced to the analyzer was $\sim 20000 \mathrm{ppm}$. Excess vapor was vented to the atmosphere through the WVISS exhaust. Further modifications were made in a custom 2014 setup, which uses two ceramic heating elements $(122 \mathrm{~mm}, 250 \mathrm{~W}$, and $230 \mathrm{~V})$ to heat a stainless steel evaporation block to $165^{\circ} \mathrm{C}$. The block is painted with high-temperature black paint to uniformly absorb radiant heat generated by the elements within a reflective cavity. The inner surface of the block is electro-polished. The same nebulizer is used as in the 2013 setup, and the mixing chamber is of similar dimensions. Dry air is pre-warmed in baffles and introduced adjacent to the nebulizer. Compared to the 2013 setup, a higher sample flow of $\sim 150 \mu \mathrm{L} \mathrm{min}^{-1}$ matched with dry air flow to achieve 20000 ppm water vapor concentrations is used. Preliminary results from the 2014 setup are reported here and differ only in the vaporizer construction and in delivery of mixed vapor to the IWA directly through an open split. The 2014 open split is a simple step down in PFA tubing sizes rather than within the WVISS plumbing and exhaust system: 1/4" Outer Diameter (O.D.) tubing is connected to the IWA and inserted $5 \mathrm{~cm}$ and centered within the larger size tubing 1/2" O.D. carrying flow from the vaporizer.

\section{Reduction of travel distance of the sample}

The 1/4" PFA tubing between the WVISS and the IWA, which provides the analyzer with sample, was kept short $(59 \mathrm{~cm})$ and a heat tape was wrapped around the tubing to prevent condensation and reduce adsorption to the tubing walls. The sample flow from the ice core melt head separates the sample stream from the inner and outer parts of the core, allowing for clean chemical sampling from the inner section. 
For CFA $\delta$ measurements it is not necessary to have an ultra-clean sampling regime, but we recommend taking the sample stream from the inner line to prevent blocking of the nebulizer. The $\delta$-measurement flow requires only 50 to $150 \mu \mathrm{L} \mathrm{min}^{-1}$ and thus represents a minimal draw on the available sample volume. The melt rate was monitored to allow the association of each continuous ice core measurement with a depth. The old air entrapped in the ice is first separated from the water sample by a debubbler (DB1) and passed to spectroscopic analyzers to measure $\mathrm{CH}_{4}$ and $\delta^{18} \mathrm{O}$ in the air. After this step air bubbles are introduced to the keep the water sample flow segmented. To keep the water vapor mixing ratio generated from the evaporation unit constant, the introduced bubbles are removed in DB2 before the evaporation unit and multiport valve (V2). A more detailed description of the melt head and the sealed debubbler (DB1, Figure 2.2) used during the 2013 and 2014 RICE melting campaign is provided in Bigler et al. [2011]. The multi-port valve (C25-3186EMH, VICI) enables us to switch between samples from the ice core and multiple water standards (V2, Figure 2.2 and Table 2.2). Switching between sample and calibration cycles was initiated through a control and data acquisition interface that was built in Lab-VIEW software (National Instruments). Once the calibration cycle was initiated, switches between water standards were automated. RS-232-to-USB cables were used to control and log positions of the valves (stored in calibration log files). P3 provides a constant water flow rate of 50 to $150 \mu \mathrm{L} \mathrm{min}{ }^{-1}$ to the nebulizer (Savillex, PFA C-flow 50 nebulizer, part no. 800-1-005-0100). PFA tubing was used for the water and vapor flows. The custom 2013 setup has proven to be reliable. The system performed without malfunction during the entire 2013 RICE melting campaign of 35 processing days.

Table 2.2. $\delta^{18} \mathrm{O}$ and $\delta \mathrm{D}$ discrete-IWA measurements of water standards in relation to the VSMOW/SLAP scale and their role during two-point calibration.

\begin{tabular}{ccccccc}
\hline Standard & $\mathrm{N}$ & $\delta^{18} \mathrm{O}(\%)$ & $\pm \sigma$ & $\delta \mathrm{D}(\%)$ & $\pm \sigma$ & Calibration \\
\hline WS 1 & 4 & -10.84 & 0.099 & -74.15 & 0.938 & QA/QC \\
RICE & 30 & -22.54 & 0.049 & -175.02 & 0.193 & $\begin{array}{c}\text { Slope and } \\
\text { normalization }\end{array}$ \\
ITASE & 30 & -37.39 & 0.046 & -299.66 & 0.183 & Slope \\
\hline
\end{tabular}




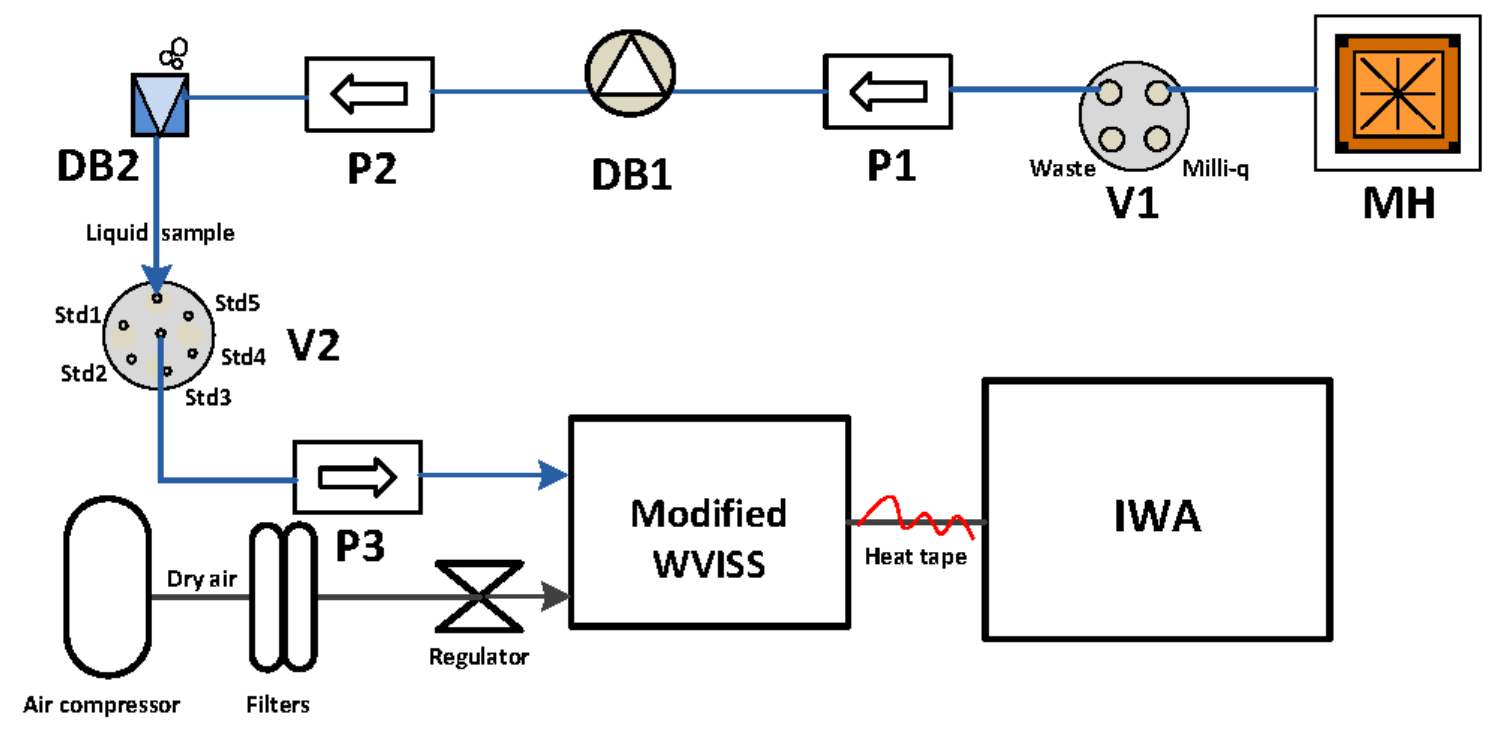

Figure 2.2. Flow chart of CFA IWA-custom vaporizer setup, where MH stands for melt head, V for valve, $\mathrm{P}$ for peristaltic pump and DB for debubbler. Blue lines represent the liquid part of the setup and the black lines represent the dry and moist air portion.

\subsection{Results and Discussion}

\subsubsection{Signal Stability (Instrument Drift)}

Stability tests were performed to determine precision for different lengths of averaging times $\left(\tau_{\mathrm{m}}\right)$ and to quantify at which timescales instrumental drift affects the $\delta$ signal [Allan, 1966; Werle, 2011]. Allan deviation ( $\sigma_{\text {Allan }}$, square root of Allan variance, Eq. (2.1)) [Werle, 2011] was calculated using several stability tests consisting of measurements on the Lower Hutt Milli-Q water (LHW) standard for extended time periods. Tests were performed on the 2013 and 2014 custom and the WVISS setups at water vapor concentrations of 20 $000 \mathrm{ppm}$ (Table 2.3).

$$
\sigma_{\text {Allan }}^{2}\left(\tau_{m}\right)=\frac{1}{2 m} \sum_{j=1}^{m}\left(\bar{\delta}_{j+1}-\bar{\delta}_{j}\right)^{2}
$$

where $\tau_{\mathrm{m}}$ is the averaging time and $\bar{\delta}_{\mathrm{j}+1}$ and $\bar{\delta}_{\mathrm{j}}$ are the mean values of neighboring time intervals $\mathrm{j}$ and $\mathrm{j}+1$.

Representative results from the 29 June 2013 are provided in Figure 2.3. For $\delta^{18} \mathrm{O}$ two relatively stable periods can be seen separated by a transition period of instrumental drift 
between 11 and $13 \mathrm{~h}$. We find that the instrumental drift is nonlinear and therefore challenging to correct for.

Table 2.3. Date, duration, mean water vapor concentration and standard deviation for stability tests.

\begin{tabular}{ccccc}
\hline Date & Setup & Duration (h) & Mean $(\mathrm{ppm})$ & Std (ppm) \\
\hline 24 May 2013 & Custom 2013 & 18.45 & 21,466 & 639 \\
1 June 2013 & Custom 2013 & 23.81 & 19,941 & 479 \\
9 June 2013 & Custom 2013 & 22.04 & 19,530 & 400 \\
23 June 2013 & Custom 2013 & 23.98 & 19,870 & 456 \\
29 June 2013 & Custom 2013 & 23.26 & 19,642 & 401 \\
24 January 2014 & WVISS & 31.22 & 18,092 & 145 \\
28 January 2014 & WVISS & 24.47 & 19,770 & 135 \\
30 January 2014 & WVISS & 31.67 & 19,641 & 144 \\
19 July 2014 & Custom 2014 & 30.49 & 20,216 & 304 \\
20 July 2014 & Custom 2014 & 18.92 & 21,486 & 132 \\
30 May 2014 & Gkinis 2014 & 30.00 & - & - \\
\hline
\end{tabular}



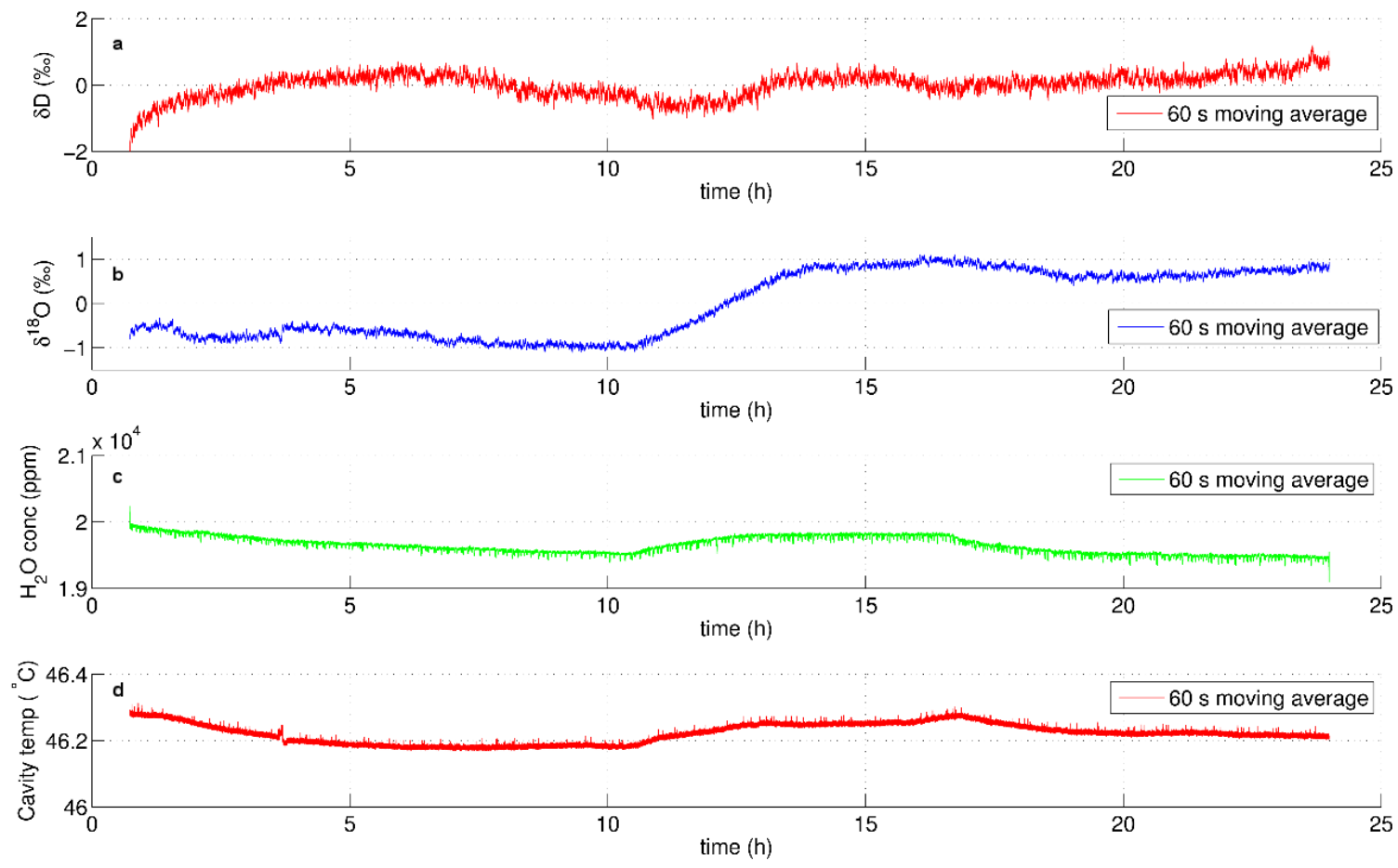

Figure 2.3. Results from a stability test using the 2013 custom vaporizer setup, measured over a $24 \mathrm{~h}$ period. Moving averages of $60 \mathrm{~s}$ of the $2 \mathrm{~Hz}$ data are displayed. Deviation from mean value is shown for each point in (a) for $\delta \mathrm{D}$ and (b) for $\delta^{18} \mathrm{O}$. (c) Water vapor concentration (ppm) and (d) analyzer cavity temperature $\left({ }^{\circ} \mathrm{C}\right)$.

\subsubsection{Custom Vaporizer}

The Allan deviation analysis for the custom 2013 setup shows that precision increases with longer averaging times until the optimal averaging time is reached after $\sim 200$ and $\sim 600 \mathrm{~s}$ with a precision of $\sim 0.04$ and $\sim 0.07 \%$ for $\delta^{18} \mathrm{O}$ and $\delta \mathrm{D}$, respectively (Figures. 2.4 and 2.5). For longer averaging times, instrumental drift becomes apparent. For this reason, averaging times beyond these values will have poorer precision. After an averaging time of $60 \mathrm{~s}$ (approximately the response time of the whole ice core CFA setup) a precision of 0.05 and $0.15 \%$ is achieved for $\delta^{18} \mathrm{O}$ and $\delta \mathrm{D}$, respectively. This level of precision is comparable to IRMS analyzers for $\delta^{18} \mathrm{O}$ (IRMS $\delta^{18} \mathrm{O}: 0.024$ to $0.1 \%$ ) and outperforms IRMS analyzers for $\delta \mathrm{D}$ (IRMS $\delta \mathrm{D}: 0.5$ to $1.0 \%$; Sturm and Knohl, [2010], and references therein). Due to competing requirements of various CFA analytical lines, calibrations were not run frequently enough during the 2013 RICE ice core processing campaign to avoid an influence from instrumental drift on the CFA $\delta$ data. Calibrations were on average conducted every $2.4 \mathrm{~h}$. Thus, the maximum temporal distance of 
any $\delta$-CFA measurement to a calibration event is $\sim 1.2 \mathrm{~h}$. The peak uncertainty is therefore given by the Allan deviation after $1.2 \mathrm{~h}$, which is $\sim 0.17$ and $\sim 0.13 \%$ for $\delta^{18} \mathrm{O}$ and $\delta \mathrm{D}$, respectively (Figures. 2.4 and 2.5). Analytical uncertainty in d-excess was estimated to range between 0.31 and $1.37 \%$ using Eq. (2.2). We note that Eq. (2.2) assumes $\sigma_{\delta 18 \mathrm{O}}$ and $\sigma_{\delta \mathrm{D}}$ are uncorrelated, which was verified to be true for the vast majority of our measurements on standards averaged at $15 \mathrm{~s}$ intervals. Peak uncertainty (1.37\%) occurs at the center point between calibrations (Figures 2.4 and $2.5 ; 1.2 \mathrm{~h}=4320 \mathrm{~s})$ and the minimum uncertainty $(0.31 \%$ occurs near calibration points, within the optimal integration time for $\delta^{18} \mathrm{O}(200 \mathrm{~s})$.

$$
\sigma_{d}=\left[\left(\sigma_{\delta \mathrm{D}}\right)^{2}+\left(8 \cdot \sigma_{\delta^{18} \mathrm{O}}\right)^{2}\right]^{1 / 2}
$$

For d-excess ice core measurements, a precision of $\leq 0.1$ and $\leq 1.0 \%$ for $\delta^{18} \mathrm{O}$ and $\delta \mathrm{D}$, respectively, is required $\left(\sigma_{d}=1.28 \%\right.$ ) [Masson-Delmotte et al., 2008]. The $\delta^{18} \mathrm{O}$ measurements are more drift sensitive compared to $\delta \mathrm{D}$ data and are therefore the limiting factor for d-excess data. To achieve high-precision measurements for $\delta^{18} \mathrm{O}(<0.1 \%)$, a standard would have to be run for drift correction every $\sim 1 \mathrm{~h}$, which is incompatible with CFA methane gas analyses. To reduce the response time and the influence from instrumental drift, we are currently working towards a new setup, focusing on reducing the response time and the influence from instrumental drift even further. A reduced response time would allow us to run a drift standard during melting, only missing a small quantity of ice core analysis. Such an approach would accommodate competing requirements, such as frequent calibrations for isotope measurements and long periods of uninterrupted melting for methane measurements. Furthermore, if the instrumental drift is reduced then less frequent calibrations will be required.

\subsubsection{WVISS System}

For the WVISS system the optimum averaging times are 700, 1000 and $1500 \mathrm{~s}$ with precisions of $0.04,0.06$ and $0.04 \%$ for $\delta^{18} \mathrm{O}, \delta \mathrm{D}$ and $\delta^{17} \mathrm{O}$, respectively. The optimal averaging time is reached faster for the custom setups compared to the WVISS system, indicating that the custom setup has higher precision compared to the WVISS during shorter integration times (e.g., 0 to $300 \mathrm{~s}$ for $\delta^{18} \mathrm{O}$, Figure 2.4). However, the 2013 custom setup is more susceptible to longterm drift beyond the optimal averaging time (Figures 2.4 and 2.5). 
The variability observed at long averaging times (beyond the optimum averaging time) shows the randomness of the drift, as drift occurs after different lengths of times for different tests (Figures. 2.4, 2.5 and S2.1 in the Supplement). Previous studies have shown results from singular tests [Gkinis et al., 2010; Sturm and Knohl, 2010; Aemisegger et al., 2012], averages from several tests [Steig et al., 2014] or from several tests but only for short integration times ( $\leq 1000 \mathrm{~s})$ [Maselli et al., 2013]. Showing results from a suite of tests provides an improved estimate of the uncertainty of the results and the nonlinear nature of the drift. However, if the system is less drift sensitive, a single long-term test can be sufficient to characterize the stability of the system.

Aemisegger et al. [2012] conducted stability test comparisons for averaging times from 0 to $10^{4} \mathrm{~s}(2.78 \mathrm{~h})$. However, to investigate drift for longer averaging times, we consider averaging times up to $10^{5} \mathrm{~s}(27.8 \mathrm{~h}$ ) and compare these results to the UC setup (Picarro instrument; L2140i). Our results show that the custom and WVISS setups are affected by instrumental drift. At averaging times of $10^{4} \mathrm{~s}$ the WVISS setup has $\sigma_{\text {Allan }}$ values of $0.15,0.06$ and $0.10 \%$ for $\delta^{18} \mathrm{O}, \delta \mathrm{D}$ and $\delta^{17} \mathrm{O}$, respectively. For the custom 2013 setup the $\sigma_{\text {Allan }}$ values at $10^{4} \mathrm{~s}$ are and 0.3 and $0.25 \%$ for $\delta^{18} \mathrm{O}$ and $\delta \mathrm{D}$, respectively. For the custom 2013 setup the precision after integration times of $10^{3} \mathrm{~s}$ are 0.060 and $0.070 \%$ for $\delta^{18} \mathrm{O}$ and $\delta \mathrm{D}$, respectively.

For the WVISS setup the precision is $0.035,0.070$ and $0.042 \%$ after $10^{3} \mathrm{~s}$ for $\delta^{18} \mathrm{O}, \delta \mathrm{D}$ and $\delta^{17} \mathrm{O}$, respectively. Preliminary data from the updated custom 2014 setup (blue lines, Figures. 2.4, 2.5, and S2.1) show that this system is less affected by instrumental drift compared to the 2013 setup; after integration times of $10^{3} \mathrm{~s}$ the 2014 system achieves $\sigma_{\text {Allan }}$ values of $0.030 \%$ for $\delta^{18} \mathrm{O}, 0.043 \%$ for $\delta^{17} \mathrm{O}$ and $0.060 \%$ for $\delta \mathrm{D}$. Results from the University of Copenhagen setup show that the Picarro CRDS analyzer (L2140-i) and vaporizer achieve $\sigma_{\text {Allan }}$ values of $0.011 \%$ for $\delta^{18} \mathrm{O}, 0.010 \%$ for $\delta^{17} \mathrm{O}$ and $0.048 \%$ for $\delta \mathrm{D}$, after averaging times of $10^{3} \mathrm{~s}$. The University of Copenhagen setup achieves higher precision and is less affected by drift compared to the custom and WVISS setups. No instrumental drift can be detected for $\delta^{18} \mathrm{O}$ and $\delta^{17} \mathrm{O}$ for the L2140-i setup (Figures 2.4 and S2.1).

When analyzing for secondary parameters, such as d-excess and ${ }^{17} \mathrm{O}$-excess, a system that is optimized for stability, like the UC setup, has an advantage over the custom and WVISS setups (Figure S2.2), which to a larger extent are influenced by instrumental drift (with $\delta^{18} \mathrm{O}$ 
being more drift sensitive than $\delta \mathrm{D}$ ). The susceptibility of OA-ICOS analyzers to instrumental drift for $\delta^{18} \mathrm{O}$ has also been shown by Aemisegger et al. [2012]. Therefore, more frequent measurements of drift correction standards will have to be performed for the custom setups in order to achieve the high precision measurements achieved by the L2140-i setup.

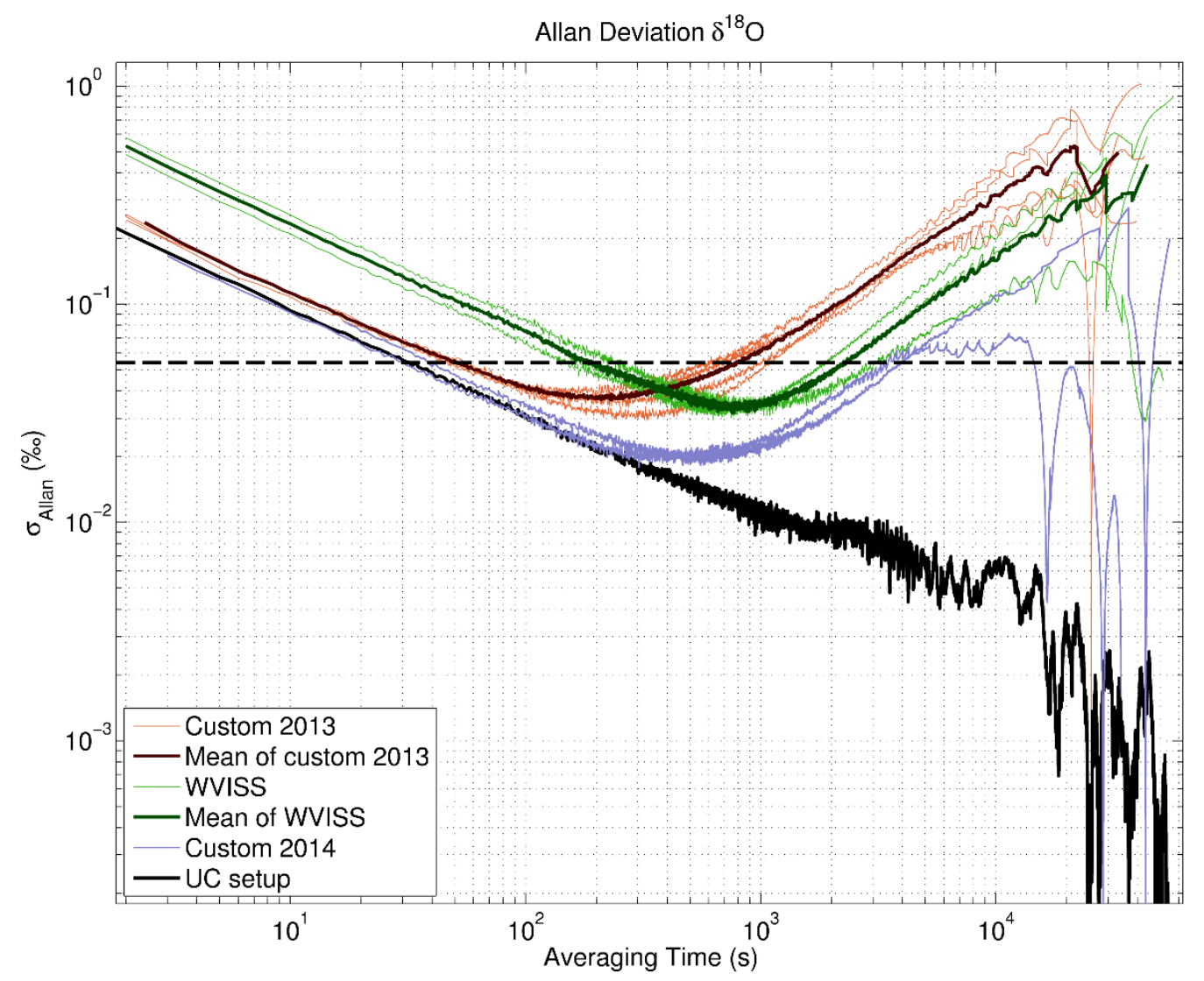

Figure 2.4. Allan deviation as a function of averaging time for $\delta^{18} \mathrm{O}$ from stability tests of the custom vaporizer setups (2013 setup brown lines and 2014 setup blue lines), the WVISS setup (green line) and the University of Copenhagen setup (UC, black line). Average precision ( $1 \sigma$; standard deviation) for individual discrete samples measured on the IWA-35EP analyzer is shown as a black dashed horizontal line. 


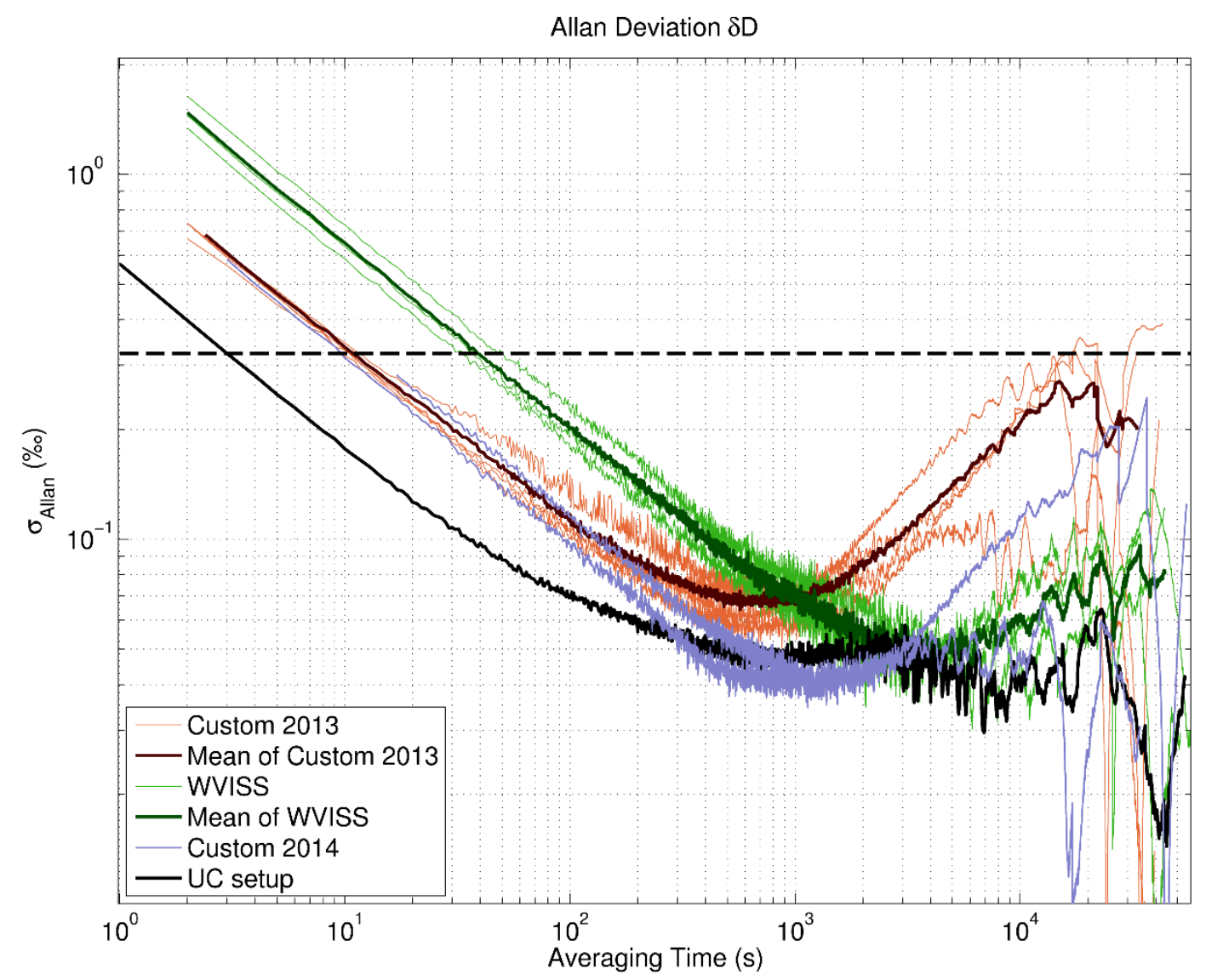

Figure 2.5. Allan deviation as a function of averaging time for $\delta \mathrm{D}$ from stability tests of the custom vaporizer setups (2013 setup brown lines and 2014 setup blue lines), the WVISS setup (green line) and the University of Copenhagen setup (UC, black line). Average precision ( $1 \sigma$; standard deviation) for individual discrete samples measured on the IWA-35EP analyzer is shown as a black dashed horizontal line.

\subsubsection{Response Time}

Isotopic step changes between water standards are used to calculate response times for the customized and the WVISS setup (Tables 2.4 and 2.5). The water vapor concentration was kept constant over the isotopic step change ( 20 000 ppm). Cumulative distribution functions of the $\log$ normal distribution were fitted to the isotopic steps following Gkinis et al. [2010].

$$
\delta_{f i t}(t)=\frac{K_{1}}{2}\left[1+\operatorname{erf}\left(\frac{\ln t-t_{\text {valve }}}{s \sqrt{2}}\right)\right]+K_{2}
$$

where $\mathrm{t}$ is the time and $\mathrm{K}_{1}, \mathrm{~K}_{2}, \mathrm{t}_{\mathrm{valve}}$ and $\mathrm{S}$ are constants which are estimated using least square optimization (LSO). The isotopic transition period, and thus the response time, was defined 
between 5\% and 95\% of the total isotopic step change (Eqs. 2.4 and 2.5). Beyond these limits, it becomes difficult to distinguish a step change from random signal noise.

$$
\begin{aligned}
& \Delta \delta_{\text {step }}=\delta_{\text {std } 1}-\delta_{\text {std2 }}, \\
& \delta_{\%}=\frac{\delta_{\text {fit }}-\delta_{\text {std } 2}}{\Delta \delta_{\text {step }}}
\end{aligned}
$$

where $\Delta \delta_{\text {step }}$ is the size of the $\delta$-step between standard $1\left(\delta_{\text {std1 }}\right)$ and standard $2\left(\delta_{\text {std2 } 2}\right)$ and $\delta \%$ is the percent change using the $\delta$-signal from the fitted function in Eq. $2.3 \delta_{\text {fit }}$.

The response times for the customized setups are $\sim 54$ and $\sim 18$ s for the 2013 and 2014 setup, respectively. This is an improvement compared to the WVISS setup, which has a response time of $\sim 62 \mathrm{~s}$ (Figure 2.6, Tables 2.4 and 2.5). The UC L2140-i (Picarro) analyzer and vaporizer unit setup achieves response times of $90 \mathrm{~s}$ for $\delta^{18} \mathrm{O}$ and $\delta^{17} \mathrm{O}$ and $94 \mathrm{~s}$ for $\delta \mathrm{D}$ (Figure 2.6e and $\mathrm{f}$, Tables 2.4 and 2.5). The custom setups (the 2014 version in particular) are more responsive compared to the WVISS and UC setup.

We hypothesize that a more responsive system can often become less stable when optimized for responsiveness by reducing evaporation chamber volume or increasing the amount of dry air flow. This could partially be due to the fact that it can be harder to control and keep environmental parameters constant in a more responsive system. For example, if the dry air flow is increased to reduce the response time, the system can become more sensitive to ambient temperature changes (as it will be harder to preheat a larger volume of air), which can induce drift. However, another way to obtain a more responsive system would be to minimize the amount of dead volume and mixing volumes in the water sample lines, which would not necessarily result in a less stable system. The dead volume in the sample lines for the custom setups was not minimized due to lab space limitations and due to the fact that the $\delta$-CFA system shared sample lines with other CFA analytical equipment. Furthermore, the $\delta \mathrm{D}$ isotopic step transition for the WVISS setup (Figure 2.6d) is influenced by memory effects. A long tail is evident in the data before the final isotopic value is reached. The fit with the cumulative distribution function (Eq. 2.3) is poor while an exponential function improves the fit with the data. In contrast, the 2013 and 2014 custom setup reaches the final stable isotopic value faster (Figure 2.6b), which suggests it is less influenced by memory effects. Figure 2.6 provides an 
example of a step change between two water standards RICE and ITASE for the custom setups (Figure 2.6a and b) and WVISS (Figure 2.6c and d) setup. A step change from the UC setup of similar isotopic size is also provided for comparison (Figure 2.6e and f). The impulse response functions, the derivative of the isotopic fit $\left(\partial \delta_{\mathrm{fit}} / \partial \mathrm{t}\right)$ for the setups, are shown in Figure $2.6 \mathrm{~g}$ and h.

The response time values presented in Table 2.4 are valid as a comparison between the WVISS and custom setups. However, the response times for the custom setups are not representative of the whole CFA system, as the V2 valve is located downstream of the melter and debubbler (Figure 2.2). Hence the attenuation of the $\delta$ signal prior to the valve is not taken into account. Gkinis et al. [2011] presented a method to calculate the attenuation for the CFA system using a power spectrum of the CFA data and a spectrum from discrete offline measurements (ice pieces cut directly from the core) over the same depth interval as the CFA measurements. Aemisegger et al. [2012] reported $\delta \mathrm{D}, \delta^{18} \mathrm{O}$ and water vapor mixing ratio response times of 4.5, 3 and $2.9 \mathrm{~s}$, respectively, for an IWA-WVISS setup. However, their isotopic step change is between one standard from the WVISS unit and the ambient air, which provides the response times of the IWA. This way the evaporation chamber volume does not have to be replaced for the isotopic step to be complete. When an evaporation unit is used for switching between multiple standards and/or a changing CFA signal (e.g., from CFA sample stream from an ice core), it becomes critical to have a small evaporation chamber volume, as the vapor volume in the evaporation chamber needs to be replaced before the current signal can be analyzed. The lag bias introduced by the IWA-vaporizer setups are negligible (for both the custom setups and WVISS setups). On average $\delta \mathrm{D}$ lags $\delta^{18} \mathrm{O}$ by $1 \mathrm{~s}$ (Table 2.4). A $\delta$ signal without lag bias enables the calculation of high-frequency d-excess values. For the WVISS and the custom 2014 setup we can also confirm there is no observable bias between $\delta^{18} \mathrm{O}$ and $\delta^{17} \mathrm{O}$, which is relevant for ${ }^{17} \mathrm{O}$-excess measurements (Tables 2.4 and 2.5). Furthermore, for the custom setups we find no relationship between the size of the isotopic step and the response time or the response time and the direction of the step (positive or negative). 

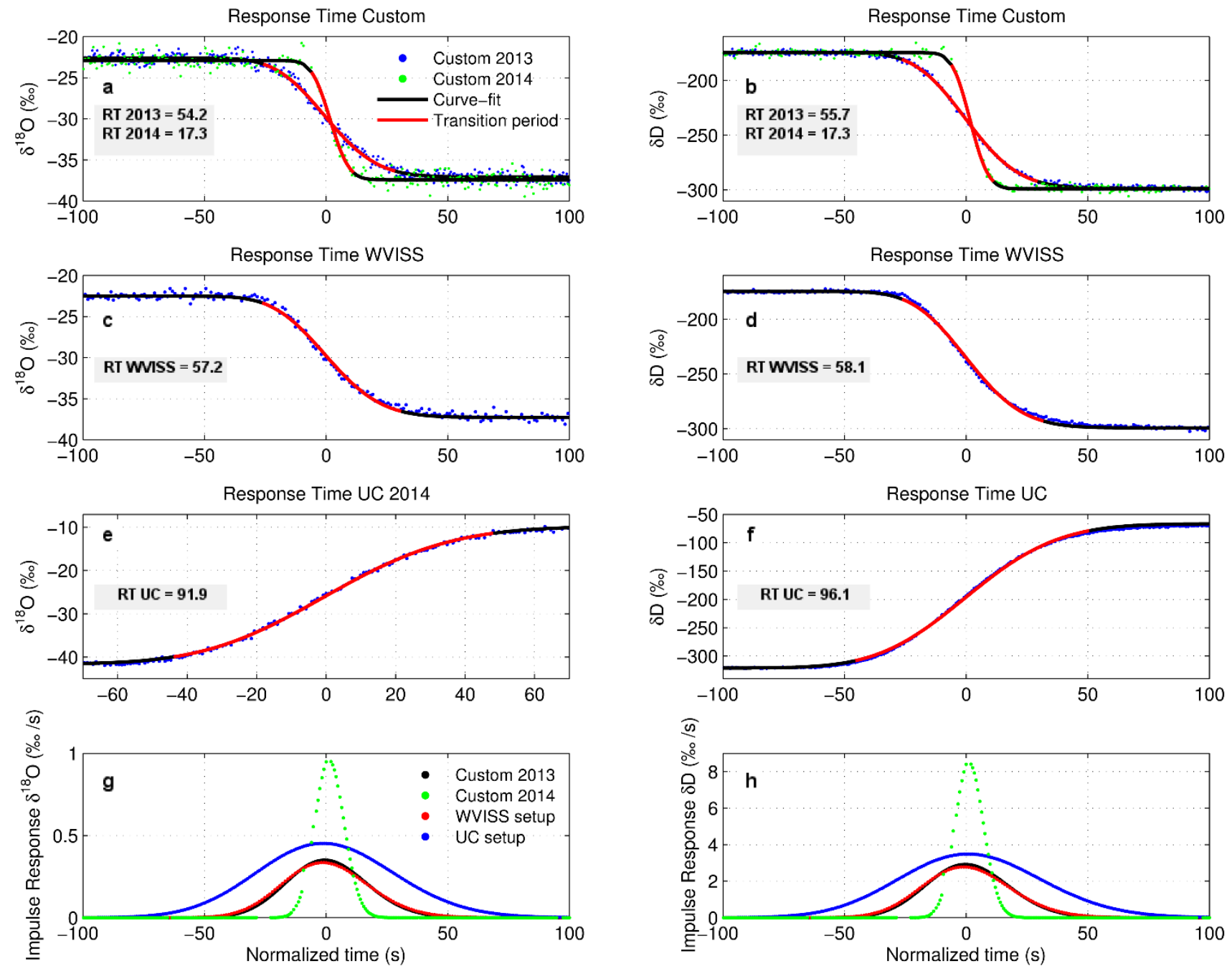

Figure 2.6. (a-f) Shows $\delta$-CFA data (blue dots and green dots for the 2013 and 2014 custom setup, respectively), a LSO fitted curve (black line), 5 and 95\% of change in the response time (RT) transition period (red line) for the custom setups (a and b) and WVISS setup (c and d) and the University of Copenhagen setup (UC; $\mathbf{e}$ and $\mathbf{f}) .(\mathbf{g}-\mathbf{h})$ The impulse response function for the fit for the 2013 custom (black line), the 2014 custom (green line), the Gkinis 2014 (blue line) and the WVISS (red line) setup. The left column of plots (a,, $\mathbf{e}$ e and $\mathbf{g}$ ) are for $\delta^{18} \mathrm{O}$ and the right column of plots (b, $\mathbf{d}, \mathbf{f}$ and $\mathbf{h})$ are for $\delta \mathrm{D}$.

We reduced the tubing length in our system for the vapor introduction to the analyzer compared to a typical atmospheric science setup, where it is necessary to have longer air intake lines. We hypothesize that our setup experiences less adsorption to tubing walls. This is important, as adsorption can cause a bias between $\delta^{18} \mathrm{O}$ and $\delta \mathrm{D}$. The tubing between evaporation chamber and analyzer is only $59 \mathrm{~cm}$, which required orientating the analyzer with the back towards the WVISS. Moreover, we applied heat tape to the tubing to reduce adsorption to tubing 
walls. To conclude discussion on this topic, we note that the response times reported above do not represent the full response time of the entire CFA system, as measured from the melt head. Limited experimentation produced an estimate of $\sim 43 \mathrm{~s}$ for the response time of the entire 2014 CFA system. This is a more rapid response than all systems reported in Table 2.3 except the custom 2014 setup. Thus, to take full advantage of the fastest response times, the isotope analysis system could be placed closer to the melt head by changing the overall CFA design or shortening the sample line between the melt head and DB1.

Table 2.4. Response times for $\delta^{18} \mathrm{O}$ and $\delta \mathrm{D}$ from isotopic step tests between water standards.

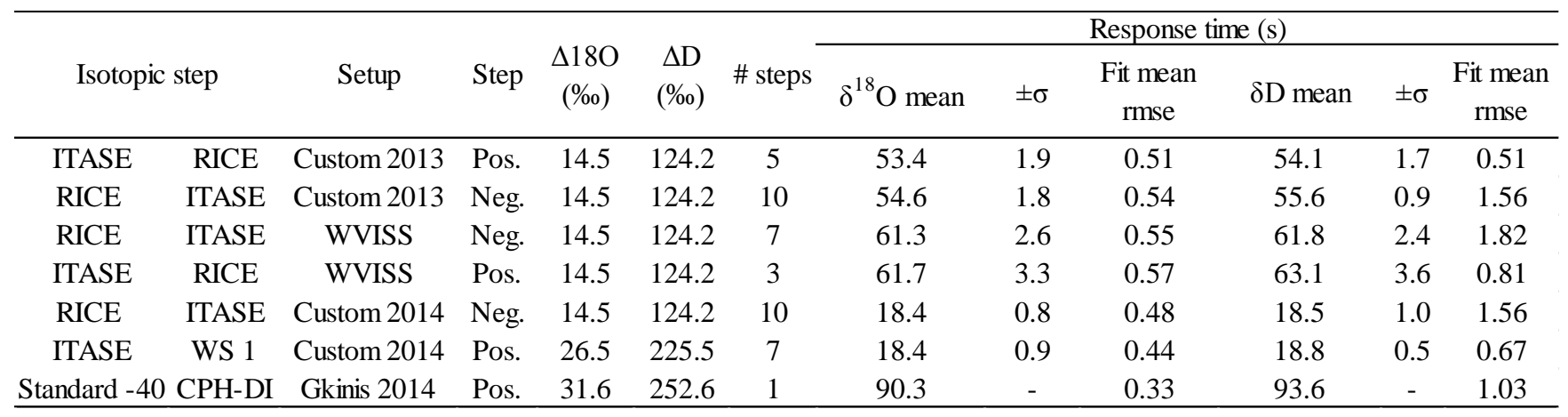

Table 2.5. Response times for $\delta^{17} \mathrm{O}$ for water standard isotopic step tests.

\begin{tabular}{ccccccccc}
\hline & & & & & \multicolumn{3}{c}{ Response time (s) } \\
\cline { 5 - 8 } \multicolumn{2}{c}{ Isotopic step } & Setup & Step & $\begin{array}{c}\Delta 170 \\
(\%)\end{array}$ & \# steps & $\begin{array}{c}\delta^{17} \mathrm{O} \\
\text { mean }\end{array}$ & $\pm \sigma$ & $\begin{array}{c}\text { Fit mean } \\
\text { rmse }\end{array}$ \\
\hline RICE & ITASE & Custom 2014 & Neg. & 7.7 & 10 & 19.2 & 1.7 & 0.74 \\
ITASE & WS 1 & Custom 2014 & Pos. & 13.7 & 7 & 19.2 & 2.2 & 0.67 \\
Standard -40 & CPH-DI & Gkinis 2014 & Pos. & 17.0 & 1 & 90.3 & - & 0.34 \\
\hline
\end{tabular}

\subsubsection{Calibration}

We use four internal standards (Table 2.2 and Figure 2.7): LHW, Working Standard 1 (WS1), RICE (derived from RICE snow) and ITASE (derived from US-ITASE, West Antarctic snow). The values of the internal standards in relation to the VSMOW/SLAP scale were determined using discrete laser absorption spectroscopy measurements on the IWA-35EP analyzer (Table 2.2). The CFA data import and processing is handled with MATLAB routines (MATLAB version 8.0.0.783 (R2012b), MathWorks, Inc., Natick, Massachusetts, United States). A semiautomatic MATLAB script was set up for extracting standard measurements 
during calibrations and associating calibration events with the corresponding ice core melt section.

Water vapor generated from Milli-Q water (18 M $\Omega$ water) is supplied to the analyzer between calibration and ice core melting periods, allowing us to easily distinguish between these events. We identify the start of the calibration measurement after the transition from Milli-Q to standard by finding the first time where the derivative of the $\delta$ CFA measurement drops below a threshold. The time lag between the V2 valve and the analyzer is found using the calculated start time of the standard measurement and the time of the valve switch recorded in the calibration log file. Running Milli-Q water when the sample or standards are not analyzed also has the advantage that there is less risk of deposit buildup that can block the nebulizer.

Figure 2.7 shows an example of a typical section from $\delta$-CFA processing of the RICE ice core. Three or four $1 \mathrm{~m}$ ice core sections were typically melted between calibrations, by stacking consecutive cores on top of each other during melting. Normally the stack of cores takes up to $2.4 \mathrm{~h}$ between calibrations, and one calibration cycle takes $30 \mathrm{~min}$. The multiple water standard calibration cycle consists of three internal standards: WS1, RICE and ITASE. The values of the internal standards in relation to the VSMOW/SLAP scale are provided in Table 2.2. The isotope standards bracket the isotopic ice core record (Figure 2.7). 


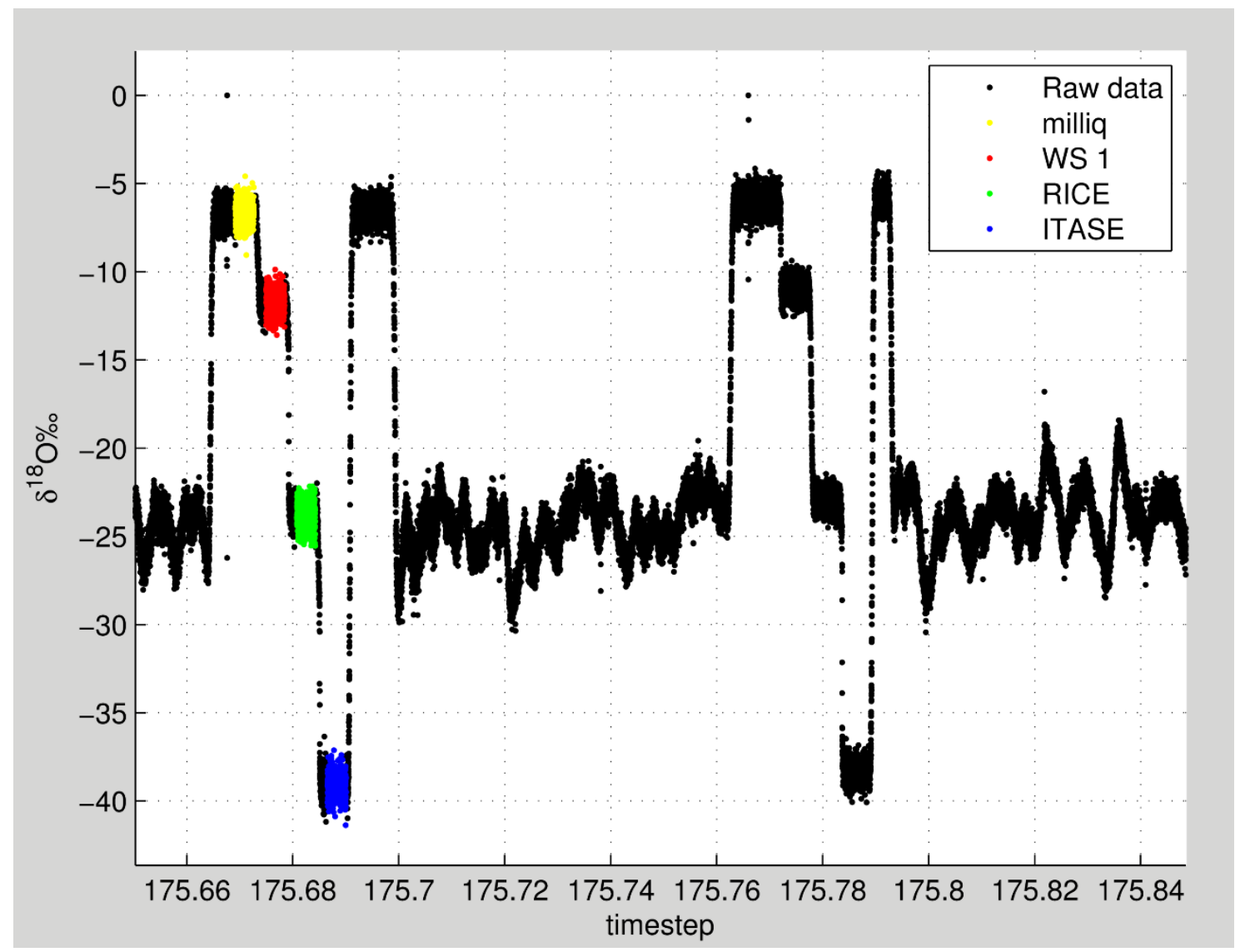

Figure 2.7. Example of raw data from a melting session and calibration events from 25 June 2013. Ice core sections of $1 \mathrm{~m}$ were stacked on top each other during melting sessions. The ice core data are bracketed by calibration events. Water standards from the first calibration event are color marked. Yellow marking is for LHW standard, red for WS1, green for RICE and blue for the ITASE water standard.

Throughout our measurements the water vapor mixing ratio was kept at $20000 \mathrm{ppm}$ in order to ensure data stability. To remove data that are affected by sudden changes in water mixing ratios (often caused by small air bubbles or drips) we used the following criteria: CFA data are removed when the difference between the $30 \mathrm{~s}$ moving average and $200 \mathrm{~s}$ moving average of water mixing ratio (ppm) exceeds 1 standard deviation $(\sigma)$ of the 60 s moving average. In addition, a cutoff limit of 15000 ppm was implemented, which removes data that are stable but measured at mixing ratios that deviate from our set measurement level ( 20 $000 \mathrm{ppm})$. If an offset occurred from the target water mixing ratio, the analyzer's water vapor dependence is corrected accurately if the magnitude of the offset in between calibrations is constant. 
Each standard is analyzed for $500 \mathrm{~s}$; the first 100 and last $100 \mathrm{~s}$ of each standard measurement are discarded to conservatively avoid influence from memory effects. Measurements shorter than $250 \mathrm{~s}$ are omitted. Figure 2.7 shows an example of the standards analyzed during a calibration cycle. Average values over $300 \mathrm{~s}$ were calculated for each standard.

We follow the recommendation by the International Atomic and Energy Agency (IAEA) of measuring multiple water standards for calibration [Kurita et al., 2012]. We fit a multi-port valve to switch between different water standards to the nebulizer to perform calibrations. The RICE and ITASE standards are used for the two-point linear correction of the CFA data. Correction slopes were calculated using the RICE and ITASE standards directly before and directly after each melting period. The data are normalized to the RICE standard to reduce the influence from instrument drift and WS1 is used as a QA/QC standard. The calibration and normalization were linearly time weighted between the calibration events.

The average of correction slopes from calibrations throughout the RICE processing campaign are $\delta^{18} \mathrm{O}=0.941 \pm 0.0057$ (mean $\pm 1 \sigma ; \mathrm{N}=324$ ) and $\delta \mathrm{D}=0.997 \pm 0.0043$. The average of the correction slopes are shown here for characterization purposes. However, for isotope raw-data correction we use adjacent calibration slopes to calibrate the data. This approach was applied as correction slopes have been shown to be instrument specific and vary slightly over time, due to instrumental drift [Kurita et al., 2012]. To correct for drift, our system is designed for calibrations performed at a time interval averaging 2.4 hours. Recent studies have obtained similar correction slopes $\left(\delta^{18} \mathrm{O}=0.941 \pm 0.008\right.$ and $\delta \mathrm{D}=0.994 \pm 0.003$ [Aemisegger et al. , 2012] and $\delta^{18} \mathrm{O}=0.946 \pm 0.005$ and $\delta \mathrm{D}=1.00 \pm 0.003$ [Kurita et al., 2012]) using an IWAWVISS setup. It is important to use a two-point calibration correction, as it is not feasible to calculate correction slopes using a single-standard correction approach, and any resulting deviation from the predominant slope would bias the calibration.

The custom setups can be applied to the field of atmospheric science, enabling rapid, automated and robust calibration cycles using multiple water standards (two-point calibration), compared to the one-standard setup that the unaltered WVISS is fitted with by the manufacturer. Reducing the length of calibration while including multiple standards should maximize data quality while minimizing the loss of atmospheric measurements during calibration cycles. 
Additionally, the setup has proven to be a robust system that can run continuously for months and operate unattended for days.

\subsubsection{Long-Term Precision and Accuracy}

The RICE and ITASE standards are used for the two-point linear correction of the $\delta$-CFA data, and the RICE standard is also used for normalization to minimize influence from drift. Measurement of a QA/QC standard (WS1) was conducted as a check throughout the RICE processing campaign (35 days). The corrected CFA measurements of the QA/QC standard provide a measure of the long-term precision and accuracy of the corrected $\delta$-CFA data measured on the custom 2013 setup (Figure 2.8). The data in Figure 2.8 have been normalized using the VSMOW/SLAP value of the QA/QC standard (WS1; Table 2.2). The overall precision of the 177 standard measurements over the 35 days was 0.11 and $0.75 \%$ for $\delta^{18} \mathrm{O}$ and $\delta \mathrm{D}$, respectively. The mean anomaly values of the corrected QA/QC standard values are -0.07 and $-0.51 \%$ for $\delta^{18} \mathrm{O}$ and $\delta \mathrm{D}$, respectively, and they provide an estimate of the overall accuracy of the measurements (black dashed line in Figure 2.8). On 16 June 2013 (day 167), problems were diagnosed with the vacuum pump for the IWA (N940, KNF), which appears to have affected the accuracy of $\delta \mathrm{D}$ (Figure 2.8b). 

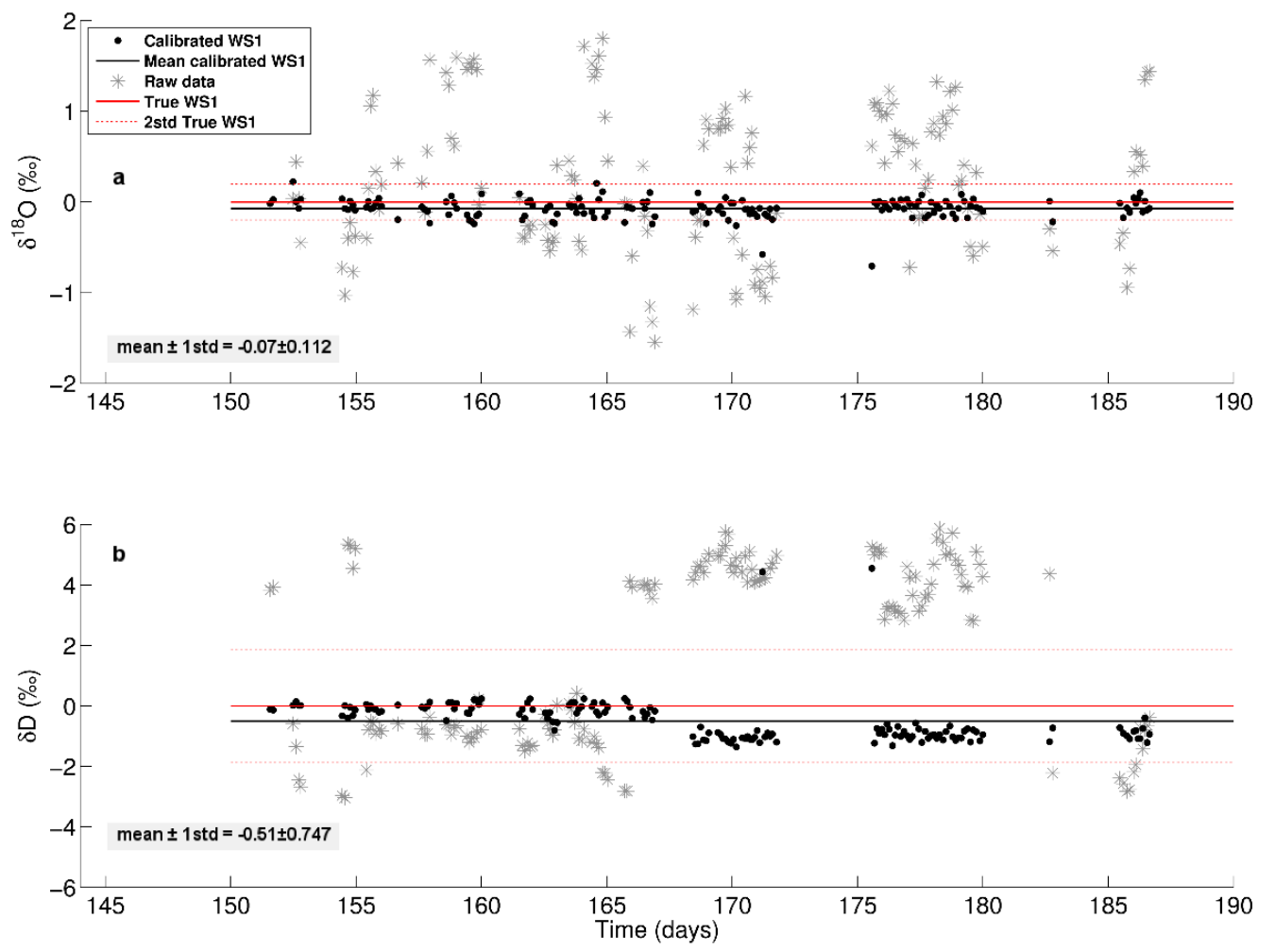

Figure 2.8. Normalized measurement of QA/QC standard (WS1) over 35 days. Raw data are shown as gray stars and corrected data as black dots (a) for $\delta^{18} \mathrm{O}$ and (b) for $\delta \mathrm{D}$. The corrected data have a standard deviation of 0.11 and $0.75 \%$ for $\delta^{18} \mathrm{O}$ and $\delta \mathrm{D}$, respectively. The mean corrected anomaly (black line) from the true WS1 standard value (thick red line) is -0.07 and $-0.51 \%$ for $\delta^{18} \mathrm{O}$ and $\delta \mathrm{D}$, respectively.

\subsubsection{High-Resolution Ice Core Record}

To evaluate the quality of the calibration procedure, the corrected $\delta$-CFA data were compared to discrete data (Figure 2.9). Discrete measurements measured on an IWA-35EP (green dots) and DLT-100 analyzer (yellow dots) can be compared with $\delta$-CFA data integrated over the discrete vial depth intervals (red dots). Figure 2.9 verifies the validity of the calibration procedure. The discrete and CFA data for the 133 to $144 \mathrm{~m}$ section of the RICE ice core were investigated further by creating histograms of the difference between the discrete data measured on the IWA-35EP analyzer and the CFA data. A difference was calculated for each discrete sample $(\mathrm{N}=215)$. The averages of the CFA $\delta$ over the discrete vial depth intervals were calculated to make a direct comparison with the lower resolution discrete measurements. The difference between the averaged CFA and discrete data was calculated to be $0.09 \pm 0.16$ and 0.70 
$\pm 1.07 \%$ (mean $\pm 1 \sigma$ ) for $\delta^{18} \mathrm{O}$ and $\delta \mathrm{D}$, respectively (Figure 2.10). d-excess was calculated for the discrete and averaged CFA data, the difference being $-0.05 \pm 0.25 \%$ (Figure 2.10c).
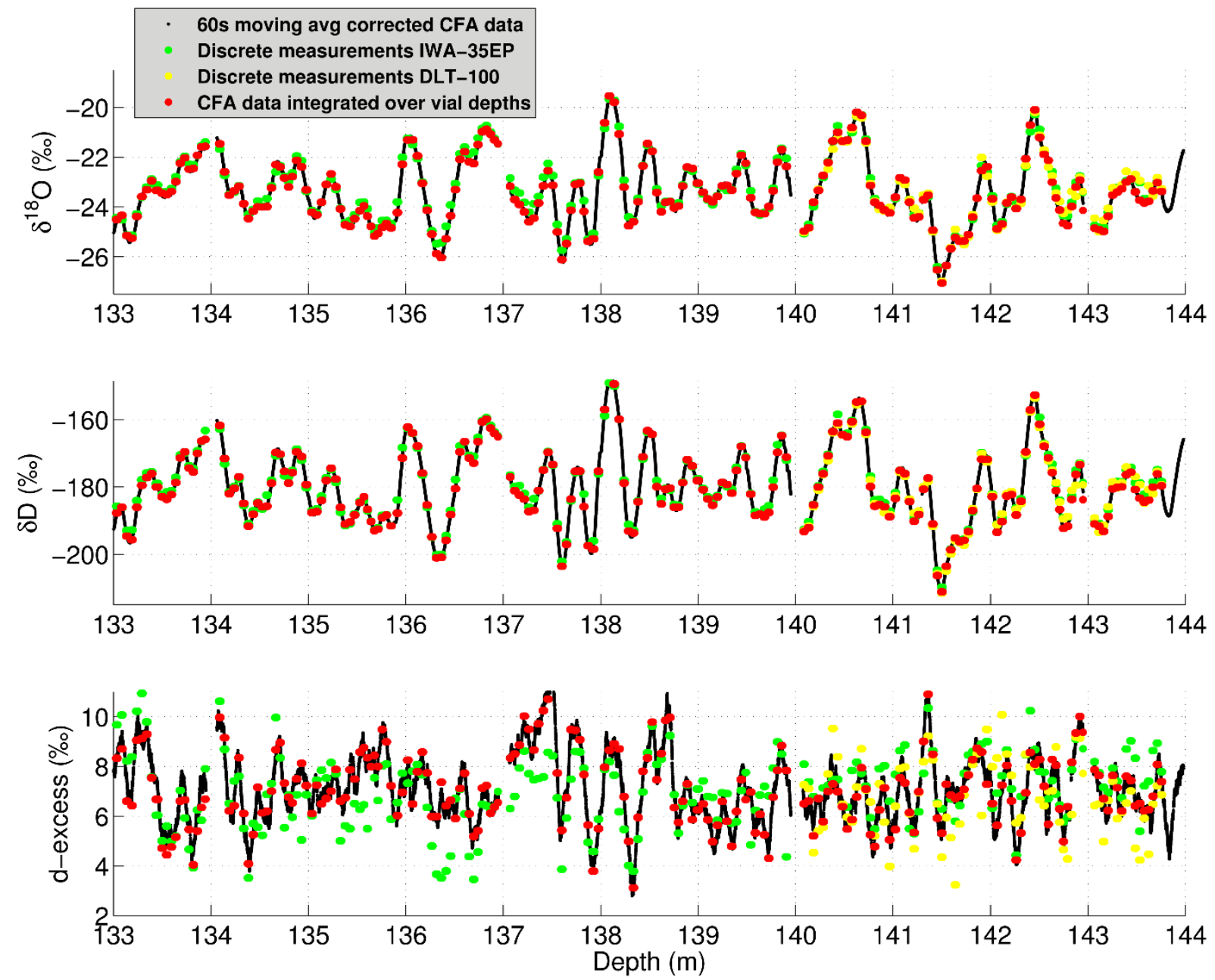

Figure 2.9. The $60 \mathrm{~s}$ moving average of the corrected $2 \mathrm{~Hz} \delta$ CFA data (black line), results from discrete measurements (green dots for measurements from the IWA-35EP analyzer and yellow dots for measurements on the DLT-100 analyzer) and $\delta$-CFA data integrated over the discrete vial depth intervals (red dots); (a) for $\delta^{18} \mathrm{O}$, (b) for $\delta \mathrm{D}$ and (c) for d-excess. 

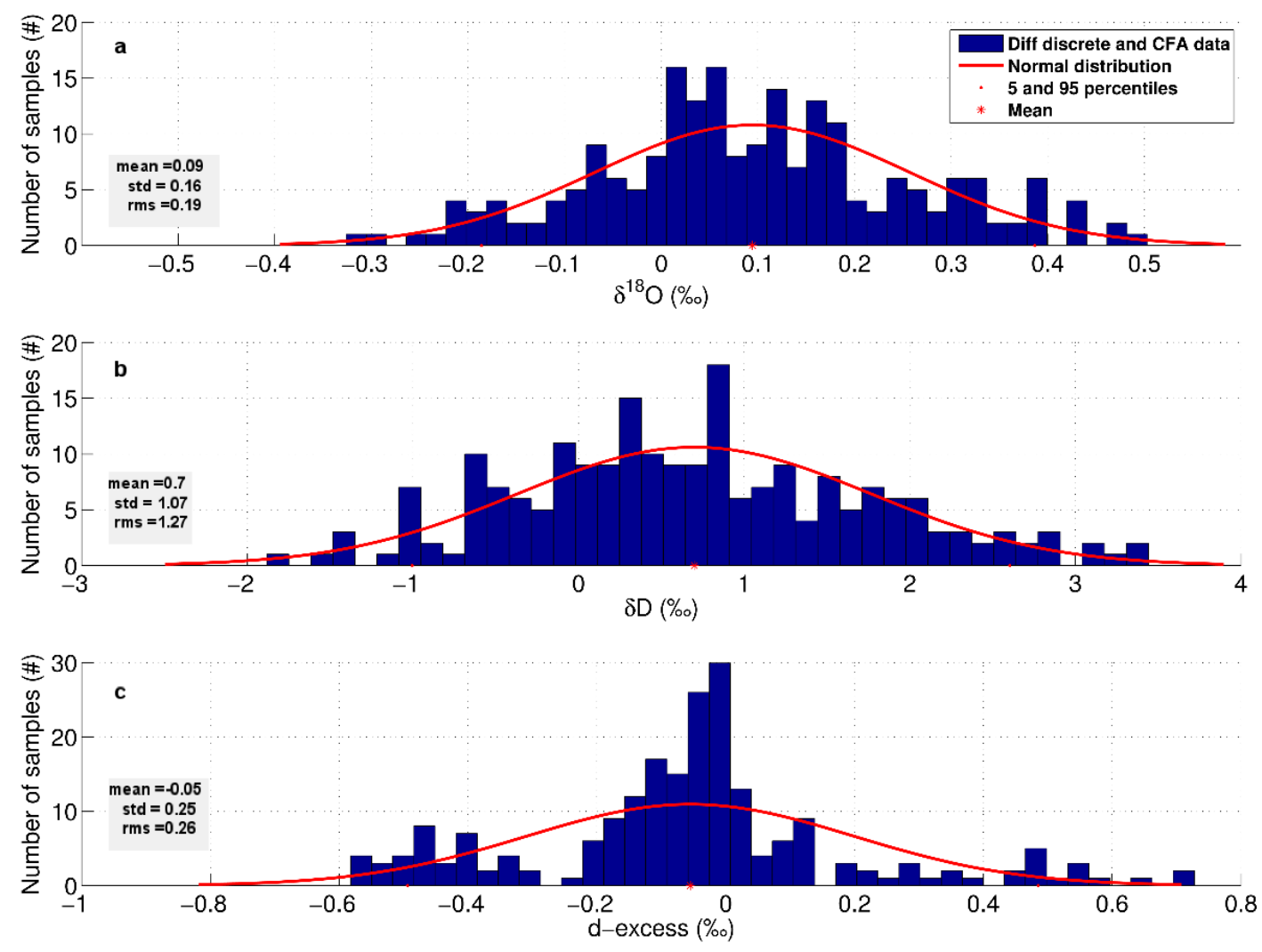

Figure 2.10. Histograms showing the difference between discrete and the CFA data: (a) for $\delta^{18} \mathrm{O}$, (b) for $\delta \mathrm{D}$ and (c) d-excess for depths from 133 to $144 \mathrm{~m}$ of the RICE ice core. 


\subsection{Conclusions}

This study outlines the process used to develop experimental CFA equipment for $\delta$ measurements with high temporal resolution (sub-annual) in the RICE ice cores and describes the performance and operation of the equipment as well as potential improvements. This continuous-flow laser system is the first to use OA-ICOS in combination with a vaporizer unit to continuously analyze sample from an ice core. Stability tests comparing the custom and the WVISS setups were performed and Allan deviations $\left(\sigma_{\text {Allan }}\right)$ were calculated to determine precision at different averaging times. For the 2013 modified setup, the ( $\left.\sigma_{\text {Allan }}\right)$ after integration times of $10^{3} \mathrm{~s}$ are 0.060 and $0.070 \%$ for $\delta^{18} \mathrm{O}$ and $\delta \mathrm{D}$, respectively. The corresponding $\sigma_{\text {Allan }}$ values for the custom 2014 setup are $0.030,0.060$ and $0.043 \%$ for $\delta^{18} \mathrm{O}, \delta \mathrm{D}$ and $\delta^{17} \mathrm{O}$, respectively. For the WVISS setup the precision is $0.035,0.070$ and $0.042 \%$ after $10^{3} \mathrm{~s}$ for $\delta^{18} \mathrm{O}$, $\delta \mathrm{D}$ and $\delta^{17} \mathrm{O}$, respectively. Both the modified and WVISS setup are influenced by instrumental drift, and $\delta^{18} \mathrm{O}$ is more drift sensitive than $\delta \mathrm{D}$. The peak precision uncertainty for the custom 2013 CFA $\delta$ data is given by the Allan deviation after $1.2 \mathrm{~h}$ (center point between calibrations), which is $\sim 0.17$ and $\sim 0.13 \%$ for $\delta^{18} \mathrm{O}$ and $\delta \mathrm{D}$, respectively. Allan deviation for d-excess was estimated to range between 0.31 and $1.37 \%$ using Eq. (2.2). $1.37 \%$ is the peak uncertainty $(1.2 \mathrm{~h})$ and the minimum uncertainty $(0.31 \%$ ) occurs near calibration points, within the optimal integration time for $\delta^{18} \mathrm{O}(200 \mathrm{~s})$. Results from the UC setup show that the Picarro CRDS analyzer (L2140-i) and vaporizer achieves $\sigma_{\text {Allan }}$ values of $0.011 \%$ for $\delta^{18} \mathrm{O}, 0.010 \%$ for $\delta^{17} \mathrm{O}$ and $0.048 \%$ for $\delta \mathrm{D}$, after averaging times of $10^{3} \mathrm{~s}$. The UC setup outperforms the custom setups on the basis of precision. The mean response times for the customized setup are 54 and $18 \mathrm{~s}$ for 2013 and 2014 setup, respectively. This is an improvement compared to the WVISS setup, which has a response time of $62 \mathrm{~s}$. The UC L2140-i (Picarro) analyzer and vaporizer unit setup achieves response times of $90 \mathrm{~s}$ for $\delta^{18} \mathrm{O}$ and $\delta^{17} \mathrm{O}$ and $94 \mathrm{~s}$ for $\delta \mathrm{D}$. The custom setups (the 2014 version in particular) are more responsive compared to the WVISS and UC setup and can therefore provide measurements with higher temporal resolution. The two-point calibration process was evaluated by comparing the CFA data to discrete measurements. The overall difference between CFA and IWA-35EP discrete measurements was $0.09 \pm 0.16$ and $0.70 \pm 1.07 \%$ (mean $\pm 1 \sigma$ ) for $\delta^{18} \mathrm{O}$ and $\delta \mathrm{D}$, respectively. The custom setups used during the 2013 and 2014 RICE ice core processing 
campaign achieved high precision measurements, in particular for $\delta \mathrm{D}$, with high temporal (subannual) resolution for the upper part of the core.

Acknowledgements. The authors would like to thank two anonymous reviewers for their comments that helped to improve the final version of the paper. We thank Cedric Douence and Andy Phillips for analyzing discrete samples on the DLT-100 LGR analyzer and Valerie Claymore, Bruce Crothers, Ed Hutchinson, Rebecca Pyne and Steve Mawdesley for help with modification of the WVISS. Doug Baer and Manish Gupta (LGR) assisted with optimization discussions and provision of additional equipment. We thank Stefanie Semper for LabVIEW programming. Additionally, responses to reviewers are available online. http://www.atmosmeas-tech-discuss.net/7/C5303/2015/amtd-7-C5303-2015-supplement.pdf. The funding for the project was provided by the New Zealand Government through GNS Science (Global Change through Time Programme, GNS-540GCT12 and GNS-540GCT32) and Victoria University of Wellington (RDF-VUW-1103). This work is a contribution to the Roosevelt Island Climate Evolution (RICE) Program, funded by national contributions from New Zealand, Australia, Denmark, Germany, Italy, People's Republic of China, Sweden, United Kingdom and the United States of America. The main logistic support was provided by Antarctica New Zealand (K049) and the US Antarctic Program. 


\subsection{References}

Aemisegger, F., P. Sturm, P. Graf, H. Sodemann, S. Pfahl, A. Knohl, and H. Wernli (2012), Measuring variations of $\delta 18 \mathrm{O}$ and $\delta 2 \mathrm{H}$ in atmospheric water vapour using two commercial laser-based spectrometers: An instrument characterisation study, Atmos. Meas. Tech., 5, 1491-1511, doi:10.5194/amt-5-1491-2012.

Allan, D. W. (1966), Statistics of atomic frequency standards, Proc. IEEE, 54(2), doi:10.1109/PROC.1966.4634.

Baer, D. S., J. B. Paul, M. Gupta, and a. O'Keefe (2002), Sensitive absorption measurements in the near-infrared region using off-axis integrated-cavity-output spectroscopy, Appl. Phys. B Lasers Opt., 75, 261-265, doi:10.1007/s00340-002-0971-z.

Berman, E. S. F., N. E. Levin, A. Landais, S. Li, and T. Owano (2013), Measurement of $\delta 180$, $\delta 17 \mathrm{O}$, and $17 \mathrm{O}$-excess in Water by Off-Axis Integrated Cavity Output Spectroscopy and Isotope Ratio Mass Spectrometry, Anal. Chem., 85(21), 10392-10398, doi:10.1021/ac402366t.

Bigler, M., A. Svensson, E. Kettner, P. Vallelonga, M. E. Nielsen, and Jø. P. Steffensen (2011), Optimization of high-resolution continuous flow analysis for transient climate signals in ice cores, Environ. Sci. Technol., 45, 4483-4489, doi:10.1021/es200118j.

Conway, H. (1999), Past and Future Grounding-Line Retreat of the West Antarctic Ice Sheet, Science (80-. )., 286(5438), 280-283, doi:10.1126/science.286.5438.280.

Coplen, T. B. (1996), New guidelines for reporting stable hydrogen, carbon, and oxygen isotoperatio data, Geochim. Cosmochim. Acta, 60(17), 3359-3360, doi:10.1016/00167037(96)00263-3.

Craig, H., L. I. Gordon, and Y. Horibe (1963), Isotopic exchange effects in the evaporation of water, J. Geophys. Res., 68(17), 5079-5087.

Crosson, E. R. (2008), A cavity ring-down analyzer for measuring atmospheric levels of methane, carbon dioxide, and water vapor, Appl. Phys. B Lasers Opt., 92, 403-408, doi:10.1007/s00340-008-3135-y.

Dansgaard, W. (1964), Stable isotopes in precipitation, Tellus A, doi:10.3402/tellusa.v16i4.8993.

Emanuelsson, B. D., W. T. Baisden, N. A. N. Bertler, E. D. Keller, and V. Gkinis (2015), Highresolution continuous-flow analysis setup for water isotopic measurement from ice cores using laser spectroscopy, Atmos. Meas. Tech., 8(7), 2869-2883, doi:10.5194/amt-8-28692015.

EPICA Community Members (2004), Eight glacial cycles from an Antarctic ice core, Nature, 429, 623-628, doi:http://www.nature.com/nature/journal/v429/n6992/suppinfo/nature02599_S1.html.

Epstein, S., and T. Mayeda (1953), Variations of 180 content of waters from natural sources, Geochim. Cosmochim. Acta, 4, 213-224.

Gkinis, V., T. J. Popp, S. J. Johnsen, and T. Blunier (2010), A continuous stream flash evaporator for the calibration of an IR cavity ring-down spectrometer for the isotopic 
analysis of water., Isotopes Environ. Health Stud., 46, 463-475, doi:10.1080/10256016.2010.538052.

Gkinis, V., T. J. Popp, T. Blunier, M. Bigler, S. Schüpbach, E. Kettner, and S. J. Johnsen (2011), Water isotopic ratios from a continuously melted ice core sample, Atmos. Meas. Tech., 4, 2531-2542, doi:10.5194/amt-4-2531-2011.

Goebel, T., and R. Lascano (2012), System for high throughput water extraction from soil material for stable isotope analysis of water, J. Anal. Sci. Methods ..., 2(4), 203-207.

Gonfiantini, R. (1978), Standards for stable isotope measurements in natural compounds, Nature, $271,534-536$.

Johnson, L. R., Z. D. Sharp, J. Galewsky, M. Strong, A. D. Van Pelt, F. Dong, and D. Noone (2011), Hydrogen isotope correction for laser instrument measurement bias at low water vapor concentration using conventional isotope analyses: application to measurements from Mauna Loa Observatory, Hawaii, Rapid Commun. Mass Spectrom., 25(5), 608-616, doi: $10.1002 / \mathrm{rcm} .4894$.

Jouzel, J. et al. (1997), Validity of the temperature reconstruction from water isotopes in ice cores, J. Geophys. Res. Ocean., 102(C12), 26471-26487, doi:10.1029/97JC01283.

Kerstel, E. R. T., R. van Trigt, J. Reuss, and H. A. J. Meijer (1999), Simultaneous Determination of the $2 \mathrm{H} / 1 \mathrm{H}, 17 \mathrm{O} / 16 \mathrm{O}$, and $18 \mathrm{O} / 16 \mathrm{O}$ Isotope Abundance Ratios in Water by Means of Laser Spectrometry, Anal. Chem., 71(23), 5297-5303, doi:10.1021/ac990621e.

Kurita, N., B. D. Newman, L. J. Araguas-Araguas, and P. Aggarwal (2012), Evaluation of continuous water vapor $\delta \mathrm{D}$ and $\delta 18 \mathrm{O}$ measurements by off-axis integrated cavity output spectroscopy, Atmos. Meas. Tech., 5, 2069-2080, doi:10.5194/amt-5-2069-2012.

Küttel, M., E. J. Steig, Q. Ding, A. J. Monaghan, and D. S. Battisti (2012), Seasonal climate information preserved in West Antarctic ice core water isotopes: Relationships to temperature, large-scale circulation, and sea ice, Clim. Dyn., 39, 1841-1857, doi:10.1007/s00382-012-1460-7.

Lee, X., K. Kim, and R. Smith (2007), Temporal variations of the 18O/16O signal of the wholecanopy transpiration in a temperate forest, Global Biogeochem. Cycles, 21(3), doi:10.1029/2006GB002871.

Maselli, O. J., D. Fritzsche, L. Layman, J. R. McConnell, and H. Meyer (2013), Comparison of water isotope-ratio determinations using two cavity ring-down instruments and classical mass spectrometry in continuous ice-core analysis., Isotopes Environ. Health Stud., 49, 387-398, doi:10.1080/10256016.2013.781598.

Masson-Delmotte, V. et al. (2008), A review of antarctic surface snow isotopic composition: Observations, atmospheric circulation, and isotopic modeling, J. Clim., 21(188), 33593387, doi:10.1175/2007JCLI2139.1.

Merlivat, L., and J. Jouzel (1979), Global climatic interpretation of the deuterium-oxygen 18 relationship for precipitation, J. Geophys. Res. Ocean., 84(C8), 5029-5033, doi:10.1029/JC084iC08p05029.

Petit, R. J., D. Raynaud, I. Basile, J. Chappellaz, C. Ritz, M. Delmotte, M. Legrand, C. Lorius, 
and L. Pe (1999), Climate and atmospheric history of the past 420,000 years from the Vostok ice core, Antarctica, Nature, 399, 429-413, doi:10.1038/20859.

Rambo, J., C. T. Lai, J. Farlin, M. Schroeder, and K. Bible (2011), On-site calibration for high precision measurements of water vapor isotope ratios using off-axis cavity-enhanced absorption spectroscopy, J. Atmos. Ocean. Technol., 28, 1448-1457, doi:10.1175/JTECHD-11-00053.1.

Rhodes, R. H., N. a N. Bertler, J. a. Baker, H. C. Steen-Larsen, S. B. Sneed, U. Morgenstern, and S. J. Johnsen (2012), Little Ice Age climate and oceanic conditions of the Ross Sea, Antarctica from a coastal ice core record, Clim. Past, 8, 1223-1238, doi:10.5194/cp-81223-2012.

Schmidt, M., K. Maseyk, C. Lett, P. Biron, P. Richard, T. Bariac, and U. Seibt (2010), Concentration effects on laser-based $\delta 18 \mathrm{O}$ and $\delta 2 \mathrm{H}$ measurements and implications for the calibration of vapour measurements with liquid standards, Rapid Commun. Mass Spectrom., 24(24), 3553-3561, doi:10.1002/rcm.4813.

Sinclair, K. E., N. A. N. Bertler, W. J. Trompetter, and W. T. Baisden (2012), Seasonality of Airmass Pathways to Coastal Antarctica: Ramifications for Interpreting High-Resolution Ice Core Records, J. Clim., 26(6), 2065-2076, doi:10.1175/JCLI-D-12-00167.1.

Steen-Larsen, H. C. et al. (2013), Continuous monitoring of summer surface water vapor isotopic composition above the Greenland Ice Sheet, Atmos. Chem. Phys., 13, 4815-4828, doi:10.5194/acp-13-4815-2013.

Steig, E. J. et al. (2013), Recent climate and ice-sheet changes in West Antarctica compared with the past 2,000 years, Nat. Geosci., 6(5), 372-375, doi:10.1038/ngeo1778.

Steig, E. J., V. Gkinis, a. J. Schauer, S. W. Schoenemann, K. Samek, J. Hoffnagle, K. J. Dennis, and S. M. Tan (2014), Calibrated high-precision ${ }^{17} \mathrm{O}$-excess measurements using cavity ring-down spectroscopy with laser-current-tuned cavity resonance, Atmos. Meas. Tech., 7, 2421-2435, doi:10.5194/amt-7-2421-2014.

Sturm, P., and A. Knohl (2010), Water vapor $\delta 2 \mathrm{H}$ and $\delta 18 \mathrm{O}$ measurements using off-axis integrated cavity output spectroscopy, Atmos. Meas. Tech., 3(1), 67-77, doi:10.5194/amt-367-2010.

Thomas, E. R., T. J. Bracegirdle, J. Turner, and E. W. Wolff (2013), A 308 year record of climate variability in West Antarctica, Geophys. Res. Lett., 40(20), 5492-5496, doi:10.1002/2013GL057782.

WAIS Divide Project Members (2013), Onset of deglacial warming in West Antarctica driven by local orbital forcing, Nature, 500(7463), 440-444.

Werle, P. (2011), Accuracy and precision of laser spectrometers for trace gas sensing in the presence of optical fringes and atmospheric turbulence, Appl. Phys. B Lasers Opt., 102(2), 313-329, doi:10.1007/s00340-010-4165-9. 


\subsection{Supplementary Information}

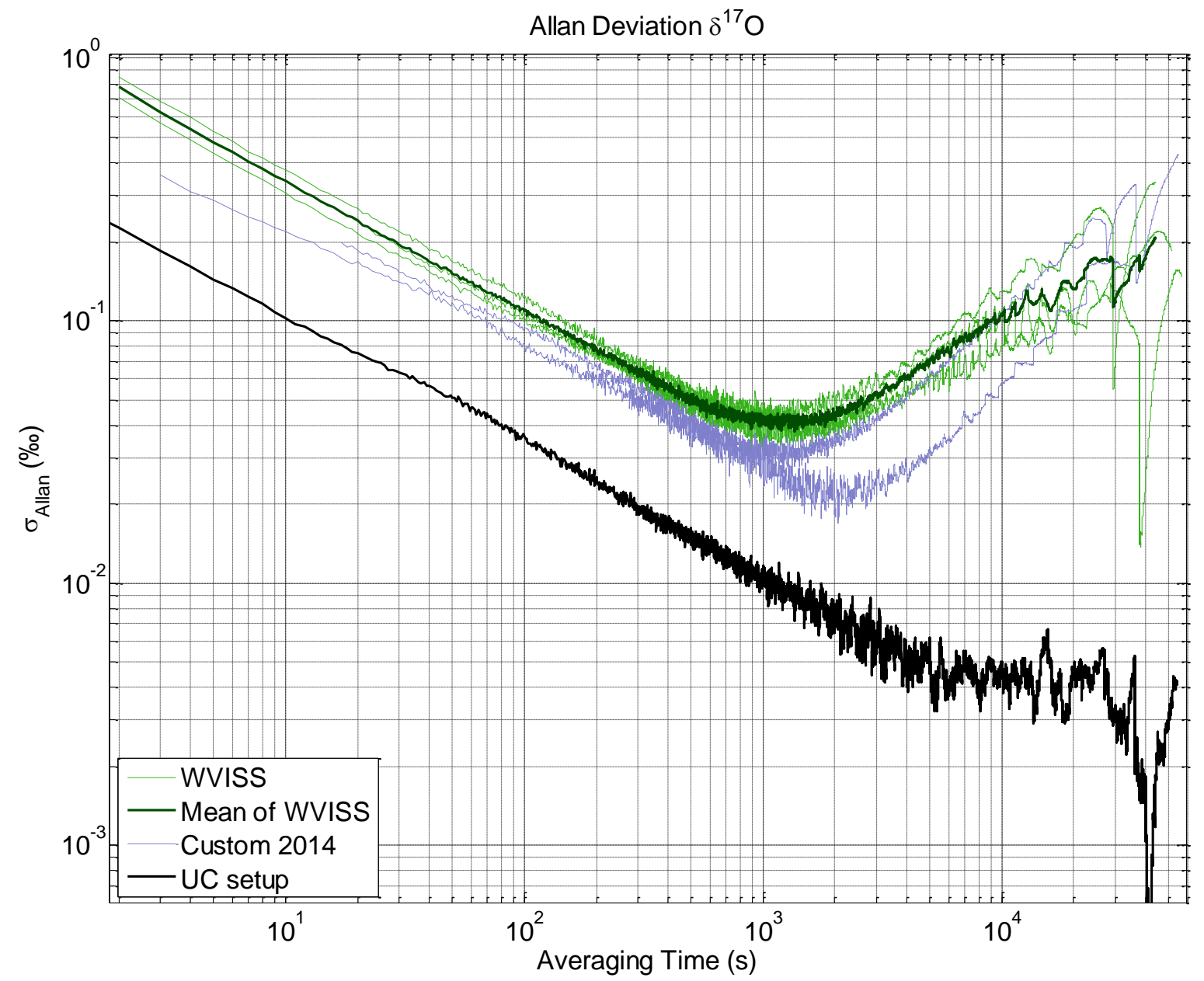

Figure S2.1. Allan deviation as a function of averaging time for $\delta^{17} \mathrm{O}$ for stability tests on the WVISS (green lines), the custom 2014 (blue lines) and from the UC setup (black line). 


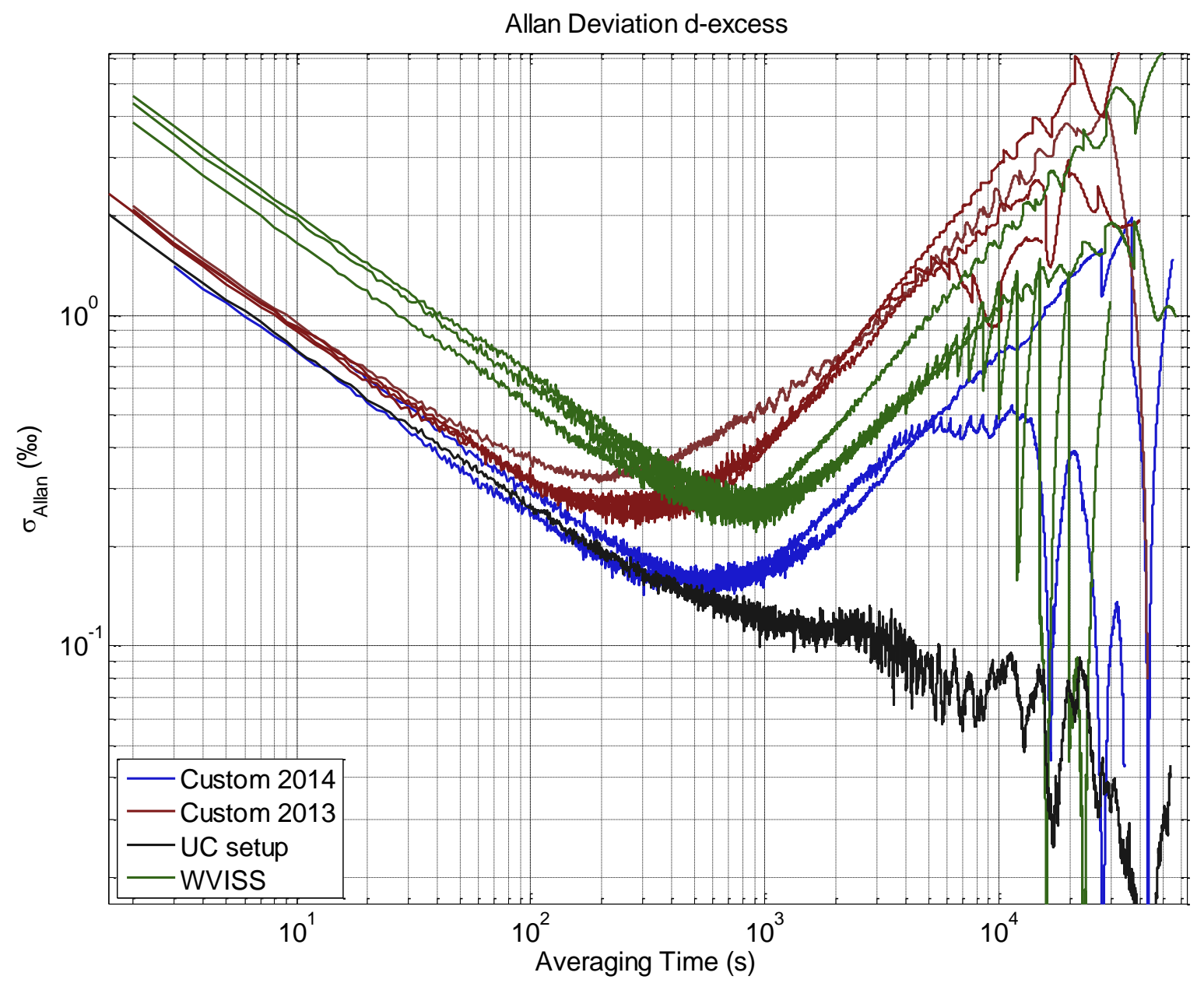

Figure S2.2. Allan deviation as a function of averaging time for d-excess for stability tests on the custom setups (2013 brown lines and 2014 blue lines), the WVISS (green lines), and from the UC setup (black line). 


\section{Chapter 3: $\quad$ The role of the Amundsen-Bellingshausen Sea anticyclonic circulation for marine air mass intrusions and West Antarctic climate}

B. D. Emanuelsson ${ }^{1,2}$, N. A. N. Bertler ${ }^{1,2}$, J. A. Renwick ${ }^{3}$, B. R. Markle ${ }^{4}$, W. T. Baisden $^{2}$, E. D. Keller ${ }^{2}$, and P. D. Neff ${ }^{1,2, *}$

This chapter has been prepared for submission to the international journal Climate Dynamics (Clim Dyn).

[1]\{Antarctic Research Centre, Victoria University of Wellington, PO Box 600, Wellington 6140, New Zealand $\}$

[2]\{ National Isotope Centre, GNS Science, 30 Gracefield Road, Lower Hutt 5010, New Zealand $\}$

[3] \{School of Geography, Environment and Earth Sciences, Victoria University of Wellington, PO Box 600, Wellington 6140, New Zealand\}

[4]\{Quaternary Research Center and Department of Earth and Space Sciences, University of Washington, Seattle, Washington 98195, USA

[*] $\{$ Present address: Department of Earth and Environmental Sciences, University of Rochester, Rochester, New York 14627, USA\}

Keywords Anticyclones, Precipitation rates, Amundsen Sea Low, Modes of variability, Ice cores, West Antarctica

Correspondence to: B. D. Emanuelsson (d.emanuelsson@gmail.com) 


\begin{abstract}
Persistent positive anomalies in 500-hPa geopotential height fields from the ECMWF ERAInterim reanalysis are used to quantify Amundsen-Bellingshausen Sea (ABS) anticyclonic and cyclonic event occurrences associated with precipitation in West Antarctica (WA). We demonstrate that intermittent, low-frequency anticyclones play a key role in the ABS in providing enhanced non-zonal transport, associated with heat and moisture advection into WA, affecting surface climate, precipitation rates and isotopic signatures. El Niño events, negative Southern Annular Mode (SAM), and a positive first Pacific-South American pattern (PSA1) are characterized by frequent ABS anticyclones, which are associated with air mass advection over western Marie Byrd Land/eastern Ross Sea, high precipitation rates and isotope ratios at RICE. The opposite phases are associated with increased cyclonic activity over the ABS and anticyclones occurring farther northeast, over South America. Under these conditions, air mass advection over Ellsworth Land and Antarctic Peninsula is enhanced and air mass intrusion over western Marie Byrd Land/eastern Ross Sea is reduced. These conditions are associated with reduced snowfall and a depleted isotopic signal at RICE. The phase-relationships of the aforementioned climate modes are well preserved in RICE isotope and snowfall, as anticyclone frequencies and thus direct northerly air mass intrusions primarily occur during one polarity phase modes. In WA large precipitation events can occur during both ENSO polarity phases, during both El Niño and La Niña events, when ABS anticyclonic and ABS cyclone frequencies are high, respectively. For this reason, WA precipitation rates and water stable isotopes ratios do not preserve an ENSO signal.
\end{abstract}

\title{
3.1 Introduction
}

Sothern Hemisphere (SH) anticyclones (including long-lived blocking events) have an important role in determining high-latitude weather and climate conditions (Sinclair 1981; Bromwich 1988; Cullather et al. 1996; Noone et al. 1999; Goodwin et al. 2003; Massom et al. 2004; Renwick 2005; Nicolas and Bromwich 2011; Oliveira et al. 2014). Here, the relationship between the occurrence of anticyclones and cyclones, and WA precipitation and water stable isotope fractionation is investigated. Recent research efforts have emphasized the role of the Amundsen Sea Low (ASL) (Hosking et al. 2013; Turner et al. 2013) and the Amundsen Sea atmospheric circulation (Ding et al. 2011; Ding et al. 2012; Bracegirdle 2013) for especially WA 
climate. The ASL is a quasi-stationary low-pressure cell with large geopotential height variability, which is located in the ABS/Ross Sea region (Cullather et al. 1996; Kreutz et al. 2000; Turner et al. 2013). The ASL is an area characterized by a high density of synoptic and subsynoptic scale cyclonic low pressure systems (Hosking et al. 2013). The ASL is present because of the large number of depressions in the South Pacific sector of the Southern Ocean, that have either moved south from mid-latitudes, or developed at high-latitudes from interactions between the strong westerly-zonal flow and Antarctica orography (Baines and Fraedrich 1989; Walsh et al. 2000; Lachlan-Cope et al. 2001; Turner et al. 2013; Raphael et al. 2015). It is however, challenging to relate the storm density and depths of the depressions to the ASL, since the climatological location of the ASL does not occur at a clear maximum of storm activity (Hosking et al. 2013; Raphael et al. 2015). The ASL region, which contains the ABS region, is characterized by large geopotential height variability (Connolley 1997; Renwick 2002; LachlanCope and Connolley 2006; Ding et al. 2012), with a standard deviation maximum located over the Amundsen Sea (Ding et al. 2012). The large geopotential height variability in the ABS has been attributed to a combination of zonal asymmetry of the Antarctic orography (Lachlan-Cope et al. 2001) and tropical Pacific SH high-latitude influence via Rossby waves (Lachlan-Cope and Connolley 2006; Ding et al. 2012).

The ASL is the deepest of three sea level pressure cells present around Antarctica, imposing a strong meridional flow component, impacting Antarctic heat and moisture transport and sea ice distribution (Hosking et al. 2013; Raphael et al. 2015). The imposed meridional flow conditions breaks up the dominate zonal-westerly flow regime and thus also WA isolation from lowerlatitudes. Blocking events are characterized by long-lived, near-stationary anticyclones that "block" the progression of the westerly circulation and associated storm tracks. They can be classified according to a split westerly flow (Lejenäs and Økland 1983; Lejenäs 1984; Tibaldi et al. 1994; Wiedenmann et al. 2002) or as persistent positive anomalies (PPA) in the geopotential height (Dole and Gordon 1983; Trenberth and Mo 1985; Dole 1986; Blackmon et al. 1986; Renwick 2005). Regions of large overall geopotential height variability are likely to be associated with large both positive and negative geopotential height anomalies. Blocking has been shown to frequently occur in the Amundsen-Bellingshausen Sea (ABS) region (van Loon and Shea 1987; Sinclair 1996; Renwick 1998; Renwick 2005) but relationships between ABS anticyclones and WA air mass intrusions are poorly understood. 
The Amundsen Sea atmospheric circulation impacts the distribution of sea ice extent, in a dipole-like manner between the Ross Sea and ABS (Simmonds and Jacka 1995; Harangozo 2004; Turner et al. 2015), that influences precipitation amounts and water stable isotope ratios in the region (Bromwich and Weaver 1983; Küttel et al. 2012). The quasi zonally-symmetric Southern Annular Mode (SAM) is the primary mode of large-scale atmospheric variability in the $\mathrm{SH}$, characterized by phase reversals between height anomalies in high and mid-latitudes and often defined as the first empirical orthogonal function (EOF) of sea-level pressure or geopotential height fields (Thompson and Wallace 2000; Mo 2000; Ding et al. 2012). El NiñoSouthern Oscillation (ENSO) is the leading mode of oceanic and atmospheric variability over the tropical Pacific, which impacts climate and weather globally (on sub-decadal to daily scales), through the excitation of large-scale atmospheric Rossby wave trains (Karoly 1989; Trenberth et al. 1998; Alexander et al. 2002; Turner 2004). The Pacific-South American patterns (PSA1 and PSA2) wave trains connect the central tropical Pacific with SH high-latitudes (Mo and Ghil 1987; Mo and Higgins 1998). PSA1 is known to be associated with ENSO variability (Karoly 1989; Mo and Higgins 1998; Mo and Paegle 2001; Schneider et al. 2012). PSA-like patterns also provide a non-annular component that is part of SAM (Yuan and Li 2008; Fogt et al. 2012; Ding et al. 2012).

This study focuses on the role of synoptic weather impact on WA surface climate. Previous studies explored the role of cyclones in the ABS (Hosking et al. 2013; Turner et al. 2013; Raphael et al. 2015), this study highlights the role of low-frequency anticyclones, demonstrating that marine air mass intrusions into WA are associated with anticyclones. Furthermore, knowledge of the regional atmospheric circulation regime and its effect and interaction with other parts of the climate system is essential for the interpretation of ice core records (Noone et al. 1999; Nicolas and Bromwich 2011; Küttel et al. 2012). We employ 36 years of ERA-Interim reanalysis data to characterize atmospheric variability. Records from the newly obtained Roosevelt Island Climate Evolution (RICE) ice core and previously published data from the International Trans-Antarctic Scientific Expedition (ITASE) ice core sites (Fig.3.1) are used to assess the role of anticyclones and cyclonic events for air mass intrusions into WA and their impact on regional precipitation and the water stable isotope variability. Section 3.2 presents the data and methods. The first part of Section 3.3, the Result and discussion section, demonstrates the role of anticyclones for WA air mass intrusions and subsequent snowfall. The second part of 
Section 3.3 investigate why climate signals in WA snowfall and water stable isotopes ratios from the ENSO, SAM, and the PSA patterns only are well-preserved at certain locations. Lastly, the Conclusion is provided in Section 3.4.

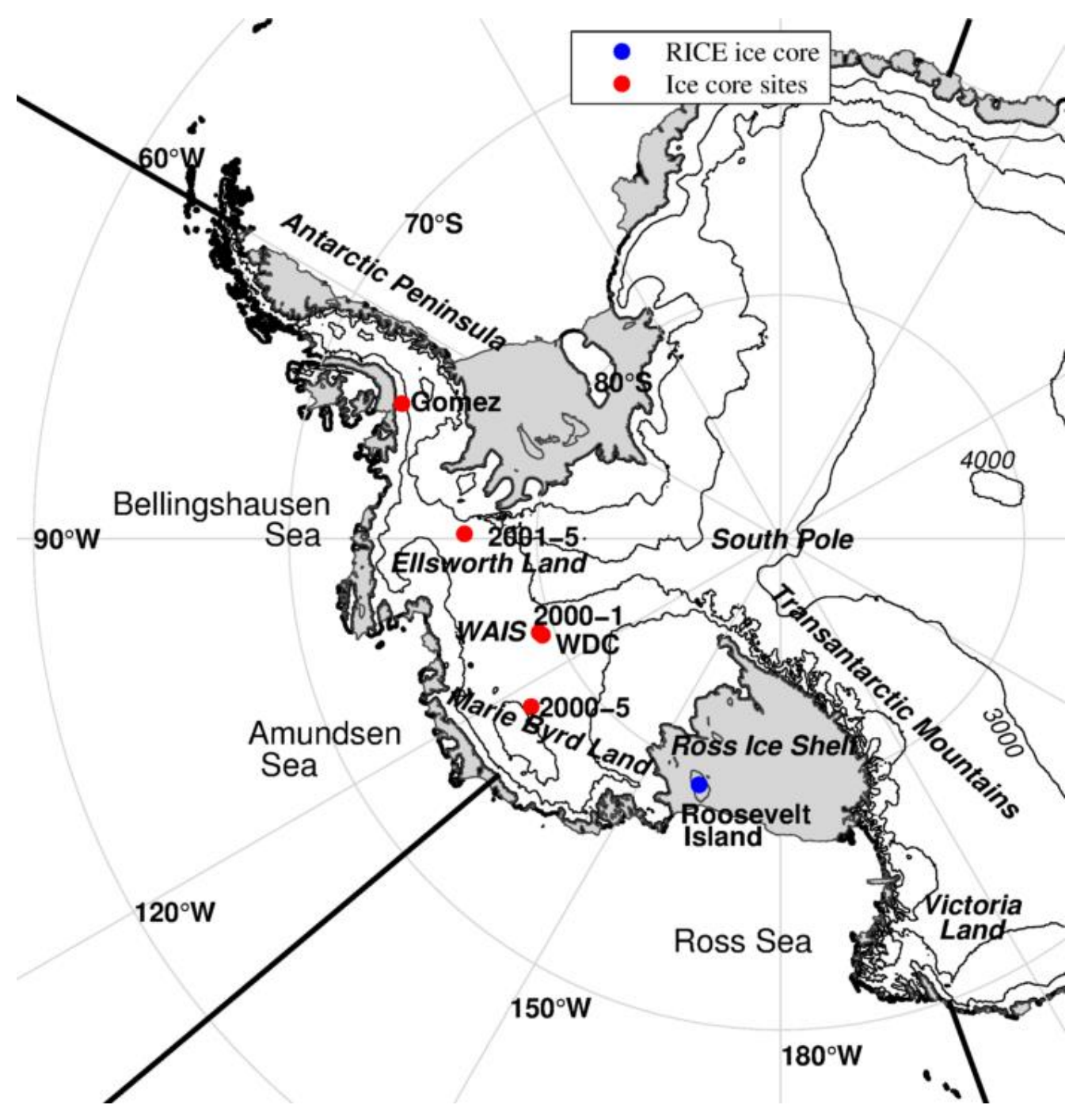

Fig. 3.1 Map indicating the location of the RICE ice core drill site (blue dot). Other ice core sites (ITASE 2000-5, ITASE 2000-1, WDC, ITASE 2001-5, and Gomez) used in this study are indicated by red dots. Contours (thin black lines) with $1000 \mathrm{~m}$ spacing indicates the elevation above sea level (geographic data from Fretwell et al. (2013)). The acronyms: WDC - WAIS Divide Ice Core and ITASE - International Trans-Antarctic Scientific Expedition. 


\subsection{Data and methods}

\subsubsection{Reanalysis data}

We use the Interim Reanalysis datasets (ERA-Interim, Dee et al. (2011)) from the European Center for Medium-Range Weather Forecasts (ECMWF) for the 36-year period, 19792014. The ERA-Interim datasets have been shown to be the most reliable reanalysis product for high southern latitudes (Bracegirdle and Marshall 2012; Bracegirdle 2013; Jones et al. 2016). We employ 6-hourly SH ERA-Interim data, gridded at $0.75^{\circ}$ x $0.75^{\circ}$ (latitude x longitude) for geopotential height at $500 \mathrm{hPa}(\mathrm{z} 500)$, meridional and zonal winds at $850 \mathrm{hPa}(\mathrm{v} 850, \mathrm{u} 850)$, and $2 \mathrm{~m}$ air temperature $(2 \mathrm{mT})$, and vertically integrated northward and eastward water vapor flux (VINWF, VIEWF). Three-hourly ERA-Interim total precipitation values $\left(0.75^{\circ} \mathrm{x} 0.75^{\circ}\right)$ are used to extract time series from grid points closest to several WA ice core sites (RICE, ITASE 2000-5, ITASE 2000-1, ITASE 2001-5 and Gomez; Fig. 3.1).

\subsubsection{Characterization of precipitation events}

The difference between adjacent 3-hourly precipitation values is calculated to identify the timing of precipitation events and to classify different size ranges of events for the different sites. An ERA-Interim precipitation exceedance for each ice core site is identified if the difference between adjacent precipitation data points is larger than a certain precipitation amount (in units of mm per 3-hourly time step) associated with cumulative frequency of precipitation (CFP) limits of $75 \%, 50 \%, 5 \%$ or $1 \%$ (i.e. percentage of all time steps with precipitation amounts below or equal to their respective precipitation amount, Table 3.1). To isolate weather conditions that are truly congruent with precipitation, we chose three-hourly time steps over daily averages. We use the $>5 \%$ and $>50 \%$ precipitation thresholds to identify the timing of individual precipitation events. For example, for RICE this means that $\leq 0.87 \mathrm{~mm}$ per 3-hourly time step make up $50 \%$ of the annual precipitation. Additionally, we investigate the relationship between different sizes of precipitation event and the magnitude of the ERA-Interim parameter fields that are concurrent with the precipitation. We classify major, large, moderate and small precipitation events as precipitation amount differences that are $>75 \%, 75 \%$ to $50 \%, 50 \%$ to $5 \%$, and $<5 \%$, respectively. A percentage-based precipitation-limit approach was chosen to allow us to compare results for sites characterized by large difference in total annual amount of precipitation with one another (e.g. between western and eastern WA sites). The timing of the CFP threshold 
exceedances is used to extract concurrent conditions in the 6-hourly ERA-Interim parameter fields: z500, v850, z850, 2mT, VINWF, and VIEWF for each ERA-Interim grid point in the SH. Anomalies for the ERA-Interim parameter fields are calculated by subtracting the monthly 36-yr climatological mean associated with each SH grid point. Hereafter we use the p-subscript to denote conditions concurrent with precipitation (e.g. z500p).

Table 3.1 Cumulative frequency of precipitation (CFP) threshold amounts (mm per 3-hourly time step) for five Antarctic ice core sites

\begin{tabular}{cccccc}
\hline & & ITASE & \multicolumn{3}{c}{ ITASE } \\
$(\mathrm{CFP}, \%)$ & RICE & $2000-5$ & WDC & $2001-5$ & Gomez \\
\hline 75 & 1.79 & 1.03 & 1.10 & 2.48 & 5.35 \\
50 & 0.87 & 0.50 & 0.55 & 1.17 & 2.53 \\
25 & 0.37 & 0.23 & 0.27 & 0.51 & 1.11 \\
5 & 0.11 & 0.09 & 0.10 & 0.16 & 0.28 \\
1 & 0.06 & 0.06 & 0.06 & 0.08 & 0.09 \\
\hline
\end{tabular}

\subsubsection{Characterization of ABS anticyclonic and cyclone events}

We investigate anticyclone and cyclone frequencies to understand prevailing circulation patterns leading to precipitation. The PPAp methodology establishes the synoptic conditions that are associated with precipitation at different sites. The composite PPAp plots therefore provide insight into predominant air mass advection paths to the considered sites. We define $\mathrm{SH}$ anticyclonic events using persistent positive anomalies (PPA, e.g. Renwick (2005)) and persistent negative anomalies (PNA) for cyclones in the z500 field, when a given magnitude and persistency threshold is exceeded. We use magnitude threshold of $100 \mathrm{~m}$ and focus on a duration of at least 3 days, as the percentage of precipitation events associated with short-lived anticyclonic events (duration of at least 3 days) is higher compared to 5 day events. ERA-Interim precipitation records from the different sites are extracted to investigate if PPA events coincide with precipitation. We first check for exceedances of the $100 \mathrm{~m}$ magnitude threshold for each 6hourly time step/grid point and if the 3-day threshold is also fulfilled, the event is classified as a PPA event. If precipitation occurred within the boundaries of the PPA events, we infer that precipitation is associated with the anticyclonic event, which is referred to as PPAp. Spatial magnitude exceedance patterns are generated for the PPA and PPAp events. A value of 1 is assigned if the magnitude and persistency thresholds are exceeded for the z500 anomalies or a 0 
if it is not. In the case of PPAp events, we also consider the precipitation threshold (e.g. CFP: > $50 \%$, Table 3.1). Annual time series of exceedances are generated (1/0) for each grid point. The exceedance time series is smoothed with a window size set to the persistency duration term (3 or 5 days). A PPA (or PPAp) event is identified when a change from $<1$ to 1 occurred in the smoothed time series. The number of magnitude-duration or precipitation-magnitude-duration threshold exceedances is then calculated for each SH grid point to obtain the mean PPA event frequencies (events year ${ }^{-1}$ ). Exceedances are summed spatially and annually across the entire record (1979-2014). In the case of PPA, regions of high anticyclonic event frequencies are identified. In the case of PPAp, we distinguish regions of anticyclonic activity associated with precipitation for the ice core sites. Furthermore, annual time series of PPA and PPAp counts for the ice core sites are created (1979-2014). We locate the maximum mean frequency center for the sites and calculate the average of annual mean frequency of PPAp events that fall inside the site-specific area. The PPAp maximum region is defined by the $95^{\text {th }}$ percentile of the mean PPAp frequency of all grid points south of $45^{\circ} \mathrm{S}$ for the considered site. Additionally, we use thresholds of $-100 \mathrm{~m}$ and 3 days to quantify SH low-frequency cyclone frequencies. Cyclones in general, have a shorter life span and are more mobile compared to blocking event. PNA cyclones that are captured by the method, only represents quasi-stationary low-frequency cyclones. However, we note that these events appear to be as frequent as the more known blocking counterpart.

\subsubsection{Large-scale atmospheric variability}

Patterns of atmospheric variability examined here were calculated from the EOF analysis of monthly ERA-Interim 500-hPa geopotential height field $\left(20^{\circ}-90^{\circ} \mathrm{S}\right)$ for 37 complete years, 1979 through 2015. The EOFs were determined using singular value decomposition (SVD). ERA-Interim data gridded at a regular $1.5^{\circ}$ grid were used to derive the EOF patterns of SH atmospheric circulation variability. The data is weighted using square root of the cosine of latitude, to provide equal weighting of equal areas. The seasonal cycle is removed at each grid point by subtracting the corresponding monthly climatology for each grid. The SAM, PSA1, and PSA2 are defined as the leading, second, and third EOFs of monthly mean 500-hPa geopotential height anomalies, respectively. The SAM, PSA1, and PSA2 EOFs are linearly orthogonal (not correlated with one another) on monthly time-scales (e.g., Mo 2000; Deser et al. 2010). Each EOF pattern is associated with a principal component (PC) time series, which describes the temporal evolution of the EOF pattern. The PC indices are obtained by projecting the EOF 
pattern onto the original z500 anomaly field at each time step to find the sign and amplitude of the pattern at any given time. The SAM and PSA patterns PCs indices are standardized so that they have a mean of zero and a standard deviation of one and are used as climate indices for large-scale atmospheric circulation variability. The leading monthly PC index (SAM) is highly correlated to the NOAA SAM (Antarctic Oscillation, AAO) index $(r=0.95, p<0.001)$ (Mo 2000). Figure 3.2 provides a visual representation of the pattern in the form of regression maps, generated by linearly regressing the original geopotential height field onto the PC time series. ENSO events are defined using averages of sea surface temperatures in the Niño-3.4 region (NOAA/Climate Prediction Center). The monthly geopotential height fields is regressed upon the monthly Niño-3.4 index to obtain the atmospheric circulation pattern associated with ENSO (Fig. 3.2a). We define ENSO, SAM and PSA pattern polarity years, as years where their respective indices are outside the threshold of \pm 0.75 standard deviations (1979-2014, Table 3.2). Anticyclone and cyclone frequency composite plots were generated for the climate modes positive, negative and neutral phases. A percentile-based approach was also used and our results are not sensitive to the method that is employed.

Table 3.2 ENSO, SAM and PSA pattern polarity years*

\begin{tabular}{cccccccc}
\hline El Niño & La Niña & SAM- & SAM+ & PSA1+ & PSA1- & PSA2+ & PSA2- \\
\hline 1982 & 1984 & 1980 & 1979 & 1982 & 1985 & 1986 & 1985 \\
1983 & 1985 & 1988 & 1985 & 1986 & 1988 & 1991 & 1988 \\
1987 & 1988 & 1991 & 1989 & 1991 & 1989 & 1996 & 1997 \\
1991 & 1989 & 1992 & 1998 & 1993 & 1996 & 2009 & 1998 \\
1992 & 1999 & 2002 & 1999 & 1994 & 1998 & & 1999 \\
1993 & 2000 & 2007 & 2001 & 1997 & 1999 & & 2000 \\
1997 & 2007 & 2009 & 2008 & 2002 & 2010 & & 2007 \\
2002 & 2008 & & 2010 & 2004 & 2011 & & \\
& 2011 & & & 2012 & & & \\
\hline
\end{tabular}

${ }^{*}$ Polarity phases for the PSA patterns are defined as in Kidson et al. (1988), their figure 4. 

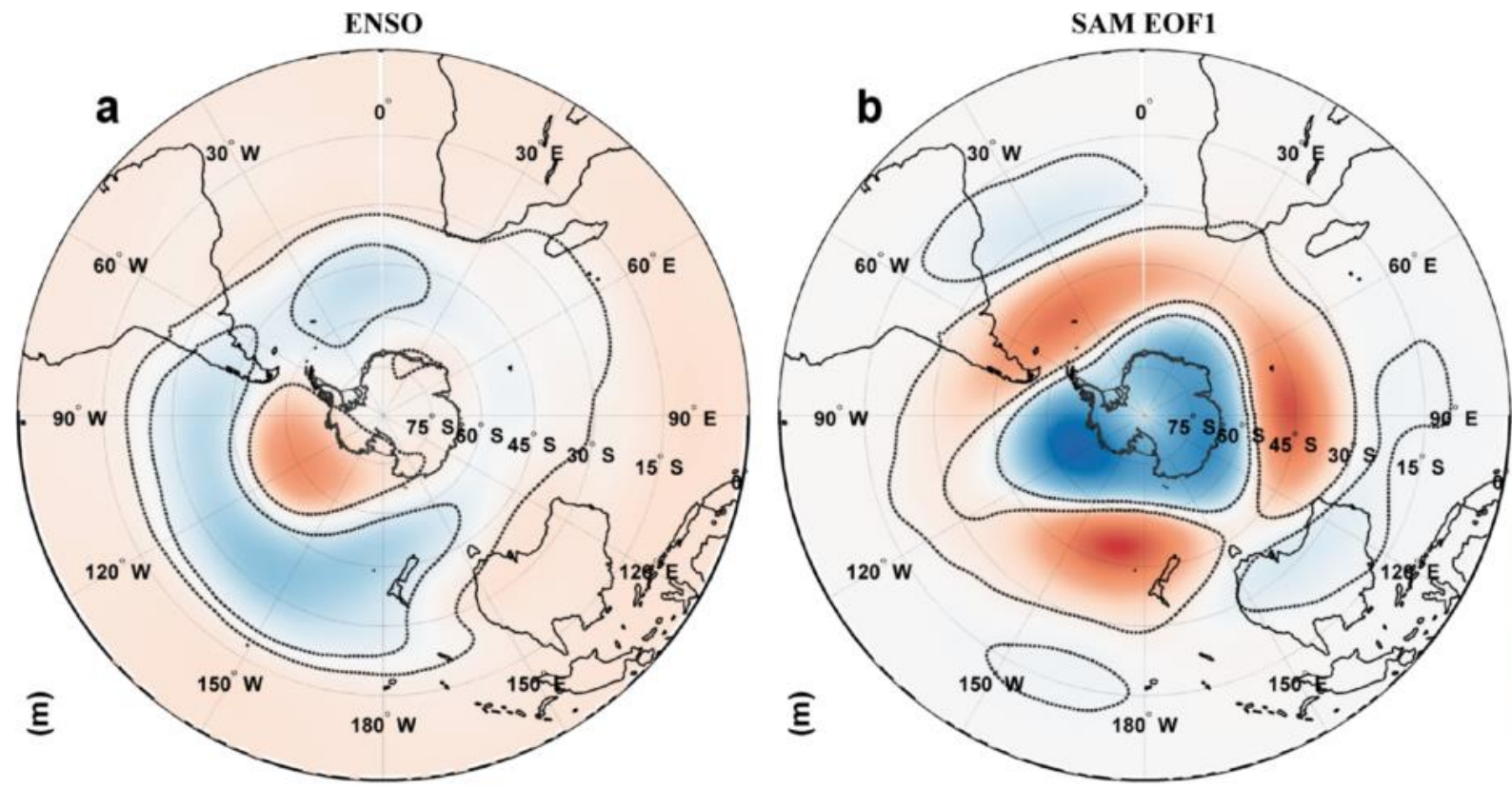

40
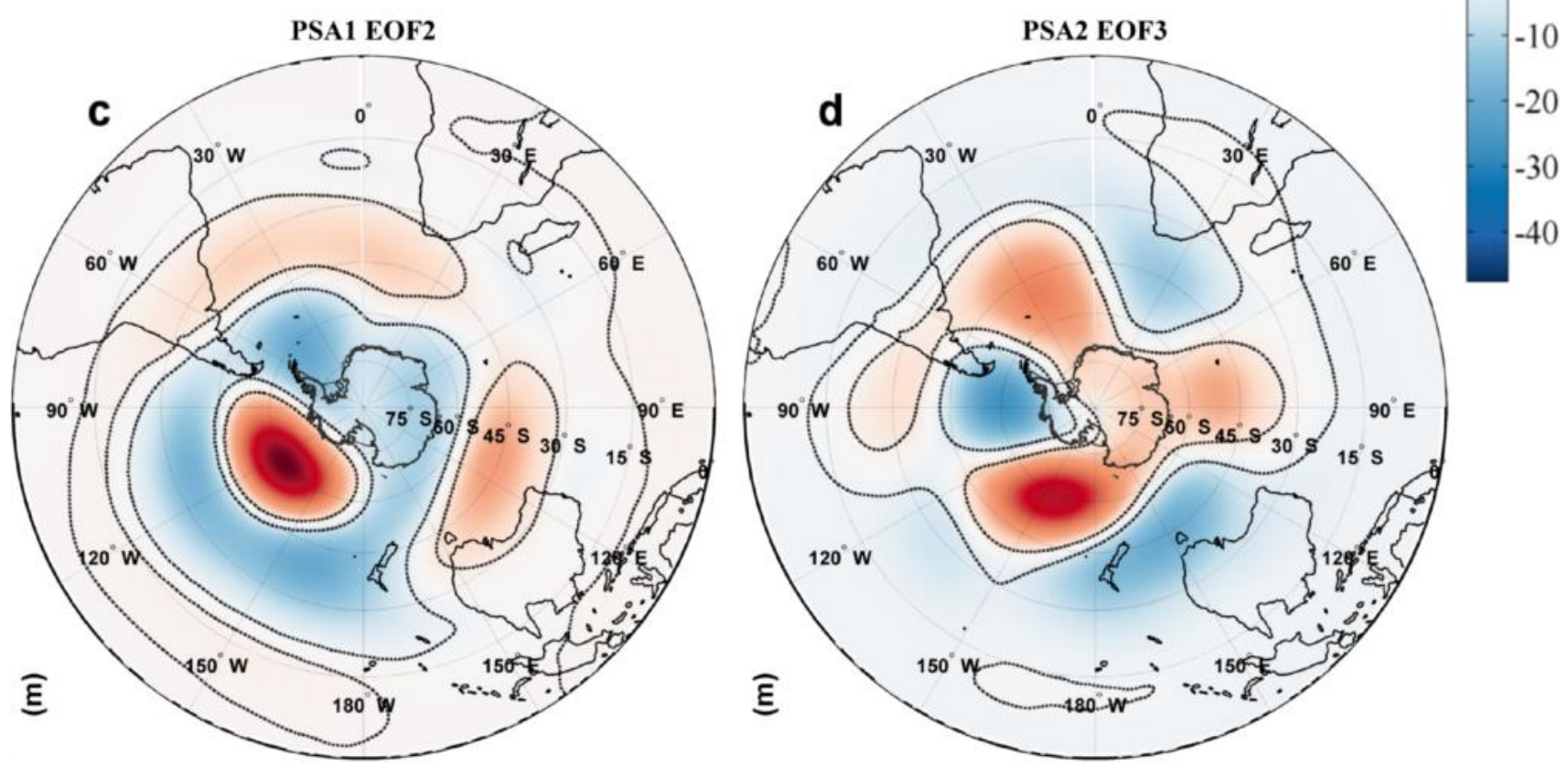

Fig. 3.2 Regression maps showing the spatial patterns of SH large-scale atmospheric circulation variability associated with: (a) ENSO; (b) the leading EOF, the SAM; (c) the second EOF, PSA1; and the (d) third EOF, PSA2. The EOFs were obtained using the 500-hPa ERA-Interim geopotential heights field between $20^{\circ} \mathrm{S}$ and $90^{\circ} \mathrm{S}$ from all calendar months (January $1979-$ December 2015). The 500-hPa geopotential heights field are regressed upon the standardized ENSO and PC time series. The ENSO regression map was generated using monthly Niño-3.4 SST. All modes are show during their positive phase. The positive polarity phases for the PSA patterns are defined according to Kidson et al. (1988), their figure 4. Black contours enclose areas where regression coefficients are significant at the $p<0.05$ confidence level. 


\subsubsection{Ice core records}

We use records from the newly drilled to bedrock $763 \mathrm{~m}$ deep RICE core, which was recovered over two field seasons (2011-2012, 2012-2013) at Roosevelt Island, an independent grounded ice rise $\left(79.36^{\circ} \mathrm{S}, 161.70^{\circ} \mathrm{W}, 560 \mathrm{~m}\right.$ a.s.l.) situated at the north-eastern margin of the Ross Ice Shelf (Fig. 3.1). Here we present the water stable isotope data and calculated snow accumulation data for 1979-2009 to match the available reanalysis data. The isotope record of a 19.4 m RICE 12/13 B firn core (the age at the bottom of the core is 1964) is used in this study. We neglect the top part $(1.86 \mathrm{~m})$ of the isotope record due to the uncompact snow at the top part of the core, which is difficult to measure with continuous-flow analysis (CFA) setups. Annuallayer counting was primarily performed by identifying non-sea salt sulfate $\left(\mathrm{nssSO}_{4}\right)$ peaks in the main RICE core and the 12/13 B firn core (see supplementary material). In addition to the RICE water stable isotope record, we use published water isotope records from cores retrieved during the ITASE expedition 2000-5, 2000-1, and 2001-5 (Fig.3.1) (Mayewski 2005; Steig et al. 2005). The ITASE 2000-1 core (that we use) predates and is located adjacent to the deep WAIS Divide ice core (WDC) (Küttel et al. 2012). The water isotope records from these ITASE 2000-1 and WDC cores share common climate characteristics (Küttel et al. 2012).

The $\delta$-notation is the common way to represent the abundance of rare isotopes as a deviation from a reference ratio: $\delta=1000 \mathrm{x}\left[\mathrm{R} / \mathrm{R}_{\mathrm{V}-\mathrm{SMOW}}-1\right]$ (given in per mil, \%), where $\mathrm{R}$ and $\mathrm{R}_{\mathrm{V} \text {-SMOw }}$ are the ratio between rare and abundant isotopes $\mathrm{R}=\mathrm{n}\left({ }^{18} \mathrm{O}\right) / \mathrm{n}\left({ }^{16} \mathrm{O}\right)$, or $\mathrm{R}=\mathrm{n}(\mathrm{D}) / \mathrm{n}(\mathrm{H})$ in the sample and in V-SMOW, respectively. The RICE $\delta$-records were measured on a CFA system using a Los Gatos Research (LGR) Isotope Water Analyzer (IWA-35EP) (Chapter 2, Emanuelsson et al. 2015). Internal standards calibrated to the Vienna-Standard Mean Ocean Water/Standard Light Antarctic Precipitation (V-SMOW/SLAP) scale (Gonfiantini 1978), were used to calibrate the $\delta$-records.

All data used in correlation tests have been detrended (removing linear trends) before Pearson's correlations coefficients $(r)$ were calculated. The significance level $(p)$ of the correlations accounts for autocorrelation by reducing the degrees of freedom, using the quotient $N=n\left(1-r_{1} r_{2}\right) /\left(1+r_{1} r_{2}\right)$, where $n$ is the number of timesteps correlated, $r_{i}$ is the lag-1 autocorrelation of the time series $i$, and $N$ the adjusted degrees of freedom (Santer et al. 2000). 
All time series that are shown as anomalies were standardized to have a zero mean and unit variance, by subtracting the mean and dividing by the standard deviation.

\subsection{Results and discussion}

The correlation between the RICE snow accumulation and $\delta \mathrm{D}$ (not shown) records with the z500 field generate a significant positive correlation in the ABS region (Fig. 3.3a). This suggests that the snow accumulation rate is higher at RICE when anticyclones are present in the ABS and the ASL is anomalously weak (boundaries of the ASL region depicted by the green box in Fig. 3.3a). Figure 3.3b displays the mean low-frequency anticyclone composite field concurrent with RICE precipitation events (PPAp, > 50\%, 100 m, 3 days; 1979-2014). RICE site-specific anticyclone activity cell in the PPAp composite field is centered at $120^{\circ} \mathrm{W}$, which coincides with the ABS center of the RICE snow accumulation-z500 correlation pattern in Fig. 3.3a. Previous work has described the presence of blocking events in the ABS region (van Loon and Shea 1987; Sinclair 1996; Renwick 1998; Oliveira et al. 2014). The maximum frequency of RICE PPAp events is 7.2 (5.0) events year ${ }^{-1}$, (> 50\%, $100 \mathrm{~m}, 3$ days (5 days)). The maximum RICE PPAp is centered at $66^{\circ} \mathrm{S}, 120^{\circ} \mathrm{W}$ (Fig. 3.2b). This region lies adjacent to the location $\left(67.5^{\circ} \mathrm{S}, 120^{\circ} \mathrm{W}\right.$ ) in the Amundsen Sea region which is characterized by the highest geospatial height variability in the SH polar region (Renwick 2002; Ding et al. 2012). 

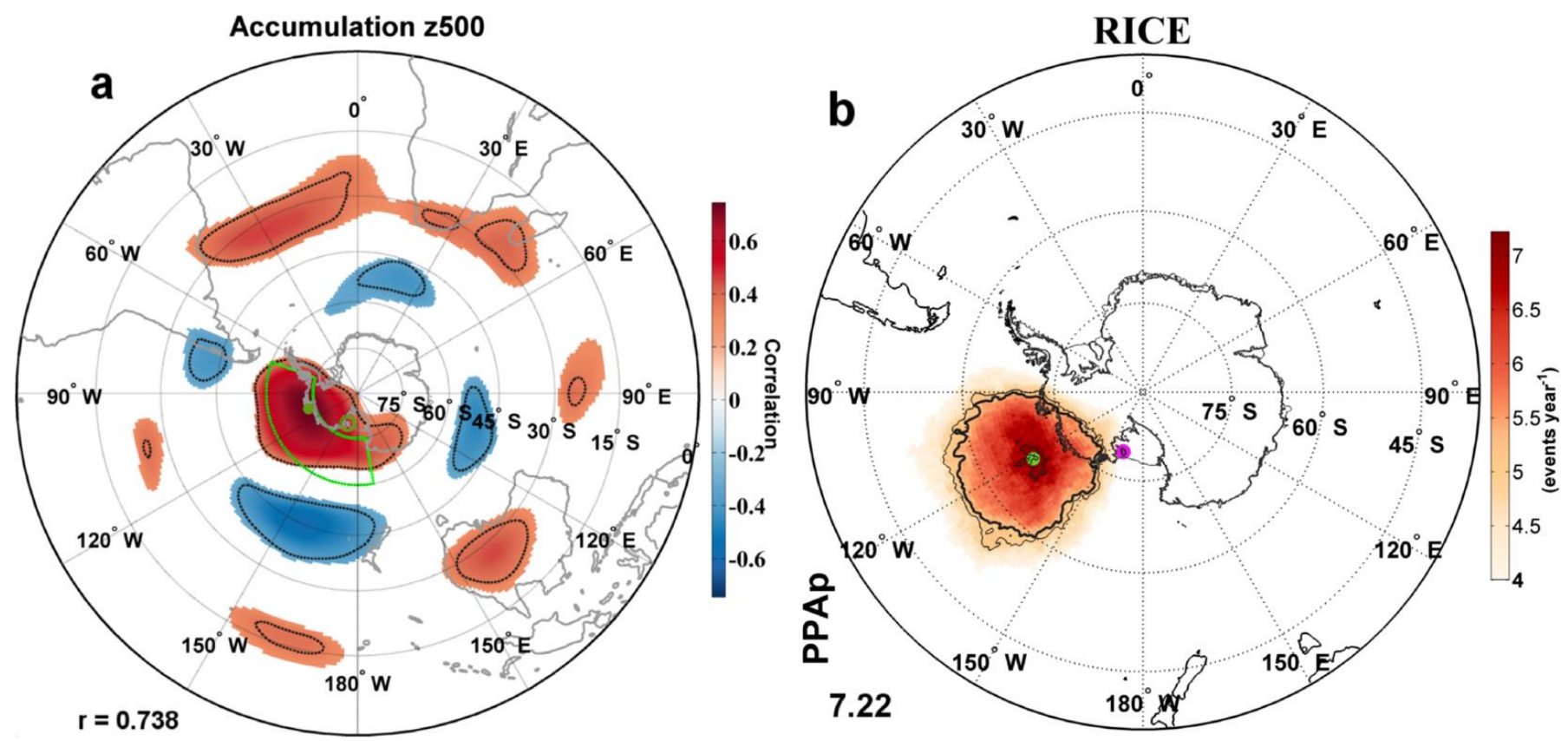

Fig. 3.3 (a) Correlation map of RICE snow accumulation record with 500-hPa geopotential height (z500; 1979-2009). Correlation coefficients ( $r, p<0.1$, shading) and the black contours enclose $p<0.05$ confidence level regions. The ASL region $\left(60^{\circ}-75^{\circ} \mathrm{S}, 170^{\circ}-290^{\circ} \mathrm{E}\right)$ is outlined by the green box using boundaries as defined by Hosking et al. (2013). The green circle indicates the location of RICE site and the green dot displays the location of the correlation maxima. (b) Climatological mean PPAp frequency field (events year ${ }^{-1}$, shading, starting at 4 events year ${ }^{-1}$ ) for RICE for the precipitation-magnitude-duration threshold (> 50\%, $100 \mathrm{~m}, 3$ days). The thick black line outlines the $95^{\text {th }}$ percentile polygon. The RICE core site locations is indicated by a magenta circle. Contour increments (thin black lines) are 2 events per year, starting at 4.

\subsubsection{The ASL and anticyclonic events influence on RICE}

Here, we explore the dynamical role that anticyclones play for advecting marine air masses into WA and assess if the frequency and location of anticyclones are linked to the climate signal preserved in snowfall and water isotope records from WA ice cores. We find that anticyclonic events lasting for at least 3 days (5 days) occur 12\% (10\%) of the time in the ABS region (Fig. 3.3). Earlier studies have reported similar frequencies of persistent anticyclones for this region (Renwick 2005; Cohen et al. 2013). The average anticyclone (100 m, 3 days (5 days)) occurrence frequency within the Amundsen Sea region - the main anticyclonic region that affects RICE - is slightly lower with $8.0 \%$ (7.5\%). This explains the lower PPAp frequencies for RICE compared to the other WA sites. However, over $73 \%(84 \%)$ of the total number of anticyclone events (CFP $>50 \%, 100$ m, 3 days (5 days)) in Amundsen Sea region are associated with precipitation at RICE (Table 3.3). Moreover, over $88 \%$ (82\%) of all large RICE precipitation threshold 
exceedances (CFP > 50\%) coincide with anticyclones (100 m, 3 days (5 days)) in the Amundsen Sea (Table 3.3).

Table 3.3 Ratios between PPAp and total PPA event and PrPPA/total Pr (precipitation-magnitudeduration (PMD) threshold: > 50\%, $100 \mathrm{~m}, 3$ and 5 days) for four WA ice core sites: RICE, ITASE 2000-5, WDC, and ITASE 2001-5*

\begin{tabular}{|c|c|c|c|c|c|c|c|c|c|}
\hline $\begin{array}{l}\text { PMD: }>50 \%, \\
100 \text { m, } 3 \text { days }\end{array}$ & RICE & $\begin{array}{l}\text { ITASE } \\
2000-5\end{array}$ & WDC & $\begin{array}{l}\text { ITASE } \\
2001-5\end{array}$ & $\begin{array}{l}\text { PMD: }>5 \% \text {, } \\
100 \text { m, } 3 \text { days }\end{array}$ & RICE & $\begin{array}{l}\text { ITASE } \\
2000-5 \\
\end{array}$ & WDC & $\begin{array}{l}\text { ITASE } \\
2001-5 \\
\end{array}$ \\
\hline PPAp/PPA ${ }^{1}$ & 0.73 & 0.82 & 0.88 & 0.81 & PPAp/PPA ${ }^{1}$ & 0.91 & 0.98 & 0.98 & 0.91 \\
\hline $\mathrm{PR}_{\mathrm{PPA}} /$ totalPR $^{2}$ & 0.88 & 0.92 & 0.90 & 0.90 & $\mathrm{PR}_{\mathrm{PPA}} /$ totalPR $^{2}$ & 0.83 & 0.91 & 0.91 & 0.92 \\
\hline $\begin{array}{l}\text { PMD: }>50 \%, \\
100 \text { m, } 5 \text { days }\end{array}$ & RICE & $\begin{array}{l}\text { ITASE } \\
2000-5 \\
\end{array}$ & WDC & $\begin{array}{l}\text { ITASE } \\
2001-5 \\
\end{array}$ & $\begin{array}{l}\text { PMD: }>5 \%, \\
100 \mathrm{~m}, 5 \text { days }\end{array}$ & RICE & $\begin{array}{l}\text { ITASE } \\
2000-5 \\
\end{array}$ & WDC & $\begin{array}{l}\text { ITASE } \\
2001-5 \\
\end{array}$ \\
\hline PPAp/PPA ${ }^{1}$ & 0.84 & 0.90 & 0.83 & 0.69 & PPAp/PPA ${ }^{1}$ & 0.86 & 0.95 & 0.95 & 0.86 \\
\hline $\mathrm{PR}_{\mathrm{PPA}} /$ totalPR $^{2}$ & 0.82 & 0.84 & 0.83 & 0.78 & $\mathrm{PR}_{\mathrm{PPA}} /$ totalPR $^{2}$ & 0.74 & 0.79 & 0.78 & 0.75 \\
\hline
\end{tabular}

${ }^{*} 1$. The ratio of anticyclonic events congruent with precipitation (PPAp) to the total number of anticyclones calculated at the maximum site-specific PPAp location. 2. The ratio of precipitation events associated with anticyclones $\left(\mathrm{PR}_{\mathrm{PPA}}\right)$ to the total number of precipitation events. $\mathrm{PR}_{\mathrm{PPA}}$ are calculated using a composite record from all the grid points within their site-specific polygon. Boundaries of the polygon were defined by the $95 \%$ percentile of the mean PPAp frequency of grid points south of $45^{\circ} \mathrm{S}$ (Fig. 3.10).
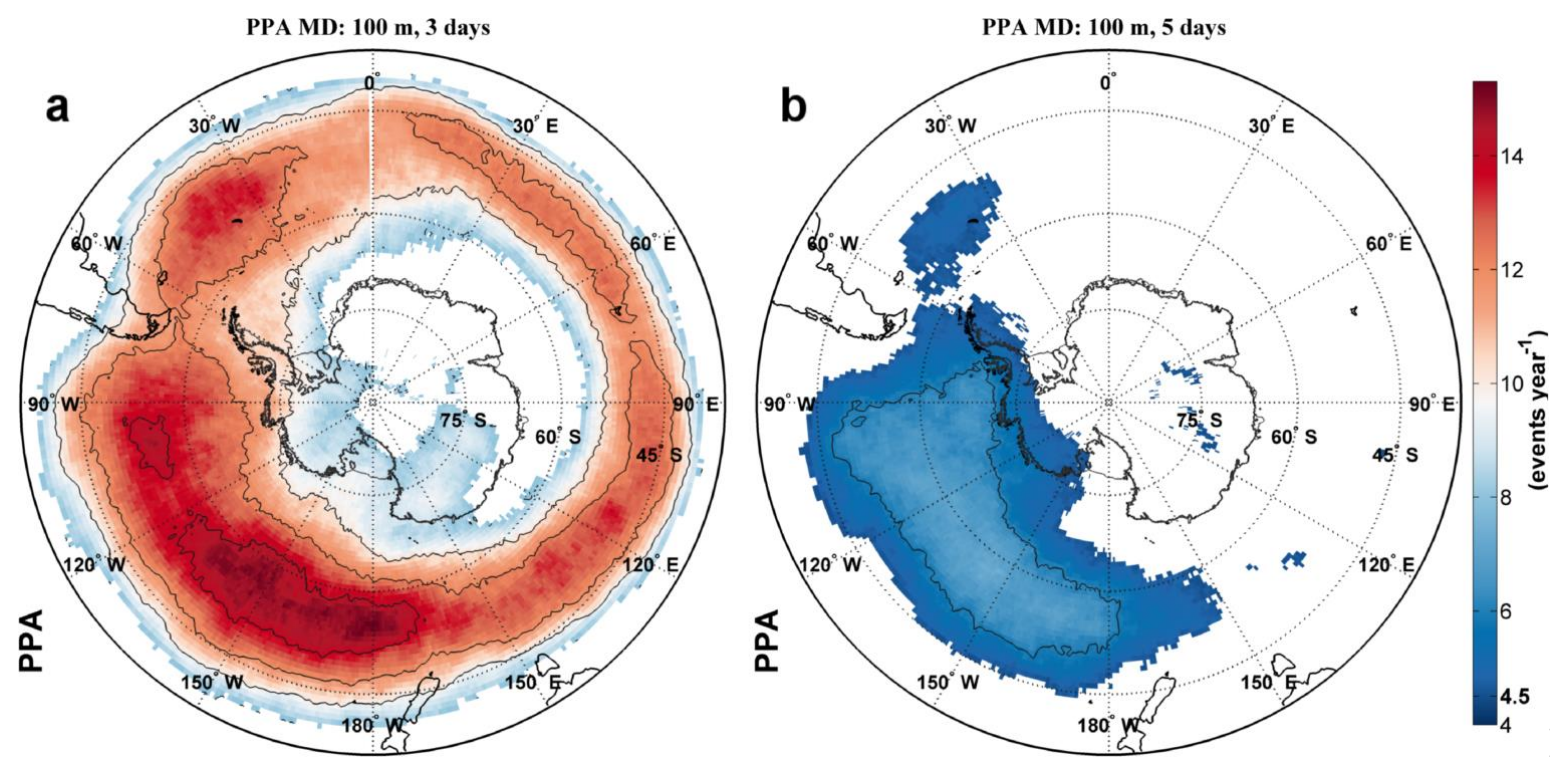

Fig.

3.4 Annual mean frequency PPA events (events $y^{-a r^{-1}}$ ) of at least $100 \mathrm{~m}$ and lasting at least (a) 3 days (shading, starts at 8 events year ${ }^{-1}$ ) and (b) 5 days (shading, starts at 4.5 events year $^{-1}$ ). 
We observe that anticyclonic events associated with precipitation at RICE impede zonal westerly winds in the $45^{\circ}-70^{\circ} \mathrm{S}, 90^{\circ}-150^{\circ} \mathrm{W}$, region (Fig. 3.5a), diverting the blocked westerly flow towards WA (enhancing the meridional flow). Amundsen Sea anticyclonic events are associated with northerly winds and moisture flux over the eastern Ross Sea/Western Marie Byrd Land region and offshore winds over Ellsworth Land and the Antarctic Peninsula (AP) and western Ross Sea (Fig. 3.5a, b). These results are consistent with previous studies that have reported a dipole-like pattern between the Ross Sea and AP regions (called the Antarctic dipole) (Yuan and Martinson 2000; Harangozo 2006). Anticyclonic cells advect air masses along their western flank and interact with the eastern sector of low pressure cells centered over the Ross Sea. Cyclones predominantly provides the water vapor for precipitation (Bromwich 1988). The meridional wind component associated with marine air mass intrusions tends to separate into two flows in the Roosevelt Island region (Fig. 3.5a). The northeasterly flow component is related to Ross Sea cyclonic circulation, which causes northeasterly winds over the Roosevelt Island region (Fig. 3.5a) and contributes to the anti-phase relationship between eastern and western Ross Sea (Clausen et al. 1979; Schneider and Steig 2002; Markle et al. 2012; Sinclair et al. 2012). This is confirmed by the RICE Automatic Weather Station (AWS) wind data (Fig. 3.5c, d). Wind speeds in the Roosevelt Island region are on average low, as the site is away from the Ross Ice shelf Airstream, and variable, with a resultant southeasterly component (Costanza et al. (2016); Fig. 3.5c). The Ross Ice Shelf airstream is a semipermanent passage of high-velocity low-level, northward flowing cold-dry air that often span from the interior of Antarctica to the northern margins of the Ross Ice Shelf and predominantly impact the western Ross Sea (e.g., Parish et al. 2006; Nigro and Cassano 2014). In contrast, during large precipitation events the winds tend to be northeasterly at RICE (Fig. 3.5d). The RICE AWS data only span three years (2011-2014), but similar results are obtained using the Margaret AWS (2009-2014), although with more pronounced easterly and reduced northerly components concurrent with precipitation (not shown). 


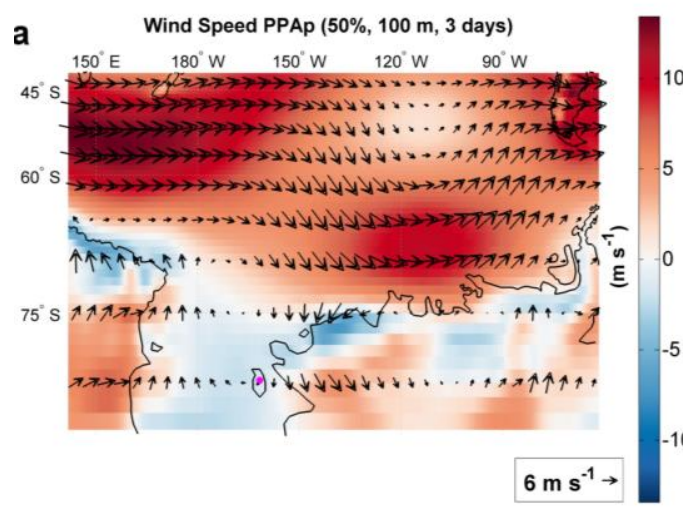

Wind Speed [m/s] RICE AWS

C

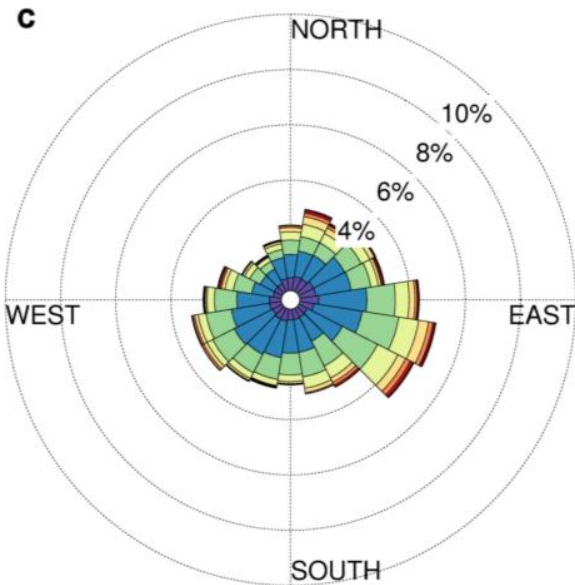

b Vapor Flux PPAp $(50 \%, 100 \mathrm{~m}, 3$ days $)$

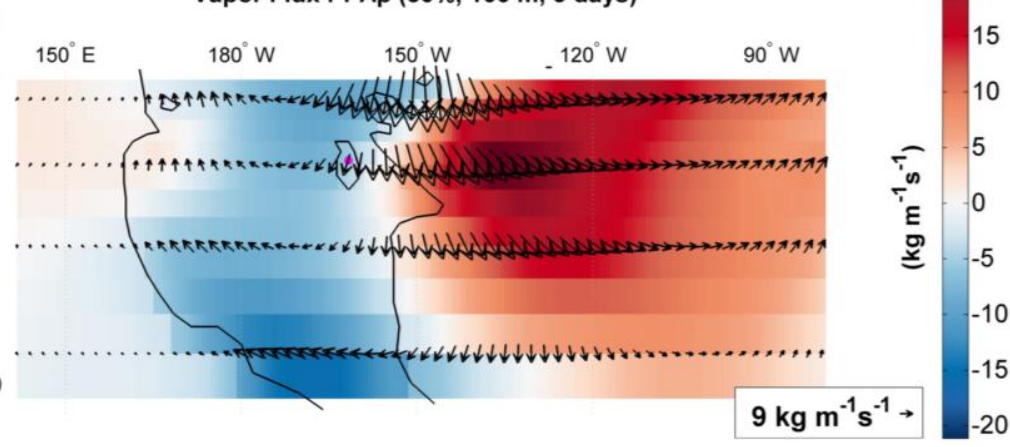

Wind $_{p}$ RICE AWS Wind $[\mathrm{m} / \mathrm{s}] 75 \%$

d

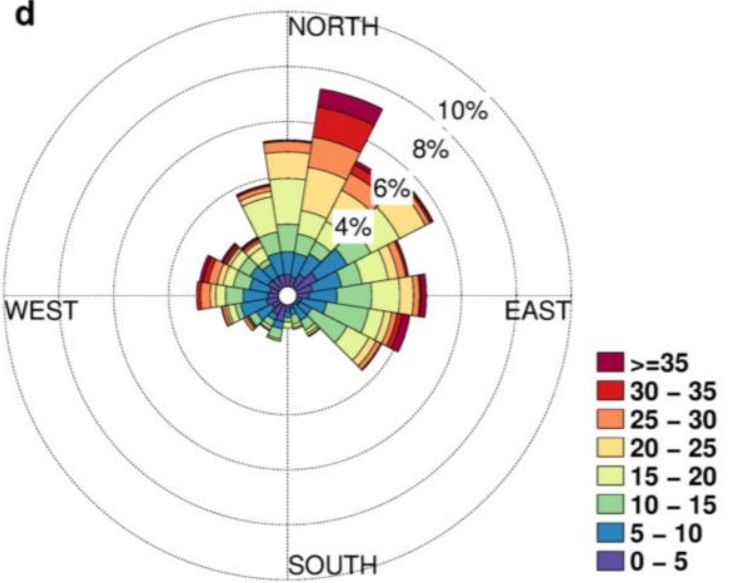

Fig. 3.5 (a) Wind speed (ERA-Interim) associated with RICE precipitation and anticyclones (u850 PPAp). Vectors provide the combined meridional and zonal wind, (b) Water vapor flux associated with anticyclones and precipitation at RICE. Vectors are generated using the zonal and meridional vapor flux. The color shading in (a) and (b) indicates the zonal wind vapor flux fields, westerly winds and flux are displayed with positive values (red shading). (c) predominant wind speed $\left(\mathrm{m} \mathrm{s}^{-1}\right)$ and direction determined using RICE AWS data 2011-2013. (d) Wind speed $\left(\mathrm{m} \mathrm{s}^{-1}\right)$ and direction associated with precipitation for the RICE AWS (2011-2013). The timing of precipitation events displayed in (c) was identified using Margaret acoustic depth gauge (ADG) data. 


\subsubsection{Binned precipitation sizes}

The depth and seasonal migration of the ASL has been shown to impact the meridional winds and WA surface climate (Hosking et al. 2013; Turner et al. 2013). Here we investigate if a similar relationship exists between the magnitude of anticyclones, meridional winds, air temperature ( $2 \mathrm{mT})$, and sea ice concentration (SIC). We classify major, large, moderate and small precipitation events as precipitation amount differences that are > 75\%, 75\% to 50\%, 50\% to $5 \%$, and $<5 \%$, respectively (Table 3.1 ). We employ the classified bin sizes for different RICE precipitation intervals (Section 2.2) to investigate the relationship between precipitation size and the magnitude of anticyclonic circulation events and associated changes to meridional winds, SIC, and air temperature. The timing of the ERA-Interim fields is concurrent with RICE precipitation events. We generate z500p, v850p, SICp and 2mTp ERA-Interim 36-yr climatology fields for the different binned precipitation categories (Fig. 3.6). Our analysis shows that events with higher precipitation rates are associated with:

1. Higher positive z500p anomalies in the Amundsen Sea region. The $160 \mathrm{~m}$ and $116 \mathrm{~m}$ z500 36-yr climatological anomaly maxima are linked to major and large precipitation events, respectively (Fig. 3.6a). The major and large z500p anomalies can be compared to the weaker moderate z500p anomaly of $49 \mathrm{~m}$ (Fig. 3.6a, right panel). A similar magnitude relationship exists between the low pressure system in the Ross Sea and the precipitation amount, but with a slightly lower amplitude difference between the major $(-137 \mathrm{~m})$ and moderate events $(-98 \mathrm{~m})$.

2. Stronger northerly v850p meridional winds. The analysis shows that $>18 \mathrm{~m} \mathrm{~s}^{-1}$ and $>14 \mathrm{~m} \mathrm{~s}^{-1}$ northerly-meridional wind anomaly maxima for the major and large precipitation event bins, respectively (Fig. 3.6b), compared to $7.2 \mathrm{~m} \mathrm{~s}^{-1}$ for moderate events.

3. On average stronger onshore winds over the eastern Ross Sea/Amundsen Sea and therefore a reduction in SIC over the Amundsen Sea and an increase in SIC in the Bellingshausen Sea and western Ross Sea region (Fig. 3.6c). The SIC anomaly associated with moderate precipitation events and weaker northerly winds resembles the pattern for the other precipitation magnitudes but with a weaker dipole anomaly pattern (Fig. 3.6c, right hand panel). This is in agreement with previous work, which found that areas dominated by southerly (offshore) flow show an increase in SIC, while regions 
influenced by northerly winds (onshore), SIC is decreasing (Holland and Kwok 2012; Fan et al. 2014; Turner et al. 2015).

4. Precipitation at RICE is associated with anomalously warm air temperatures. We find $12 \mathrm{~K}$ and $10 \mathrm{~K} \mathrm{~m} 2 \mathrm{mTp} 36-\mathrm{yr}$ climatological anomaly maxima for major and large precipitation events, respectively (Fig. 3.6d), in contrast to a $6.5 \mathrm{~K}$ increase associated with moderate precipitation events.

Thus, our analysis shows that precipitation events associated with larger amounts of precipitation are related to enhanced anticyclonic circulation and meridional winds, and cause dipole pattern for SICp and air temperature anomalies. The Ross Sea anti-phase and Antarcticdipole pattern are marked in the wind, air temperature and SIC fields with stronger offshore winds, colder surface air temperatures and increased SICp over the western Ross Sea and Ellsworth Land/AP. In contrast, we find onshore winds, warm air temperatures and decreased SICp over western Marine Byrd Land and eastern Ross Sea, during major and large precipitation events (Fig. 3.6). 

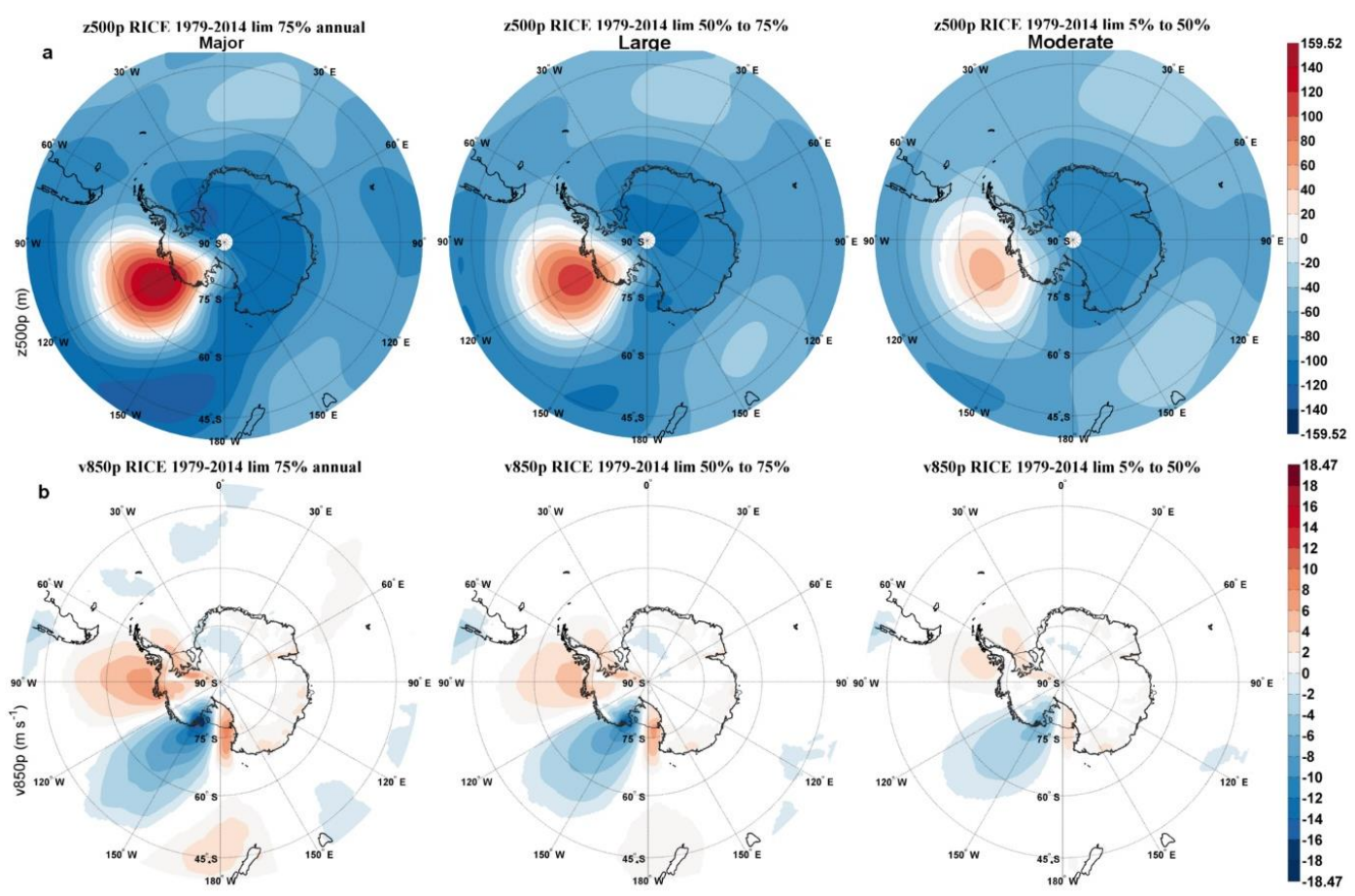

v850p RICE $1979-2014 \lim 50 \%$ to $75 \%$
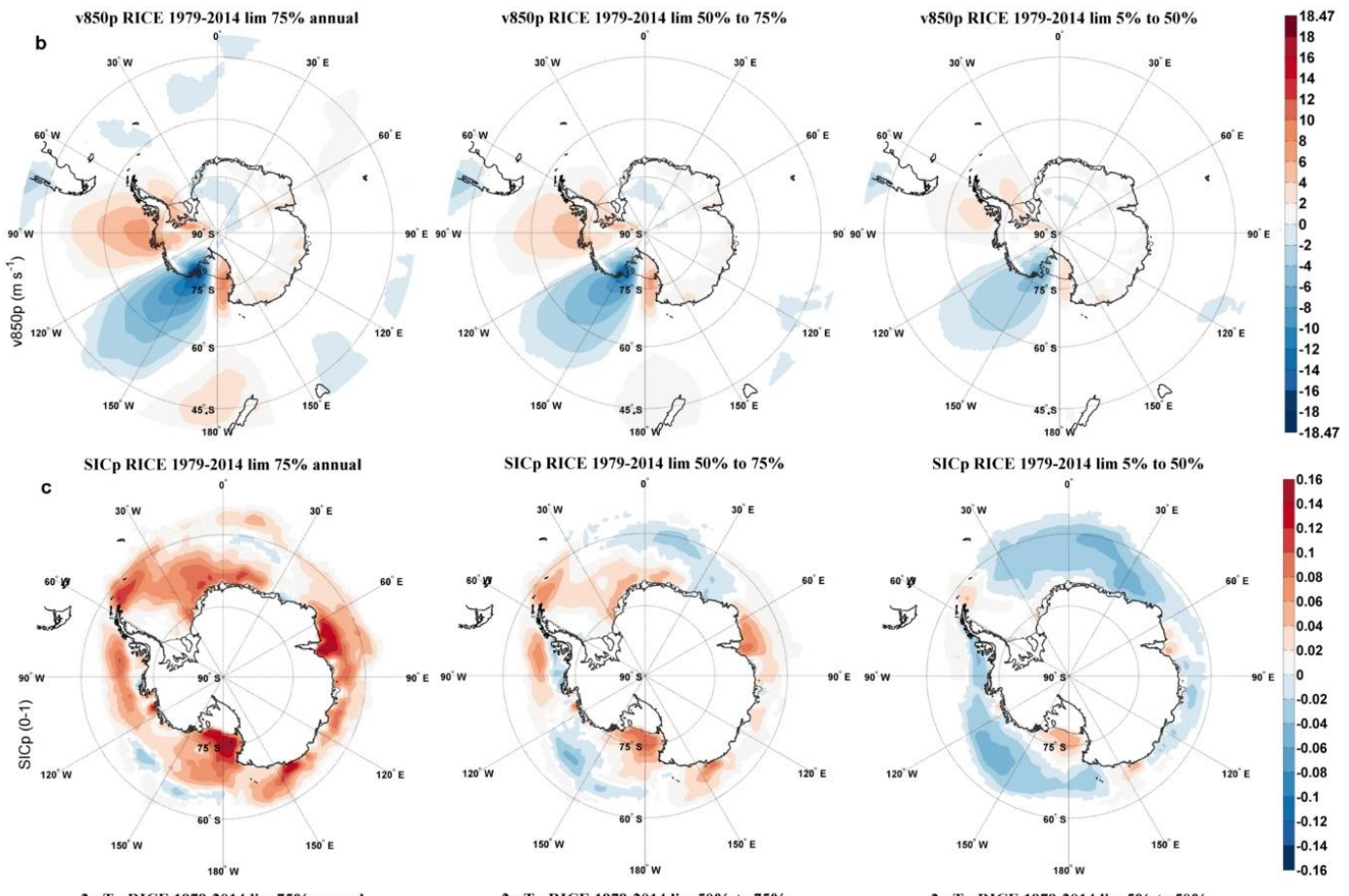

ICp RICE 1979-2014 $\lim 50 \%$ to $75 \%$

SICP RICE 1979-2014 lim 5\% to 50\%

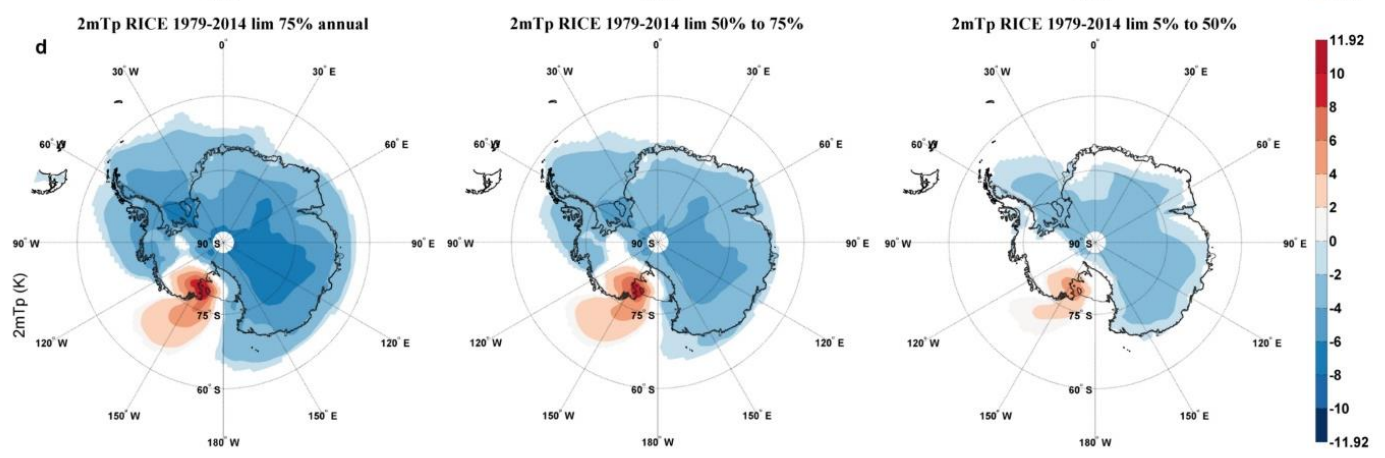

Fig. 3.6 ERA-Interim parameters fields, concurrent with RICE precipitation of different size ranges: major events (> 75\%, left-side column of plots), large events $(75 \%-50 \%$, middle column), and moderate events (50\%-5\%, right-side column) for, (a) geopotential height (z500p), (b) meridional winds (v850p), (c), sea ice concentration (SICp) and (d), air temperature (2mT). 


\subsubsection{RICE $\delta \mathrm{D}$ and snow accumulation variability}

The annual averaged Amundsen Sea anticyclonic time series, 100 m, 3 days; events year ${ }^{-1}$, annually averaged anticyclone frequency (PPA) from within the site-specific $95^{\text {th }}$ percentile polygon in Figure 3.2b, is positively correlated with the RICE snow accumulation (Fig. 3.6a, $r=$ $0.72, p<0.001,1979-2009$ ) and the $\delta \mathrm{D}$ records (Fig. 3.6b, $r=0.63, p<0.001,1979-2009$ ). We characterize the general geopotential height state in the ASL region using the z500, averaged across all seasons, with boundaries as defined by Hosking et al. (2013) (Fig. 3.2a). The influence of seasonality on RICE $\delta \mathrm{D}$ is investigated in a separate companion study. The annual average z500 in the ASL sector is significantly correlated with the RICE snow accumulation ( $r=0.72, p$ $<0.001)$ and $\delta \mathrm{D}$ records $(r=0.62, p<0.001)$ over the $1979-2009$ period. The variance of the snow accumulation record $(r=0.72)$ is equally well explained by the local Amundsen Sea z500, the ASL z500, and the PPA anticyclone time series. Similar correlations are obtained for $\delta \mathrm{D}$, but with slightly lower $r$-values (Fig. 3.6b). From this we conclude that a highly significant ( $p<$ 0.001 ) proportion of the observed variance in RICE snow accumulation and $\delta \mathrm{D}$ records can be explained by the variability of the anticyclonic frequency in the ABS. More broadly, the records preserve interannual geopotential height conditions in the ABS region, the average state of the ASL. 

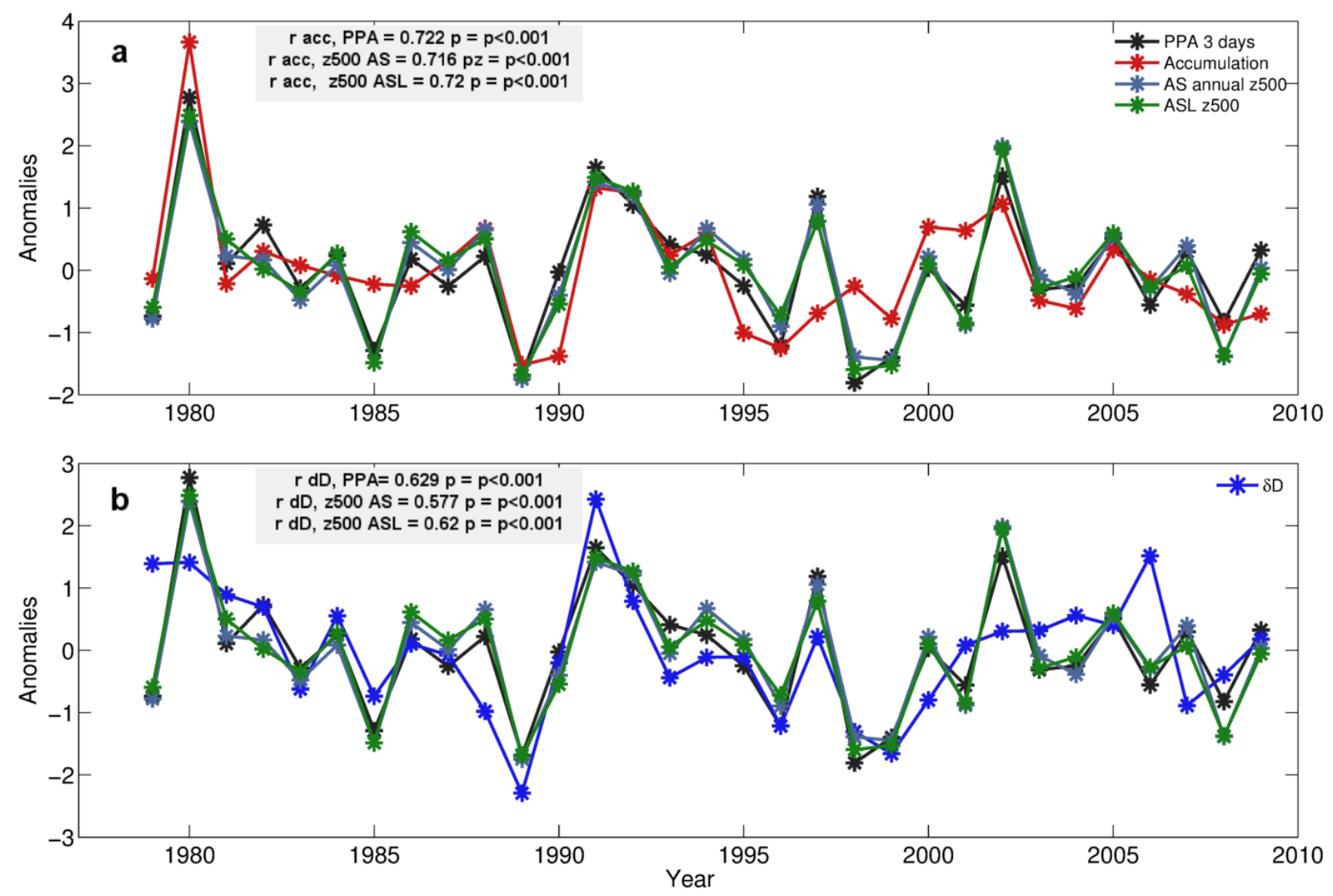

Fig. 3.7 Anomaly time series (1979-2009) of (a) the RICE snow accumulation record (red line), annual averaged PPA in the Amundsen Sea (AS) region (100 m, 3 days; black line) and annual averaged z500 in the Amundsen Sea (light blue) and Amundsen Sea Low (ASL, green line) region. (b) As in (a) but for the RICE $\delta \mathrm{D} 12 / 13 \mathrm{~B}$ firn core record (blue line).

\subsubsection{Low-frequency anticyclonic and cyclonic events influence on West Antarctica}

Here we further examine the role of anticyclones for WA air mass intrusions. We calculate spatial fields of the ratio between PPA events that are associated with precipitation and total number of PPA events for the different ice core sites (PPAp/PPA), i.e. the occurrence ratio of PPA events that is associated with precipitation (Table 3.3). The PPAp/PPA ratios at the maximum grid point for 3 days ( 5 days) are high, $\geq 0.73(\geq 0.69$, CFP $>50 \%$, Table 3.3) for all the sites, demonstrating the important dynamical role that anticyclones play in initiating WA marine air mass intrusions. The ratios $\geq 0.69(\geq 0.86)$ remain high even if smaller size precipitation events (CFP > 5\%) are included. However, the associated spatial footprint of the PPAp centers becomes larger (not shown). Additionally, Table 3.3 provides ratios between the numbers of time steps with precipitation that are associated with anticyclones and the total number of time steps with precipitation (PrPPA/total Pr). To account for spatial variability of 
PPAp events, we calculate the $\operatorname{PrPPA}_{\mathrm{PP}} /$ total Pr ratio within the $95^{\text {th }}$ percentile polygon of the considered sites. This is achieved by adding records for grid points within the polygon and checking whether the composite record coincides with anticyclonic activity with a 3- or 5-day duration (i.e. the occurrence ratio of precipitation events that are associated with anticyclones). We focus on the 3-day persistency duration threshold, since the 3-day PPA events exhibit an approximately $8 \%$ higher frequencies compared to 5 days (Fig. 3.3, Table 3.3). For all the WA sites over $88 \%$ (78\%) of their large precipitation events CFP > 50\%, 3 days (5 days) is associated with anticyclonic (PPA) events (Table 3.3). Surface climate variability over West Antarctica is not driven by zonal westerly winds, but by the location of the ASL and associated meridional winds (Hosking et al. 2013; Coggins and McDonald 2015). Our results demonstrate that anticyclones, congruent with cyclones, located in the ASL region have a key role in providing non-zonal transport and subsequent WA precipitation.

\subsubsection{Preservation of climate signal in WA Ice Cores}

The overarching goal of this section is to determine the impact of ENSO, SAM, and PSA patterns on Antarctic Pacific sector precipitation and isotopes, and to investigate why their signatures only are well preserved in certain regions. We explore the high-latitude impact of SAM, ENSO, and the PSA patterns and the preservation of these climate modes phaserelationship in snowfall and $\delta \mathrm{D}$ for five Antarctic ice core sites. Site-specific anticyclonic and cyclonic dynamical patterns associated air mass transport pathways to these five Antarctic ice core sites is determined, as well as whether there is a significant difference in anticyclone and cyclone occurrences in these regions between the positive and negative polarity phases of ENSO, SAM, and the PSA climate modes.

Weak and/or intermittent correlation for water isotopes with the ENSO Southern Oscillation Index (SOI) has been reported for various Antarctic sites (Bromwich et al. 2000; Turner 2004; Schneider and Noone 2007; Gregory and Noone 2008; Divine et al. 2009). Western WA ice core sites (RICE, ITASE 2000-5) exhibit a strong positive precipitation rate correlation with z500 in the ASL region. The correlation becomes weaker for the more easterly located WDC core; and is not statistically significant further east for the 2001-5 core (Table 3.4a). Even further east, at the AP Gomez site, precipitation is negatively correlated with the z500 in the ASL region. For eastern AP sites, the phasing of climate modes can be well preserved in isotope 
records from ice core, for instance Gomez and James Ross Island cores exhibit a statistically significant correlation with the SAM (Thomas and Bracegirdle 2009; Abram et al. 2011; Abram et al. 2014). A similar dipole correlation relationship exists for $\delta \mathrm{D}$, but with slightly lower significance levels (Table 3.4b). Amundsen Sea atmospheric circulation conditions are governed by forcings related to the ENSO, SAM, and the PSA patterns (Mo and Ghil 1987; Karoly 1989; Lachlan-Cope and Connolley 2006; Yuan and Li 2008; Ding et al. 2012). Among the sites, the ENSO, SAM, and PSA1 correlations all display a similar west-east dipole pattern (Fig. 3.8) as for the precipitation- and $\delta \mathrm{D}$-correlation with the $\mathrm{z} 500$ in the ASL region (Table 3.4). These results are consistent with previous studies, which have reported a dipole-like pattern (named the Antarctic dipole), in Antarctic surface climate and sea ice between the western Marie Byrd Land/Ross Sea and Bellingshausen Sea/AP region (Yuan and Martinson 2000; Liu et al. 2002; Harangozo 2004; Turner et al. 2015). The ENSO Niño-3.4 index explain less of the variance in precipitation and $\delta \mathrm{D}$. Of the examined sites, RICE is the only location where the ENSO-signal is preserved in precipitation and $\delta \mathrm{D}$ (Table 3.4). 
Table 3.4. Interannual correlation of (a) precipitation and (b) $\delta \mathrm{D}$ with annual averages $z 500$ in the ASL region, Niño-3.4 sea surface temperatures, and the first three PC indices: SAM, PSA1, and PSA2*

\begin{tabular}{|c|c|c|c|c|c|c|c|c|c|c|}
\hline \multirow{2}{*}{$\begin{array}{l}\text { ERA-Interim } \\
\text { Precipitation } \\
\text { Ice Core Site }\end{array}$} & \multicolumn{2}{|c|}{$\begin{array}{l}\text { z500 in ASL Region } \\
(1979-2014)\end{array}$} & \multicolumn{4}{|c|}{ Niño-3.4 (1979-2014) SAM (1979-2014) } & \multicolumn{2}{|c|}{ PSA1 (1979-2014) } & \multicolumn{2}{|c|}{ PSA2 (1979-2014) } \\
\hline & $\mathrm{r}$ & $\mathrm{p}$ & $\mathrm{r}$ & $\mathrm{p}$ & $\mathrm{r}$ & $\mathrm{p}$ & $\mathrm{r}$ & $\mathrm{p}$ & $\mathrm{r}$ & $\mathrm{p}$ \\
\hline RICE & 0.81 & $<0.001$ & 0.45 & $<0.01$ & -0.61 & $<0.001$ & 0.44 & $<0.01$ & -0.07 & 0.68 \\
\hline ITASE 2000-5 & 0.72 & $<0.001$ & 0.33 & $<0.1$ & -0.55 & $<0.001$ & 0.45 & $<0.01$ & 0.06 & 0.72 \\
\hline ITASE 2000-4 & 0.66 & $<0.001$ & 0.23 & 0.18 & -0.50 & $<0.01$ & 0.40 & $<0.05$ & -0.05 & 0.75 \\
\hline WDC & 0.48 & $<0.01$ & 0.10 & 0.55 & -0.35 & $<0.05$ & 0.22 & 0.19 & -0.30 & $<0.1$ \\
\hline ITASE 2001-5 & -0.20 & 0.24 & -0.24 & 0.16 & 0.21 & 0.24 & -0.14 & 0.42 & -0.33 & $<0.1$ \\
\hline Gomez & -0.54 & $<0.001$ & -0.28 & 0.10 & 0.68 & $<0.001$ & -0.28 & $<0.1$ & -0.29 & $<0.1$ \\
\hline
\end{tabular}

b

\begin{tabular}{|c|c|c|c|c|c|c|c|c|c|c|}
\hline \multirow{2}{*}{$\begin{array}{c}\delta \mathrm{D} \\
\text { Ice Core Site }\end{array}$} & \multicolumn{2}{|c|}{ z500 in ASL Region } & \multicolumn{2}{|c|}{ Niño-3.4 (1979-2000) } & \multicolumn{2}{|c|}{ SAM (1979-2000) } & \multicolumn{2}{|c|}{ PSA1 (1979-2000) } & \multicolumn{2}{|c|}{ PSA2 (1979-2000) } \\
\hline & $\mathrm{r}$ & $\mathrm{p}$ & $\mathrm{r}$ & $\mathrm{p}$ & $\mathrm{r}$ & $\mathrm{p}$ & $\mathrm{r}$ & $\mathrm{p}$ & $\mathrm{r}$ & $\mathrm{p}$ \\
\hline RICE 12/13 B & 0.74 & $<0.001$ & 0.53 & $<0.05$ & -0.60 & $<0.01$ & 0.66 & $<0.001$ & 0.31 & 0.18 \\
\hline ITASE 2000-5 & 0.60 & $<0.001$ & 0.14 & 0.52 & -0.72 & $<0.001$ & 0.02 & 0.94 & 0.44 & $<0.05$ \\
\hline ITASE 2000-4 & 0.40 & $<0.1$ & -0.10 & 0.66 & -0.32 & 0.16 & -0.0034 & 0.99 & 0.02 & 0.92 \\
\hline ITASE 2000-1 & 0.22 & 0.31 & 0.06 & 0.82 & -0.24 & 0.25 & -0.19 & 0.41 & 0.00 & 0.98 \\
\hline ITASE 2001-5 & 0.12 & 0.59 & -0.34 & 0.13 & -0.14 & 0.54 & -0.26 & 0.24 & 0.00 & 0.99 \\
\hline
\end{tabular}

"For WA ice core sites from west to east: RICE, ITASE 2000-5, ITASE 2000-4, ITASE 2000-1 and ITASE 2001-5. The ASL region, $60^{\circ}-70^{\circ} \mathrm{S}, 170^{\circ} \mathrm{E}-70^{\circ} \mathrm{W}$ (as defined in Hosking et al. (2013)). The correlation period between 1979 and 2000 for $\delta \mathrm{D}$ is chosen as the ice core records overlap and match available reanalysis data during this period. Correlations in bold face are significant at the $p<0.01$ level.

El Niño, negative SAM and positive PSA1 (PSA2) patterns polarity phases are associated with high ABS (eastern Ross Sea) anticyclone frequencies (Fig. 3.9a, e, i, m). In contrast, La Niña, positive SAM and negative PSA patterns are associated with high ABS (eastern Ross Sea) cyclonic frequencies (Fig. 3.9d, h, 1, p) and an easterly shift of their anticyclonic centers, with anticyclones centered over and east of South America (Fig. 3.9c, g, k), and over the Bellingshausen Sea for PSA2 (Fig. 3.9o). The PSA wave trains appear to be a dominant source of low-frequency anticyclones and cyclones in the SH (Fig. 3.9). The characteristic PSA-like wave train pattern is clear in all the ENSO, SAM and PSA composite plots (Fig. 3.9). Our results therefore add to previous research, which has shown that the PSA wave trains significantly contribute to the intrinsic variability of ENSO (Karoly 1989; Mo and Paegle 2001) and to SAM's non-zonally symmetric component (L'Heureux and Thompson 2006; Yuan and Li 2008; Ding et al. 2012). 


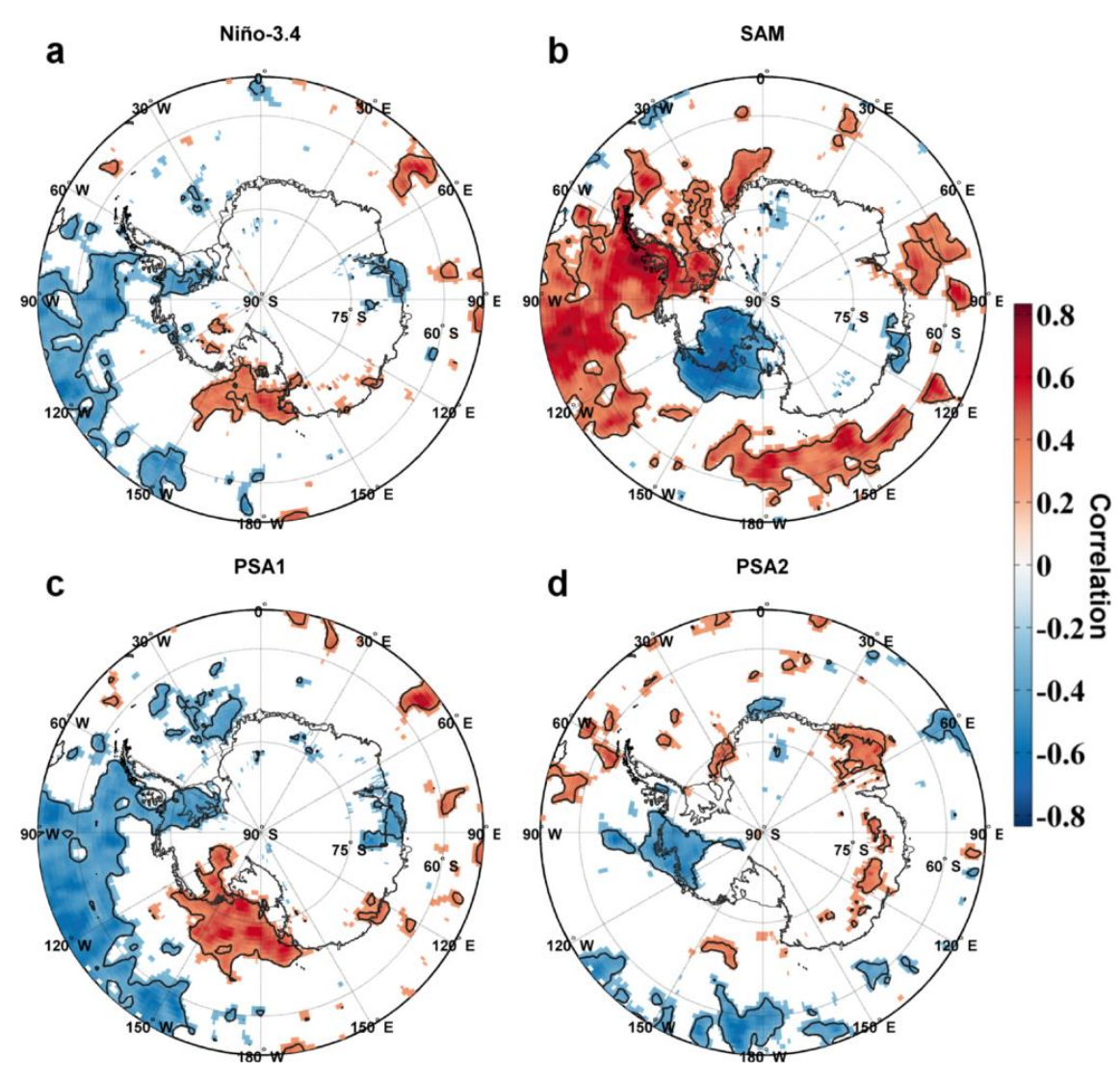

Fig. 3.8 Interannual correlation maps (1979-2014). ERA-Interim precipitation correlation with, (a) ENSO (Niño-3.4), (b) SAM, (c) PSA1, and (d) PSA2. Correlation coefficients $(r, p<0.1$, shading) and the black contour lines indicates the $p<0.05$ confidence level.

Site-specific PPAp and PNAp $95^{\text {th }}$ percentile polygons are displayed in Figure 3.10. We determine significant low-frequency anticyclone and cyclone differences between the climate modes polarity phases (Figs. 3.11-3.14). Figures 3.11 and 3.12 are generated using PPA and PNA frequencies and the site-specific $95^{\text {th }}$ percentile polygons from Figure 3.10 are projected upon the PPA and PNA patterns. From the generated panels we can assess where the dynamical loading pattern associated with the climate modes occur in relation to the cite-specific circulation. Differences in PPAp and PNAp frequencies are shown in Figures 3.13 and 3.14. The difference between the first set of PPA/PNA composites (Figs. 3.11-3.12) and the PPAp/PNAp composites (Figs. 3.13-3.14) is that the latter takes into account the local site-specific orographic setting by only considering circulation events that results in subsequent precipitation at the considered site. 

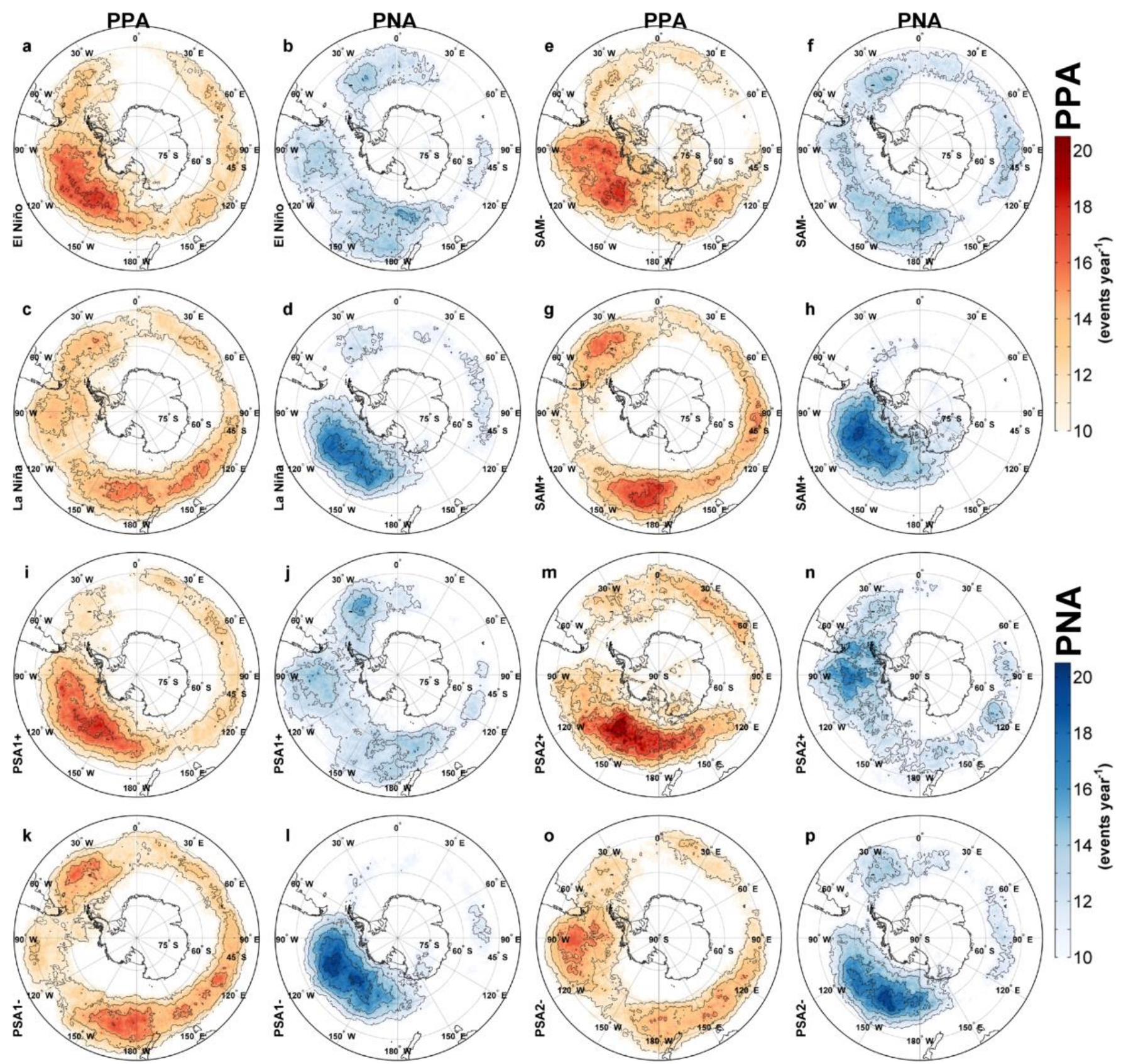

Fig. 3.9 Anticyclonic (PPA, $100 \mathrm{~m}$ and 3 days; red shading, starting at 10 events year $^{-1}$ ) and cyclonic (PNA, $-100 \mathrm{~m}$ and 3 days; blue shading, starting at 10 events year $^{-1}$ ) mean frequency composite plots for the (a-d, top-left corner) ENSO, (e-h, top-right side) SAM, (i-l, bottom-left corner) PSA1 and (m-p, bottom-right corner) PSA2 polarity phases. ENSO, SAM and the PSA patterns polarity years are provided in Table 3.2. Contour increments (thin black lines) are 2 events per year. The scale is fixed between all panels, but different coloring is used for anticyclones and cyclones. 
The anticyclonic and cyclonic patterns associated with the first three SH PCs (Figs. 3.113.12) resemble the SAM, PSA1 and PSA2 EOF geopotential height regression patterns (Fig. 3.2) (Kidson 1988; Lau et al. 1994; Mo 2000; O’Kane et al. 2012). The main purpose of these two figures is to show the marked difference in the Pacific Sector anticyclone and cyclone frequencies between the positive and negative polarity phases of ENSO, SAM and the PSA patterns. From the first part of this study, we established that anticyclone occurrences are closely linked with WA precipitation. Marked differences in anticyclone and cyclonic frequencies in the ABS between different polarities are therefore likely to result in different WA precipitation regimes (high/low) between the modes polarities.

If a site has either a climatological anticyclone (PPAp; green polygon, as defined in Fig. 3.10; Figs. 3.11-3.12) and/or cyclone (PNAp; yellow polygon, as defined in Fig. 3.10; Figs. 3.11-3.12) pattern that coincides with a significant $(p<0.05)$ difference in the ENSO, SAM, PSA1 and/or PSA2 dynamical PPA or PNA pattern (shading in Figs. 3.11 and 3.12), the snowfall at the considered site tend to preserves the considered modes signal. In other words, the signal from a climate mode has a potential to be preserved when there is a significant difference in lowfrequency anticyclone and/or cyclone occurrences between the climate mode polarity phases in the site-specific regions. Our results show that there are significant differences in anticyclone and cyclone frequencies east of New Zealand, in the ABS region, and over South America between the ENSO, SAM, and PSA1 polarity phases (Figs. 3.11 and 3.12). The site-specific climatological anticyclonic activity center for the western Marie Byrd Land/eastern Ross Sea sites (RICE and ITASE 2000-5) displays considerable overlap with regions of significant PPA differences between the SAM, and PSA1 polarity modes (Fig. 3.11a-b, k-1). High anticyclone frequencies in the Amundsen Sea result in increased precipitation for western WA and reduced precipitation over the AP (Table 3.5). The inverse relationship holds true for ABS cyclones (Table 3.5).

Large precipitation events at the westernmost sites (RICE, ITASE 2000-5) and WDC are associated with an anomalously high z500 in the ASL region (Table 3.4a) and high Amundsen Sea anticyclone frequencies (Fig. 3.10a-c). The ABS anticyclone center causes an enhanced northerly meridional transport (over western Marie Byrd Land and eastern Ross Sea). The westernmost sites (RICE and ITASE 2000-5) and WDC primarily receive high precipitation 
amounts during negative SAM and positive PSA1 polarity phases, when anticyclonic frequencies are high in the ABS (Figs. 3.11a-c, k-m; 3.13a-c, k-m), which explains why precipitation for these westernmost sites are negatively correlated with SAM and positively correlated with PSA1 (Table 3.4a). The preservation of the SAM and PSA1 signal for the westernmost sites appears to be less well explained by low-frequency cyclone occurrences (Figs. 3.11f-h, p-r; 3.13f-h, p-r), as there is a reduced overlap between the site-specific and SAM and PSA1 cyclone dynamical patterns, compared to its anticyclone counterpart. Additionally, correlations between site-specific synoptic PPA and PNA indices indicate that WA precipitation is primarily controlled by anticyclones (Section 3.3.4.2, Table 3.5). Perhaps surprisingly, the site-specific cyclone regions (Fig. 3.10) primarily occur southwest of New Zealand and west of South America, and not in the ABS region, for western WA sites and WDC, indicating that the PNA quasi-stationary cyclones are associated with the PSA patterns. Low-frequency ABS cyclones therefore appear to have a low direct impact, i.e. result in large precipitation events, for RICE and western WA sites precipitation, as both the cyclonic cells appears north of the ABS (over South America and south east of New Zealand, Fig. 3.10). The upstream PSA-like cyclonic circulation cell impact RICE circulation but the circulation center is located outside of the ASL region. Storm tracks in the ABS region associated with transient lows that are diverted towards the coast by quasi-stationary anticyclones will of course also effect the westernmost sites. However, these events are not identified as PNA events due to their short-lived and mobile nature. The composite plots demonstrate the importance of the PSA patterns for SH low-frequency anticyclones and cyclones variability. These results are consistent with recent studies, which have demonstrated the importance of western and central Pacific wave-train connections with the SH high-latitudes (Ding et al. 2012; Ciasto et al. 2014; Rodrigues et al. 2015). 

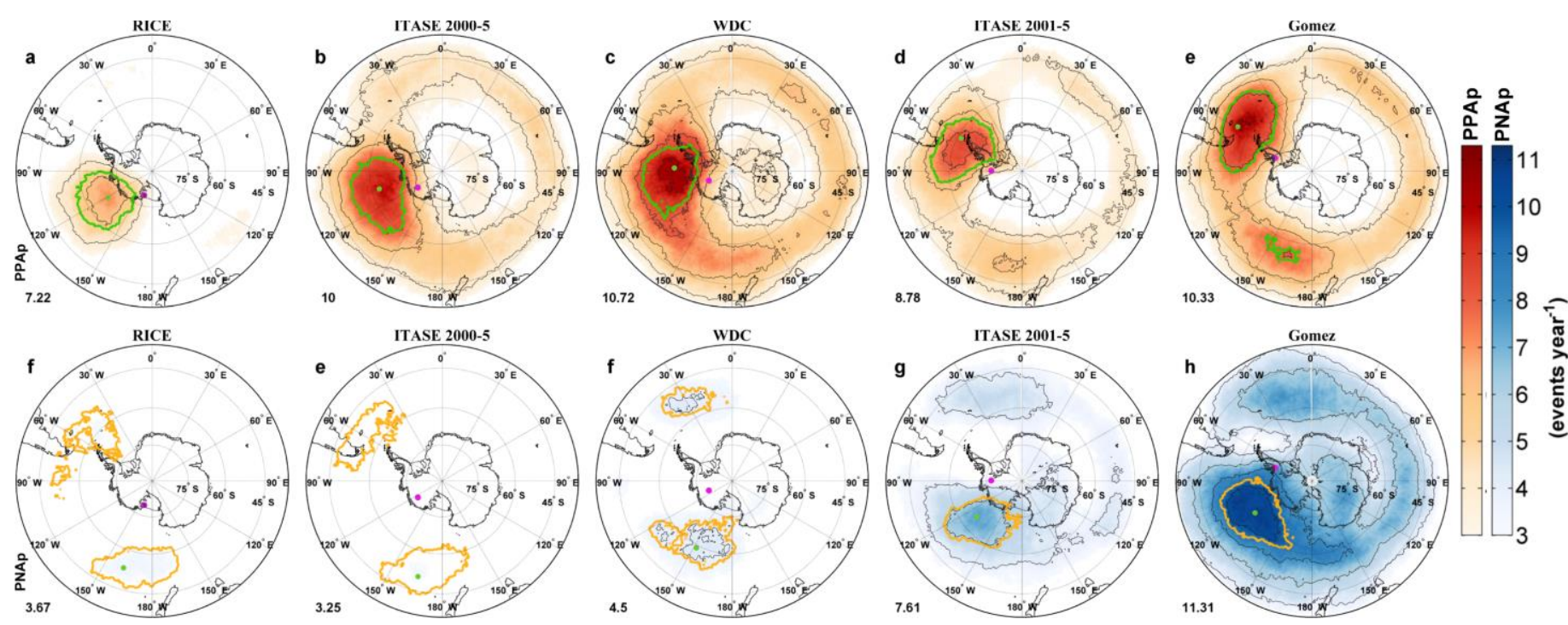

Fig. 3.10 Low-frequency (a-e, top row) anticyclone (PPAp, red shading) and (f-h, bottom row) cyclone (PNAp, blue shading) occurrences associated with snowfall at RICE (a, f), ITASE 20005 (b, e), WDC, (c, f), ITASE 2001-5 (d, g), and Gomez (e, h). The 95th percentile polygon of PPAp and PNAp are shown as green and yellow polygons, respectively. Site locations are depicted by magenta dots. Maximum frequency values are given in the lower-left corner and the max location is depicted by a green dot. 


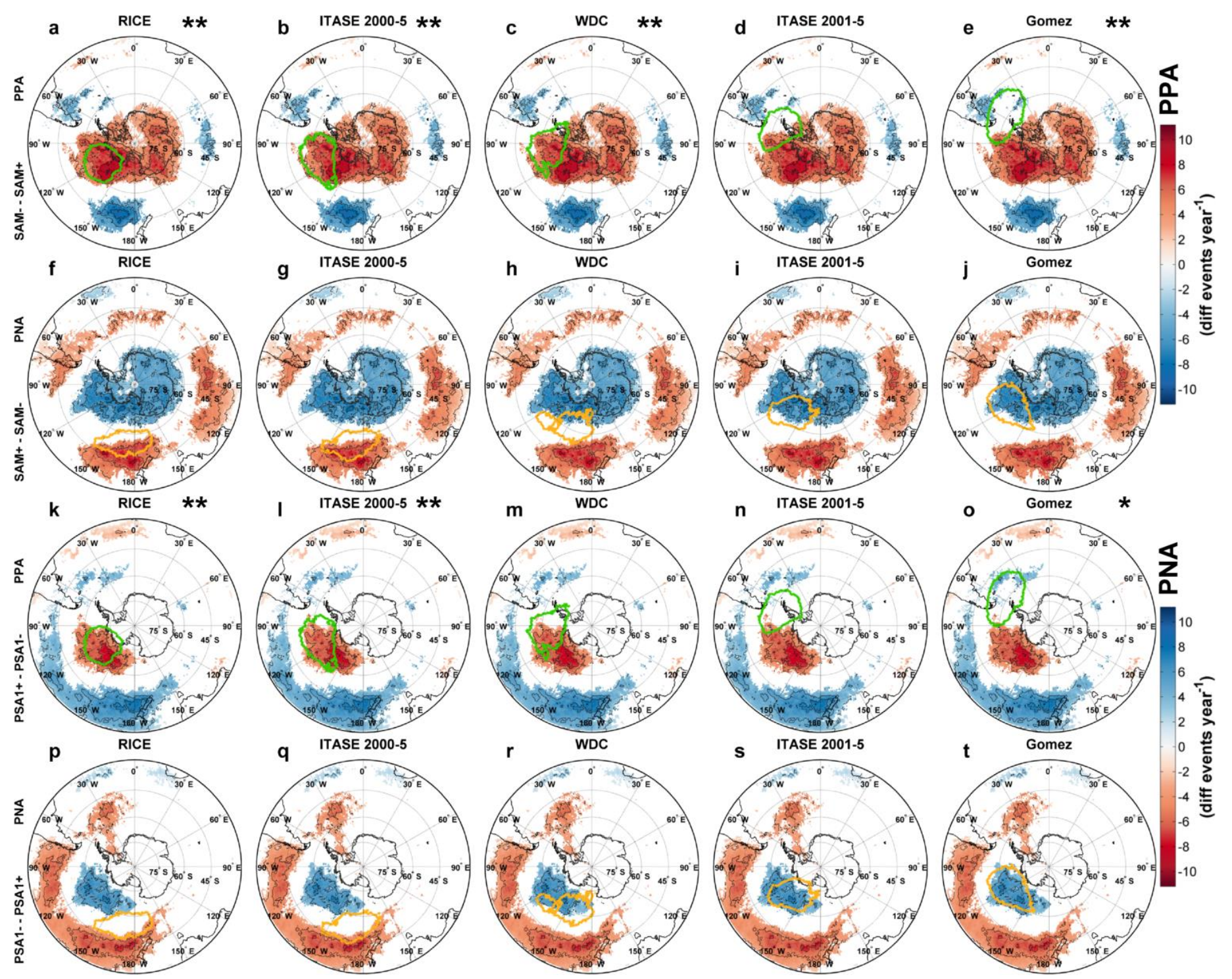

Fig. 3.11 Anticyclone (PPA: 100 m, 3 days) and cyclone (PNA: -100 m, 3 days) composite differences (shading) between SAM $(\mathbf{a}-\mathbf{j})$ and PSA1 $(\mathbf{k}-\mathbf{t})$ polarity phases. Projected on to the panels are the site-specific anticyclone (PPAp $95^{\text {th }}$ percentile, green polygon) and cyclone (PNAp $95^{\text {th }}$ percentile, yellow polygon) climatology patterns from Figure 3.10. Shading and contours (increments are 2 events year ${ }^{-1}$ ) are only displayed where the significance level is $p<$ 0.05. The scale is fixed between panels, but the color scheme is inverted for cyclone events. Two asterisks $* *$ (one asterisk *) indicate that precipitation at the site is significantly correlation (from Table 3.4) with the considered mode at the $p<0.01(p<0.1)$ confidence level. 


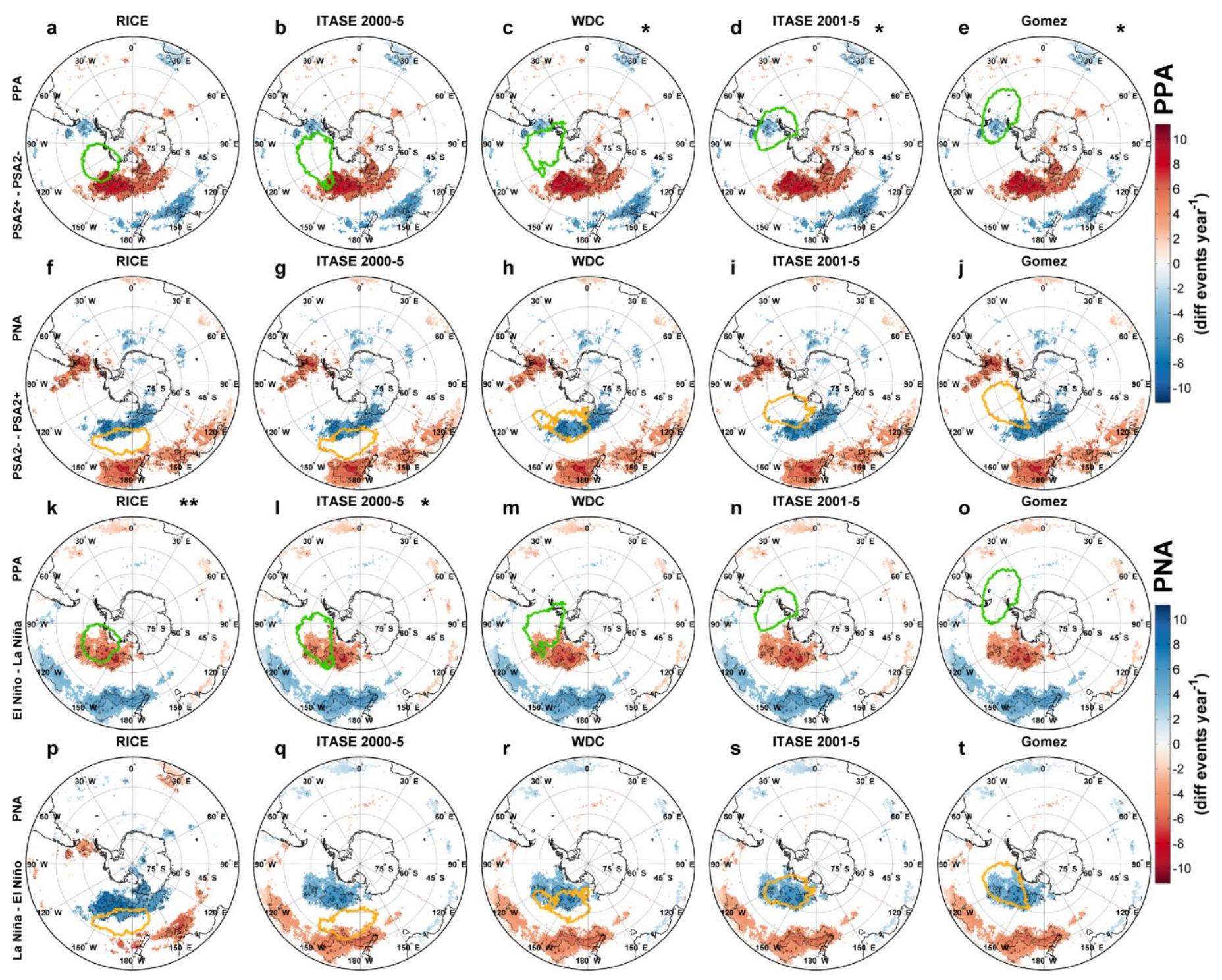

Fig. 3.12 Anticyclone (PPA: 100 m, 3 days) and cyclone (PNA: -100 m, 3 days) composite differences (shading) between (a-j) PSA2 and (k-t) ENSO polarity phases. Detail as in Figure 3.11 . 


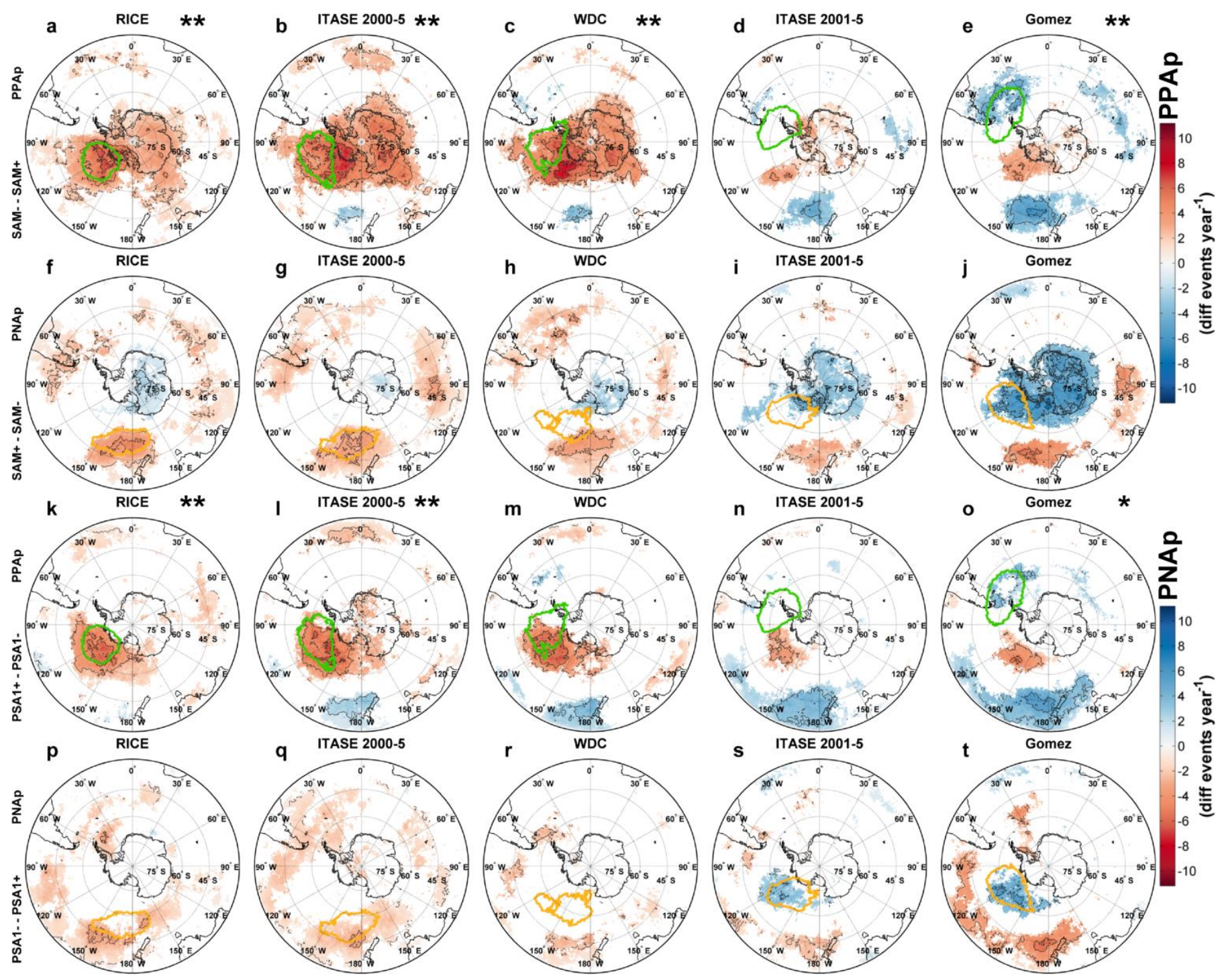

Fig. 3.13 Site-specific anticyclone (PPAp: 50\%, 100 m, 3 days) and cyclone (PNAp: 50\%, -100 m, 3 days) composite differences (shading) between (a-j) SAM and (k-t) PSA1 polarity phases. Projected on to the panels are the site-specific anticyclone (PPAp 95 th percentile, green polygon) and cyclone (PNAp 95 th percentile, yellow polygon) climatology patterns from Figure 3.10. Shading and contours (increments are 2 events year $^{-1}$ ) are only displayed where the significance level is $p<0.05$. The scale is fixed between panels, but the color scheme is inverted for cyclone events. Two asterisks ** (one asterisk *) indicate that precipitation at the site is significantly correlation (from Table 3.4) with the considered mode at the $p<0.01(p<0.1)$ confidence level. 


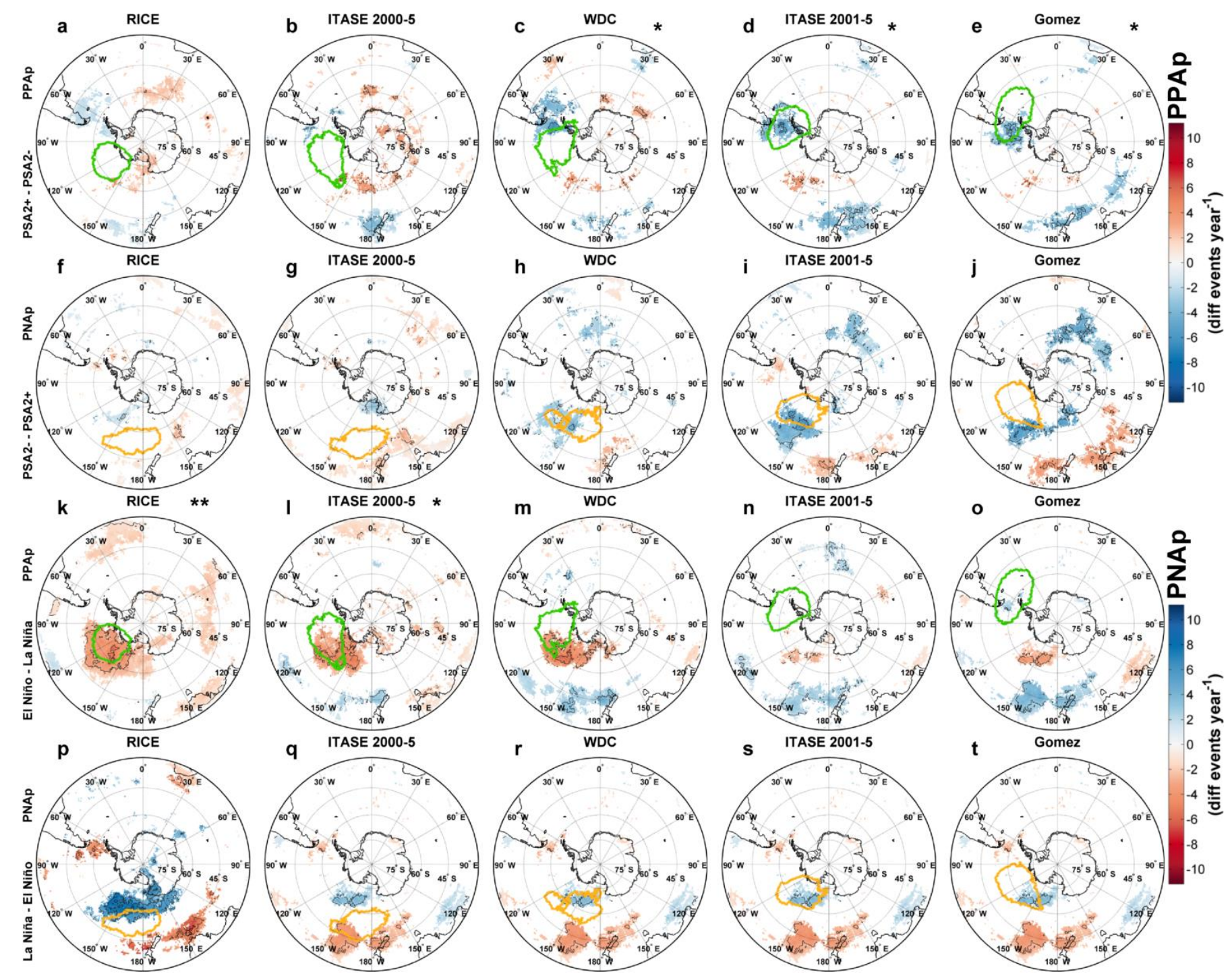

Fig. 3.14 Site-specific anticyclone (PPAp: 50\%, 100 m, 3 days) and cyclone (PNAp: 50\%, -100 m, 3 days) composite differences (shading) between (a-j) PSA2 and (k-t) ENSO polarity phases. Detail as in Figure 3.13.

\subsubsection{SAM}

All the sites preserve a significant SAM signal, except ITASE 2001-5 (Table 3.4). The phase-relationship for the SAM is well preserved for western Marie Byrd Land/eastern Ross Sea and Gomez on the AP. The reason for this is that anticyclonic (PPAp) and cyclonic (PNAp) frequency differences are marked between the climate modes positive, negative, and neutral phases. This indicates that meridional transport to these sites and large precipitation events (CFP $>50 \%$ ) primarily occur during one polarity phase. During negative SAM and positive PSA1 polarities for western Marie Byrd Land/eastern Ross Sea and during the positive SAM polarity 
phases for AP. The preservation of SAM phase-relationship for western Marie Byrd Land/eastern Ross Sea can be explained by the sensitivity of these sites to their respective anticyclonic frequency centers that coincide with the ABS region, which is a region that is characterized by marked differences in anticyclonic and cyclone frequencies for the different SAM polarity phases (Figs. 3.9 and 3.11). This is attributed to the ABS regions strong influenced from SAM. Compared to the ABS region, the difference in PPA frequency between the SAM polarity phases is reduced and largely insignificant over the AP (Fig. 3.11). The reduced difference in anticyclonic frequencies can be attributed to that AP centered circulation is located in a transition region between the downstream ABS and upstream, over and east of South American, PSA-like SAM pressure-anomaly-reversal cells, i.e. the SAM-z500 pattern do not project onto the AP (Figs 3.2) and thus, do not impact geopotential height anomalies in the region. The ITASE 2001-5's site-specific anticyclone circulation center coincide with the AP (Fig. 3.10). The SAM phase-relationship is therefore not preserved in ITASE 2001-5 snowfall (Table 3.4).

Evidence for this comes from that the easterly located WA site (ITASE 2001-5), do not display significant PPA-SAM differences within its site-specific anticyclone region (Fig. 3.11d); nor is there a significant overlap for SAM cyclones (Fig. 3.11i). Additionally, the dynamicaldifferences associated with large precipitation events to ITASE 2001-5 are minor and insignificant, i.e. evenly distributed between negative and positive SAM polarity phases (Fig. 3.13d, i). Thus, large precipitation events occur during both polarities of SAM (Fig. 3.13). Indicating that SAM do not control the synoptic conditions related moisture input to 2001-5. Therefore, a one-point correlation of precipitation with the z500 field cancels out the anomalies, causing a weak or non-significant precipitation correlation with z500 in the ASL region and the SAM (Table 3.4a). (Note that the SAM is important for AP precipitation, but the circulation cells that effects AP's precipitation and $\delta \mathrm{D}$ is not located directly over the AP itself. Instead, AP's site-specific circulation cells are located in the Atlantic sector west of the tip of South America (anticyclones) and in the Amundsen Sea for cyclones (Fig. 3.10).)

Further east at the Gomez site, located on the southwestern AP, anticyclonic (PPAp) and cyclonic (PNAp) frequency differences are both marked between the positive and negative modes of the SAM (Fig. 3.11e, j). This indicates that northerly air mass intrusions associated 
with large precipitation events primarily occur during one polarity phase, i.e. during a positive SAM when an anticyclone center is located north of the AP and cyclone frequencies are high in the Amundsen Sea (Fig. 3.11). Compared to ITASE 2001-5, the more northeasterly-located Gomez site shows an increased influence from both cyclones in the ASL region, and anticyclones over and east of South America, that are associated with SAM's PSA-like influence (Fig. 3.11).

Table 3.5 Interannual correlation of anticyclonic (PPA) and cyclone (PNA) frequency time series with precipitation time series (1979-2014)*

\begin{tabular}{ccccccccc}
\hline & \multicolumn{2}{c}{ ERA-I P. vs PPA } & \multicolumn{2}{c}{ ERA-I P. vs PNA } & \multicolumn{2}{c}{ ERA-I P. vs AS PPA } & \multicolumn{2}{c}{ ERA-I P. vs AS PNA } \\
Ice Core Site & $\mathrm{r}$ & $\mathrm{p}$ & $\mathrm{r}$ & $\mathrm{p}$ & $\mathrm{r}$ & $\mathrm{p}$ & $\mathrm{r}$ & $\mathrm{p}$ \\
\hline RICE & $\mathbf{0 . 7 8}$ & $<\mathbf{0 . 0 0 1}$ & 0.29 & $<0.1$ & $\mathbf{0 . 7 7}$ & $<\mathbf{0 . 0 0 1}$ & $\mathbf{- 0 . 7 6}$ & $<\mathbf{0 . 0 0 1}$ \\
ITASE 2000-5 & $\mathbf{0 . 6 9}$ & $<\mathbf{0 . 0 0 1}$ & 0.11 & 0.50 & $\mathbf{0 . 7 6}$ & $<\mathbf{0 . 0 0 1}$ & $\mathbf{- 0 . 6 7}$ & $<\mathbf{0 . 0 0 1}$ \\
WDC & $\mathbf{0 . 6 3}$ & $<\mathbf{0 . 0 0 1}$ & -0.14 & 0.42 & $\mathbf{0 . 5 2}$ & $<\mathbf{0 . 0 1}$ & $\mathbf{- 0 . 5 2}$ & $<\mathbf{0 . 0 1}$ \\
ITASE 2001-5 & 0.35 & $<0.05$ & 0.29 & $<0.1$ & -0.26 & 0.11 & 0.11 & 0.50 \\
Gomez & $\mathbf{0 . 6 1}$ & $<\mathbf{0 . 0 0 1}$ & $\mathbf{0 . 4 3}$ & $<\mathbf{0 . 0 1}$ & $\mathbf{- 0 . 5 3}$ & $<\mathbf{0 . 0 0 1}$ & $\mathbf{0 . 4 3}$ & $<\mathbf{0 . 0 1}$ \\
\hline
\end{tabular}

* Interannual correlation between ERA-Interim precipitation time series and PPA and PNA time series are shown; first, for ice core sites individual circulation centers (column 2-5), then for the Amundsen Sea region (column 6-9). Precipitation time series are generated by calculating the annual sums of total precipitation from the closest grid points to the respective ice core site. PPA (100 m, 3 days) and PNA $(-100,3$ days) time series are generated by calculating annual means of PPA frequencies that fall within the site specific $95^{\text {th }}$ PPAp and PNAp polygon, respectively, or in the Amundsen Sea region $\left(60^{\circ}-75^{\circ} \mathrm{S}\right.$, $\left.90^{\circ}-150^{\circ} \mathrm{W}\right)$. Correlations in bold face are significant at the $p<0.01$ level.

\subsubsection{PSA1}

The significant dynamical pattern associated with PSA1 appears to wane towards the Bellingshausen Sea (Figure 3.11k-t). At RICE and ITASE 2000-5, that displays a significant overlap with the dynamical PSA1-pattern, snowfall is significantly correlation with PSA1. WDC and ITASE 2001-5 site-specific circulation regions display an overlap with the PSA1-transitions regions and thus, precipitation at these sites are not significantly correlated with PSA1. The atmospheric circulation response to tropical forcing appears to be less predictable over the AP and is therefore the PSA1-phasing is not preserved in subsequent precipitation over the Ellsworth Land regions (ITASE 2001-5). Snowfall at Gomez displays a tendency to being correlated with PSA1, which can be explained by a match between its site-specific cyclone center and PSA1 related cyclones in the Amundsen Sea (Figs. 3.11t and 3.13t). 


\subsubsection{PSA2}

PSA2 is associated with two high-latitude pressure reversal cells in the Pacific sector (Figs. 3.2d and 3.12), where the western cell $\left(160^{\circ} \mathrm{W}\right)$ is associated with larger anticyclone and cyclone amplitudes (Figs. 3.2 and 3.12). Circulation conditions in the Amundsen Sea differ compared to more easterly ABS circulation, because the region coincides with a transition between the two high-latitude PSA2 geopotential height anomaly reversal cells (Figs. 3.2d and 3.12), i.e. pressure anomalies over the Amundsen Sea is not controlled by PSA2. The influence from anticyclones controlled by the PSA2 pattern, therefore appear to be reduced over the Amundsen Sea, and thus also its direct northerly influence on subsequent RICE precipitation (Fig. 3.8d). PSA2 is not associated with significant difference in either PPA or PNA frequencies within RICE site specific-circulation region (Fig. 3.12). Thus, neither is RICE precipitation significantly correlated with PSA2. The WDC, ITASE 2001-5, and Gomez sites' precipitation show a tendency $(p<0.1)$ towards a negative correlation with PSA2 (Table 3.4a). These sites display a partial overlap with either region of significant cyclone (WDC) differences or anticyclones (ITASE 2001-5 and Gomez; Fig. 3.12). The same conclusion can be drawn from the analysis of PSA2 low-frequency variability associated with precipitation (Fig. 3.14a-j).

\subsubsection{ENSO}

The significant difference in cyclone frequencies between the ENSO polarity phases (Fig. 3.12) is consistent with earlier studies, which have shown that the El Niño and La Niña phases are associated with high and low pressure anomalies in the ABS region (Karoly 1989; LachlanCope and Connolley 2006; Hosking et al. 2016). We use the Niño-3.4 sea surface temperatures (SST, from NOAA Climate Prediction Center) as an index for interannual ENSO variability, but similar results are obtained using the Southern Oscillation Index (SOI, not shown). For the ENSO and PSA1 modes, the region of marked ABS differences between the polarity phases appears to be reduced compared to SAM mode (Fig. 3.12). The high-latitude anticyclone frequency differences are restricted to the Amundsen Sea region (Figs. 3.12 and 3.14). The RICE site-specific anticyclonic center closely coincides with this area in the Amundsen Sea (Fig 3.12k), which correspond with the focal point of the Amundsen Sea PSA1- and ENSOdynamical patterns (Figs. 3.11k and 3.12k). 
High precipitation rates at RICE are associated with El Niño events. In contrast, the WAIS sites and Gomez sites display high anticyclone and cyclone frequencies during both El Niño and La Niña phases (higher than the neutral phase, Fig. S3.1), indicating that these sites receive high precipitation rates during both El Niño and La Niña polarities. The phase-relationship for the ENSO mode is therefore not well preserved in snowfall over WA or at Gomez (Table 3.4). Weak and/or intermittent correlation for precipitation and water isotopes with the ENSO (SOI) index has previously been reported for various WA sites (Bromwich et al. 2000; Turner 2004; Gregory and Noone 2008). In contrast, RICE is sheltered from direct moisture from La Niña and PSA1cyclones by the marked WA orography, and thus provide a setting with marked differences in precipitation amount between Amundsen Sea cyclones and anticyclones (Fig. S3.2). Among the examined sites, RICE therefore appears to be unique in preserving a significant ENSO driven variability in precipitation rates and $\delta \mathrm{D}$ (Table 3.4, Figs. 3.12 and 3.14). We note that it is incorrect to conclude that WA snowfall is not influenced by ENSO. Snowfall at most sites are, in fact, influenced by both phases of ENSO, which prevents the phase-relationship from being preserved. As the regional high-latitude differences between the sites can be explained by the PPA/PNA dynamical pattern, it appears as the overarching differences between the sites comes from the high-latitude dynamical expression associated with the modes and not from site-specific orographic differences.

\subsubsection{Water stable isotopes}

The explanation for preservation of the imprint of the climate mode polarity-phases presented above for precipitation appears to also hold true for $\delta \mathrm{D}$. As for precipitation (Fig. S3.2), annual RICE $\delta \mathrm{D}$ values are high when anticyclone frequencies are high in the Amundsen Sea region (characteristic for prevailing El Niño, negative SAM, or positive PSA1 pattern; Figs. 3.9 and 3.15a). In contrast, RICE $\delta \mathrm{D}$ is low when cyclone frequencies are high in the Amundsen Sea (characteristic for prevailing La Niña, positive SAM, and negative PSA1 pattern; Figs. 3.9 and 3.15d). Indeed, RICE $\delta \mathrm{D}$ is significantly correlated with ENSO, SAM and PSA1 (Table 3.4b). Furthermore, the RICE $\delta$ D high-low dynamical pattern (anticyclone and cyclone frequencies associated with high and low $\delta \mathrm{D}$ anomalies, Fig. 3.15a-d) is remarkably similar to the dynamical pattern associated with ENSO (Fig. 3.9a-d). ITASE 2000-5 display a similar high-low $\delta D$ dynamical pattern as RICE (Fig. 3.15e-h), however, with a less pronounced cyclonic imprint (Fig. 3.15h) and with a marked anticyclone center southeast of New Zealand (Fig. 3.15g) for low 
$\delta \mathrm{D}$ values. This indicates that cyclones that are present during La Niña and negative PSA1 are less likely to result in a depleted $\delta$ D for ITASE 2000-5 compared to RICE, which can explain the loss of significant correlation with ENSO between these two westernmost sites. The same reasoning holds up for WDC. However, with the difference that for WDC it is clear that Amundsen Sea cyclones also are associated with enriched $\delta \mathrm{D}$ (Fig. 3.15j). Again, the difference between the RICE, ITASE 2000-5, and WDC, is that cyclonic conditions at RICE are associated with relatively more depleted $\delta \mathrm{D}$ ratios.

We hypothesize that RICE is sheltered from air mass advection related to ABS cyclones from the pronounced WA orography. Thus, air mass advection to RICE during ABS cyclonic conditions appears to have passed over pronounced western Marie Byrd Land orography and/or over the Ross Ice Shelf prior to reaching RICE. These air masses are affected by precipitation fallout and approach RICE as dry, cold flow, with associated low precipitation rates and $\delta \mathrm{D}$ values. The large variability of the RICE $\delta \mathrm{D}$ and snow accumulation record is primarily attributed to the large variability of Amundsen Sea circulation and the pronounced difference in expression of distillation effect associated with air mass advection through northerly air mass incursions and from flow of continental/Ross Ice Shelf origin. Such conditions are associated with Amundsen Sea anticyclones and cyclones, respectively.

We note that the $\delta \mathrm{D}$ results are based on a short evaluation period, as the available ITASE and ERA-interim data only match for 22-years. Finally, we note that the preserved climate signal in the ITASE cores have been examined elsewhere using longer observational record (e.g., Okumura et al. 2012). Additionally, a sister study (Chapter 4) assess the preservation of Pacific decadal-scale (Interdecadal Pacific Index) variability for the same WA isotope records that are studied here. Our analysis provides a dynamical mechanism that provides a compelling explanation to why the ENSO, SAM and the PSA patterns are preserved differently in Antarctic snowfall and isotopic signatures. 

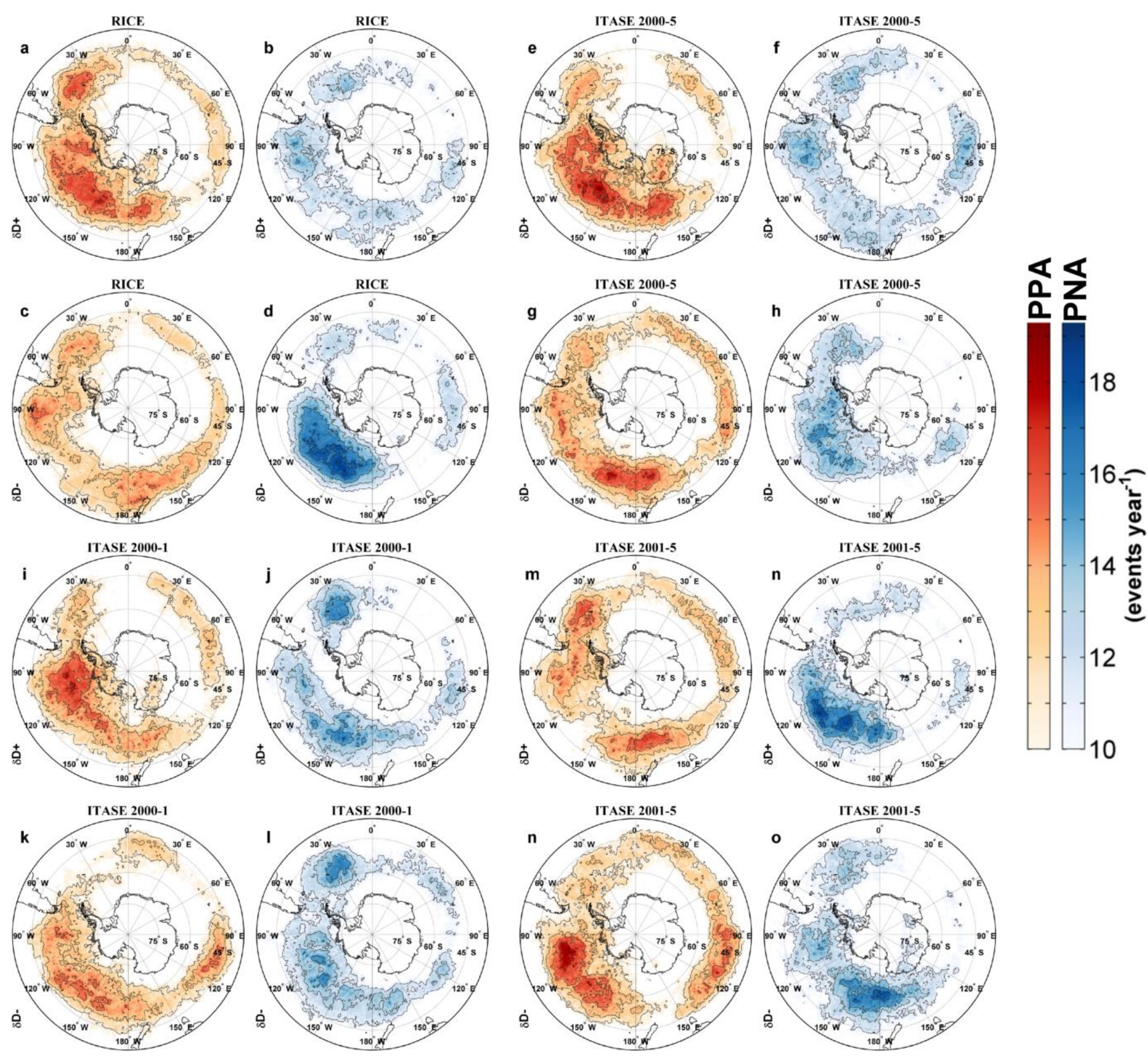

Fig. 3.15 Anticyclone composites (PPA, 3 days, $100 \mathrm{~m}$, red shading) and cyclone (PNA, 3 days, $-100 \mathrm{~m}$, blue shading) plots for high and low $\delta \mathrm{D}$ years for (a-d) RICE, (e-h) ITASE 2000-5, (il) ITASE 2000-1 and (m-p) ITASE 2001-5.

\subsubsection{High-latitude circulation indices}

We chose to employ the PPA methodology as it allows us to obtain high-latitude site-specific anticyclonic and cyclonic patterns and indices. Commonly used blocking indices for the SH are often a result of analysis covering vast hemispheric meridional sections (e.g., Tibaldi et al. 1994). The PPA and PNA climate mode polarity composite plots (Figs. 3.9, 3.11 and 3.12) are 
almost mirror images of the EOF regression patterns (Fig. 3.2). This suggests that the spatial and temporal distribution of low-frequency anticyclone and cyclone events are well captured by the PPA methodology. Other objective methods for establishing low-frequency anticyclonic indices include the identification of large amplitude persistent negative potential vorticity (PV) events in and below the tropopause (Hoskins et al. 1985; Schwierz et al. 2004). PV events have been linked to strong anticyclonic circulation (Hoskins et al. 1985; Schwierz et al. 2004). Schwierz et al. (2004) showed that employing the 500-hPa geopotential height field is sufficient for identification of blocking, however in particular the PV-methodology using a vertical integrated profile is optimal.

\subsubsection{Indicators of non-zonal flow conditions}

PPA (100 m, 3 days) and PNA (-100, 2 days) time series are generated by calculating annual means of PPA frequencies that fall within the site-specific $95^{\text {th }}$ percentile PPAp and PNAp polygon, respectively, or in the Amundsen Sea region $\left(60^{\circ}-75^{\circ} \mathrm{S}, 90^{\circ}-150^{\circ} \mathrm{W}\right)$. These low-frequency synoptic time series are correlated with annual ERA-Interim precipitation records for the different sites (Table 3.5). Anticyclones are relevant for both eastern and western WA sites. By diverting the westerly storm-tracks, they cause enhanced meridional transport conditions that affects the precipitation rates and water isotope values. The correlation coefficient $(r)$ between the cumulative annual precipitation and the site-specific PPA time series are significant for all five Antarctic sites (Table 3.5). However, the $r$-values are slightly lower for sites eastward of RICE, particularly for ITASE 2001-5, indicating that anticyclones still have a significant role in driving moisture transport into all the sites, though perhaps this is less prominently for ITASE 2001-5.

PSA1 and SAM appear to be associated with lower anticyclone and cyclone frequencies over the AP (Fig. 3.9). The lower frequencies in this region appear to be related to the fact that PSA1 pattern go through a transition from the upstream to downstream pressure anomaly reversal cell over the AP. Additionally, the strong zonal flow conditions through the Drake Passage appear to favor more transient anticyclonic systems in the AP region. ITASE 2001-5 anticyclonic circulation center coincides with this PSA1 transition region over the AP, which provides a compelling explanation as to why the correlation with the site-specific anticyclone time series is lower for ITASE 2001-5. When comparing the correlation of the low-frequency 
site-specific anticyclonic and cyclonic time series with precipitation (column 2-5, Table 3.5), anticyclones appears to explain more of the precipitation variability for all the sites and this appears to indicate that anticyclones have a key role in imposing meridional flow condition by impeding the dominant zonal flow, even for the more easterly sites, where one could perhaps expect a dominance from the upstream ASL center (Table 3.5). Only for the Gomez site do the correlation with the PNA center become significant. Gomez site-specific PNA center display overlap with cyclones in the Amundsen Sea region (Fig. 3.11j). Nevertheless, the significance of correlation of Gomez precipitation with its sites-specific PPA time series is slightly higher, compared to its PNA series (Table 3.5).

We also perform the same type of correlations, but with PPA and PNA extracted from the Amundsen region $\left(60^{\circ}-75^{\circ} \mathrm{S}, 90^{\circ}-150^{\circ} \mathrm{W}\right.$, Table 3.5, column 6-9). The Antarctic dipole relationship is marked in these results (Table 3.5, column 6-9), where the western sites have a significant positive correlation with the Amundsen Sea anticyclonic frequencies. The easternmost sites are negatively correlated with $\mathrm{ABS}$ anticyclones frequencies, as we argue that the eastern sites receive drier, colder continental flow when anticyclones are present. The reverse relationship holds true for Amundsen Sea cyclones (PNA, Table 3.5). It is apparent that the precipitation variability for the sites are equally well explained by Amundsen Sea anticyclones and cyclones. Furthermore, the variance explained by Amundsen Sea circulation is roughly equal to the site-specific PPA correlations (Table 3.5, column 2-3). Only for the ITASE 2001-5 site is the Amundsen Sea circulation (PPA or PNA) correlation weaker compared to the site-specific (PPA) correlation (Table 3.5). This indicates that the tropically driven Amundsen Sea circulation is not directly related to AP circulation, as AP circulation falls within a transition area between PSA1-circulation-reversal cells, where the response to tropical forcing changes sign. ITASE 2001-5 precipitation is neither significantly correlated with Amundsen Sea anticyclonic nor cyclonic frequencies.

Amundsen Sea anticyclonic frequencies provides a viable indicator of Amundsen Sea circulation conditions and WA surface climate (Table 3.5, column 6), as high frequencies are indicative of western WA meridional flow. In contrast, the absence of anticyclones indicates a dominating cyclonic Amundsen Sea circulation, with a meridional flow regime over eastern WA and the AP. Furthermore, the recently-retrieved RICE snow accumulation and $\delta \mathrm{D}$ records have 
the potential for proxy reconstruction of the Amundsen Sea atmospheric circulation conditions, through time, as RICE $\delta \mathrm{D}$ and snow accumulation preserves the variability of the relative distribution between Amundsen Sea anticyclonic and cyclonic activity. The PPA and PNA frequency in the ABS is largely controlled by SAM and the PSA patterns (Figs. 3.11 and 3.12), demonstrating the close link between the variability of the dynamical anticyclonic and cyclone activity and these climate modes. Recent research efforts with a focus on the AP region have mainly emphasized the dynamics and trends of the ASL (Hosking et al. 2013; Turner et al. 2013; Raphael et al. 2015). Even though synoptic and sub-synoptic lows largely define the overall climatology of the ABS region, which is characterized by the quasi-stationary ASL (Hosking et al. 2013; Turner et al. 2013). It appears that anticyclonic centers can provide a viable indicator for meridional flow conditions and WA surface climate. To explain the surface climate for the eastern, central, and western WA regions, we stress that is important to consider the circulation variability of the Amundsen Sea and not solely the maximum depth and location of the ASL.

\subsubsection{SH trends in high-latitude anticyclone occurrences}

There is a weak negative trend $(p<0.1)$ for PPA and PPAp events lasting at least 5 days in ABS (Table 3.6, 1979-2014). The decrease in persistent anticyclonic events can perhaps be associated with reduced meridional incursions over western WA (RICE, ITASE 2000-5 and WDC). A recent study by Oliveira et al. (2014) also a reported on a tendency of a reduction in SH Pacific sector blocking, but their results were not significant at the $p<0.05$ level. O'Kane et al. (2012) demonstrated a close link between SH blocking frequencies and the SAM, and showed that both the occurrence and persistency of the Pacific section blocking has declined. Even though the negative high-latitude anticyclonic trend appears to be weak, it could still be important due to the longevity of these events. As anticyclones drive meridional transport, a reduction in anticyclonic frequencies can be linked to the recent observed trend towards a zonalflow regime. A reduction in anticyclonic frequencies is consistent with the observed trend towards a positive SAM (Thompson and Solomon 2002; Marshall et al. 2004; Ding et al. 2012; Schneider et al. 2015) and deepening of the ASL (Turner et al. 2013; Raphael et al. 2015; Hosking et al. 2016). It could still be considered somewhat of a paradox, that we do not observe a stronger negative trend in anticyclonic occurrences in the SH high-latitude Pacific region, when a positive trend in SAM and a deepening of the ASL has been observed. However, we note that 
the detection of a possible trend in the ABS region is hampered by the large-atmospheric circulation variability in the region. A recent general circulation model (GCM) study indicated that La Niña-like conditions and an associated deepening and poleward migration of the ASL is likely to continue in a global warming scenario (Hosking et al. 2016). Therefore, one can speculate that the weak trend in ABS persistent anticyclone occurrences detected here can indicate that these effects have already begun to impact WA climate and that we might see a continued decreasing trend, with associated increased meridional air mass advection over AP/eastern WA and increased continental dry cold offshore flow over western WA. Future research could involve further quantification of blocking and cyclonic synoptic conditions and their importance for WA climate, perhaps using a combination of reanalysis data and GCM simulations.

Table 3.6 Trends in ABS anticyclone frequencies over the ERA-Interim reanalysis period $(1979-2014)^{*}$

\begin{tabular}{|c|c|c|c|c|c|c|c|c|c|}
\hline & \multirow{2}{*}{$\begin{array}{c}\text { Events dec }{ }^{-1} \\
1979-2014 \\
\end{array}$} & \multicolumn{2}{|c|}{ RICE } & \multicolumn{2}{|c|}{ ITASE 2000-5 } & \multicolumn{2}{|c|}{ WDC } & \multicolumn{2}{|c|}{ ITASE 2001-5 } \\
\hline & & $\mathrm{r}$ & $\mathrm{p}$ & $\mathrm{r}$ & $\mathrm{p}$ & $\mathrm{r}$ & $\mathrm{p}$ & $\mathrm{r}$ & $\mathrm{p}$ \\
\hline PPA & $\begin{array}{l}\text { MD: } 100 \mathrm{~m}, 3 \\
\text { days } \\
\text { MD: } 100 \mathrm{~m}, 5\end{array}$ & -0.74 & 0.12 & -0.64 & 0.13 & -0.57 & 0.16 & -0.14 & 0.67 \\
\hline PPA & days & -0.68 & $\mathrm{p}<0.1$ & -0.64 & $\mathrm{p}<0.1$ & -0.62 & $\mathrm{p}<0.1$ & -0.30 & 0.20 \\
\hline PPAp & $\begin{array}{l}\text { PMD: }>50 \%, \\
100 \text { m, } 3 \text { days } \\
\text { PMD: }>50 \%\end{array}$ & -0.62 & 0.11 & -0.57 & 0.14 & -0.59 & 0.12 & -0.05 & 0.87 \\
\hline PPAp & $100 \mathrm{~m}, 5$ days & -0.55 & $\mathrm{p}<0.1$ & -0.52 & $\mathrm{p}<0.1$ & -0.60 & $\mathrm{p}<0.05$ & -0.21 & 0.32 \\
\hline
\end{tabular}

${ }^{*}$ The $95^{\text {th }}$ percentile of the PPAp are used to establish site-specific polygons (Fig. 3.10), from which the PPA occurrence frequencies are extracted. 


\subsection{Conclusions}

This study investigates the role of intermittent anticyclonic circulation on WA meridional transport and WA surface climate and its impact on precipitation rates and isotope fractionation over the WAIS. We demonstrate that ABS anticyclonic events (of at least 3-day duration) have a $12 \%$ occurrence frequency but are associated with over $88 \%$ of all large precipitation events at four WA ice core sites. Amundsen Sea atmospheric circulation conditions are governed by forcings related to the ENSO, SAM, and PSA modes (Mo and Ghil 1987; Karoly 1989; LachlanCope and Connolley 2006; Yuan and Li 2008; Ding et al. 2012). We demonstrate that El Niño, negative SAM and positive PSA1 are associated with high ABS anticyclonic frequencies. In contrast, La Niña, positive SAM and negative PSA1 phases are associated with high ABS cyclonic frequencies and an easterly shift of the anticyclonic center, with ridges centered over and east of South America. High frequencies of anticyclones in the ABS cause enhanced northerly meridional flow over western Marie Byrd Land, higher frequency of marine air mass intrusion, increased central and western WA precipitation, and relatively enriched water stable isotope values. This flow regime is associated with offshore cold dry flow over Bellingshausen Sea/AP. Therefore, precipitation and $\delta \mathrm{D}$ over WA display a characteristic Antarctic dipole pattern, which change signs during the different ENSO, SAM and PSA1 polarity phases. The longitudinal shift in the location of anticyclones and cyclones action centers associated with the polarities of the climate modes, changes the flow conditions through the Amundsen Sea atmospheric circulation, which controls whether meridional incursions of moisture and heat tend to infringe over the western Marie Byrd Land or Ellsworth Land/AP. This in turn strongly influences the variability of WA surface climate. The Amundsen Sea circulation and the Antarctic dipole phase-relationship is preserved in the RICE $\delta \mathrm{D}$ and snow accumulation records. Anticyclonic circulation centers associated with the different phases of the ENSO, SAM and PSA pattern are established using PPAp composite plots for the five Antarctic ice core sites (RICE, ITASE 2000-5, WDC, ITASE 2001-5, and Gomez). Of the examined WA sites, RICE preserves the strongest ENSO and PSA1 phase-relationship in precipitation rates and $\delta \mathrm{D}$. The phase-relationship for the SAM and PSA1 are well preserved for western ITASE 2000-5, RICE and Gomez on the AP, as anticyclonic (PPAp) and cyclonic (PNAp) frequency differences are marked between the positive and negative polarity phases of the climate modes. This indicates 
that northerly meridional air mass intrusions to the sites and large precipitation events (CFP > $50 \%$ ) primarily occur during one polarity phase. These conditions are achieved during the negative SAM and positive PSA1 for western Marie Byrd Land/eastern Ross Sea and during positive SAM and negative PSA1 polarities for the AP. The preservation of PSA and SAM phase-relationship for western Marie Byrd Land/eastern Ross Sea can be explained by the sitespecific anticyclonic centers that influence RICE and ITASE 2000-5 sites coincide with the ABS region, which is a region that is characterized by marked differences in anticyclone and cyclone frequencies for the different PSA1 and SAM polarity phases. The marked differences in anticyclone and cyclone frequencies in the ABS region are attributed to the strong influence from the southernmost PSA1 pressure-anomaly-reversal cell, which results in a predictable climate response to tropical Pacific forcings. The difference in PPA frequency between the PSA phases is reduced over the AP compared to the ABS region. This can be attributed to the fact that the circulation centered over the AP is located in a transition region between the downstream ABS reversal cell and the upstream, east of South America PSA pressure reversal cells. ITASE 2001-5 site-specific circulation center coincides with the AP, thus it influence from SAM and PSA1 is low.

Among the examined sites, RICE precipitation and $\delta \mathrm{D}$ uniquely preserves ENSO variability, as it displays a marked difference in anticyclone (PPAp) and cyclone (PNAp) frequencies between El Niño (high PPAp), La Niña (low PPAp) and neutral ENSO conditions where high (low) RICE precipitation and $\delta \mathrm{D}$ values are associated with El Niño (La Niña) events. In contrast, the WAIS sites and Gomez sites display high anticyclone and cyclone frequencies during both El Niño and La Niña phases (higher than the neutral phase). Consequently, the ENSO phase-relationship is not preserved in precipitation rates and $\delta \mathrm{D}$ for these sites. The ABS region of marked PPA frequency differences between the El Niño and La Niña polarity phases appears to be less pronounced for ENSO compared to the PSA1 polarity differences. In contrast to SAM, the significant ENSO and PSA1 polarity differences are primarily confined to the Amundsen Sea region. RICE is unique in that its site-specific anticyclone center coincide with the ENSO- and PSA1-PPA pattern in the Amundsen Sea (Figs. 3.11 and 3.12), thus providing ideal setting for preservation of a tropical Pacific climate signal. In addition, the geographic setting is also essential, where RICE is sheltered from direct un-distillated moisture input from Amundsen Sea cyclones by the WA orography. These circumstances are unique for RICE and therefore, provide 
a compelling explanation to why RICE $\delta \mathrm{D}$ and precipitation records preserves ENSO and PSA1 variability.

Acknowledgements We thank the ECMWF institute for providing the ERA-Interim reanalysis datasets (http://apps.ecmwf.int/datasets/data/interim-full-daily). We would also like to thank the United States National Snow and Ice Data Center for the ITASE $\delta$-data sets (https://nsidc.org/). We are grateful for the AWS and ADG datasets provided by University of Wisconsin-Madison Automatic Weather Station Program (http://amrc.ssec.wisc.edu/). This project was supported by the New Zealand Government through GNS Science (Global Change through Time Programme, GNS-540GCT12 and GNS-540GCT32) and Victoria University of Wellington (RDF-VUW1103). This work is a contribution to the Roosevelt Island Climate Evolution (RICE) Program, funded by national contributions from New Zealand, Australia, Denmark, Germany, Italy, People's Republic of China, Sweden, United Kingdom and the United States of America. The main logistic support was provided by Antarctica New Zealand (K049) and the US Antarctic Program. 


\subsection{References}

Abram NJ, Mulvaney R, Arrowsmith C (2011) Environmental signals in a highly resolved ice core from James Ross Island, Antarctica. J Geophys Res Atmos 116:1-15. doi: 10.1029/2011JD016147

Abram NJ, Mulvaney R, Vimeux F, et al (2014) Evolution of the Southern Annular Mode during the past millennium. Nat Clim Chang 4:564-569.

Alexander MA, Bladé I, Newman M, et al (2002) The Atmospheric Bridge: The Influence of ENSO Teleconnections on Air-Sea Interaction over the Global Oceans. J Clim 15:22052231. doi: 10.1175/1520-0442(2002)015<2205:TABTIO>2.0.CO;2

Baines PG, Fraedrich K (1989) Topographic Effects on the Mean Tropospheric Flow Patterns around Antarctica. J. Atmos. Sci. 46:3401-3415.

Blackmon ML, Mullen SL, Bates GT (1986) The Climatology of Blocking Events in a Perpetual January Simulation of a Spectral General Circulation Model. J Atmos Sci 43:1379-1405. doi: 10.1175/1520-0469(1986)043<1379:TCOBEI>2.0.CO;2

Bracegirdle TJ (2013) Climatology and recent increase of westerly winds over the Amundsen Sea derived from six reanalyses. Int J Climatol 33:843-851. doi: 10.1002/joc.3473

Bracegirdle TJ, Marshall GJ (2012) The Reliability of Antarctic Tropospheric Pressure and Temperature in the Latest Global Reanalyses. J Clim 25:7138-7146. doi: 10.1175/JCLI-D$11-00685.1$

Bromwich DH (1988) Snowfall in high southern latitudes. Rev Geophys 26:149-168. doi: 10.1029/RG026i001p00149

Bromwich DH, Rogers AN, Kållberg P, et al (2000) ECMWF Analyses and Reanalyses Depiction of ENSO Signal in Antarctic Precipitation*. J Clim 13:1406-1420. doi: 10.1175/1520-0442(2000)013<1406:EAARDO>2.0.CO;2

Bromwich DH, Weaver CJ (1983) Latitudinal displacement from main moisture source controls $\delta 180$ of snow in coastal Antarctica. Nature 301:145-147.

Ciasto LM, Simpkins GR, England MH (2014) Teleconnections between Tropical Pacific SST Anomalies and Extratropical Southern Hemisphere Climate. J Clim 28:56-65. doi: 10.1175/JCLI-D-14-00438.1

Clausen HB, Dansgaard W, Nielsen JO, Clough JW (1979) Surface accumulation on Ross Ice Shelf. Antarct J United States 14:68-74.

Coggins JHJ, McDonald AJ (2015) The influence of the Amundsen Sea Low on the winds in the Ross Sea and surroundings: Insights from a synoptic climatology. J Geophys Res Atmos 120:2167-2189. doi: 10.1002/2014JD022830

Cohen L (2013) Atmospheric variability and precipitation in the Ross Sea region. Victoria University of Wellington

Cohen L, Dea S, Renwick J (2013) Synoptic weather types for the Ross Sea region, Antarctica. J Clim 26:636-649. doi: 10.1175/JCLI-D-11-00690.1 
Connolley WM (1997) Variability in annual mean circulation in southern high latitudes. Clim Dyn 13:745-756. doi: 10.1007/s003820050195

Costanza CA, Lazzara MA, Keller LM, Cassano JJ (2016) The surface climatology of the Ross Ice Shelf Antarctica. Int J Climatol n/a-n/a. doi: 10.1002/joc.4681

Cullather RI, Bromwich DH, Van Woert ML (1996) Interannual variations in Antarctic precipitation related to El Niño-Southern Oscillation. J Geophys Res Atmos 101:19109_ 19118. doi: 10.1029/96JD01769

Dee DP, Uppala SM, Simmons AJ, et al (2011) The ERA-Interim reanalysis: configuration and performance of the data assimilation system. Q J R Meteorol Soc 137:553-597. doi: 10.1002/qj. 828

Deser C, Alexander MA, Xie S-P, Phillips AS (2010) Sea surface temperature variability: Patterns and mechanisms. Ann Rev Mar Sci 2:115-143.

Ding Q, Steig EJ, Battisti DS, Kuttel M (2011) Winter warming in West Antarctica caused by central tropical Pacific warming. Nat Geosci 4:398-403.

Ding Q, Steig EJ, Battisti DS, Wallace JM (2012) Influence of the Tropics on the Southern Annular Mode. J Clim 25:6330-6348. doi: 10.1175/JCLI-D-11-00523.1

Divine D V., Isaksson E, Kaczmarska M, et al (2009) Tropical Pacific - High latitude south Atlantic teleconnections as seen in $\delta 18 \mathrm{O}$ variability in Antarctic coastal ice cores. J Geophys Res Atmos 114:1-14. doi: 10.1029/2008JD010475

Dole RM (1986) The life cycles of persistent anomalies and blocking over the North Pacific. Academic Press

Dole RM, Gordon ND (1983) Persistent anomalies of the extratropical Northern Hemisphere wintertime circulation: Geographical Distribution and Regional Persistence Characteristics. Mon Weather Rev 111:1567-1586. doi: 10.1175/15200493(1986)114<0178:PAOTEN>2.0.CO;2

Emanuelsson BD, Baisden WT, Bertler NAN, et al (2015) High-resolution continuous-flow analysis setup for water isotopic measurement from ice cores using laser spectroscopy. Atmos Meas Tech 8:2869-2883. doi: 10.5194/amt-8-2869-2015

Fan T, Deser C, Schneider DP (2014) Recent Antarctic sea ice trends in the context of Southern Ocean surface climate variations since 1950. Geophys Res Lett 41:2419-2426. doi: 10.1002/2014GL059239

Fogt RL, Jones JM, Renwick J (2012) Seasonal zonal asymmetries in the southern annular mode and their impact on regional temperature anomalies. J Clim 25:6253-6270. doi: 10.1175/JCLI-D-11-00474.1

Fretwell P, Pritchard HD, Vaughan DG, et al (2013) Bedmap2: improved ice bed, surface and thickness datasets for Antarctica. Cryosph 7:375-393. doi: 10.5194/tc-7-375-2013

Gonfiantini R (1978) Standards for stable isotope measurements in natural compounds. Nature 271:534-536.

Goodwin I, de Angelis M, Pook M, Young NW (2003) Snow accumulation variability in Wilkes 
Land, East Antarctica, and the relationship to atmospheric ridging in the $130^{\circ}-170^{\circ} \mathrm{E}$ region since 1930. J Geophys Res Atmos 108:n/a-n/a. doi: 10.1029/2002JD002995

Gregory S, Noone D (2008) Variability in the teleconnection between the El Niño-Southern Oscillation and West Antarctic climate deduced from West Antarctic ice core isotope records. J Geophys Res Atmos 113:n/a-n/a. doi: 10.1029/2007JD009107

Harangozo SA (2004) The impact of winter ice retreat on Antarctic winter sea-ice extent and links to the atmospheric meridional circulation. Int J Climatol 24:1023-1044. doi: $10.1002 /$ joc. 1046

Harangozo SA (2006) Atmospheric circulation impacts on winter maximum sea ice extent in the west Antarctic Peninsula region (1979-2001). Geophys Res Lett 33:n/a-n/a. doi: 10.1029/2005GL024978

Holland PR, Kwok R (2012) Wind-driven trends in Antarctic sea-ice drift. Nat Geosci 5:872875.

Hosking JS, Orr A, Bracegirdle TJ, Turner J (2016) Future circulation changes off West Antarctica: Sensitivity of the Amundsen Sea Low to projected anthropogenic forcing. Geophys Res Lett 43:367-376. doi: 10.1002/2015GL067143

Hosking JS, Orr A, Marshall GJ, et al (2013) The Influence of the Amundsen-Bellingshausen Seas Low on the Climate of West Antarctica and Its Representation in Coupled Climate Model Simulations. J Clim 26:6633-6648. doi: 10.1175/JCLI-D-12-00813.1

Hoskins BJ, McIntyre ME, Robertson AW (1985) On the use and significance of isentropic potential vorticity maps. Q J R Meteorol Soc 111:877-946. doi: 10.1002/qj.49711147002

Jones RW, Renfrew IA, Orr A, et al (2016) Evaluation of four global reanalysis products using in-situ observations in the Amundsen Sea Embayment, Antarctica. J Geophys Res Atmos n/a-n/a. doi: 10.1002/2015JD024680

Karoly DJ (1989) Southern Hemisphere Circulation Features Associated with El Niño-Southern Oscillation Events. J Clim 2:1239-1252. doi: 10.1175/15200442(1989)002<1239:SHCFAW>2.0.CO;2

Kidson JW (1988) Interannual Variations in the Southern Hemisphere Circulation. J. Clim. 1:939-953.

Kreutz KJ, Mayewski PA, Pittalwala II, et al (2000) Sea level pressure variability in the Amundsen Sea region inferred from a West Antarctic glaciochemical record. J Geophys Res Atmos 105:4047-4059. doi: 10.1029/1999JD901069

Küttel M, Steig EJ, Ding Q, et al (2012) Seasonal climate information preserved in West Antarctic ice core water isotopes: relationships to temperature, large-scale circulation, and sea ice. Clim Dyn 39:1841-1857. doi: 10.1007/s00382-012-1460-7

L'Heureux ML, Thompson DWJ (2006) Observed Relationships between the El Niño-Southern Oscillation and the Extratropical Zonal-Mean Circulation. J Clim 19:276-287. doi: 10.1175/JCLI3617.1

Lachlan-Cope T, Connolley W (2006) Teleconnections between the tropical Pacific and the 
Amundsen-Bellinghausens Sea: Role of the El Niño/Southern Oscillation. J Geophys Res Atmos 111:n/a-n/a. doi: 10.1029/2005JD006386

Lachlan-Cope TA, Connolley WM, Turner J (2001) The role of the non-axisymmetric antarctic orography in forcing the observed pattern of variability of the Antarctic climate. Geophys Res Lett 28:4111-4114. doi: 10.1029/2001GL013465

Lau K-M, Sheu P-J, Kang I-S (1994) Multiscale Low-Frequency Circulation Modes in the Global Atmosphere. J Atmos Sci 51:1169-1193. doi: 10.1175/15200469(1994)051<1169:MLFCMI>2.0.CO;2

Lejenäs H (1984) Characteristics of southern hemisphere blocking as determined from a time series of observational data.

Lejenäs H, Økland H (1983) Characteristics of northern hemisphere blocking as determined from a long time series of observational data. Tellus A 35A:350-362. doi: 10.1111/j.16000870.1983.tb00210.x

Liu J, Yuan X, Rind D, Martinson DG (2002) Mechanism study of the ENSO and southern high latitude climate teleconnections. Geophys Res Lett 29:24. doi: 10.1029/2002GL015143

Markle BR, Bertler NAN, Sinclair KE, Sneed SB (2012) Synoptic variability in the Ross Sea region, Antarctica, as seen from back-trajectory modeling and ice core analysis. J Geophys Res Atmos 117:1-17. doi: 10.1029/2011JD016437

Marshall GJ, Stott PA, Turner J, et al (2004) Causes of exceptional atmospheric circulation changes in the Southern Hemisphere. Geophys Res Lett 31:n/a-n/a. doi: 10.1029/2004GL019952

Massom RA, Pook MJ, Comiso JC, et al (2004) Precipitation over the Interior East Antarctic Ice Sheet Related to Midlatitude Blocking-High Activity. J Clim 17:1914-1928. doi: 10.1175/1520-0442(2004)017<1914:POTIEA>2.0.CO;2

Mayewski PA (2005) The International Trans-Antarctic Scientific Expedition (ITASE): An overview. Ann Glaciol 41:180-185.

Mo KC (2000) Relationships between Low-Frequency Variability in the Southern Hemisphere and Sea Surface Temperature Anomalies. J Clim 13:3599-3610. doi: 10.1175/15200442(2000)013<3599:RBLFVI>2.0.CO;2

Mo KC, Ghil M (1987) Statistics and Dynamics of Persistent Anomalies. J Atmos Sci 44:877902. doi: 10.1175/1520-0469(1987)044<0877:SADOPA>2.0.CO;2

Mo KC, Higgins RW (1998) The Pacific-South American Modes and Tropical Convection during the Southern Hemisphere Winter. Mon Weather Rev 126:1581-1596. doi: 10.1175/1520-0493(1998)126<1581:TPSAMA>2.0.CO;2

Mo KC, Paegle JN (2001) The Pacific-South American modes and their downstream effects. Int J Climatol 21:1211-1229. doi: 10.1002/joc.685

Nicolas JP, Bromwich DH (2011) Climate of West Antarctica and influence of marine air intrusions. J Clim 24:49-67. doi: 10.1175/2010JCLI3522.1

Nigro MA, Cassano JJ (2014) Identification of Surface Wind Patterns over the Ross Ice Shelf, 
Antarctica, Using Self-Organizing Maps. Mon Weather Rev 142:2361-2378. doi: 10.1175/MWR-D-13-00382.1

Noone D, Turner J, Mulvaney R (1999) Atmospheric signals and characteristics of accumulation in Dronning Maud Land, Antarctica. J Geophys Res Atmos 104:19191-19211. doi: 10.1029/1999JD900376

O'Kane TJ, Risbey JS, Franzke C, et al (2012) Changes in the Metastability of the Midlatitude Southern Hemisphere Circulation and the Utility of Nonstationary Cluster Analysis and Split-Flow Blocking Indices as Diagnostic Tools. J Atmos Sci 70:824-842. doi: 10.1175/JAS-D-12-028.1

Okumura YM, Schneider D, Deser C, Wilson R (2012) Decadal-Interdecadal Climate Variability over Antarctica and Linkages to the Tropics: Analysis of Ice Core, Instrumental, and Tropical Proxy Data. J Clim 25:7421-7441. doi: 10.1175/JCLI-D-12-00050.1

Oliveira FNM, Carvalho LM V, Ambrizzi T (2014) A new climatology for Southern Hemisphere blockings in the winter and the combined effect of ENSO and SAM phases. Int J Climatol 34:1676-1692. doi: 10.1002/joc.3795

Parish TR, Cassano JJ, Seefeldt MW (2006) Characteristics of the Ross Ice Shelf air stream as depicted Antarctic Mesoscale Prediction System simulations. J Geophys Res Atmos 111:112. doi: 10.1029/2005JD006185

Raphael MN, Marshall GJ, Turner J, et al (2015) The Amundsen Sea Low: Variability, Change and Impact on Antarctic Climate. Bull Am Meteorol Soc 150331122920005. doi: 10.1175/BAMS-D-14-00018.1

Renwick JA (2005) Persistent Positive Anomalies in the Southern Hemisphere Circulation. Mon Weather Rev 133:977-988. doi: 10.1175/MWR2900.1

Renwick JA (2002) Southern Hemisphere Circulation and Relations with Sea Ice and Sea Surface Temperature. J Clim 15:3058-3068. doi: 10.1175/15200442(2002)015<3058:SHCARW>2.0.CO;2

Renwick JA (1998) ENSO-Related Variability in the Frequency of South Pacific Blocking. Mon Weather Rev 126:3117-3123. doi: 10.1175/1520-0493(1998)126<3117:ERVITF>2.0.CO;2

Rodrigues RR, Campos EJD, Haarsma R (2015) The Impact of ENSO on the South Atlantic Subtropical Dipole Mode. J Clim 28:2691-2705. doi: 10.1175/JCLI-D-14-00483.1

Santer BD, Wigley TML, Boyle JS, et al (2000) Statistical significance of trends and trend differences in layer-average atmospheric temperature time series. J Geophys Res Atmos 105:7337-7356. doi: 10.1029/1999JD901105

Schneider DP, Deser C, Fan T (2015) Comparing the Impacts of Tropical SST Variability and Polar Stratospheric Ozone Loss on the Southern Ocean Westerly Winds. J Clim 28:93509372. doi: 10.1175/JCLI-D-15-0090.1

Schneider DP, Noone DC (2007) Spatial covariance of water isotope records in a global network of ice cores spanning twentieth-century climate change. J Geophys Res Atmos 112:n/a-n/a. doi: 10.1029/2007JD008652 
Schneider DP, Okumura Y, Deser C (2012) Observed Antarctic Interannual Climate Variability and Tropical Linkages. J Clim 25:4048-4066. doi: 10.1175/JCLI-D-11-00273.1

Schneider DP, Steig EJ (2002) Spatial and temporal variability of Antarctic ice sheet microwave brightness temperatures. Geophys Res Lett 29:24-25. doi: 10.1029/2002GL015490

Schwierz C, Croci-Maspoli M, Davies HC (2004) Perspicacious indicators of atmospheric blocking. Geophys Res Lett 31:n/a-n/a. doi: 10.1029/2003GL019341

Simmonds I, Jacka TH (1995) Relationships between the Interannual Variability of Antarctic Sea Ice and the Southern Oscillation. Am. Meteorol. Soc. 8:637-647.

Sinclair KE, Bertler NAN, Trompetter WJ, Baisden WT (2012) Seasonality of Airmass Pathways to Coastal Antarctica: Ramifications for Interpreting High-Resolution Ice Core Records. J Clim 26:2065-2076. doi: 10.1175/JCLI-D-12-00167.1

Sinclair MR (1981) Record-High Temperatures in the Antarctic-A Synoptic Case Study. Mon Weather Rev 109:2234-2242. doi: 10.1175/1520-0493(1981)109<2234:RHTITA>2.0.CO;2

Sinclair MR (1996) A climatology of anticyclones and blocking for the Southern Hemisphere. Mon Weather Rev 124:245.

Steig EJ, Mayewski P a, Dixon D a, et al (2005) High-resolution ice cores from USITASE (West Antarctica): development and validation of chronologies and determination of precision and accuracy. Ann Glaciol Vol 41, 2005 41:77-84.

Thomas ER, Bracegirdle TJ (2009) Improving ice core interpretation using in situ and reanalysis data. J Geophys Res Atmos 114:1-8. doi: 10.1029/2009JD012263

Thompson DWJ, Solomon S (2002) Interpretation of Recent Southern Hemisphere Climate Change. Science (80- ) 296:895-899.

Thompson DWJ, Wallace JM (2000) Annular Mode in the Extratropical Circulation. Part I : Month-to-Month Variability. 13:1000-1016. doi: http://dx.doi.org/10.1175/15200442(2000)013<1000:AMITEC>2.0.CO;2

Tibaldi S, Tosi E, Navarra A, Pedulli L (1994) Northern and Southern Hemisphere Seasonal Variability of Blocking Frequency and Predictability. Mon Weather Rev 122:1971-2003. doi: 10.1175/1520-0493(1994)122<1971:NASHSV>2.0.CO;2

Trenberth KE, Branstator GW, Karoly D, et al (1998) Progress during TOGA in understanding and modeling global teleconnections associated with tropical sea surface temperatures. J Geophys Res Ocean 103:14291-14324. doi: 10.1029/97JC01444

Trenberth KF, Mo KC (1985) Blocking in the Southern Hemisphere. Mon Weather Rev 113:321. doi: 10.1175/1520-0493(1985)113<0003:BITSH>2.0.CO;2

Turner J (2004) The El Niño-Southern Oscillation and Antarctica. Int J Climatol 24:1-31. doi: 10.1002/joc.965

Turner J, Hosking JS, Marshall GJ, et al (2015) Antarctic sea ice increase consistent with intrinsic variability of the Amundsen Sea Low. Clim Dyn 1-12. doi: 10.1007/s00382-0152708-9 
Turner J, Phillips T, Hosking JS, et al (2013) The Amundsen Sea low. Int J Climatol 33:18181829. doi: $10.1002 /$ joc. 3558

van Loon H, Shea DJ (1987) The Southern Oscillation. Part VI: Anomalies of Sea Level Pressure on the Southern Hemisphere and of Pacific Sea Surface Temperature during the Development of a Warm Event. Mon Weather Rev 115:370-379. doi: 10.1175/15200493(1987)115<0370:TSOPVA>2.0.CO;2

Walsh KJE, Simmonds I, Collier M (2000) Sigma-coordinate calculation of topographically forced baroclinicity around Antarctica. Dyn Atmos Ocean 33:1-29. doi: http://dx.doi.org/10.1016/S0377-0265(00)00054-3

Wiedenmann JM, Lupo AR, Mokhov II, Tikhonova EA (2002) The Climatology of Blocking Anticyclones for the Northern and Southern Hemispheres: Block Intensity as a Diagnostic. J Clim 15:3459-3473. doi: 10.1175/1520-0442(2002)015<3459:TCOBAF>2.0.CO;2

Yuan X, Li C (2008) Climate modes in southern high latitudes and their impacts on Antarctic sea ice. J Geophys Res Ocean 113:1-13. doi: 10.1029/2006JC004067

Yuan X, Martinson DG (2000) Antarctic Sea Ice Extent Variability and Its Global Connectivity. J Clim 13:1697-1717. doi: 10.1175/1520-0442(2000)013<1697:ASIEVA>2.0.CO;2 


\subsection{Supplementary material}

\subsubsection{Supplementary figures}
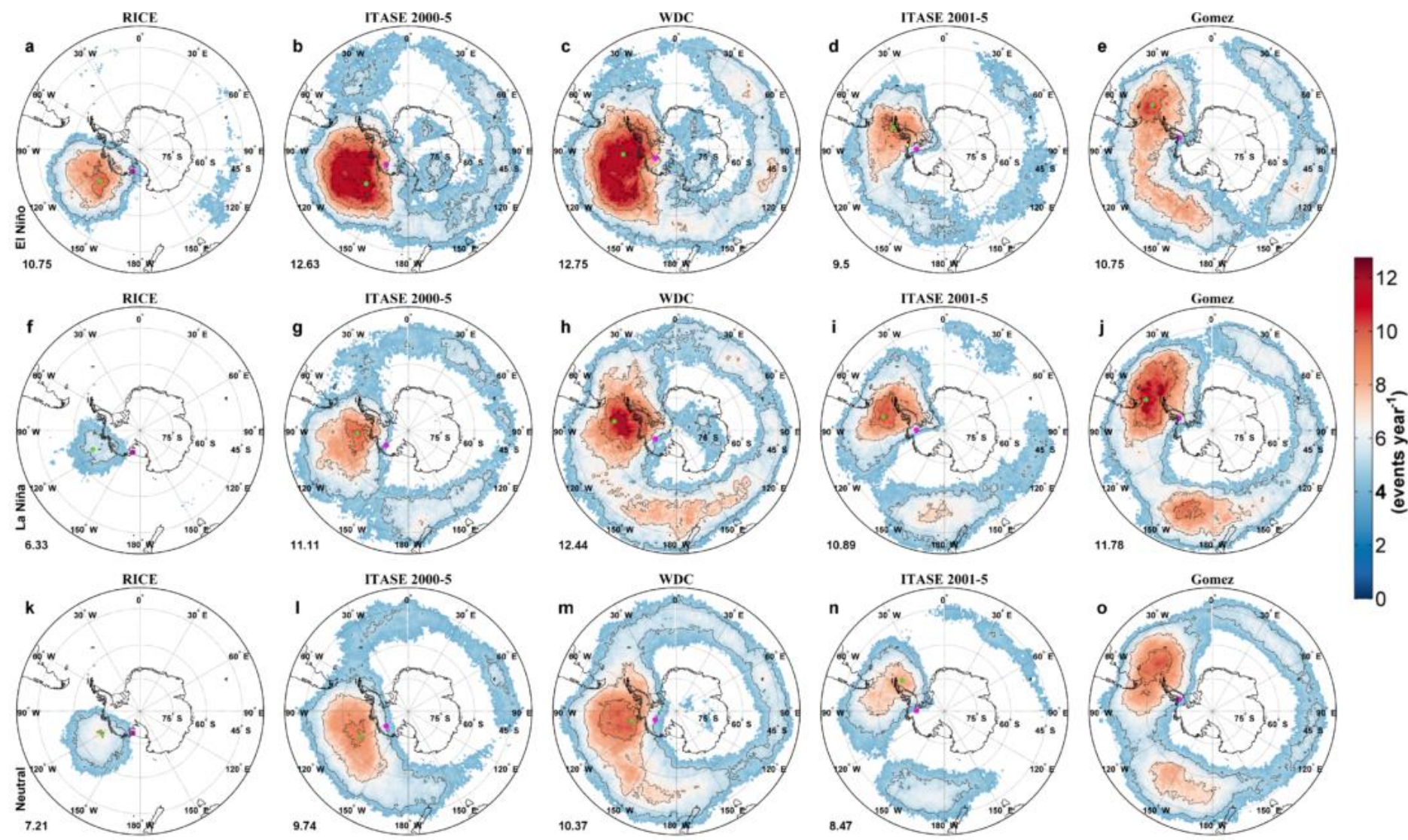

Fig. S3.1 Anticyclonic frequency (PPAp, shading, events year ${ }^{-1}$ ) composite plots, (a-d) for El Niño years (Table 3.2). For WA sites: (a) RICE, (b) ITASE 2000-5, (c) WDC and (d) ITASE 2001-5 (> 50 \%, 100 m, 3 days; 1979-2014). (e-h) same as (a-d), but for La Niña negative years. (i-l) same as $(\mathrm{a}-\mathrm{d})$, but for ENSO neutral conditions (remaining years). Core site locations are indicated by magenta dots. Contour increments (thin black line) are 2 events per year, starting at 4 . 

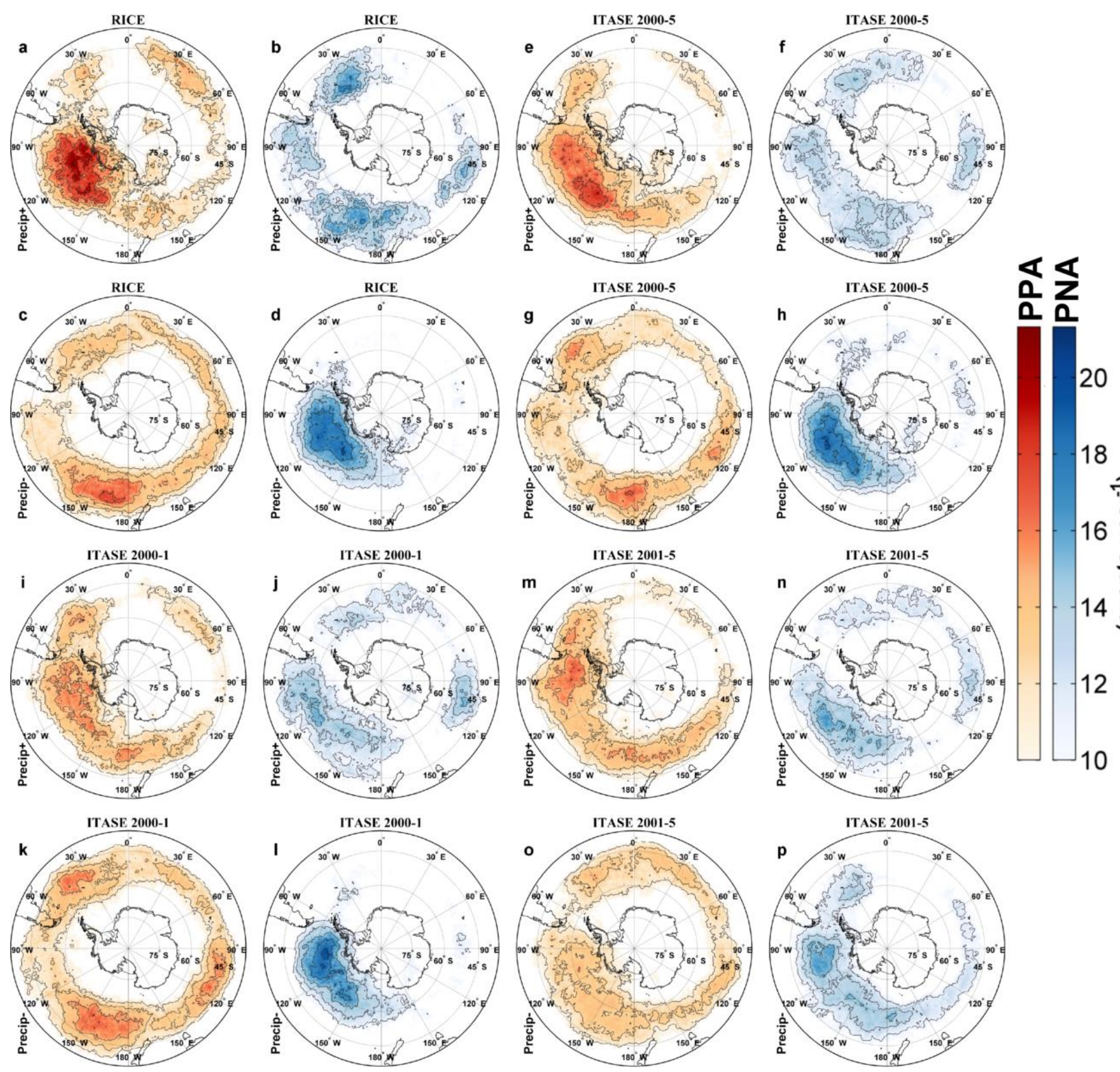

Fig. S3.2 Anticyclone composites (PPA, 3 days, $100 \mathrm{~m}$, red shading) and cyclone (PNA, 3 days, $-100 \mathrm{~m}$, blue shading) plots for high and low precipitation years for (a-d) RICE, (e-h) ITASE 2000-5, (i-l) ITASE 2000-1, and (m-p) ITASE 2001-5. Contour increments (thin black lines) are 2 events per year, starting at 10 . 


\subsubsection{Supplementary tables}

Table S3.1 Overview of Roosevelt Island ice core and snow pit records ${ }^{*}$

\begin{tabular}{|c|c|c|c|c|c|c|}
\hline Site & Latitude $(\mathrm{N})$ & Longitude (E) & $\begin{array}{c}\text { Distance from main } \\
\text { RICE core }(\mathrm{m})\end{array}$ & $\begin{array}{l}\text { Depth from } \\
\text { surface }(m)\end{array}$ & $\begin{array}{c}\text { Composite } \\
\text { isotope record }\end{array}$ & $\begin{array}{c}\text { Density } \\
\text { profile }\end{array}$ \\
\hline RICE Deep & -79.3628 & -161.7011 & - & $763(1)$ & $\mathrm{x}$ & $\mathrm{x}$ \\
\hline $12 / 13 \mathrm{~B}$ & -79.3621 & -161.6984 & 93 & 19.3 & $\mathrm{x}$ & \\
\hline $11 / 12 \mathrm{~A}$ & -79.36344 & -161.70399 & 95 & 9.96 & & $\mathrm{x}(2)$ \\
\hline $11 / 12 \mathrm{~B}$ & -79.36344 & -161.70399 & 95 & 10.77 & & $x(2)$ \\
\hline $11 / 12 \mathrm{C}$ & -79.36331 & -161.70572 & 114 & 10.36 & & $x(2)$ \\
\hline $10 / 11 \mathrm{~A}$ & -79.36396 & -161.70631 & 170 & 9.31 & & \\
\hline 10/11 B & -79.36272 & -161.7136 & 261 & 10.41 & & $x(2)$ \\
\hline RI 74/75 $51 \mathrm{~m}$ & -79.3667 & -161.6667 & 825 & 51 & & \\
\hline RI 74/75 $11 \mathrm{~m}(3)$ & - & - & - & 10.68 & & \\
\hline 10/11 4 m snow pit (4) & - & - & - & 4 & & $\mathrm{x}$ \\
\hline $11 / 123 \mathrm{~m}$ snow pit & -79.36344 & -161.70399 & 95 & 3 & & \\
\hline
\end{tabular}

"Footnotes: 1. Isotope and snow accumulation data to $38 \mathrm{~m}$ depth below the surface is used in this study. 2. Density measured using Dual Energy X-ray Absorptiometry (DEXA). 3. Retrieved from the Roosevelt Island summit (Clausen et al. 1979). 4. Source Cohen, (2013). 


\title{
Chapter 4: Central tropical Pacific ENSO variability preserved in water stable isotopes from the Roosevelt Island Climate Evolution (RICE) ice core, Antarctica
}

\author{
B. D. Emanuelsson ${ }^{1,2}$, N. A. N. Bertler ${ }^{1,2}$, B. R. Markle ${ }^{3}$, W. T. Baisden ${ }^{2}$,
}

J. A. Renwick ${ }^{4}$, E. D. Keller ${ }^{2}$ and P. D. Neff ${ }^{1,2, *}$

This chapter has been prepared for submission to Journal of Geophysical Research: Atmospheres.

[1] Antarctic Research Centre, Victoria University of Wellington, P.O. Box 600, Wellington 6140, New Zealand $\}$

[2]\{National Isotope Centre, GNS Science, 30 Gracefield Road, Lower Hutt 5010, New Zealand

[3] \{ Quaternary Research Center and Department of Earth and Space Sciences, University of Washington, Seattle, WA 98 195, USA

[4]\{School of Geography, Environment and Earth Sciences, Victoria University of Wellington, P.O. Box 600, Wellington 6140, New Zealand

[*]\{Present address: Department of Earth and Environmental Sciences, University of Rochester, Rochester, New York 14627, USA\}

Correspondence to: B. D. Emanuelsson (D.Emanuelsson@gmail.com)

Index Terms: 0724 Cryosphere: ice core (4932), 9310 Information related to geographic region: Antarctica (4207), 1616 Global change: climate variability (1635, 3305, 3309, 4215, 4513), 1610 Global change: Atmosphere (0315, 0325), 3309 Meteorology and Atmospheric Dynamics: Climatology (1620); 3349

Key Words: Central Pacific ENSO variability, decadal-scale Pacific variability, West Antarctic climate, PSA wave train connections, water isotopes, ice cores. 


\title{
Key Points:
}

- The RICE water isotope record provides a proxy that captures the intrinsic interannual variability of central-Pacific ENSO and decadal-scale tropical Pacific ENSO-like variability

- The destructive dampening SST effect between the PSA patterns seesaw SST footprints is pronounced over the southern hemisphere Pacific sector in austral summer, which in combination with a weaker sub-tropical jet can explain the weak extratropical summer ENSO signal

- A tropical Pacific SST reconstruction using RICE isotopes can potentially provide a record that allows for examination of intrinsic decadal-scale central-tropical Pacific climate variability and its extratropical impact

\begin{abstract}
Here we examine the water-isotope $(\delta \mathrm{D})$ data from a newly retrieved RICE ice core from Roosevelt Island, Antarctica. RICE $\delta$ D provides a proxy record, which captures the central tropical Pacific ENSO variability (the significant $\delta$ D-SST correlation pattern contain the Niño-4 SST region) and its influence on Antarctic climate variability, which is projected upon the Amundsen Sea region via Pacific-South American patterns (PSA) teleconnections. On interannual and seasonal time scales, the RICE $\delta$ D variability is well-explained by the PSA teleconnections and their interactions over the Southern Hemisphere Pacific sector. The influence from PSA2 on $\delta \mathrm{D}$ is strong during the beginning of the year (particularly in summer; December-February, DJF), whereas the PSA1 influence is strong during the latter part of the year, peaking in spring (September-November, SON). The destructive dampening SST effect between the PSA patterns seesaw footprints is pronounced over the southern hemisphere Pacific sector in austral summer, which in combination with a weaker sub-tropical jet can explain the weak extratropical summer ENSO signal. The isotope record preserves tropical Pacific ENSOlike interdecadal variability, particularly the central-Pacific ENSO and the Pacific-wide Interdecadal Pacific Oscillation (IPO) variability. On decadal-scales, the influence on $\delta \mathrm{D}$ appears to be primarily modulated by the central-Pacific ENSO and the Southern Annular Mode (SAM). ENSO appears to provide a "constant" signal, away from IPO transitions, and the low-frequency tropical Pacific influence on RICE $\delta \mathrm{D}$ appears to be modulated by an active and non-active
\end{abstract}


influence from SAM during IPO+ and IPO- conditions, respectively. When the correlation with SAM is strong during the IPO+ phase, the RICE $\delta$ D correlation with IPO and Niño-4 is reduced. The influence from SAM during IPO+ has increased congruent with the positive trend in SAM. A tropical Pacific SST reconstruction using RICE $\delta$ D has the potential to extending the currently available observational data sets, allowing for examination of intrinsic decadal-scale variability of central-tropical Pacific climate and its extratropical impact.

\subsection{Introduction}

El Niño-Southern Oscillation (ENSO) is the leading mode of oceanic and atmospheric variability over the tropical Pacific and is considered the dominant source of global climate variability on interannual to decadal time scales [Trenberth et al., 1998]. ENSO has a strong influence on the Southern Hemisphere (SH) extratropics, including Antarctica, through the excitation of large-scale atmospheric teleconnections [e.g., Karoly, 1989; Mo, 2000; Turner, 2004]. It is well known that positive and negative equatorial Pacific sea surface temperature (SST) anomalies are associated with El Niño and La Niña, respectively [Trenberth, 1997; Trenberth et al., 1998]. Positive SST anomaly patterns in the central tropical Pacific can result in deep atmospheric convection and force Rossby wave initiation through anomalous high-level divergent flow [Gill, 1980; Hoskins and Karoly, 1981; Lachlan-Cope and Connolley, 2006; Trenberth et al., 2014]. The SST anomaly pattern [Lachlan-Cope and Connolley, 2006], magnitude of the anomalies [Su and Jiang, 2013], tropical rainfall [Trenberth et al., 2014] and seasonality [Lee et al., 2009; Ciasto et al., 2014] are important for the initiation of the PacificSouth American patterns (PSA) wave train responses. The variability of the PSA wave train response is influenced by the strength of the jet streams and also from zonal winds in the extratropical Pacific, which in turn are linked to other climate modes, such as the Southern Annular Mode (SAM) [Turner, 2004; Bertler et al., 2006a, 2006b; Fogt and Bromwich, 2006; Lachlan-Cope and Connolley, 2006]. The PSA1 and PSA2 patterns are defined as second and third EOF of the SH extratropical geopotential height field [Kidson, 1988; Mo and Higgins, 1998; Mo, 2000]. The PSA1 wave train propagates in a poleward and eastward "great circle" arch from the tropical central Pacific (CP) [Mo and Ghil, 1987; Karoly, 1989; Mo and Higgins, 1998; Mo and Paegle, 2001; Ding et al., 2012]. The PSA wave trains' southernmost centers are located in the Ross and Amundsen-Bellingshausen Sea (ABS) region, then they continue 
northward, east of South America in the South Atlantic [Kidson, 1988; Lachlan-Cope and Connolley, 2006]. This explains the strong climatic influence of the tropical Pacific on Antarctica [Turner, 2004; Ding et al., 2011, 2012; Schneider et al., 2015]. The PSA1 connection is commonly regarded as being associated with ENSO [Karoly, 1989; Trenberth et al., 1998; Mo, 2000; Alexander et al., 2002; Schneider et al., 2011], Pacific Decadal Oscillation (PDO, the first EOF of SST in the North Pacific Ocean) [Trenberth et al., 2014; Schneider et al., 2015], and is in part also influencing the variability of SAM [L'Heureux and Thompson, 2006; Ding et al., 2012]. PSA1 can be viewed as an extension of ENSO into the SH [Mo, 2000]. However, it is only in spring that the PSA1 wave train displays an established connection with the tropical Pacific [Cazes-Boezio et al., 2003]. PSA1 displays a broad-scale Pacific sector impact. In comparison, PSA2 has a higher latitude initiation (associated with the mid-latitude jet [Ding et $a l ., 2012])$ and a western Pacific and hemispheric-wide impact [Kidson, 1988; Mo and Higgins, 1998; Mo and Paegle, 2001; Marshall and Thompson, 2016]. The PSA patterns are associated with significant impacts on West Antarctic (WA) surface climate, e.g. sea ice concentration (SIC) and air temperature anomalies [Schneider et al., 2011; Marshall and Thompson, 2016]. Recent studies indicate that western and central tropical Pacific SST forcing explains a large part of WA climate variability [Ding et al., 2011, 2012; Schneider et al., 2011; Ciasto et al., 2014; Rodrigues et al., 2015]. Rossby wave excitation is more sensitive to SST anomalies in the central tropical Pacific, where SST anomalies associated with deep atmospheric convection are easily attained [Ciasto et al., 2014].

The SAM is the primary mode of the large-scale atmospheric variability in the SH and has a strong climatic impact on high-latitude extratropical regions. SAM is often defined as the leading empirical orthogonal function (EOF) of the SH sea-level pressure or geopotential height fields [Rogers and van Loon, 1982; Thompson and Wallace, 2000; Ding et al., 2012] and is characterized by a quasi-zonally symmetric pattern with height anomalies of opposite signs over the mid-latitudes $\left(\sim 40^{\circ} \mathrm{S}\right)$ and high-latitudes $\left(\sim 65^{\circ} \mathrm{S}\right)$. Research efforts have emphasized the role of the Amundsen Sea Low (ASL), particularly for WA and the Antarctic Peninsula climate variability [Hosking et al., 2013; Turner et al., 2013; Raphael et al., 2015]. The ASL is a quasistationary low-pressure cell with large geopotential height variability located in the ABS and Ross Sea region [Cullather et al., 1996; Turner et al., 2013; Raphael et al., 2015]. The state of the ASL is modulated by a strong influence from SAM and from tropical Pacific teleconnections 
[Turner, 2004; Turner et al., 2013]. The ASL is an area characterized by a high density of synoptic and sub-synoptic scale cyclonic low-pressure systems [Hosking et al., 2013] and is a favored region for blocking [e.g., Turner, 2004; Renwick, 2005]. Furthermore, the ASL is the deepest of three sea level pressure cells that are present around Antarctica (in a wavenumber-3 pattern [e.g., Raphael, 2004]), imposing a meridional flow component on the dominant zonal flow [Hosking et al., 2013; Raphael et al., 2015]. This diversion of flow impacts Antarctic heat and moisture transport and sea ice distribution [Hosking et al., 2013]. ABS low-frequency anticyclones impede the westerly zonal flow, causing meridional flow conditions, which result in WA air mass intrusions and subsequent precipitation (Chapter 3).

SH climate is associated with large variability which acts on various time scales [e.g., Deser et al., 2004; Schneider et al., 2011; Okumura et al., 2012; Woollings et al., 2014]. Existing observations in Antarctica are spatially sparse, particularly in the central Pacific sector, and only extend back to 1979 (the onset of the satellite era) and at some particular sites to 1957. It is therefore important not to solely base our understanding on relatively short reanalysis data sets. Prior to $\sim 1950$, proxy records provide the only information for the high-latitude $\mathrm{SH}$, for natural baselines to assess trends and understand low-frequency variability [Schneider and Noone, 2007; Mulvaney et al., 2012; Okumura et al., 2012; Steig et al., 2013; Thomas et al., 2013]. This study, presents an analysis of the climate signal preserved in the water stable isotope records from a newly obtained, high-resolution ice core drilled as part of the Roosevelt Island Climate Evolution (RICE) project $\left(79.36^{\circ} \mathrm{S}, 161.70^{\circ} \mathrm{W}, 560 \mathrm{~m}\right.$ a.s.l.; Figure 4.1$)$. The $763 \mathrm{~m}$ ice core was drilled to bedrock over two field seasons (2011-2012 and 2012-2013). Roosevelt Island is a grounded coastal ice rise, situated within the northeastern margin of the Ross Ice Shelf (Figure 4.1).

To support the interpretation of the deeper part of the ice core record: (1) we characterize drivers of RICE isotope variability using modern satellite-era reanalysis and SST data,; (2) we assess the influence of the tropical Pacific and SAM on SH high-latitude, and whether the variability of these climate modes is captured in the RICE isotope record; (3) we assess how the seasonality of the modes and teleconnections affects the isotopic record; (4) we assess whether decadal-scale Pacific climate variability is preserved; and (5) lastly, we assess whether there are any significant modern-era trends in the records. 


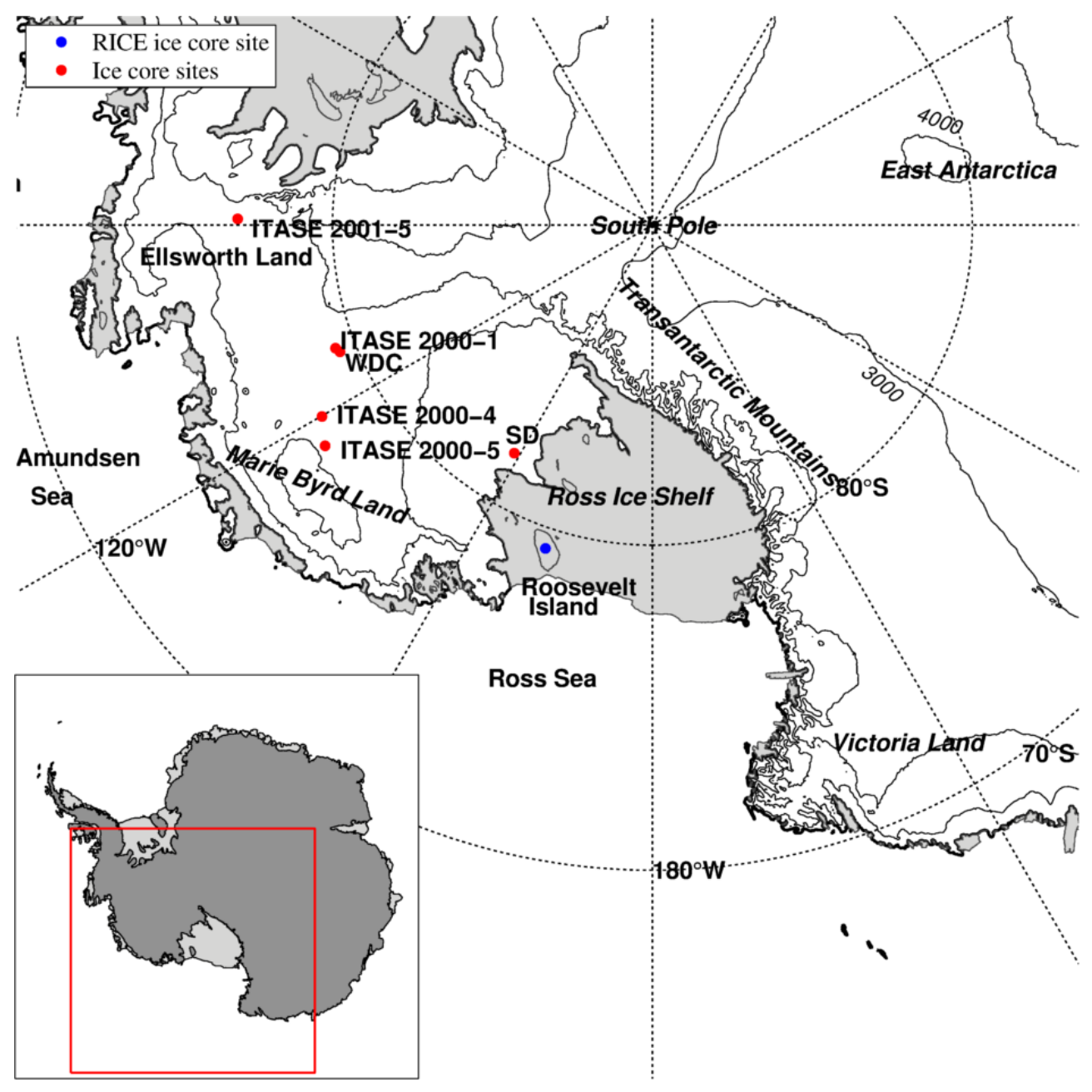

Figure 4.1. Antarctica location map. Roosevelt Island ice core drill site (RICE, blue dot); International Trans-Antarctic Scientific Expedition, ITASE; WAIS Divide Ice Core, WDC; and the Siple Dome, SD, ice core sites (red dots). Contours (black thin lines) with 1,000 m spacing indicate elevation above sea level.

\subsection{Data and Methods}

In this study, we present and interpret the water-isotope $(\delta \mathrm{D})$ data from the upper $38 \mathrm{~m}$ of the RICE ice core (1900-2009).

\subsubsection{Reanalysis and Observational Data}

We use data from the European Center for Medium-Range Weather Forecasts (ECMWF) Interim ReAnalysis (ERA-Interim) data set [Dee et al., 2011] to determine relationships with the annually averaged RICE isotope record (1979-2009). The ECMWF ERA-Interim data sets are considered the most reliable reanalysis products for Antarctic climate [Bracegirdle and Marshall, 2012; Jones et al., 2016]. Reliable data are available for the modern-satellite era 
beginning in 1979 [Bromwich et al., 2007]. Additionally, SST and sea ice concentration (SIC) data from the Hadley Centre Sea Ice and Sea Surface Temperature data sets (HadISST v. 1.1) [Rayner et al., 2003] are employed. Annually and seasonally averaged 500-hPa geopotential height fields (z500), meridional and zonal winds (v850, u850), SST and SIC are used for correlations with the RICE isotope record. Annual averages are calculated from monthly ERAInterim $\left(0.75^{\circ} \times 0.75^{\circ}\right)$ and $\operatorname{HadISST}\left(1.0^{\circ} \times 1.0^{\circ}\right)$ data. We limit the interannual spatial SST analysis to the 1950-2009 period because: (1) SST are less well-constrained by observations (particularly in the SH) prior to this date [Deser et al., 2010b; Fan et al., 2014], and (2) dating uncertainty during the early part of the record, when the dating is less well-constrained, might not allow for interannual correlations.

All data are detrended before linear Pearson's correlation coefficients $(r)$ are calculated. The significance level $(p)$ of the correlations account for autocorrelation by reducing the degrees of freedom, using the quotient $N=n\left(1-r_{1} r_{2}\right) /\left(1+r_{1} r_{2}\right)$, where $n$ is the number of timesteps correlated, $r_{i}$ is the lag-1 autocorrelation of the time series $i$, and $N$ is the adjusted degrees of freedom [Santer et al., 2000]. Linear trends and regressions are calculated using the method of least squares and their statistical significance is determined using $t$ statistics and accounting for serial autocorrelation. Results are considered statistically significant if there is less than a 5\% chance that they could arise by chance $(p<0.05)$. All time series that are shown as anomalies were standardized to have a zero mean and unit variance of one, by subtracting the mean and dividing by the standard deviation.

\subsubsection{RICE Accumulation Record}

A composite density profile was generated from several RICE cores for the top $8.6 \mathrm{~m}$, as no snow and ice density measurements were available from the 12/13 B firn core. Density measurements from the main deep RICE core were solely used below $8.6 \mathrm{~m}$, which is the depth below the snow surface that the deep RICE ice core record begins. All the firn cores $(10 / 11 \mathrm{~B}$, 11/12 A, 11/12 B, 11/12 C, and 10/11 4 m snow pit) that were used for the composite density profile were retrieved in the proximity of the main RICE drill site (261 $\mathrm{m}$ or closer to the main RICE core, Table 4.1). The RICE accumulation record was first corrected for ice thinning using the Nye model, which assumes linear vertical strain rates [Nye, 1963]. Then we use the calculated initial layer thickness record and the composite density profile to determine annual 
snow accumulation rates in $\mathrm{cm}$ water equivalent ( $\mathrm{cm}$ w.e.). The annual average snow accumulation rate is $21.54 \pm 6.5 \mathrm{~cm}$ w.e. (mean \pm 1 standard deviation $(\sigma) ; 1900-2009$, Figure 4.2a).

Table 4.1. Overview of Roosevelt Island ice core and snow pit records ${ }^{a}$

\begin{tabular}{|c|c|c|c|c|c|c|}
\hline Site & Latitude $(\mathrm{N})$ & Longitude (E) & $\begin{array}{l}\text { Distance from main } \\
\text { RICE core }(\mathrm{m})\end{array}$ & $\begin{array}{l}\text { Depth from } \\
\text { surface }(\mathrm{m})\end{array}$ & $\begin{array}{c}\text { Composite } \\
\text { isotope record }\end{array}$ & $\begin{array}{c}\text { Density } \\
\text { profile }\end{array}$ \\
\hline RICE Deep & -79.3628 & -161.7011 & - & $763(1)$ & $\mathrm{x}$ & $\mathrm{x}$ \\
\hline $12 / 13 \mathrm{~B}$ & -79.3621 & -161.6984 & 93 & 19.3 & $\mathrm{x}$ & \\
\hline $11 / 12 \mathrm{~A}$ & -79.36344 & -161.70399 & 95 & 9.96 & & $x(2)$ \\
\hline $11 / 12 \mathrm{~B}$ & -79.36344 & -161.70399 & 95 & 10.77 & & $x(2)$ \\
\hline $11 / 12 \mathrm{C}$ & -79.36331 & -161.70572 & 114 & 10.36 & & $x(2)$ \\
\hline $10 / 11 \mathrm{~A}$ & -79.36396 & -161.70631 & 170 & 9.31 & & \\
\hline $10 / 11 \mathrm{~B}$ & -79.36272 & -161.7136 & 261 & 10.41 & & $x(2)$ \\
\hline RI 74/75 $51 \mathrm{~m}$ & -79.3667 & -161.6667 & 825 & 51 & & \\
\hline RI 74/75 11 m(3) & - & - & - & 10.68 & & \\
\hline 10/11 4 m snow pit (4) & - & - & - & 4 & & $\mathrm{x}$ \\
\hline $11 / 123 \mathrm{~m}$ snow pit & -79.36344 & -161.70399 & 95 & 3 & & \\
\hline
\end{tabular}

${ }^{a}$ Footnotes: 1. Isotope and snow accumulation data to $38 \mathrm{~m}$ depth below the surface are used in this study. 2. Density measured using Dual Energy X-ray Absorptiometry (DEXA). 3. Retrieved from the Roosevelt Island summit [Clausen et al., 1979]. 4. Source Cohen, [2013].

\subsubsection{RICE Water Stable Isotope Record}

We investigate the isotope signal from a $19.4 \mathrm{~m}$ firn core RICE 12/13 B retrieved at the Roosevelt Island summit $\left(79.362^{\circ} \mathrm{S}, 161.698^{\circ} \mathrm{W}, 560 \mathrm{~m}\right.$. a.s.1.). The $12 / 13 \mathrm{~B}$ firn core was drilled $93 \mathrm{~m}$ from the main RICE drill site (Table 4.1). We exclude the top $1.86 \mathrm{~m}$ of the firn core record due to the poor core quality of un-compacted snow. The measurement of low-density firn is challenging on a continuous-flow analysis (CFA) setup. Additionally, we use a composite isotope record comprised of the main deep RICE ice core record $\left(79.363^{\circ} \mathrm{S}, 161.701^{\circ} \mathrm{W}, 560 \mathrm{~m}\right.$. a.s.1., starting at $8.6 \mathrm{~m}$ below the surface) and the 12/13 B firn core. The combined isotope record spans the 1900-2009 period (Figure 4.2b). The two cores overlap between 1991 (8.6 m) and 1963 (19.4 m). 

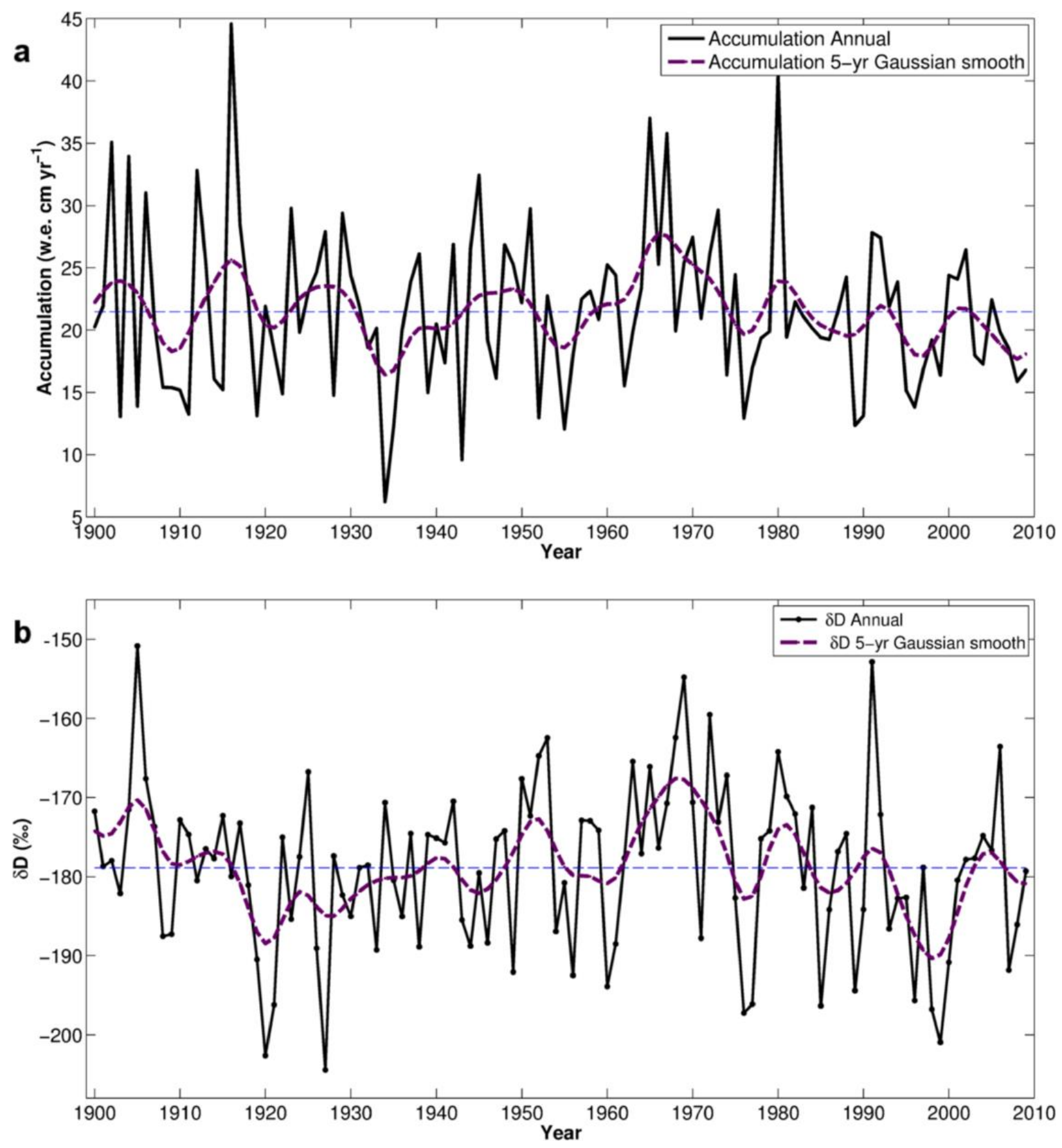

Figure 4.2. The RICE (a) annual snow accumulation record (1900-2009; black line) and (b) annual average of the $\delta \mathrm{D}$ (1900-2009; black line). The purple dashed lines depict 5-year Gaussian smoothing of the annual data and the blue dashed lines indicate the average of the annual means.

The $\delta$-notation is the common way of representing the abundance of rare isotopes, as a deviation from a reference ratio: $\delta=1000 \mathrm{x}$ [R/R $\left.\mathrm{R}_{\mathrm{V}-\mathrm{smow}}-1\right]$ (given in per mil, \%), where $\mathrm{R}$ and $\mathrm{R}_{\mathrm{V}-\mathrm{S} M O w}$ are the ratio between rare and abundant isotopes $\mathrm{R}=\mathrm{n}\left({ }^{18} \mathrm{O}\right) / \mathrm{n}\left({ }^{16} \mathrm{O}\right)$, or $\mathrm{R}=\mathrm{n}(\mathrm{D}) / \mathrm{n}(\mathrm{H})$ in 
the sample and in V-SMOW, respectively. The RICE water stable isotope records $\left(\delta \mathrm{D}\right.$ and $\left.\delta^{18} \mathrm{O}\right)$ were measured on a CFA setup using a Los Gatos Research (LGR) Isotope Water Analyzer (IWA-35EP) [Emanuelsson et al., 2015; Chapter 2]. Internal standards calibrated to the Vienna Standard Mean Ocean Water/Standard Light Antarctic Precipitation (VSMOW-SLAP) scale [Gonfiantini, 1978] were used to calibrate the $\delta$-records. The high-resolution $\delta \mathrm{D}$ and $\delta^{18} \mathrm{O}$ are highly correlated $(r=0.986, p<0.001,1900-2009)$ and have a $\left(\delta \mathrm{D} / \delta^{18} \mathrm{O}\right)$ slope of 8.15 and intercept of $10.17 \%$. The mean of the annual average $\delta \mathrm{D}$ record is $-178.9 \pm 10.39 \%$ (mean \pm $1 \sigma ; 1900-2009$, Figure 4.2b). The peak uncertainty at $1.2 \mathrm{~h}$ (the average middle point between CFA calibrations) is $0.13 \%$ and $0.17 \%$ for $\delta \mathrm{D}$ and $\delta^{18} \mathrm{O}$, respectively [Emanuelsson et al., 2015]. The RICE $\delta$ D record is used due to its relatively higher analytical certainty [Emanuelsson et al., 2015]. However, identical correlation patterns are obtained with $\delta^{18} \mathrm{O}$ and thus the conclusions presented here are not dependent on which isotope is employed.

We calculate the RICE $\delta$ D mean diffusion-length [Johnsen et al., 2000; Küttel et al., 2012] to 2.95 months, which provides a measure of the time period over which smoothing of the $\delta \mathrm{D}$ record occurs in the firn. The RICE $\delta \mathrm{D}$ diffusion-length indicates that a seasonal signal is preserved in the core. Due to the high intra-annual precipitation variability (Figure S4.1, in the supplementary material) we argue that the method of linear interpolation between age-markers to obtain sub-annual $\delta \mathrm{D}$ averages is unsuitable for the RICE $\delta \mathrm{D}$ record. Additionally, we expect that low snow accumulation years will be more sensitive to diffusion over the annual layer depths for $\delta \mathrm{D}$. For these reasons, we focus our investigation on signals at an annual resolution. The RICE $\delta$ D high-resolution data sets [Emanuelsson et al., 2015] are taken advantage of when constraining the annual averages. For example, on average, $814 \delta \mathrm{D}$ measurements are used per year for the 12/13 B core annual averages (1963-2012). An additional measure of the time scale of variability that is preserved in the $\delta \mathrm{D}$ record is provided by the 1-year lag autocorrelation of the annually averaged $\delta$ D record (1900-2009). The 0.28 1-year lag autocorrelation value indicates that RICE $\delta$ D can resolve interannual climate variability. The RICE $\delta \mathrm{D}$ autocorrelation is of similar magnitude as for western WA $\delta$-records (e.g. 0.24 and 0.25 for ITASE 2000-5 and 2000-1 records (1900-2000), respectively) and lower than the Siple Dome A ( 0.35, [Okumura et al., 2012]) record. For East Antarctic sites with low snow accumulation the autocorrelation can exceed 0.4, which indicates that the interannual signal is not preserved at these sites [Okumura et al., 2012]. We also note that even though snow accumulation is highly variable, 
only during one year (1934) does the accumulation rate not exceed $10 \mathrm{~cm}_{\text {year }}{ }^{-1}$, which is considered to be a general accumulation limit for preservation of interannual Antarctic water isotopic signatures [Okumura et al., 2012; Schneider et al., 2012]. Although the RICE record is characterized by a generally high annual snow accumulation rate of $21.54 \mathrm{~cm}$ water equivalent (w.e.) year ${ }^{-1}$ (1900-2009), we observe high snow accumulation variability ( \pm 1 standard deviation: $\pm 6.5 \mathrm{~cm}$ w.e. year). The shorter (1979-2014) ERA-Interim precipitation record shows corresponding high variability of $28.2 \pm 8.8$ (mean \pm 1 standard deviation) $\mathrm{cm}$ w.e. year ${ }^{-1}$. There is a conception that sites with high and even annual snow accumulation rates make for "good" ice core sites as these sites will be easy to date. However, in term of sites that preserve climate variability (e.g. ENSO), variable accumulation rates can be an indication that moisture transport to these sites differ between the polarity phases of the climate modes and thus an indication that a climate signal is preserved for both accumulation and isotope ratios.

The apparent lack of seasonal isotopic signal for some years (Figure 1.13b), is partly attributed to variable snowfall rates and effects from diffusion, but also importantly is from the influence of Amundsen Sea atmospheric conditions on the Roosevelt Island region, which are characterized by large geopotential height variability [Connolley, 1997; Ding et al., 2012]. The isotope-signal during individual years can therefore deviate significantly from the mean-seasonal cycle. The loss of amplitude of the seasonal signal from diffusion over time can be observed in Figure $1.14 \mathrm{~b}$ where the $74 / 75$ core and the recently drilled cores are matched. However, diffusion does not have a marked impact on the annual averages. In addition to the evidence presented above (the diffusion length and the 1-year-lag autocorrelation), the annual data does not show a marked reduction in amplitude over time (Figure 4.2b). The standard deviation for the first part of the record is 9.60\% (1900-1954) and the latter part has a standard deviation of 11.2\%o (1955-2009). The interannual isotopic variability is generally well preserved (Section 1.6), and the standard deviation of the RICE annually averaged isotopes (10.62\%o) is higher than for the 2000-5, 2000-1, and 2001-5 WA ITASE ice core sites, which have corresponding standard deviation values of $10.19,8.66$, and 9.43\%o, respectively (1900-2000). In addition to the RICE $\delta \mathrm{D}$ record, we also use published $\delta \mathrm{D}$ records from the International Trans-Antarctic Scientific Expedition (ITASE) ice core network [Mayewski, 2005; Steig et al., 2005]. The analytical methods used for the ITASE isotope records are described in Steig et al. [2005] and Schneider et al. [2005]. 


\subsubsection{Climate Indices}

Patterns of atmospheric variability examined here were calculated from EOF analysis (using singular value decomposition, SVD) of monthly ERA-Interim 500-hPa geopotential height field $\left(20^{\circ}-90^{\circ} \mathrm{S}\right)$ for 37 complete years, 1979 through 2015 . ERA-Interim data gridded at a regular $1.5^{\circ}$ grid were used to derive the $\mathrm{EOF}$ patterns of $\mathrm{SH}$ atmospheric circulation variability. The data are weighted using the square root of the cosine of latitude, to provide equal weighting of equal areas. The seasonal cycle is removed at each grid point by subtracting the corresponding monthly climatology for each grid. The SAM, PSA1, and PSA2 are defined as the leading, second, and third EOFs of monthly mean 500-hPa geopotential height anomalies, respectively. The principal component (PC) time series are obtained by projecting the EOF pattern onto the original z500 anomaly field at each time step to find the sign and amplitude of the pattern at any given time. The PC time series of the SAM and PSA patterns are standardized, so that they have a mean of zero and a standard deviation of one, and are used as climate indices for large-scale atmospheric circulation variability. The leading monthly PC index (SAM) is highly correlated to the NOAA SAM (Antarctic Oscillation, AAO) index $(r=0.95, p<0.001)$ [Mo, 2000]. Figure 4.3 shows the EOF patterns in the form of regression maps, generated by linearly regressing the original geopotential height field onto the PCs. ENSO events are defined using SSTs in the Niño-4 region (from the NOAA Climate Prediction Center). The monthly geopotential height fields were also regressed upon the monthly standardized Niño-4 SST to obtain the atmospheric circulation pattern associated with CP-ENSO (Figure 4.3a). 

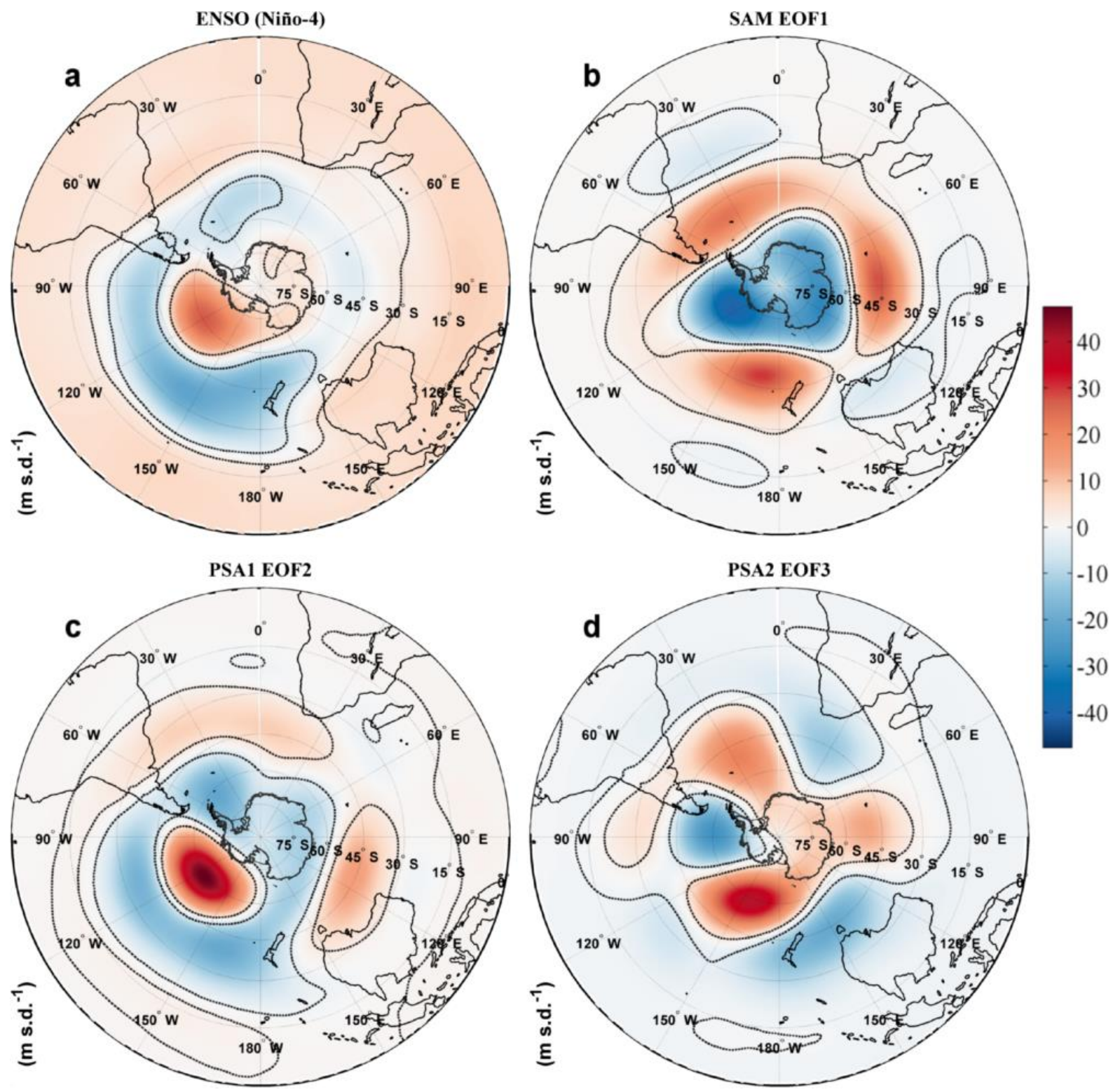

Figure 4.3. ENSO and EOF regression maps. Circulation patterns associated with ENSO and the three main SH large-scale atmospheric circulation patterns (shading, meter per standard deviation of the index (m s.d. $\left.{ }^{-1}\right)$ ). Monthly 500-hPa geopotential height fields are regressed onto: (a) the Niño-4 SST index; (b) the leading PC, SAM; (c) the second PC, PSA1; and (d) the third PC, PSA2. The EOFs were obtained using 500-hPa ERA-Interim geopotential height fields $\left(20^{\circ}-\right.$ $90^{\circ} \mathrm{S}$ ) from all calendar months (January 1979 to December 2015). All the circulation patterns are shown during their positive polarities. We use the same polarity sign convention for the PSA patterns as Kidson [1988] (his figure 4). Black contours enclose areas where regression coefficients are significant at the $p<0.05$ confidence level. 


\subsection{Results and Discussion}

\subsubsection{Tropical Forcing Impact on RICE $\delta \mathrm{D}$}

Interannual spatial correlations between RICE $\delta \mathrm{D}$ and SST (HadISST) are shown in Figures 4.4a (1979-2009) and 4.4b (1950-2009). We find statistically significant correlations between $\delta \mathrm{D}$ and annual averaged SST in Area 1,2, and 3 (Figure 4.4a): in the central tropical Pacific (CTP; $r=0.62, p<0.001$ ), in the central subtropical Pacific (CSTP; $r=-0.58, p<0.01$ ) and in the South Pacific Ocean $(r=0.71, p<0.001)$. Additionally, over the recent correlation interval (1979-2009), $\delta$ D correlation patterns display significance with SST in the Maritime Continent and with SST off the coast of Australia (Figure 4.4a). Area 1 contains the Niño-4 region $\left(5^{\circ} \mathrm{S}-5^{\circ} \mathrm{N}, 160^{\circ} \mathrm{E}-150^{\circ} \mathrm{W}\right)$, but also extends further south $\left(13^{\circ} \mathrm{S}\right)$ just east of the dateline and further east along the equator $\left(128^{\circ} \mathrm{W}\right.$, Figure $\left.4.4 \mathrm{a}\right)$. Area 2 coincides with the latitude of the subtropical jet, $\sim 30^{\circ} \mathrm{S}$. Table 4.2 shows interannual correlations of ENSO, SAM and the PC indices with $\delta \mathrm{D}$ : both for the interval that match the modern satellite-era (1979-2009; Table 4.2a), when SH reanalysis data is best constrained by observations, and for the full extent of the $\delta \mathrm{D}$ record (or starting at the beginning of the considered index; Table $4.2 \mathrm{~b}$ ). The correlation with SOI is lower when considering a longer interval $(r=-0.33, p<0.05,1958-2009)$, which is a similar significance level as reported for Hercules Dome $(r=0.32, p=0.02,1958-2002$ [Jacobel et al., 2005]). In addition to Roosevelt Island, Hercules Dome has also been suggested as a suitable site for preserving tropical Pacific ENSO variability [Jacobel et al., 2005].

\subsubsection{CP-ENSO Variability}

The RICE $\delta$ D correlation patterns with geopotential height levels have a nearly barotropic structure in the Pacific sector high-latitudes and show a phase reversal between the upper troposphere and the surface in the tropical Pacific (Figures S4.2a and S4.2b). This is a characteristic feature of stationary Rossby wave response to tropical SST forcing [e.g., Gill, 1980; Mo and Higgins, 1998; Ding et al., 2012]. Patterns of alternating positive and negative correlation anomaly centers propagating southward from the western and CTP are apparent in the $\delta \mathrm{D}$ correlation with SST and the 500-hPa geopotential height field in Figures 4.4a and 4.5a, yielding PSA-like patterns. The PSA1-like $\delta \mathrm{D}$ z500 correlation pattern propagates in a polewardarching seesaw from the CTP (positive correlation) to high southern latitudes (positive correlation over ABS), via a negative correlation region over and east of New Zealand. The 
significant patterns then continues northward into the South Atlantic sector (Figures 4.4 and 4.5a). The PSA2 wave train initiation is associated with SST off the coast of Australia and the subtropical jet $\left(\sim 30^{\circ} \mathrm{S}\right)$ [Kidson, 1988; Mo, 2000; Ding et al., 2011]. These PSA wave trains and their high-latitude impacts have also been described in several other recent studies [Ding et al., 2011, 2012; Schneider et al., 2011, 2015; Steig et al., 2012; Bromwich et al., 2013; Ciasto et al., 2014]. Compared to the origin of the canonical ENSO pattern in the central-eastern equatorial Pacific [Rasmusson and Carpenter, 1982], the main centers of significant correlation patterns of the RICE $\delta$ D correlations with SST and z500 display significance further west, over the westerncentral Pacific (Figures 4.4a, 4.4b and 4.5a).

Furthermore, RICE $\delta$ D is characterized by a stronger correlation with the Niño-4 SSTs compared to the Niño-3.4, Niño-3, and SOI index, particularly during the recent satellite-era period (1979-2009, Table 4.2 and Figures 4.4a and 4.4b). In fact, SST in Area 1 and Niño-4 (Figure 4.4c) so closely resemble one another (and thus also their correlations with $\delta \mathrm{D}$, Table 4.2) that from here on, when discussing this region, we mainly refer to the well-established Niño4 ENSO index. SST in the Niño-4 region, or regions with a substantial overlap with Niño-4, is regarded to be forcing CP-ENSO variability [Yeh et al., 2009; Khider et al., 2011; Kim et al., 2011; Ciasto et al., 2014; Yeo and Kim, 2015]. Even more striking is the close resemblance in the equatorial tropical Pacific between the RICE $\delta$ D-SST correlation pattern (Figure 4.4a) and SST regression onto the monthly standardized Niño-4 index (Figure 4.6a), and with SST composites of CP-El Niño events [Yeh et al., 2009; their figure 1b]. Furthermore, the $\delta \mathrm{D}-\mathrm{z} 500$ correlation pattern (Figure 4.5a) and the Niño-4 z500 regression pattern (Figure 4.3a) are almost identical. Our results therefore indicate that the RICE $\delta$ D record can provide an opportunity to develop a proxy for reconstruction of intrinsic CP-ENSO variability. 
RICE $\delta D$ 1213B SST correlation HadISST annual 1979 - 2009

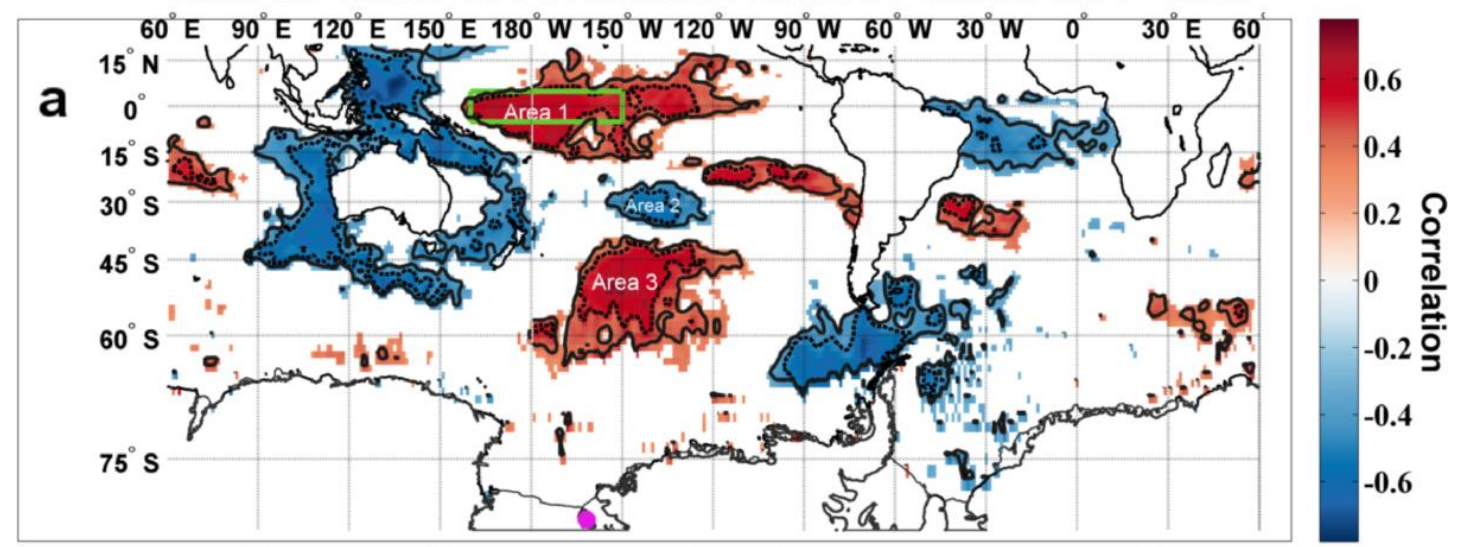

RICE $\delta$ D SST correlation HadISST annual 1950 - 2009
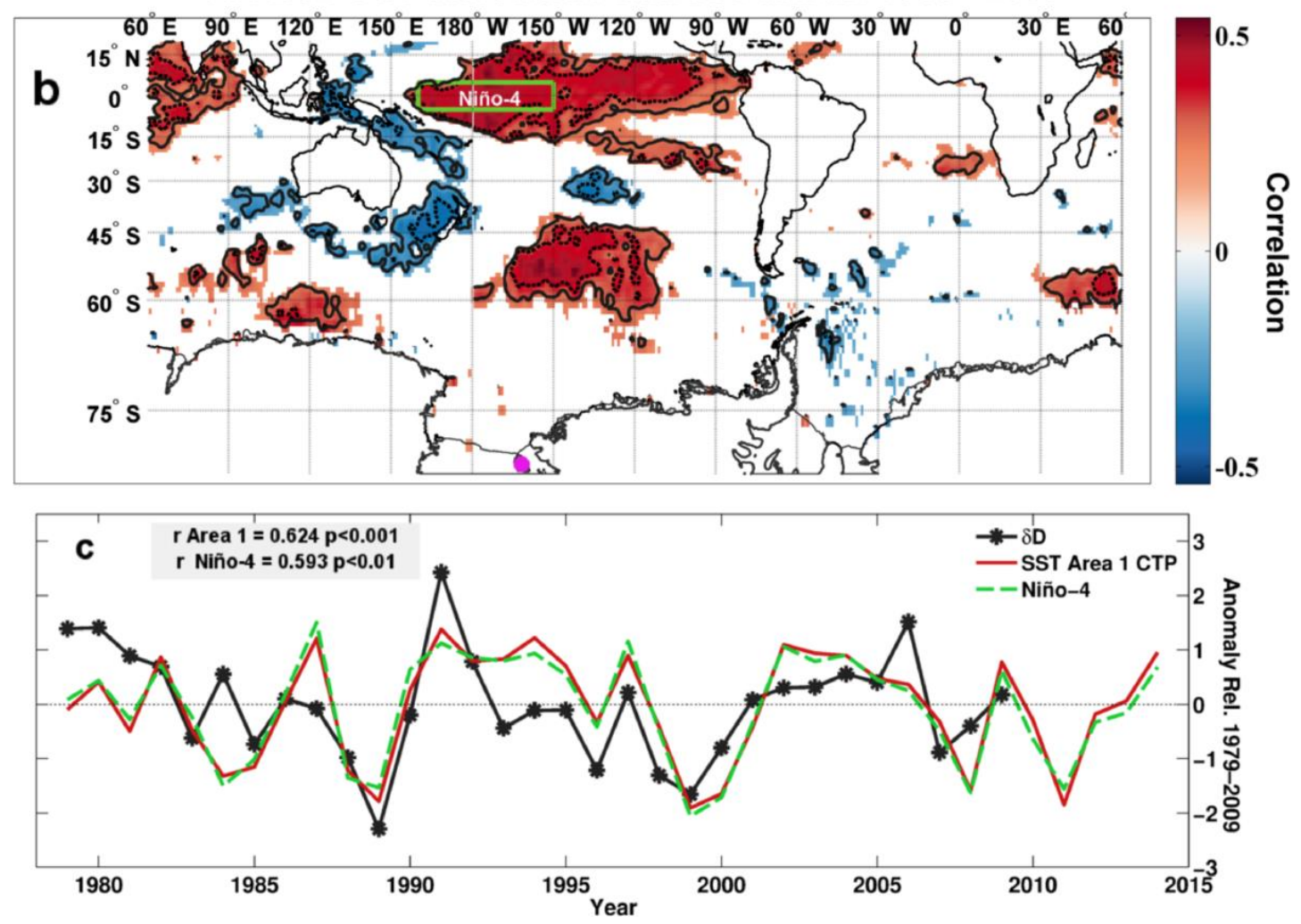

Figure 4.4. (a-b) Interannual correlation maps between the RICE $\delta$ D record and HadISST SST. Correlation coefficients ( $r, p<0.1$, shading), the $p<0.05$ confidence level (black contours) and $p<0.01$ confidence level (dashed-black contours). The Niño-4 region is depicted by a green box. RICE location is indicated by a magenta dot (here and in subsequent correlation maps with the RICE $\delta$ D record). (a) Correlation for 1979-2009. Areas with significant $(p<0.01)$ positive SST correlation within the CTP, CSTP and the Pacific Southern Ocean are indicated as Area 1, 2 and 3, respectively. (b) As in (a) but for 1950-2009. Note the difference in the correlation scale between (a) and (b). (c) Interannual anomaly time series of RICE $\delta \mathrm{D}$ (black line) and SST averaged within Area 1 in the CTP (red line), and SST from the Niño-4 region (1979-2009, green dashed line). 
Table 4.2. Interannual correlations of $\delta \mathrm{D}$ with ENSO and the PC indices ${ }^{\mathrm{a}}$

\begin{tabular}{|c|c|c|c|c|c|c|}
\hline \multirow{2}{*}{$\begin{array}{c}\mathbf{a} \\
\delta \mathrm{D}\end{array}$} & \multicolumn{3}{|c|}{$12 / 13 \mathrm{~B}$} & $\mathbf{b}$ & \multicolumn{2}{|c|}{ 12/13 B + Deep } \\
\hline & Range & $\mathrm{r}$ & $\mathrm{p}$ & Range & $\mathrm{r}$ & $\mathrm{p}$ \\
\hline CTP Area 1 & $1979-2009$ & 0.62 & $p<0.001$ & 1900-2009 & 0.28 & $<0.01$ \\
\hline Niño-4 & 1979-2009 & 0.59 & $\mathbf{p}<0.01$ & 1900-2009 & 0.29 & $<0.01$ \\
\hline Niño-3.4 & 1979-2009 & 0.52 & $\mathrm{p}<0.01$ & 1900-2009 & 0.29 & $<0.01$ \\
\hline Niño-3 & 1979-2009 & 0.38 & $<0.05$ & 1900-2009 & 0.27 & $<0.01$ \\
\hline SOI & 1979-2009 & -0.48 & $<0.05$ & 1958-2009 & -0.33 & $<0.05$ \\
\hline PC1 SAM & 1979-2009 & -0.42 & $<0.01$ & $1958-2009^{1}$ & -0.37 & $<0.01$ \\
\hline PC2 PSA1 & 1979-2009 & 0.59 & $<0.001$ & - & - & - \\
\hline PC3 PSA2 & 1979-2009 & 0.42 & $<0.05$ & - & - & - \\
\hline PC1 SAM- + Niño-4 & 1979-2009 & 0.61 & $<0.001$ & - & - & - \\
\hline Niño-4 + PSA2 & 1979-2009 & 0.64 & $<0.001$ & - & - & - \\
\hline PSA1+ PSA2 & 1979-2009 & 0.66 & $<0.001$ & - & - & - \\
\hline PSA $1+$ PSA $2-$ SAM & 1979-2009 & 0.69 & $<0.001$ & - & - & - \\
\hline
\end{tabular}

${ }^{a}$ All time series have been detrended. Correlations in boldface are significant at the $p<0.01$ level. Footnote: 1. Marshall-SAM index [Marshall, 2003]. 

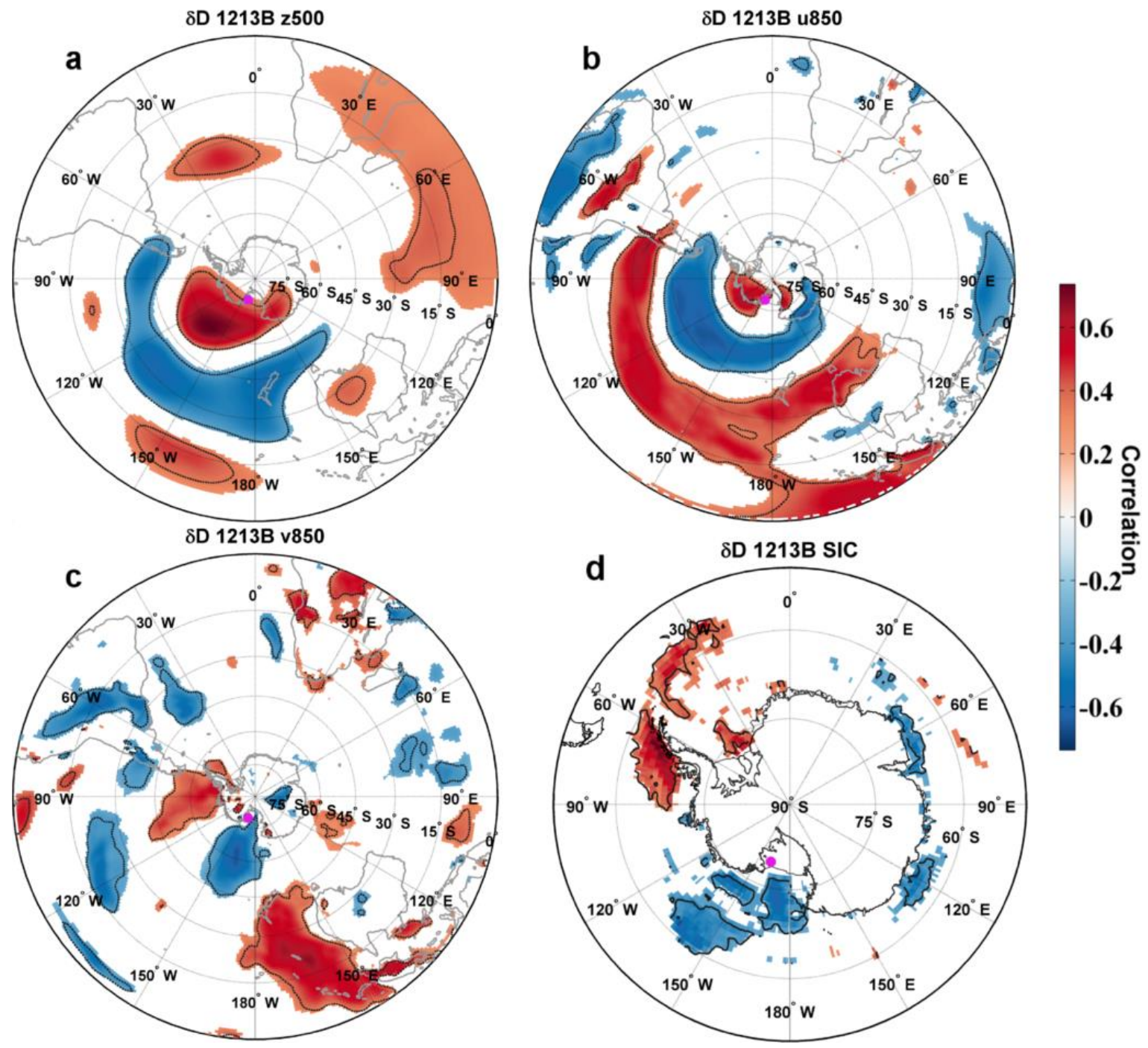

Figure 4.5. Interannual correlation maps (1979-2009) between RICE $\delta D$ and annual averages and (a) ERA-Interim geopotential heights (z500), (b) zonal wind (u850), (c) meridional wind (v850), and (d) HadISST SIC for the fall/winter season (MAMJJA). Correlation coefficients ( $r, p$ $<0.1$, shading) and the $p<0.05$ confidence level (black contours). Note the different latitudinal extent in $(\mathrm{a}-\mathrm{c})$, and $(\mathrm{d})$. 

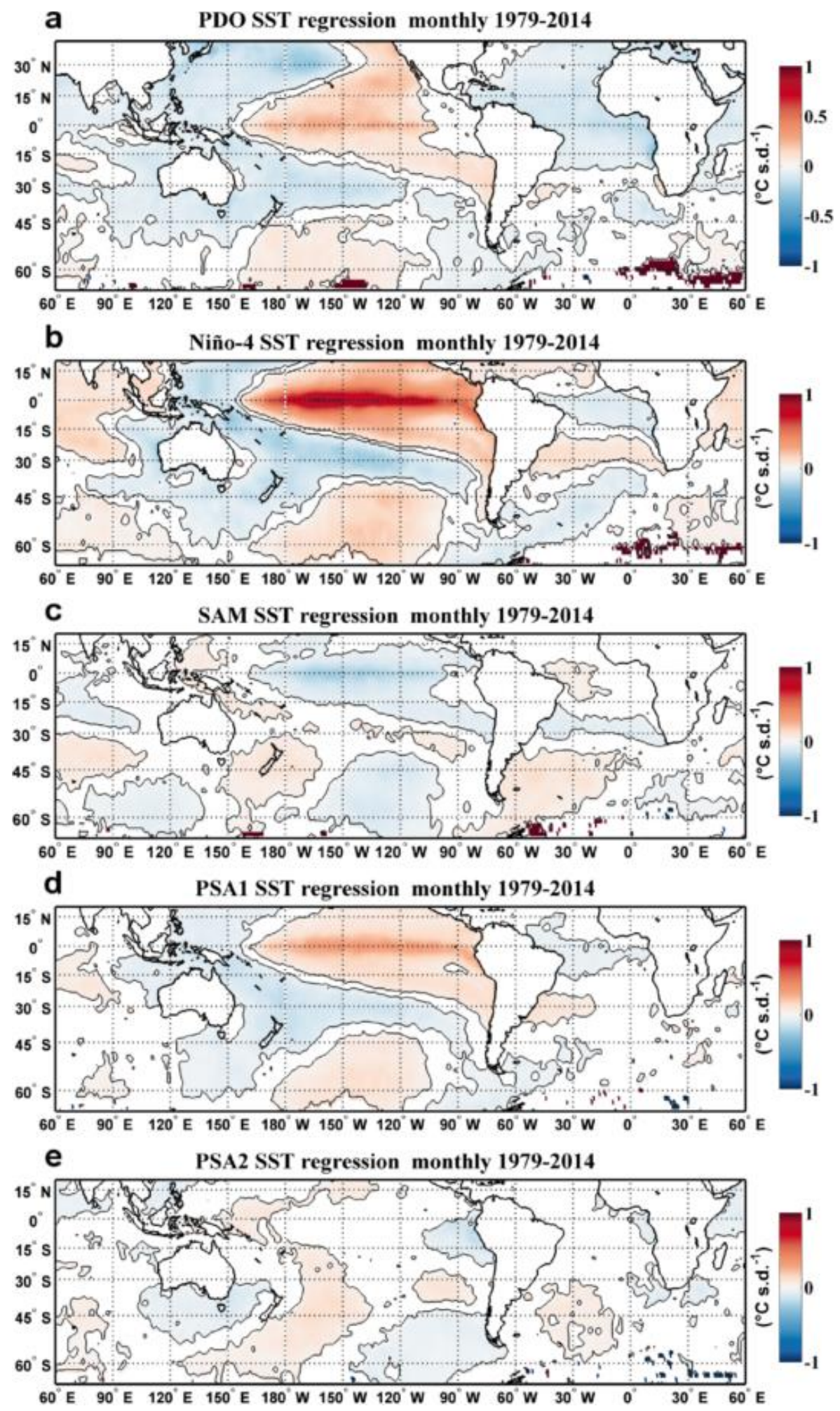

Figure 4.6. Regression of monthly SST fields onto monthly climate indices: (a) PDO, (b) Niño4, (c) PC1 SAM (d) PC2 PSA1, and (e) PC3 PSA2. Regression coefficients $(r, p<0.05$, shading) and the $p<0.05$ confidence level (black contours). Positive polarities are displayed for all regression maps. 
According to the location of the positive anomalous SST patterns, ENSO can be divided into two types: eastern Pacific (EP) ENSO and central Pacific (CP) ENSO [Larkin and Harrison, 2005; Ashok et al., 2007; Kao and Yu, 2009; Kug et al., 2009; Yeh et al., 2009; Yeo and Kim, 2015; Hu et al., 2016]. The SST anomalies in the Niño-4 and Niño-3 regions have been used to distinguish between these two ENSO types [Yeh et al., 2009]. The CP-El Niño has become more frequent over recent decades [Ashok et al., 2007; Kao and Yu, 2009; Kug et al., 2009; Latif and Keenlyside, 2009; Yeh et al., 2009; Lee and McPhaden, 2010], which has imposed changes on teleconnections and climate for countries surrounded by the Pacific Ocean [Seager et al., 2010; Thompson et al., 2011]. The same major $\delta$ D-SST significant Pacific regions appear when the correlation interval is extended (1950-2009, Figure 4.4b). However, the correlations are slightly weaker and display some important differences. The significant pattern extends further towards the eastern equatorial Pacific and becomes insignificant in parts of the west Pacific, south and west of Australia. Additionally, when extending the correlation interval the significance of the $\delta \mathrm{D}$ correlation with Niño-4 and Niño-3.4 becomes equal (Table 4.2b). The reduced significance of the correlation pattern over the eastern tropical Pacific for the recent correlation interval (1979-2009) appears to be related to the increased frequency of CP-El Niño during recent decades. The occurrence frequency of CP-El Niño over recent decades is 0.278 (1979-2014), compared to 0.103 between 1950 and 1978. We define CP-El Niño events as occasions when austral summer (DJF) Niño-4 SST is outside of a +1.0 standard deviation threshold. Similar results are obtained using SON and annual SST averages (not shown).

\subsubsection{Drivers of Marine Air Mass Intrusions into RICE}

Annual mean averages (1979-2009) of ERA-Interim reanalysis and HadISST data are correlated with the annual $\delta \mathrm{D}$ record (Figure 4.5). Anomalous high RICE $\delta \mathrm{D}$ values are associated with positive z500 anomalies in the ABS/Ross Sea region (Figure 4.5a), negative correlation with zonal winds (u850) in the westerly wind belt and positive correlation over the WA continent (Figure 4.5b), northerly meridional winds (v850, Figure 4.5c), warm air temperature (2mT, not shown) and a reduction in Amundsen Sea/Ross Sea SIC (Figure 4.5d). The RICE $\delta \mathrm{D}$ interannual correlation patterns indicate that anticyclonic conditions have a significant role in moisture transport to RICE. Figure 4.5 demonstrates that $\delta \mathrm{D}$ is significantly correlated with all the aforementioned parameters (z500, v850, z850, 2mT and SIC), which all covary during WA air mass intrusions driven by Amundsen Sea anticyclonic circulation (Chapter 
3). Hence, individual components previously linked to $\delta \mathrm{D}$ variability, such as temperature [Dansgaard, 1964], atmospheric circulation [Küttel et al., 2012], SIC [Bromwich and Weaver, 1983; Küttel et al., 2012] and precipitation amount [Noone and Simmonds, 2002]) all vary in concert during non-zonal ABS conditions associated with anticyclones (Chapter 3).

Positive CTP SST anomaly patterns (CP-El Niño) are associated with high ABS geopotential heights and enhanced Amundsen Sea anticyclonic activity (positive PSA1, Figure 4.3c), which in turn leads to an increased frequency of northerly (onshore) air mass advection over the eastern Ross Sea (Figure 4.5a). These conditions are associated with high snow accumulation rates and an enriched $\delta \mathrm{D}$ signal at RICE. In contrast, negative CTP anomalies (CPLa Niña, PSA1-) are associated with a deepening of the ASL (increased Amundsen Sea cyclonic activity), an increased frequency of air mass intrusions east of the WAIS-Divide, and a depleted RICE $\delta$ D (Figure 4.5a). Meridional transport into western Marie Byrd Land/eastern Ross Sea is reduced during Amundsen Sea cyclonic activity (negative PSA1, Figure 4.3c), as the clockwise Amundsen Sea cyclonic circulation causes an increase in air mass advection east of the WAISDivide, imposing a low precipitation state in western Marie Byrd Land [Genthon et al., 2003].

\subsubsection{Influence from the Southern Annular Mode}

The $\delta \mathrm{D}-\mathrm{z} 500$ correlation pattern has an annular component (Figure $4.5 \mathrm{a}$ ) and the $\delta \mathrm{D}$ zonal wind correlation pattern (Figure 4.5b) indicates that weaker westerly winds, a weaker polar front jet $\left(60^{\circ} \mathrm{S}\right)$, is associated with enriched $\delta \mathrm{D}$. These conditions are associated with a negative SAM. Further evidence of a strong influence from SAM comes from the displayed significant negative correlation between the SAM indices and $\delta \mathrm{D}$ (Table 4.2). In contrast, stronger westerlies related to the subtropical jet $\left(30^{\circ} \mathrm{S}\right)$ are associated with higher $\delta \mathrm{D}$ values, likely due to related enhanced Rossby wave propagation with a tropical Pacific connection. The subtropical jet tends to be stronger during El Niño events [Chen et al., 1996; Turner, 2004]. In contrast, the polar front jet is stronger (linked to a positive SAM) during La Niña events [Chen et al., 1996; Fogt and Bromwich, 2006]. 


\section{RICE $\delta D$ 1213B SST correlation HadISST annual 1979 - 2009}

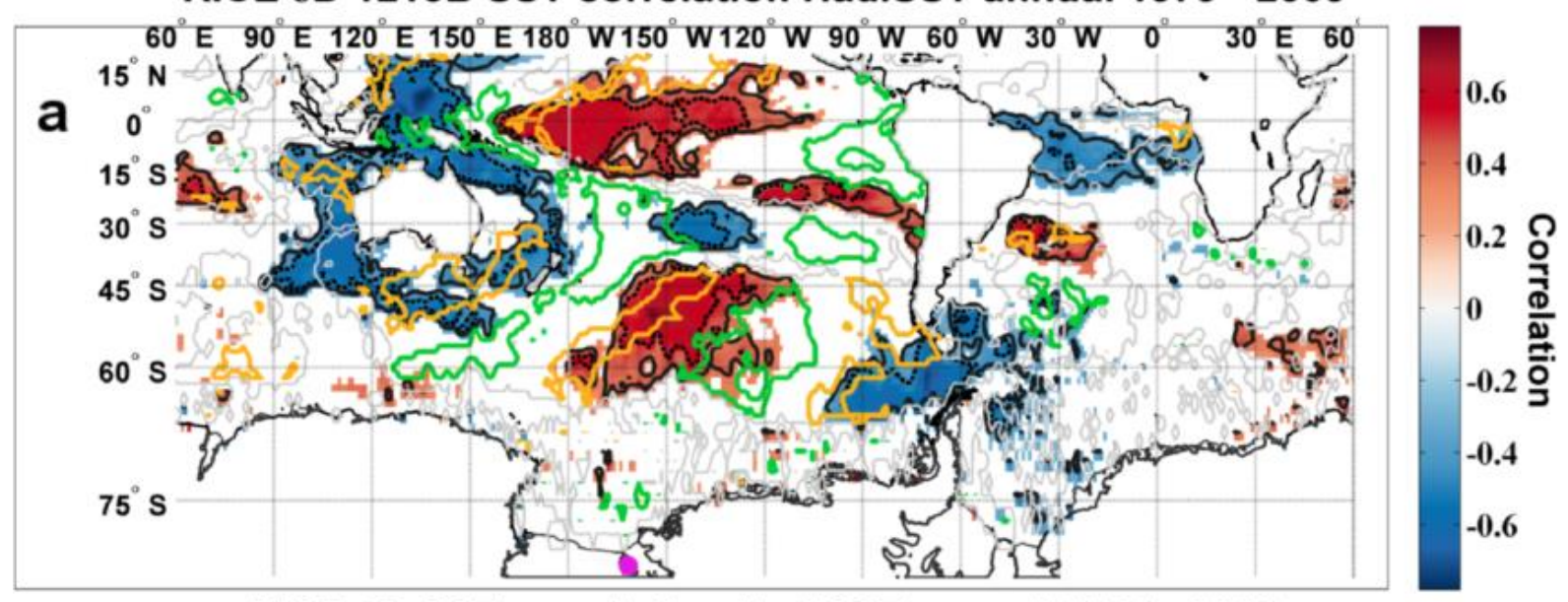

RICE SD SST correlation HadISST annual 1950 - 2009

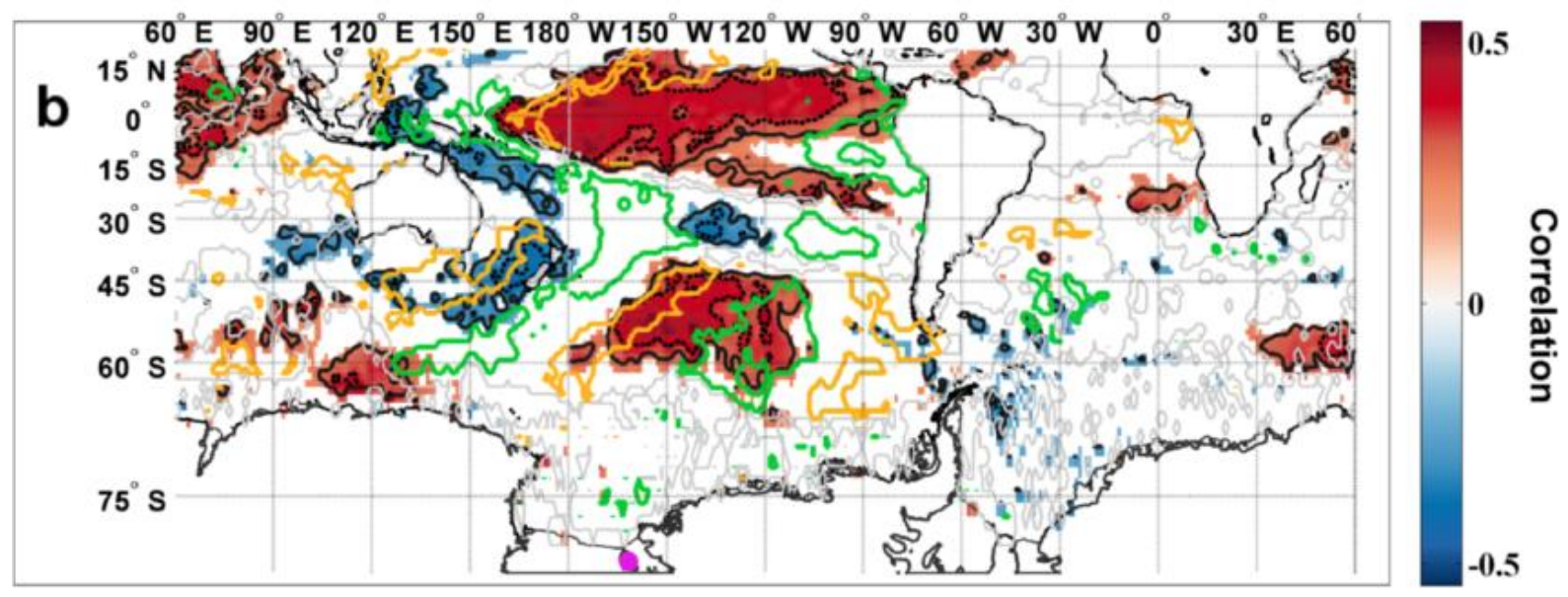

Figure 4.7. Correlation maps between RICE $\delta$ D and SST, for the (a) 1979-2009 and (b) 19502009 intervals. Details as in Figure 4.4. PSA-SST regression patterns are overlain, depicting regions where both PSA patterns are active and constructively interact (yellow contours) and destructively interact (green contours), and where neither PSA are active (gray contours).

\subsubsection{PSA patterns}

Among the climate modes and teleconnections, the PSA patterns explain most of the variance in RICE $\delta \mathrm{D}$ (Table 4.2a). The positive polarity of PSA1 is associated with an anticyclone center in the Amundsen ( $120^{\circ} \mathrm{W}$, Figure $\left.4.3 \mathrm{c}\right)$ and the positive PSA2 phase is associated with anticyclones in the Ross Sea ( $150^{\circ} \mathrm{W}$, Figure 4.3d) [Kidson, 1988; Mo, 2000; Marshall and Thompson, 2016]. The positive PSA (PSA1 and PSA2) patterns display opposing effects for surface air temperature at RICE and western Marie Byrd Land [Marshall and Thompson, 2016]. The positive polarity of PSA1 is associated with warming over western Marie Byrd Land and the eastern Ross Sea and the positive PSA2 polarity is associated with cooling 
across WA and the Ross Ice Shelf [Marshall and Thompson, 2016] (their figure 3d). We obtain a similar pattern when regressing surface temperature fields onto our PSA2 index (not shown). In contrast, RICE $\delta \mathrm{D}$ is positively correlated with both PSA1 and PSA2 (Table 4.2a). RICE $\delta \mathrm{D}$ displays a similar PSA1 relationship, as air temperature, i.e. both are associated with a warming when the Amundsen Sea anticyclones frequency increases. However, the positive PSA2 polarity is associated with Ross Sea anticyclones and with relatively enriched $\delta \mathrm{D}$ values. This is surprising as PSA2+ Ross Sea anticyclones have been shown to be associated with significant cooling across WA and the Ross Ice Shelf [Marshall and Thompson, 2016]. Depleted RICE $\delta \mathrm{D}$ values display a marked dynamical cyclonic pattern in the PSA2 Ross Sea region $\left(\sim 150^{\circ} \mathrm{W}\right.$; Chapter 3), i.e. PSA2 Ross Sea cyclones are associated with a depleted $\delta \mathrm{D}$ signature. Thus, it appears that PSA2 polarities are associated with a different response for temperature and $\delta \mathrm{D}$ over the eastern Ross Sea. Air mass advection over the western Marie Byrd Land orography are likely to be associated with pronounced distillation effects, which can result in differences in temperature and isotopic signatures. Additionally, we demonstrated earlier in Chapter 1 that $\delta \mathrm{D}$ is a higher skilled circulation and SST proxy as opposed to an Antarctic air temperature proxy. However, the PSA2 influence on $\delta \mathrm{D}$ is unstable compared to PSA1 and Niño-4 (Section 4.3.4). PSA2's influence appears to have increase congruent with the positive trend in SAM.

Furthermore, RICE site-specific anticyclonic circulation centers coincide with the Amundsen Sea (Chapter 3). The influence from PSA2 on Amundsen Sea circulation is reduced compared to adjacent regions, as PSA2 transition, from its western Ross Sea to its Bellingshausen Sea circulation center, coincide with the Amundsen Sea, i.e. PSA2 will not significantly affect geopotential height anomalies over the Amundsen Sea (Figure 4.3d). Thus, we primarily attribute the direct influence from northerly air mass advection into RICE, to PSA1 Amundsen Sea anticyclones. In contrast, the two main transportation paths to RICE associated with the PSA2 pattern are advection over Marie Byrd Land (associated with Ross Sea cyclones, PSA2-, Figure 4.3d) and advection over the western Ross Ice Shelf prior to reaching RICE (from Ross Sea anticyclones, PSA2+), which both are indirect, i.e. not originating from direct northerly meridional winds. The RICE $\delta \mathrm{D}$ signature for both PSA2 polarities therefore appears to be relatively depleted, compared to PSA1+ conditions. Air mass advection over the western Ross Ice Shelf associated with PSA2+ anticyclones, however, appears to be linked to relatively enriched $\delta \mathrm{D}$, compared to PSA2- and Ross Sea cyclones. This is attributed to the strong 
distillation effect associated with air mass advection over the Marie Byrd Land pronounced topography (> 2,000 m), and to RICE being relatively sheltered by WA from the PSA2cyclonic clockwise circulation. Future research using general circulation models or backtrajectory analysis equipped with isotope capabilities can perhaps shed further light on differences between air temperature and $\delta \mathrm{D}$ in the northeastern Ross Sea region.

Regions that display statistically significant RICE $\delta$ D-SST correlations in Figure 4.7 are regions where: (1) only one PSA regression pattern is active or (2) the significant PSA1 and PSA2 CP-SST regression patterns coincide and the SST anomalies of the PSA patterns constructively reinforce one another (the PSA patterns are associated with SST anomalies of the same sign; yellow contours). In contrast, regions that display a non-statistically significant RICE $\delta$ D-SST correlation in Figure 4.7 ( $p>0.1$, masked areas) are regions where: $(1)$ the significant PSA1 and PSA2 CP-SST regression patterns coincide and the PSA regression patterns destructively interact (SST anomalies are dampened or cancelled-out; green contours) or (2) neither of the PSA regression patterns are active (gray contours). Contours are generated by assigning a value of $+1(-1)$ if the considered PSA-SST, PSA1 or PSA2, regression pattern is significant at the $p<0.05$ level, thin black contours in Figures $4.6 \mathrm{~d}-4.6 \mathrm{e}$, and associated with a positive (negative) polarity, or a 0 if insignificant. Then the PSA patterns layers are summed and the absolute |2|, SST of-the-same sign, and 0, SST of-opposing sign, contours are displayed. 


\section{a}

Trend SST regression monthly 1979-2014
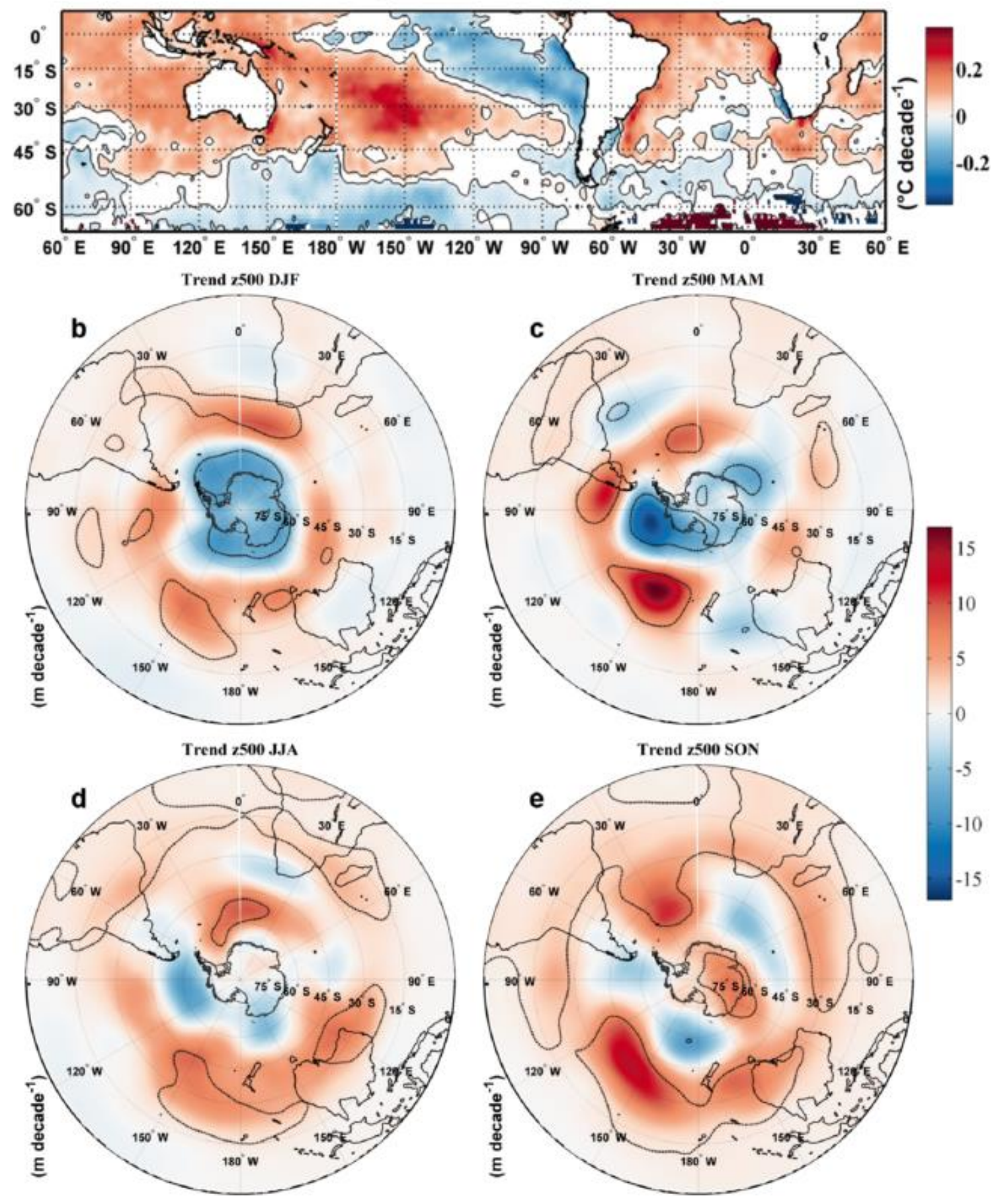

Figure 4.8. Trends using all months (1979-2014) for (a) SST, (b) seasonal 500-hPa geopotential height field (z500; 1980-2014) in austral: summer (DJF), (c) fall (MAM), (d) winter (JJA), and (e) spring (SON). Shading shows trend coefficients. Black contours enclose regions where the trend coefficients are significant at the $p<0.05$ level. 
The RICE's $\delta$ D-SST correlation pattern is remarkably well explained by the PSA patterns and their interaction (Figure 4.7). The PSA-SST regression patterns coincide over vast regions of the Pacific sector (Figure 4.7). Several of the regions in the western-central and subtropical Pacific where the teleconnections paths overlap (Figures 4.6d and 4.6e) are important for RICE and SH Pacific sector climate. The central-eastern tropical Pacific emanating PSA1 wave train and the south of Australia emanating PSA2 wave train display common areas, where the sign of SST anomalies associated with the wave trains are in-phase (yellow contours, Figure 4.7), and of opposing sign (green contours, Figure 4.7). Destructive interaction areas occur across the subtropical Pacific and over the eastern Pacific south of the equator (west of South America). It appears that there will be an interaction between the PSA patterns in these regions. In regions where SST-regression pattern are of opposing sign, SST anomalies will tend to dampen/cancelout. In contrast, regions with in-phase SST anomalies can be amplified. Even though it is likely that the PSA patterns interact in the overlapping regions, SST anomalies do not necessarily have to cancel-out for the $\delta \mathrm{D}-\mathrm{SST}$ correlation to become weak. The weak correlations in overlapping out-of-phase regions are partly attributed to that enriched $\delta \mathrm{D}$ signal at RICE, is associated with both negative and positive SST in these areas, (from either PSA1 or PSA2), and thus the correlation will cancel-out or become weak over the span of the correlation interval.

\subsubsection{West Antarctic Ice Cores}

For the pattern to be significant in regions of active PSA patterns there also has to be a marked difference in isotopic signatures between the considered PSA patterns' polarities. Local orographic setting and the sites' relation to the circulation reversal cells of the wave trains are important for the preservation of the signature of the PSA patterns and thus ENSO. For example, if either polarity phase of PSA1 can be associated with enriched $\delta \mathrm{D}$, the polarity-phase relationship will not be preserved and regions with solely an active PSA1 pattern will not display a significant correlation (at neither high or low latitudes). This appears to be the case for the ITASE cores (2000-5, 2000-1, and 2000-5; Figures 4.1 and 4.9), where none of the core sites preserve a clear PSA1 signal. ITASE 2000-5 and 2001-5 only display a significant $\delta$ D-SST correlation in a limited region in the tropical Pacific (Figures 4.9a and 4.9c). Interestingly, this region at the northwestern outskirts of the horseshoe pattern coincides with a region where the PSA overlap and are in-phase and thus potentially can interact to generate an amplified SST anomaly. Other regions that display significance for the ITASE cores primarily occur over the 
western Pacific southeast of Australia. Positive SST anomalies south of Australia trigger a wave train response that is associated with cyclones over the Ross Sea and anticyclones over Bellingshausen Sea and vice versa for negative SST anomalies. A particularly pronounced pattern is apparent for ITASE $2000-5\left(\sim 110^{\circ} \mathrm{E}\right)$. In contrast, the ITASE $2000-1$ (located in the vicinity of the WAIS Divide ice core site) and 2001-5 (Ellsworth Land) sites display an inverse relationship with PSA2 pattern (anticorrelation), however weak (Figures $4.9 \mathrm{~b}$ and $4.9 \mathrm{c}$ ). To summarize, the ITASE sites are influenced by both PSA patterns, but only preserve the polarity of PSA2, and thus the examined ITASE cores do not preserve a readily interpretable ENSO signal. RICE is unique in that it preserves the polarities of both PSA1 and PSA2. In particular, the preservation of PSA1 in WA $\delta \mathrm{D}$ appears to be rare. 
ITASE 2000-5 $\delta$ D SST correlation HadISST annual 1950 - 2000

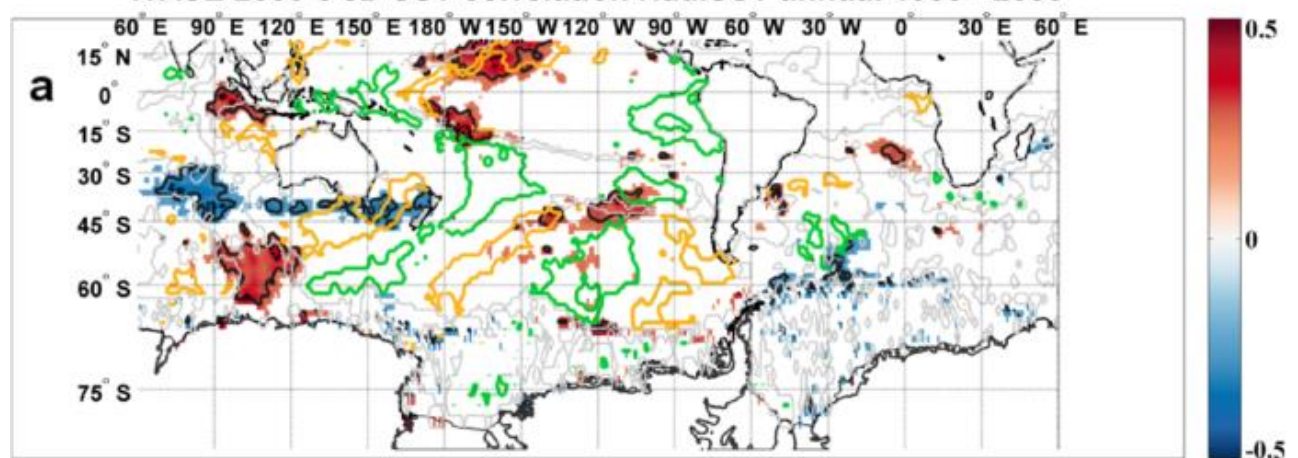

ITASE 2000-1 $\delta D$ SST correlation HadISST annual 1950 - 2000

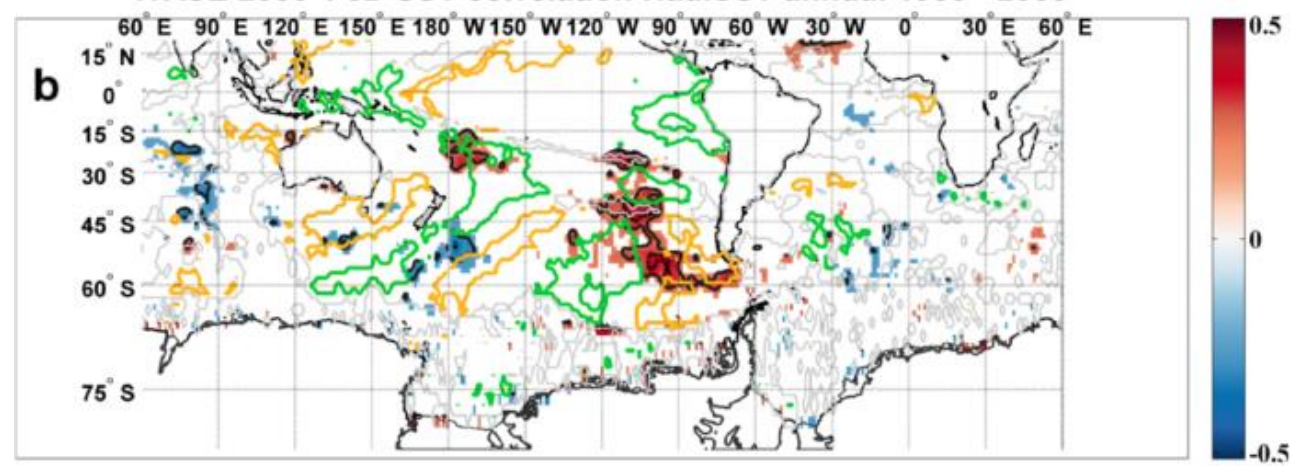

ITASE 2001-5 $\delta$ D SST correlation HadISST annual 1950 - 2000

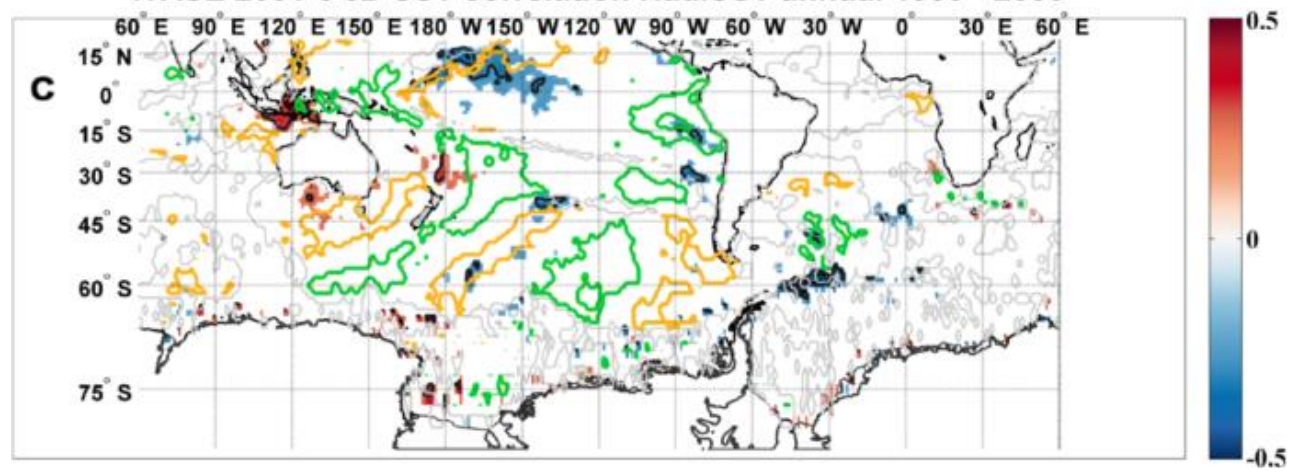

Figure 4.9. Interannual $\delta D-S S T$ correlation maps for ITASE cores: (a) 2000-5, (b) 2000-1, and (c) 2001-5 (1950-2009). Correlation coefficient ( $r, p<0.1$, shading), with overlain PSA-SST regression patterns, depicting regions where both PSA patterns are active and constructively interact (amplification of SST anomalies, yellow contours), destructively interact (dampening of SST anomalies, green contours), and where neither PSA is active (gray contours).

\subsubsection{Seasonality of SH Extratropical Teleconnections}

The ENSO signal at high SH latitudes peaks in spring and is associated with a rapid decline in summer [Jin and Kirtman, 2009; Schneider et al., 2012]. The reduced SH high-latitude ENSO signal during summer has been considered somewhat of a paradox, as summer is the most mature ENSO stage (the season with the largest amplitude of tropical Pacific SST anomalies) 
[e.g., Deser et al., 2010a]. The mechanism behind the lack of extratropical connection in summer is an area of debate [Cazes-Boezio et al., 2003; Jin and Kirtman, 2009, 2010; Lee et al., 2009; Schneider et al., 2012; Ciasto et al., 2014]. It has been suggested that the tropical atmosphere continuously responds to SST forcing [Jin and Kirtman, 2009, 2010]. However, regional seasonality of the SH has been proposed to impact the atmospheric-bridge channeling of PSA1 pattern and therefore, the extratropical ENSO signal [Jin and Kirtman, 2009, 2010]. Other studies have suggested that the subtropical jet tends to be too far poleward, from the equatorial tropical Pacific heating source in DJF [Lee et al., 2009]. Additionally, a weakening of the subtropical jet in summer can reduce the frequency of Rossby waves and make it a less effective waveguide between equatorial and high-latitudes [Jin and Kirtman, 2009; Ding et al., 2012;

Schneider et al., 2012; Ciasto et al., 2014]. However, the suggested mechanisms do not necessarily have to be mutually exclusive.

\subsubsection{Seasonality Teleconnections Influence on RICE $\delta D$}

The seasonality of RICE $\delta$ D influence from PSA1 (Table 4.3) and $\delta$ D correlation with seasonally averaged z500 (Figure 4.10) is consistent with the reported high-latitude SH response to ENSO that peaks in spring and is weak during summer (Table 4.3) [Jin and Kirtman, 2009; Schneider et al., 2012], and with the reported tropical PSA1-SST (and SOI-SST) correlation maxima in SON $[M o, 2000]$. The correlation between RICE $\delta \mathrm{D}$ and seasonal HadISST SST also reflects typical SH high-latitude ENSO seasonality in the strength of the extratropical teleconnections, with the correlation displaying weak SST significance over the western-central tropical Pacific in DJF and MAM, and an increasing significance with CTP SST throughout the year (Figures 4.11a-4.14a). In contrast, PSA2 displays a stronger seasonal influence on $\delta \mathrm{D}$ in DJF and MAM (Table 4.3). Both the $\delta \mathrm{D}-\mathrm{SST}$ and the $\delta \mathrm{D}-\mathrm{z} 500$ correlation patterns display a PSA2-like signature in DJF. The DJF and MAM $\delta \mathrm{D}-\mathrm{z} 500$ and SST correlation patterns are centered towards the western Pacific (the Maritime Continent and surrounding Australia), indicative of a strong seasonal high-latitude influence from PSA2 (Figures 4.11 and 4.12), i.e. the SST-correlation pattern resembles the PSA2-SST regression pattern (Figures $4.11 \mathrm{~d}$ and 4.12d). The only significant $\delta$ D-SST CTP region in DJF and MAM coincides with the outskirts of the "horseshoe" feature. Note that PSA2 displays a SST regression pattern in this region (Figure 4.12d). Therefore, the significant correlation is not necessarily indicative of a PSA1- 
ENSO influence. Compared to DJF, the significant CTP $\delta$ D-SST correlation pattern is slightly more pronounced in MAM.

\subsubsection{PSA Patterns and SH High-latitude Seasonality}

Areas where the PSA patterns (PSA1 and PSA2) SST regression patterns coincide in the Pacific sector are indicated with contours in the seasonal RICE $\delta$ D-SST correlation maps (Figures 4.11-4.14); these regions are affected by both PSA wave trains. The PSA wave trains' seesaw impact on SST across the Pacific will cause vast regions to be associated with constructive (PSA1 and PSA2 patterns' SST anomalies of the same sign that coincide, yellow contours) and destructive interference (dampening, the PSA1 and PSA2 patterns' SST anomalies display opposing signs, green contours). It is evident from the seasonal plots that the destructive

dampening PSA overlap (green contours) is more substantial over the central Pacific in DJF and MAM (particularly in DJF, Figure 4.11a) compared to the latter part of the year.

Note that we overlay the SST regression pattern from the two first EOFs for DJF (as the DJF SST EOF1 contain a PSA1-like pattern) and then the second and third (the typical PSA EOF ranks) EOF-SST pattern are overlaid for the remaining seasons. Green contours cover central high-latitudes $\left(\sim 45-60^{\circ} \mathrm{S}, 100^{\circ}-170^{\circ} \mathrm{W}\right)$ and the eastern subtropical Pacific $\left(30^{\circ} \mathrm{S}\right)$ in DJF (Figure 4.11a). The PSA2-SST regression pattern is weak in JJA. In SON, the PSA2-SST regression pattern is evident, but not in the central extratropics $\left(110^{\circ}-150^{\circ} \mathrm{W}\right.$, Figure $\left.4.14 \mathrm{~d}\right)$ and thus SON displays a reduced PSA1-PSA2 overlap over central Pacific high-latitudes. The reduced overlap in SON provides a plausible explanation as to why an unperturbed PSA1 (ENSO) signal can propagate south and impact high-latitudes. The stronger PSA1 signal in SON (Figures 4.13c and 4.14c) compared to JJA appears to be due to ENSO's more mature state in SON. The weak ENSO (PSA1) signal in the extratropics and Antarctica in austral summer, compared to spring, therefore, at least in part, appears to be caused by SST-interference from the PSA2-like wave train with the southward bound PSA1 wave train over the South Pacific. Additionally, the polar front jet can partly reflect or refract the PSA1 wave train north. However, as the PSA-like pattern is part of EOF1 and PC1 in DJF is moderately significantly correlated with $\delta \mathrm{D}(r=-0.32, p<0.1$, Table 4.3), PSA (ENSO) still appears to have a high-latitude influence in DJF. These results are consistent with previous research that has shown that SAM 
displays an ENSO influence in summer [Karoly, 1989; L'Heureux and Thompson, 2006; Schneider et al., 2015].

PSA2 is strongest in DJF and MAM (Figure 4.16). PSA2 is associated with the midlatitude jet and known not to be significantly correlated with ENSO (Table 4.4) [Cazes-Boezio et al., 2003; Ding et al., 2011]. The seasonal $\delta$ D-z500 correlation displays a clear PSA2-like pattern in DJF and MAM, with significant patterns over the western subtropical Pacific (Figures 4.10a and 4.10b). The PSA2-z500 (Figure 4.16) and PSA2-SST regression patterns (Figures 4.11-4.14) indicate that PSA2 is strongest in DJF and MAM, and weaker throughout the rest of the year. The PSA1-SST regression pattern is pronounced in the tropics in DJF, which is consistent with ENSO being in its mature stage (Figure 4.11b). The PSA1-z500 regression pattern is weaker compared to other seasons, but is still clear in DJF (Figure 4.16e). In fact, it appears to have atmospheric cells that straddle the equator, and therefore can provide a viable connection for ENSO into the SH. However, the subtropical jet is weak and the polar front jet is relatively strong in DJF (200-hPa zonal winds in Figure 4.10). The weak subtropical jet appears to be associated with a reduction in Rossby wave generation, causing weakening of the linkage to the central tropical Pacific. The seesaw structure of the $\delta \mathrm{D}-\mathrm{z} 500$ correlation anomalies is distinct in DJF compared to the rest of the year (Figure 4.10). The DJF $\sim 30^{\circ} \mathrm{S}$ z500 anomalies are out-ofphase with the subtropical jet-related z500 anomalies during the latter part of the year. We therefore suggest that the DJF wave train is associated with the PSA2 pattern, driven by the midlatitude jet $\left(\sim 45^{\circ} \mathrm{S}\right)$, and thus appears to have a different wave train structure compared to the rest of the seasons (Figure 4.10a), which primarily are associated with the subtropical jet. SAM is known to have a strong ENSO influence in summer [Karoly, 1989; L'Heureux and Thompson, 2006; Schneider et al., 2015]. Recent studies suggest that high-latitudes are still influenced by ENSO in summer through an eddy momentum flux mechanism, which exhibits a greater zonal symmetry, and therefore is distinct from the typical PSA patterns [Seager et al., 2005, 2010; L'Heureux and Thompson, 2006; Schneider et al., 2012]. Both the PSA1 itself and the PSA-like component of SAM appear to be weaker in DJF (Figures 4.16a and 4.16e). Throughout the rest of the year, a wavenumber-3 feature is apparent as part of SAM (Figure 4.16). The $\delta \mathrm{D}-\mathrm{z} 500$ correlation pattern displays an annular western Pacific pattern with an Antarctic continental impact (projecting onto SAM). Even though it appears further west, the $\delta \mathrm{D}$-z500 correlation pattern resembles the "Indian Ocean" SAM-dipole pattern associated with the mid-latitude jet 
that was described by Ding et al. [2012], which also appears to be part of PSA2 in DJF (Figure 4.16i). The influence from this dipole feature appears to be important for $\delta \mathrm{D}$ in DJF as the z500 correlation pattern is anchored over the East Antarctic and does not appear to continue into the Atlantic Ocean.

In addition to the weak subtropical jet in DJF and MAM, the existence of two pronounced wave trains (associated with the polar front jet/mid-latitude jet) at high-latitudes provides a setting where the already weak central tropical pacific connection encounters interference/refraction at high-latitudes on its southeastward path (Figure 4.11). A split jet appears in MAM, allowing for a continued strong PSA2 influence through the polar front jet and also an emerging influence from the subtropical jet, and therefore a strengthening of the wavebridge connection with the equatorial tropical Pacific (Figure 4.10b, Table 4.3). The PSA1 Rossby wave initiation appears primarily to be associated with the subtropical Pacific, over and east of New Zealand (Figures 4.10b-4.10d). The subtropical jet is further strengthened in JJA and SON (Figure 4.10). The split-jet is also present in JJA and SON (Figure 4.10). However, as the subtropical jet strengthens substantially in JJA and SON, the relative influence from the polar front jet and PSA2 (Figures 4.15k and 4.15l) appears to wane. The impact, in the form of a PSA2-altered SST over the central Pacific, therefore also appears to diminish due to a weaker PSA2, but also perhaps more importantly because the SST anomalies associated with a stronger PSA1 will be increasingly difficult to dampen/cancel-out by the now relatively weak PSA2. Thus, the stronger subtropical jet in JJA and SON allows for an established PSA1-link between the equatorial tropical Pacific and high-latitudes, with reduced interference/refraction from the polar front jet and from PSA2-SST "residue" over high-latitudes. The difference between JJA and SON conditions is that ENSO is in a more mature state in SON (Figures 4.13c and 4.14c). Additionally, only in SON does the PSA1 wave train display a significant connection with the central-equatorial tropical Pacific $\left(130^{\circ}-180^{\circ} \mathrm{W}\right.$; Figure $\left.4.10 \mathrm{~d}\right)$. This is in agreement with previous studies that have shown that an established PSA1 connection with the tropical Pacific primarily commences in spring, and thus the SH impact from ENSO mainly ensues in spring [Mo, 2000; Cazes-Boezio et al., 2003; Jin and Kirtman, 2009]. The linkage throughout the rest of the year is weaker, partly because PSA1 does not appear to have an established connection with the tropical Pacific. Importantly, the subtropical jet is weak in DJF and thus the polar jet is of a more comparable magnitude, which allows for PSA2 and PSA2 SST-interference over the high- 
latitude central Pacific, reducing the influence even further from an already anomalously weak PSA1. To summarize, as the influence from polar front jet wanes slightly during the latter part of the year, and the influence from the subtropical jet increases (Figures 4.10 and 4.15), a relatively unperturbed PSA1 (CP-ENSO) signal can propagate south. Thus, the strength of the jets can explain the seasonality of the high-latitude ENSO signal and the significant RICE $\delta$ D correlation with PSA2 during the first part of the year and weak correlation with PSA1 and CTP SST in summer (Table 4.3).

Also, note the close resemblance between the spring $\delta \mathrm{D}$-SST correlation pattern and the interannual SST- $\delta \mathrm{D}$ correlation pattern, indicative of the dominant spring ENSO influence in the SH (Figures 4.4 and 4.14). In fact, the $\delta \mathrm{D}-\mathrm{SST}$ correlation pattern is almost a mirror image of the correlation of the Niño-4 SON index with the SON seasonally averaged SST (not shown). However, seasonal differences are not quite as pronounced when correlating $\delta \mathrm{D}$ with the seasonal PC index for PSA1. Furthermore, when correlating $\delta \mathrm{D}$ with seasonal Niño-4, the effect from seasonality is less pronounced (Table 4.3). In fact, the Niño-4 correlation peaks in JJA.

Table 4.3. Seasonal correlations of ENSO and PC indices with annual $\delta D^{a}$

\begin{tabular}{|c|c|c|c|c|c|c|c|c|}
\hline \multirow{2}{*}{$\begin{array}{c}\mathbf{a} \\
\delta \mathrm{D}(1980-2009)\end{array}$} & \multicolumn{2}{|c|}{ EOF1 SAM } & \multicolumn{2}{|c|}{ EOF2 PSA1 } & \multicolumn{2}{|c|}{ EOF3 PSA2 } & & \\
\hline & $\mathrm{r}$ & $\mathrm{p}$ & $\mathrm{r}$ & $\mathrm{p}$ & $\mathrm{r}$ & $\mathrm{p}$ & & \\
\hline$\delta \mathrm{D}$ DJF & -0.32 & $<0.1$ & -0.08 & 0.68 & 0.36 & $<0.1$ & & \\
\hline MAM & -0.28 & 0.14 & 0.42 & $<0.05$ & 0.50 & $<0.01$ & & \\
\hline JJA & -0.31 & $<0.1$ & 0.44 & $<0.05$ & 0.07 & 0.72 & & \\
\hline SON & -0.25 & 0.14 & 0.52 & $<0.01$ & -0.01 & 0.97 & & \\
\hline b & \multicolumn{2}{|c|}{$\begin{array}{c}\text { Niño-4 } \\
(1980-2009)\end{array}$} & \multicolumn{2}{|c|}{$\begin{array}{l}\text { CTP Area } 1 \\
(1980-2009)\end{array}$} & \multicolumn{2}{|c|}{$\begin{array}{c}\text { Niño-4 } \\
(1950-2009)\end{array}$} & \multicolumn{2}{|c|}{$\begin{array}{l}\text { CTP Area 1 } \\
(1950-2009)\end{array}$} \\
\hline$\delta \mathrm{D}$ & $\mathrm{r}$ & $\mathrm{p}$ & $\mathrm{r}$ & $\mathrm{p}$ & $\mathrm{r}$ & $\mathrm{p}$ & $\mathrm{r}$ & $\mathrm{p}$ \\
\hline DJF & 0.51 & $<0.01$ & 0.52 & $<0.01$ & 0.35 & $<0.01$ & 0.34 & $<0.01$ \\
\hline MAM & 0.46 & $<0.05$ & 0.52 & $<0.01$ & 0.40 & $<0.01$ & 0.43 & $<0.01$ \\
\hline JJA & 0.61 & $<0.001$ & 0.65 & $<0.001$ & 0.44 & $<0.001$ & 0.48 & $<0.001$ \\
\hline SON & 0.59 & $<0.001$ & 0.60 & $<0.001$ & 0.37 & $<0.01$ & 0.39 & $<0.01$ \\
\hline
\end{tabular}

a(a) Correlations using the PC indices. (b) Correlations using SST indices for two intervals: 1980-2009, and 1950-2009. All time series have been detrended. Correlations in boldface are significant at the $p<$ 0.01 level. 

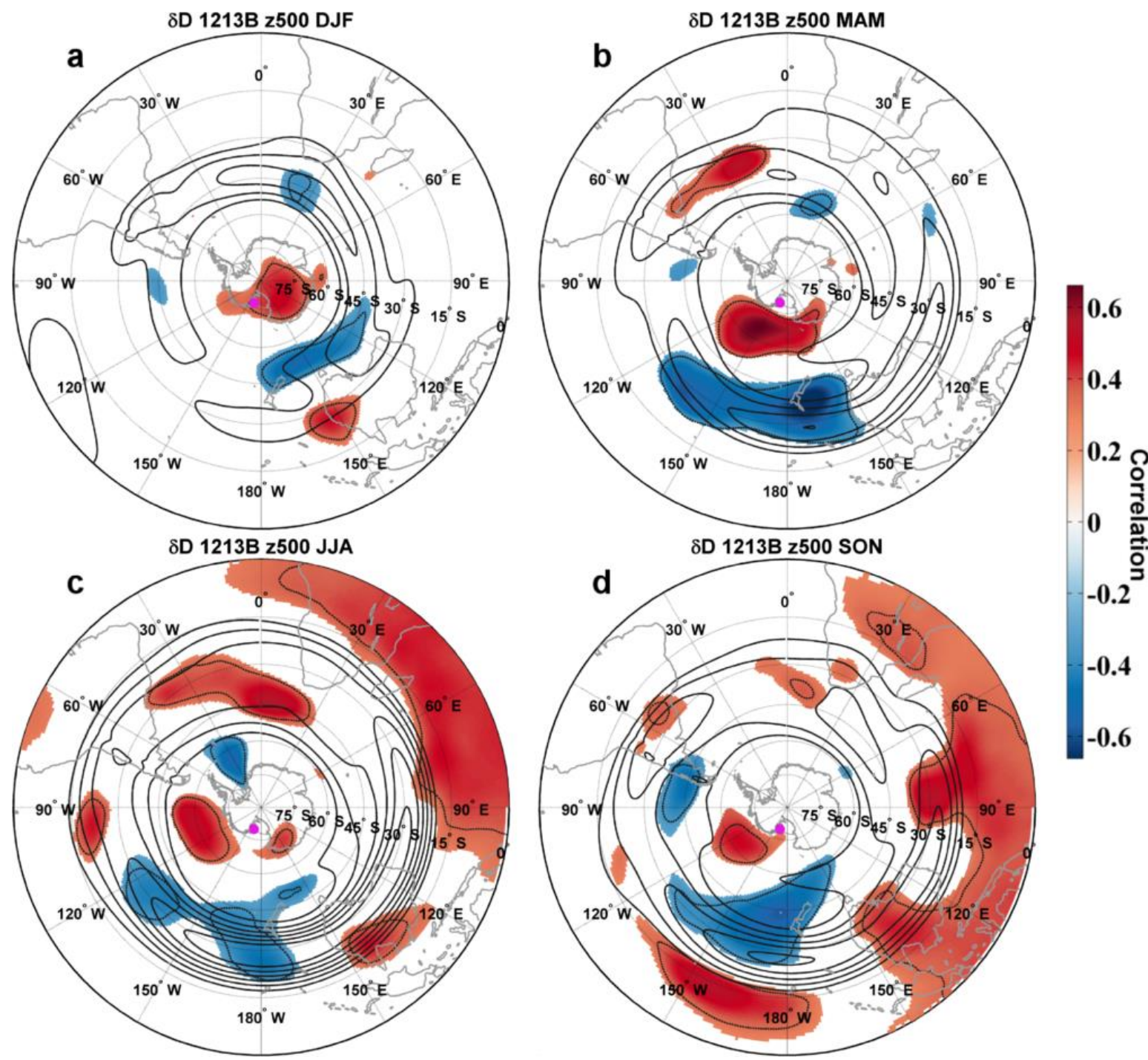

Figure 4.10. Correlation maps of annual RICE $\delta \mathrm{D}$ with seasonally averaged $500-\mathrm{hPa}$ geopotential height fields for (a) austral summer (DJF), (b) fall (MAM), (c) winter (JJA), and (d) spring (SON). Spatial correlation coefficients $(r, p<0.1$, shading) and thin-black contours enclose $(r, p<0.05)$ regions. Jet stream climatology (200-hPa zonal wind, black contours; interval $5 \mathrm{~m} \mathrm{~s}^{-1}$, starting at $20 \mathrm{~m} \mathrm{~s}^{-1}$ ). 
RICE $\delta$ D 1213B SST correlation HadISST DJF 1980 - 2009

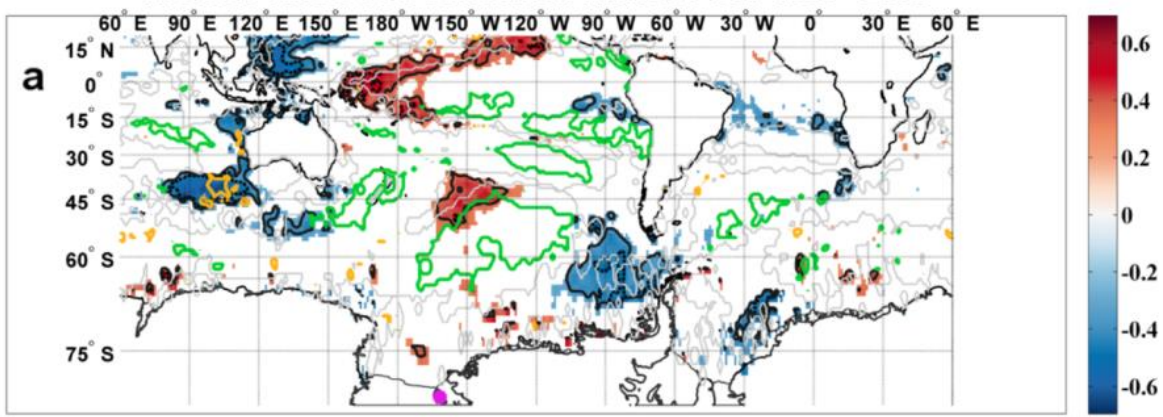

b

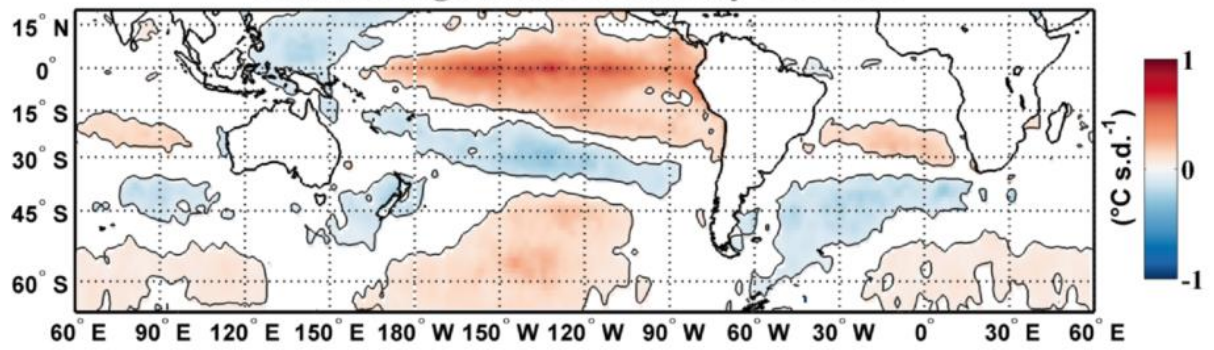

$C \quad$ PSA1 SST regression DJF monthly 1979-2014
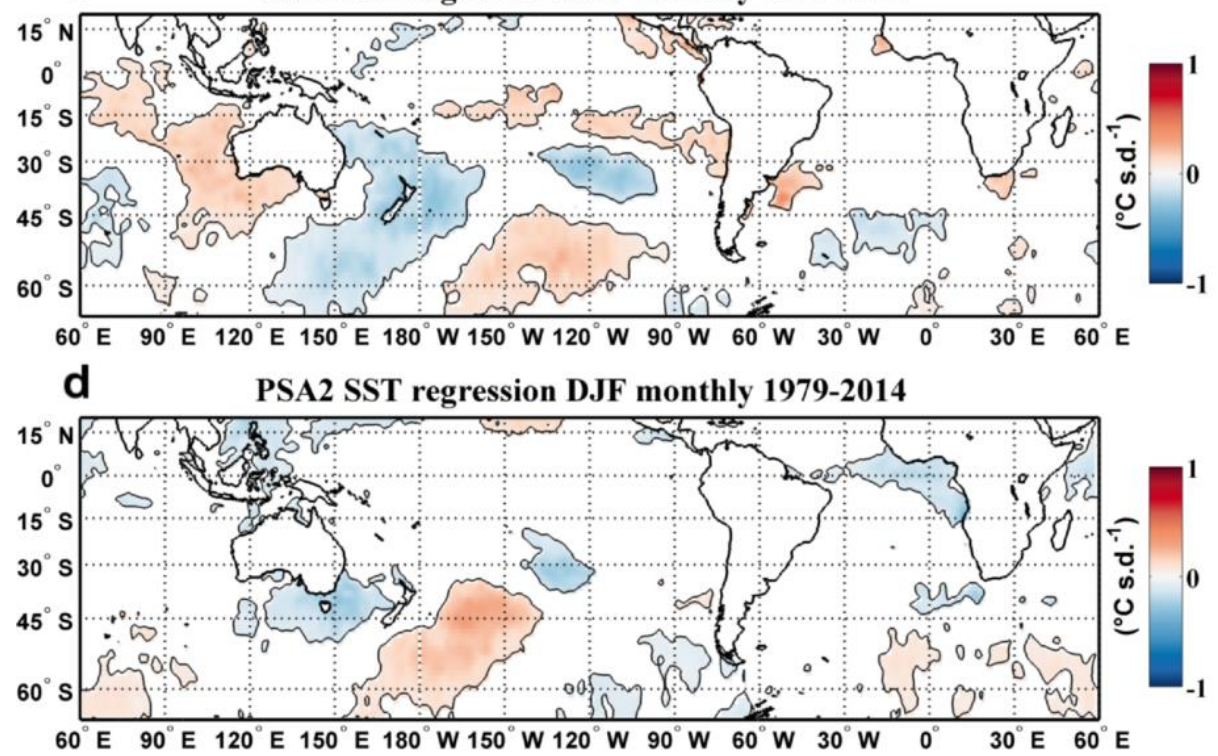

Figure 4.11. (a) Spatial correlation of annually averaged RICE $\delta D$ with seasonal HadISST SST for austral summer (DJF). Correlation coefficients ( $r, p<0.1$, shading) and the black contour lines enclose $p<0.05$ confidence level regions. SAM and PSA1 SST regression patterns enclose regions where both teleconnections are active, and constructively interact (yellow contours) and destructively interact (green contours). Note that we use EOF1 and EOF2 here (SAM and PSA1), as the two first SST EOFs are PSA-like in DJF. In subsequent figures (Figures 4.114.14) we use the PSA-SST regression (EOF1 and EOF2) pattern for the PSA regression contours. (b-d) Regression of SST upon: (b) PC1, (c) PC2, (d) and PC3. Shading shows regression coefficients $(r, p<0.05)$ and black contours enclose regions with a significant $(r, p<0.05)$ confidence level. 


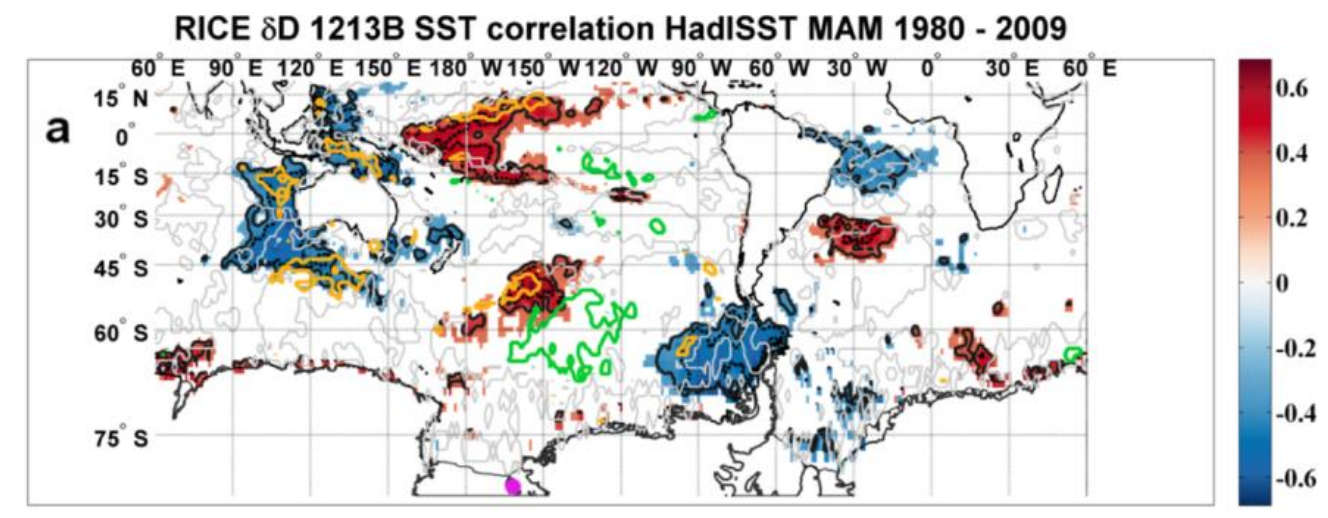

\section{b SAM SST regression MAM monthly 1979-2014}

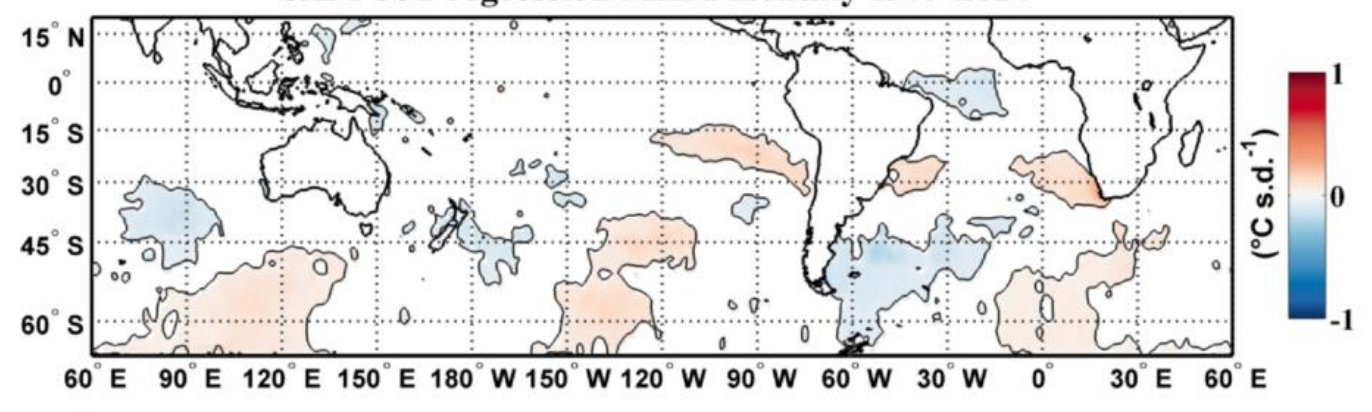

C PSA1 SST regression MAM monthly 1979-2014
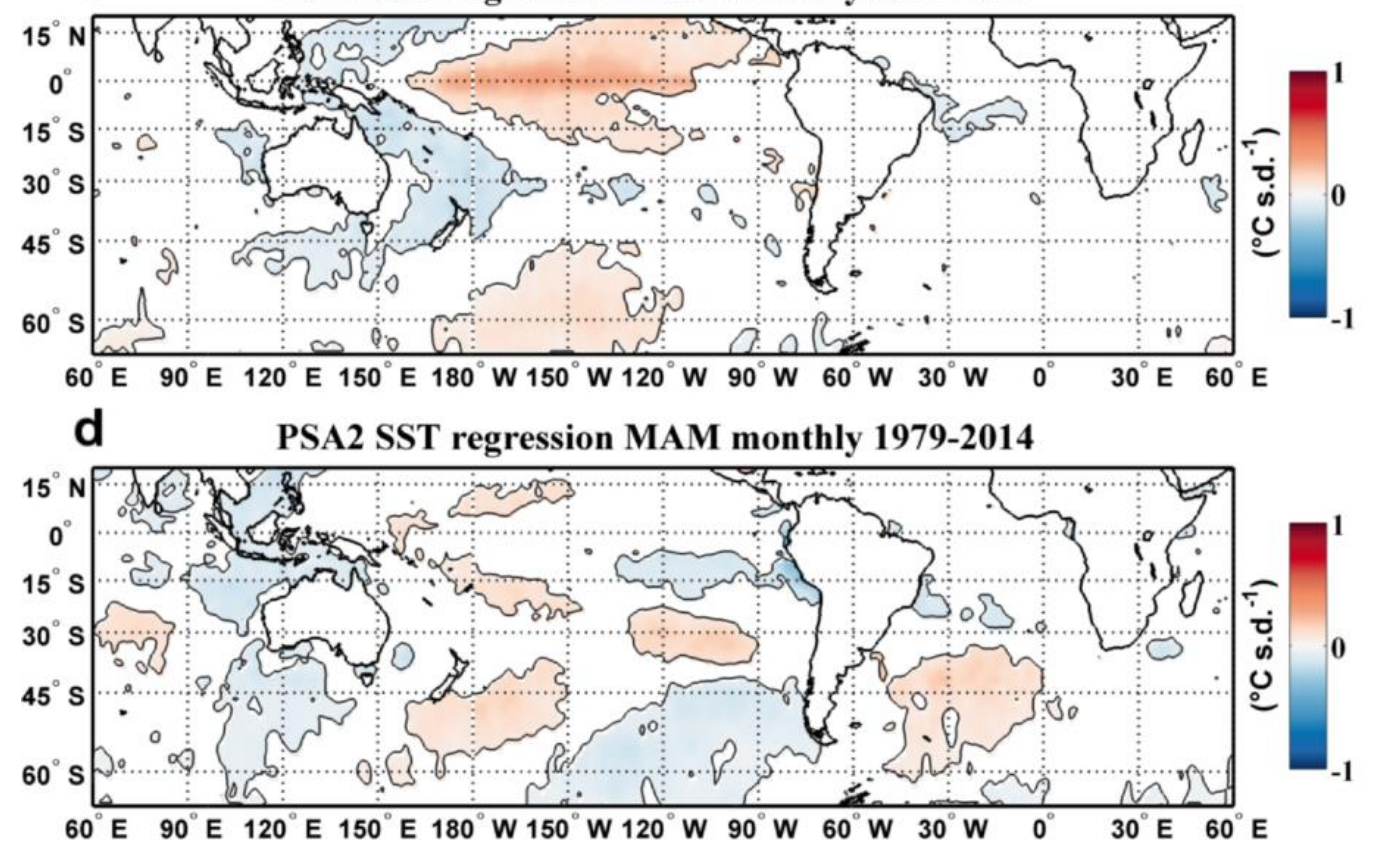

Figure 4.12. RICE $\delta$ D correlation with MAM SST and seasonal SST regression patterns for the circulation modes. Overlain contours enclose regions where both teleconnections are active, and where they constructively interact (yellow contours) and destructively interact (green contours). The overlain significant PSA-SST regression patterns in (a) are from (c) and (d). Details as in Figure 4.11. 


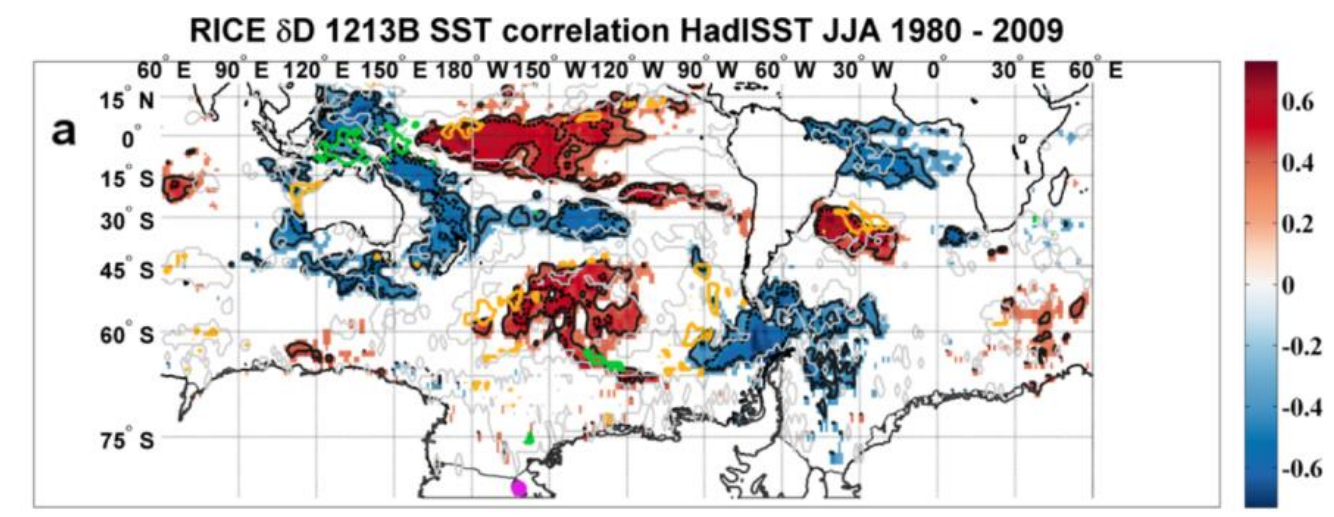

b
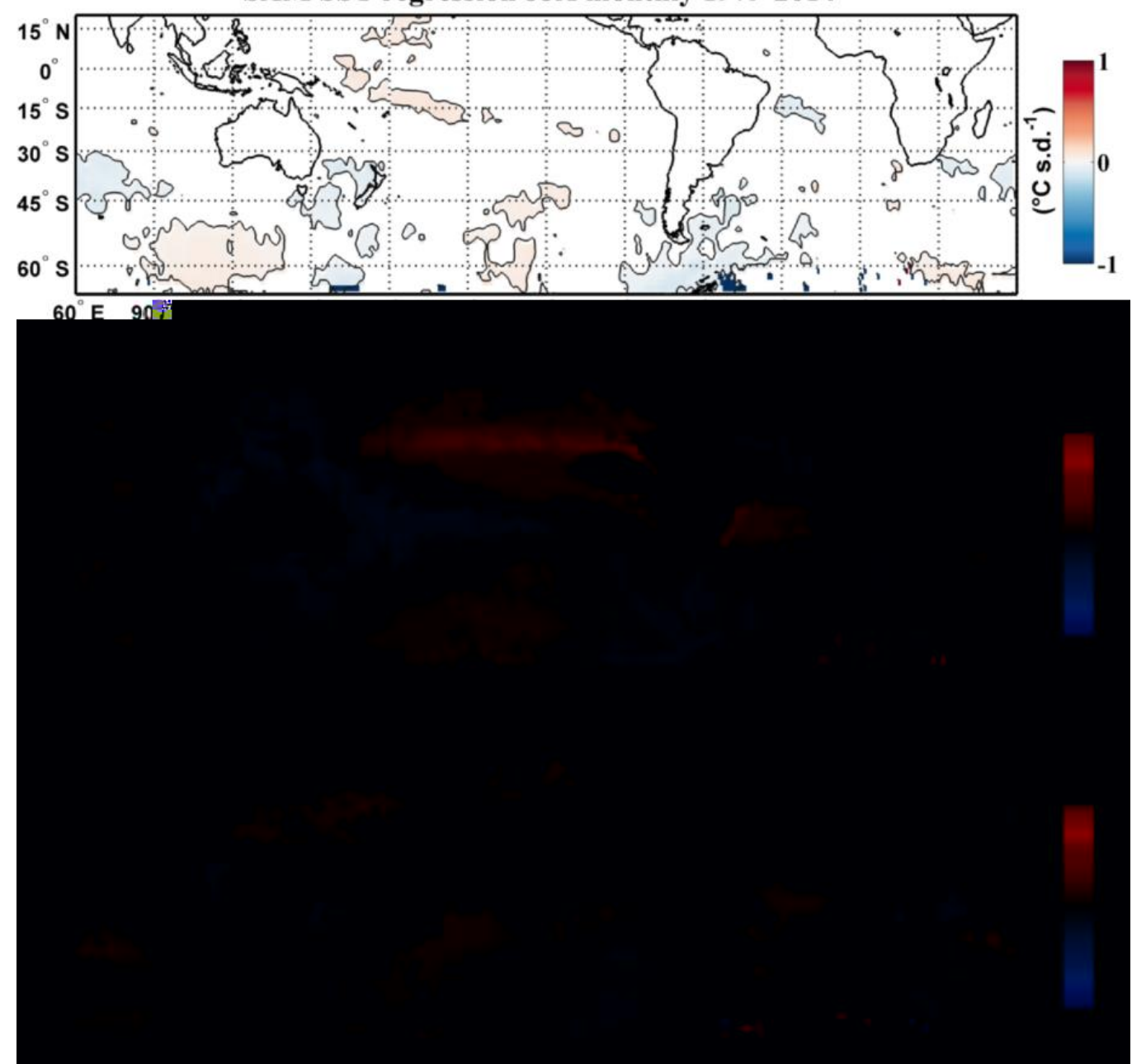

Figure 4.13. RICE $\delta$ D correlation with JJA SST and seasonal SST regression patterns for the circulation modes. Overlain contours enclose regions where both teleconnections are active, and where they constructively interact (yellow contours) and destructively interact (green contours). Details as in Figure 4.11. 
RICE $\delta D$ 1213B SST correlation HadISST SON 1980 - 2009

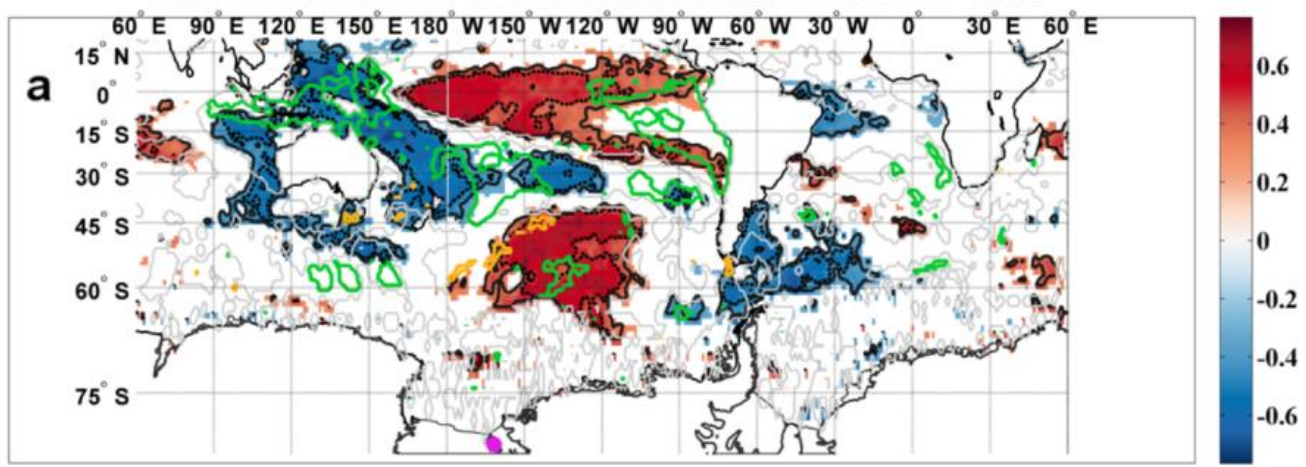

b

SAM SST regression SON monthly 1979-2014

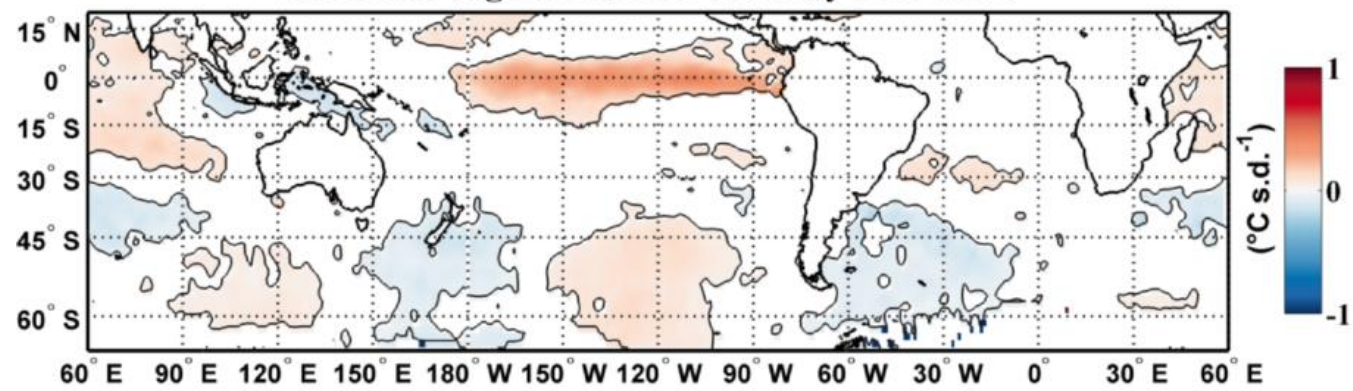

C

PSA1 SST regression SON monthly 1979-2014

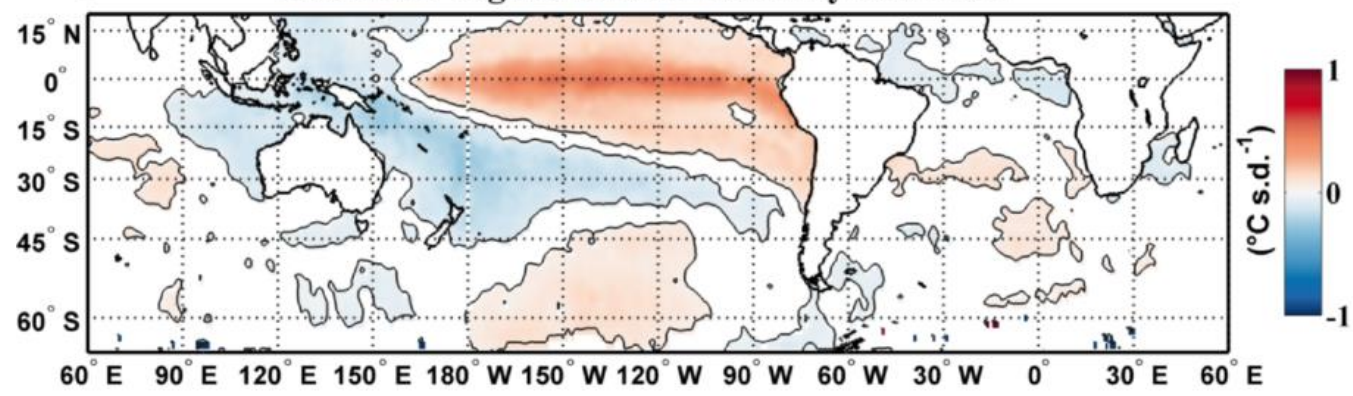

d

PSA2 SST regression SON monthly 1979-2014

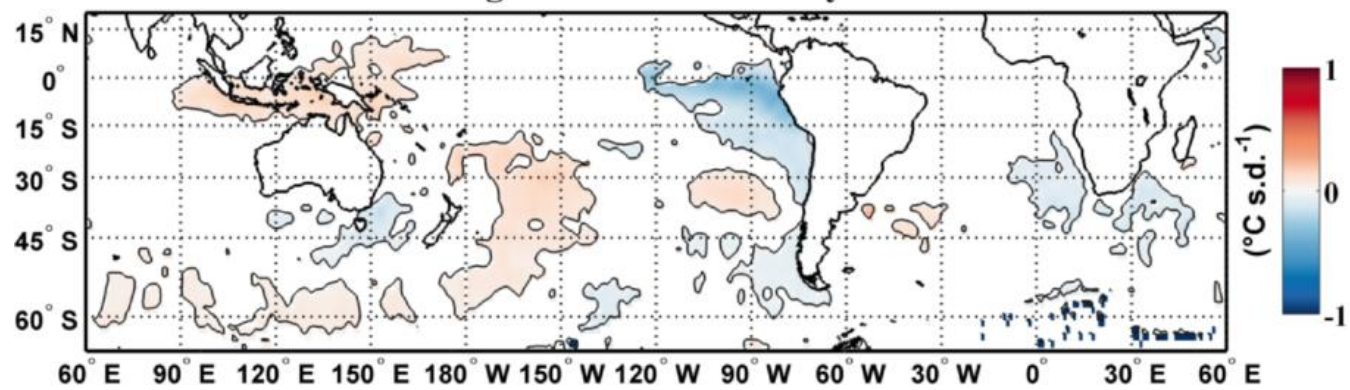

Figure 4.14. RICE $\delta$ D correlation with SON SST and seasonal SST regression patterns for the circulation modes. Overlain contours encloses regions where both teleconnections are active, and where they constructively interact (yellow contours) and destructively interact (green contours). Details as in Figure 4.11. 

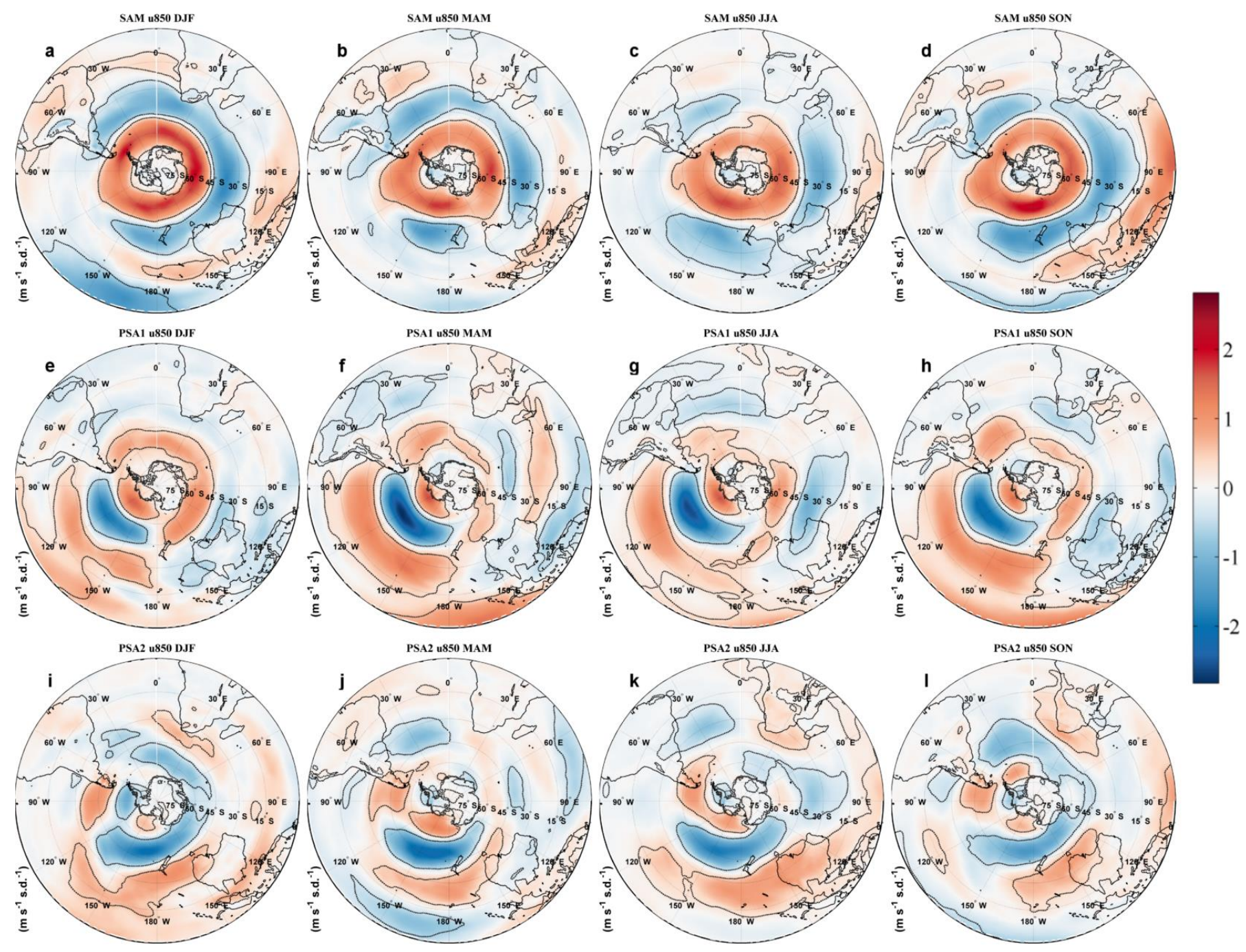

Figure 4.15. Seasonal regression of monthly 850-hPa zonal wind (1980-2014) upon the three first PC indices: (a-d, upper row) EOF1 SAM, (e-h, middle row) EOF2 PSA1, and (i-l, bottom row) EOF3 PSA2. Regression panels are shown for austral summer (DJF, left column), fall (MAM, second column to the left), winter (JJA, second column to the right), and spring (SON, left column). Units are in $\mathrm{m} \mathrm{s}^{-1}$ per standard deviation (s.d.) of the PCs. Regression maps are shown for positive polarity of SAM and the PSA patterns. 

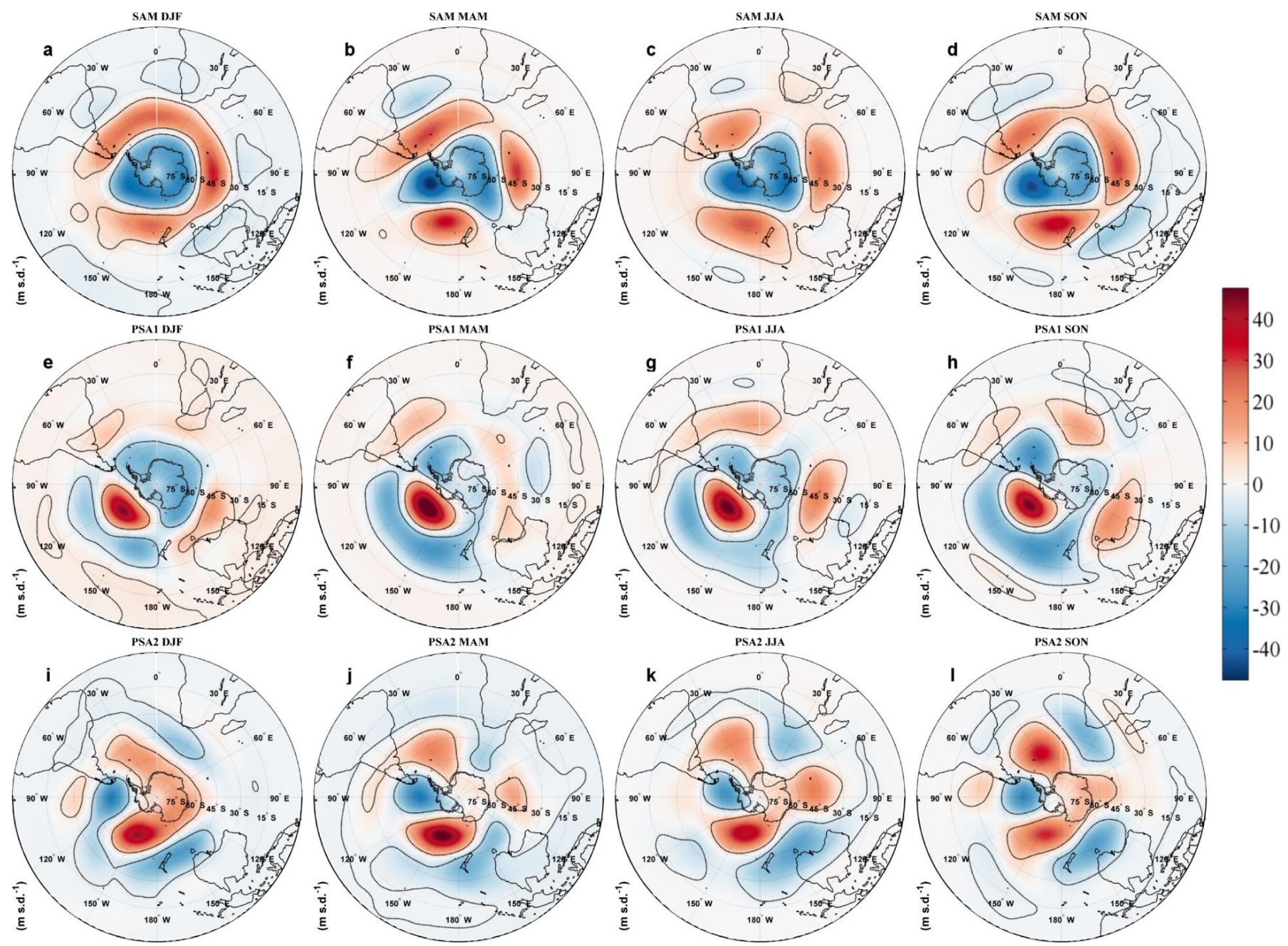

Figure 4.16. Seasonal regression of monthly z500 fields (1980-2014) upon the three first PC indices: (a-d, upper row) EOF1 SAM, (e-h, middle row) EOF2 PSA1, and (i-l, bottom row) EOF3 PSA2. Regression panels are shown for austral summer (DJF, left column), fall (MAM, second column to the left), winter (JJA, second column to the right), and spring (SON, left column). Units are in m per standard deviation (s.d.) of the PCs. Regression maps are shown for positive polarities of SAM and the PSA patterns. 


\subsubsection{Pacific Decadal-Scale Variability}

In addition to interannual variability related to ENSO, SST in the tropical Pacific also varies on time scales of decades and longer [Mantua et al., 1997; Wang et al., 2012]. Pacific decadal-variability is associated with an ENSO-like SST pattern throughout the tropical Pacific, which is associated with far reaching extratropical links in both hemispheres [e.g., England et al., 2014; Trenberth et al., 2014]. The decadal-variability in tropical Pacific SST has been linked to the state of the PDO [Deser et al., 2010a; Trenberth et al., 2014] and the Interdecadal Pacific Oscillation (IPO, [Power et al., 1999; Salinger et al., 2001; Folland et al., 2002]). In fact, all the major modes of Pacific decadal climate contain an El Niño-like pattern [Di Lorenzo et al., 2015]. The IPO has been defined as the $2^{\text {nd }}$ PC of low frequency global SST [Power et al., 1999; Folland et al., 2002] and PDO is the leading PC of monthly SST anomalies over the North Pacific [Mantua et al., 1997; Deser et al., 2010a]. The PDO can be regarded as the North Pacific manifestation of the quasi-symmetric Pacific-wide IPO [Power et al., 1999; Salinger et al., 2001; Folland et al., 2002; Henley et al., 2015]. The South Pacific Decadal Oscillation is PDO's SH counterpart [e.g., Chen and Wallace, 2015]. The IPO appears to be the "reddened" (increasing energy at lower frequencies caused by the integrating effect of the upper ocean mixed layer) ENSO component, driven by both interannual and decadal ENSO variability, which is coherent between the North and South Pacific [Di Lorenzo et al., 2015; Newman et al., 2016]. The source of decadal ENSO variability is an area of debate. The PDO has both been suggested to be modulating ENSO variability [Power et al., 1999; Wang et al., 2008], as well as being influenced by ENSO [Pierce, 2002; Newman et al., 2003]. Di Lorenzo et al. [2015] suggested that the initiation phase of the El Niño-like interdecadal pattern is influenced by meridional modes that project onto the extratropics and tropics and thus provide an extratropical influence on ENSO. The signal is amplified in tropics through atmosphere-ocean interactions and during its mature and decay phase a zonal mode prevails (i.e. ENSO), where tropical variability affects the extratropics in both hemispheres through teleconnections [Di Lorenzo et al., 2015]. The PDO is not a single process, rather the PDO-SST pattern is the result of a combination of different physical process, including both distant tropical Pacific and North Pacific atmosphere-ocean interactions [Newman et al., 2016]. The positive phase of the IPO/PDO is associated with El Niño-like SST pattern (but wider and with reduced amplitude compared to the actual ENSO pattern), with positive SST anomalies in the east-central Pacific and negative anomalies in the 
western tropical Pacific [e.g., England et al., 2014; Trenberth et al., 2014]. The decadal-scale phasing of the PDO and the IPO coincides (Figures 4.17b and 4.18a). As RICE is influenced by the SH expression of Pacific decadal climate variability, we focus our analysis on the IPO, specifically the IPO Tripole Index (TPI, [Henley et al., 2015]). The TPI IPO index, which closely resembles its IPO predecessor, is based on differences between SST anomalies averaged over the central equatorial Pacific and the average of SST anomalies in the Northwest and Southwest Pacific [Henley et al., 2015]. There has been five decadal-scale IPO/PDO polarity changes since 1900 (Figure 4.17b). Considering the brevity of the observational records and the time scale of the IPO phase changes ( 15-30 years), it is important to obtain skillful palaeoclimate reconstructions of Pacific decadal-variability [e.g., Henley et al., 2015; Newman et al., 2016]. Here we primarily investigate whether the influence from low-frequency Pacific variability is preserved in $\delta \mathrm{D}$ for the newly retrieved RICE core. We also examine the variability in $\delta \mathrm{D}$ for ITASE cores.

\subsubsection{Decadal-Scale Variability in RICE $\delta D$}

We explore temporal variability in the preservation of the interdecadal signal in RICE $\delta \mathrm{D}$, by performing 11-year moving-window correlations of $\delta \mathrm{D}$ with the IPO, the Niño-4 index, the PDO, the North Pacific Gyre Oscillation (NPGO) index, SAM indices, and PSA2 indices (Figures 4.17 and 4.18). We adopt this method from Vance et al. [2013], who used it to examine whether Pacific decadal-scale variability was preserved in the Law Dome ice core sea salt record. The RICE $\delta \mathrm{D}$ correlation with IPO tends to remain positive during both negative and positive IPO phases. To explore the origin of the low-frequency $\delta \mathrm{D}$ variability, we also perform sliding decadal-scale correlations with ENSO and SAM indices. The $\delta$ D-IPO correlation closely resembles the Niño-4 correlation (Figure 4.17), and in contrast to the other decadal-scale indices (PDO and NPGO), the IPO and Niño-4 correlation does not break down during the most recent positive IPO phase (Figures 4.17 and 4.18). There is a significant correlation between annual averages of Niño-4 and IPO ( $r=0.86, p<0.001,1900-2009)$. Our analysis is therefore consistent with a recent study that suggested that the IPO mainly is a manifestation of the interannual/decadal-scale ENSO signal, which is coherent between the North and South Pacific [Newman et al., 2016]. We use the Marshall-SAM, Fogt-SAM and the PC1 indices [Marshall, 2003; Fogt et al., 2009] for the $\delta$ D SAM moving-window correlations. The low-frequency relationship between RICE $\delta$ D and SAM is unstable (Figure 4.18b). During the most recent 
positive IPO phase, 1979-1999, RICE $\delta$ D displayed its strongest significant negative SAM correlation (Figure 4.18b), coinciding with a relatively depleted $\delta \mathrm{D}$ state. However, in the past the correlation have broken down (e.g. 1966-1982) and has displayed a weak positive correlation (1933-1955).

In contrast, the RICE $\delta \mathrm{D}$ correlation with Niño-4 SST, as for IPO, tends to stay positive throughout both positive and negative IPO phases. However, the $\delta$ D Niño-4 correlation is weaker when SAM displays an active influence (Figures $4.17 \mathrm{~b}$ and $4.18 \mathrm{~b}$ ). Furthermore, almost without fail the IPO and Niño-4 correlation breaks down when IPO switches phase (1915, 1925, 1944 and 1978; Figure 4.17). Similar results are obtained when $\delta D$ is correlated with the Niño-3.4 SST index and with SST within Area 1 in the CTP (not shown). Thus, the modulation of the $\delta \mathrm{D}$ decadal-scale variability occurs through CP-ENSO and SAM. This is demonstrated by adding together the correlation coefficient time series for the Niño-4 and SAM indices, where the combined correlation coefficients series (red lines in Figure 4.18d) tracks the decadal-scale $\delta \mathrm{D}$ variability. The isotopic record is in a depleted state when the correlation with SAM is active and the correlation with Niño-4 is weak, and relatively enriched when the correlation with SAM breaks down and the correlation with Niño-4 is strong (Figures 4.18b and 4.18d). The breakdowns with SAM seem to be associated with negative IPO phases and the $\delta \mathrm{D}-\mathrm{SAM}$ correlations appear to be significant and negative during positive IPO phases (Figure 4.18b, d).

Decadal-scale tropical Pacific variability (IPO and Niño-4) appears to be preserved in the RICE $\delta \mathrm{D}$ record (Figure 4.18 and Table 4.5). However, the $\delta \mathrm{D}$ correlation with IPO and Niño-4 is weaker when the $\delta \mathrm{D}-\mathrm{SAM}$ correlation is significant. The occasions when the IPO and Niño-4 indices correlations break down coincide with IPO phase transitions and/or periods with lowIPO/PDO amplitude (neutral IPO). However, $\delta \mathrm{D}$ does not display low ratios during the first half of the 1979-2000 positive IPO interval. This is attributed to a large broad Niño-4 peak (Figure 4.19), which exerts influence even if the Niño-4 correlation coefficients are weak during this part of the IPO interval (Figure 4.18d).

Note that the $~ 1915-1925$ breakdown of the IPO and Niño-4 correlations coincides with three close IPO switches (two for PDO; Figures 4.17a and 4.18a) and with a weak negative PDO/IPO index (neutral IPO [Henley et al., 2015]). Interestingly, the $\delta \mathrm{D}-\mathrm{Niño-4}$ correlation appears to be negative during this period, but the correlation is weak. However, SST are less well 
constrained prior to the 1950s. Furthermore, this version of the RICE age-scale (Section 1.6) is not as well-constrained during the first part of the twentieth-century, thus, perhaps not allowing for interannual correlations. Additionally, the depleted $\delta \mathrm{D}$ in the 1920 s and weaker Niño-4 correlation coincide with the negative correlation with SAM and positive correlation with SST south off the coast of Australia. This can be related to a positive SST south off the coast of Australia anomaly period in the 1920s and thus an increased SAM influence, through SAM's PSA-like influence (Figure 4.6c). The $\delta \mathrm{D}-\mathrm{SST}$ correlation south off the coast of Australia do not appear to display a clear relationship with IPO phases (Figure 4.18c). Instead, the $\delta D-S S T$ correlation south off the coast of Australia displays a significant correlation congruent with a 1920s warm SST period, and then in general a positive correlation throughout the latter part of the twentieth-century congruent with the positive trend in SST south of Australia (Figure 4.18c). SST south of Australia display a significant positive trend $\left(0.113^{\circ} \mathrm{C} \operatorname{decade}^{-1}, p<0.01,1979-\right.$ 2014, Figure 4.8a). However, the trend was even stronger between the 1930s and late 1970s $\left(0.132^{\circ} \mathrm{C} \mathrm{decade}^{-1}, p<0.001,1930-1977\right.$, Figure 4.19). 

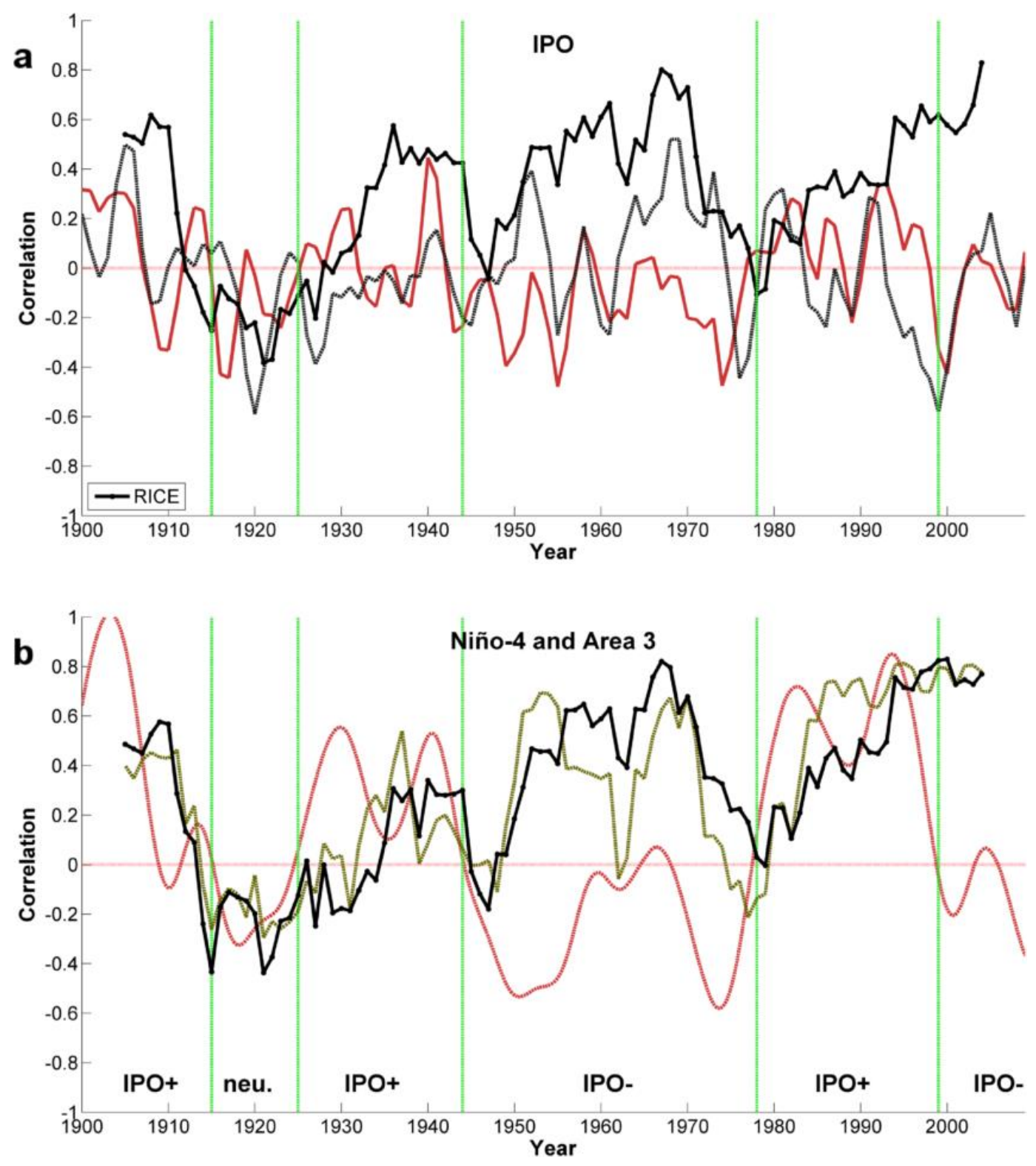

Figure 4.17. (a) Eleven-year moving-window correlation (black line) of annual RICE $\delta \mathrm{D}$ (gray line, shown as anomalies) with annual averages of Interdecadal Pacific Oscillation (IPO, [Henley et al., 2015], red line, shown as anomalies). (b) As in (a) but for the Niño-4 SST index (NOAA Climate Prediction Center, black line $)$ and SST in Area $3\left(44^{\circ}-56^{\circ} \mathrm{S}, 140^{\circ}-163^{\circ} \mathrm{W}\right.$; green line). Gaussian smoothed (equivalent to an 11-years running mean) monthly IPO index (red line; scaled by dividing by 2). Green vertical lines indicate IPO/PDO polarity transitions in 1915 , 1925, 1944, 1978, and 1999 (also depicted in Figures 4.18-4.20). 

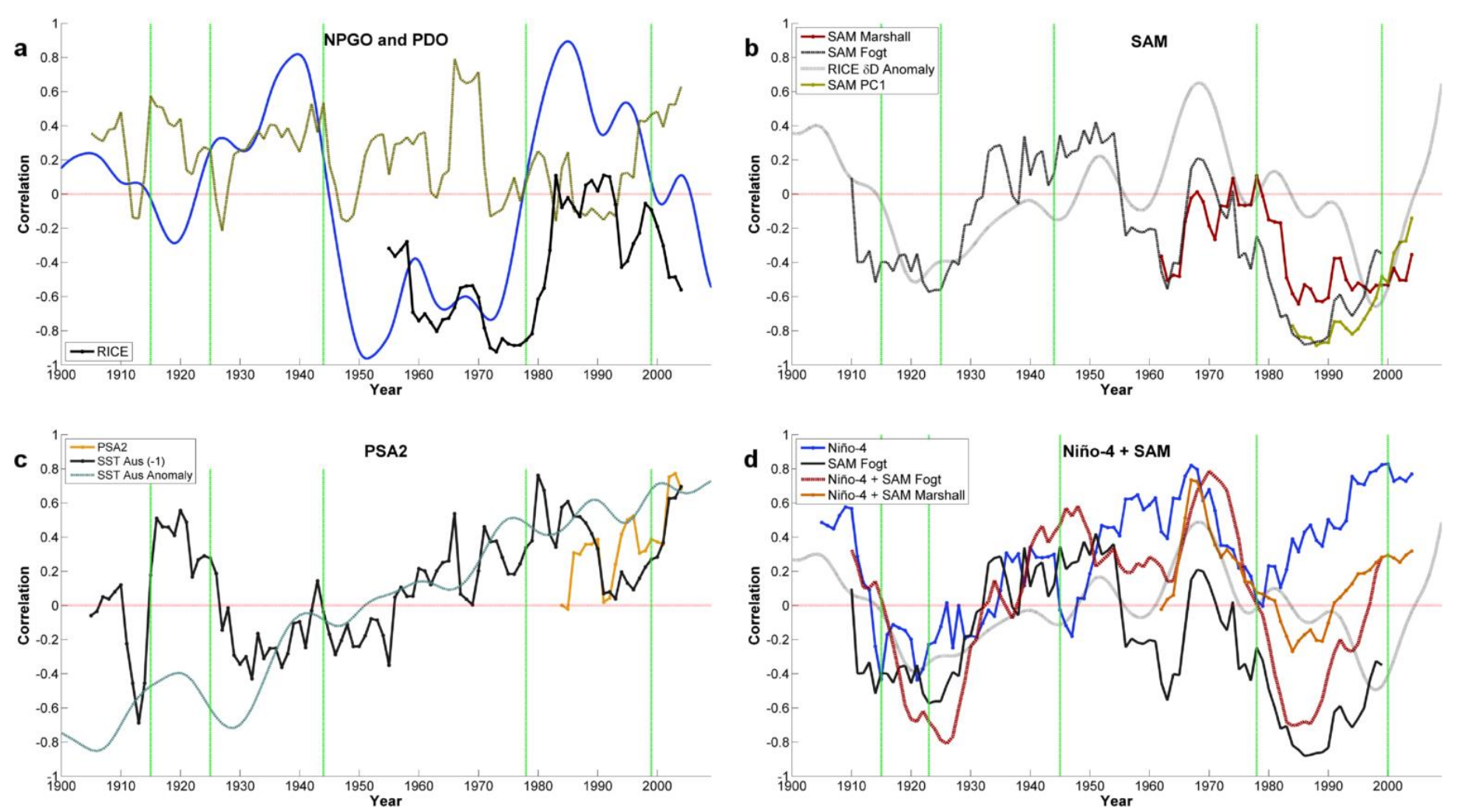

Figure 4.18. (a) Eleven-year moving-window correlation of annual RICE $\delta D$ with the North Pacific Gyre Oscillation index (NPGO, [Di Lorenzo et al., 2008]; black line) and Pacific Decadal Oscillation index (PDO, [Mantua et al., 1997], green line). Also shown is the 11-yr Gaussian smoothed PDO index (blue line). (b) As (a) but correlations with the Fogt-SAM index ([Fogt et al., 2009], black line), Marshall-SAM index ([Marshall, 2003], red line) and the SAM PC (green line). Also shown is the RICE $\delta \mathrm{D} 11-\mathrm{yr}$ Gaussian smoothed record (gray line). (c) As in (a) the PSA2 PC (yellow line), and with SST south off the coast of Australia (black line, inverted) and south off the coast of Australia SST anomalies (gray line, scaled dividing by 2). (d) 11-year moving-window correlation of RICE $\delta \mathrm{D}$ with the Niño-4 (blue line) and Fogt-SAM index (black line). Difference between the Niño-4 and Fogt-SAM correlation coefficients (red line), and difference between the Niño-4 and Marshall-SAM index correlation coefficients (yellow line). 


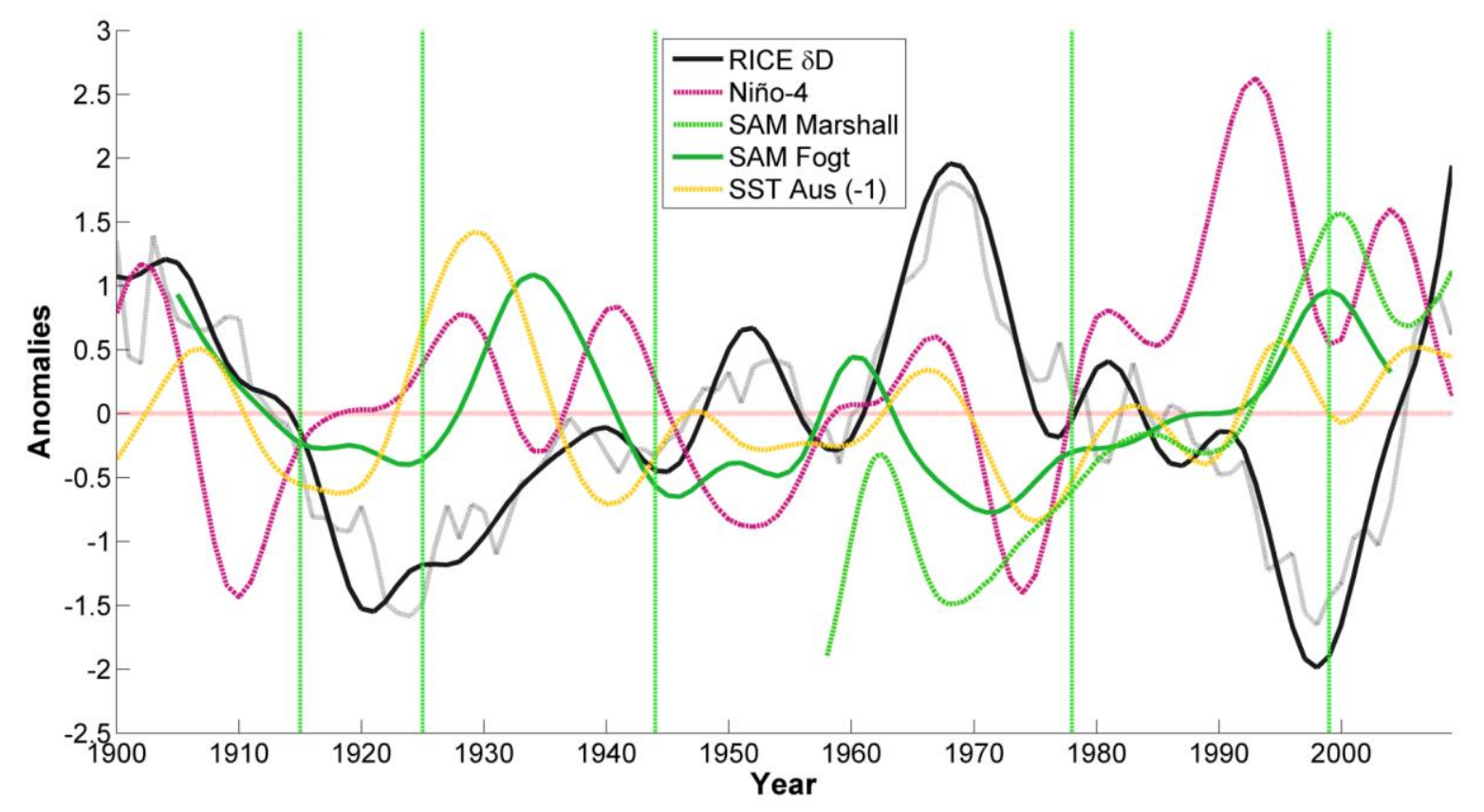

Figure 4.19. RICE $\delta \mathrm{D}$ (black line), Niño-4 (magenta line), the Marshall-SAM index (green line), the Fogt-SAM index (green line), and SST south of the coast of Australia (yellow line, inverted, detrended and scaled by dividing by 2). All records are shown as anomalies and have been smoothed with a Gaussian filter (equivalent to 11-years running mean). Also shown is the 11 -years running mean of RICE $\delta \mathrm{D}$ (gray line) is depicted behind $\delta \mathrm{D}$ Gaussian smooth.

The $\delta$ D-PDO correlation also tends to be positive (Figure 4.18a), with the exception of a recent mid-1970 to the late 1990s period, when influence from SAM increased and appears to have been larger compared to the Niño-4 ENSO index in the 1980s (Figure 4.18d). PDO's correlation is weaker compared to IPO and Niño-4 (which compared to PDO have a stronger central-Pacific SH influence). Additionally, we correlate $\delta \mathrm{D}$ with North Pacific Gyre Oscillation index (NPGO; 1950-2009). RICE $\delta$ D appears to be more sensitive to NPGO, compared to PDO, as central Pacific ENSO events project upon the NPGO. Whereas, PDO is associated with a stronger influence from the eastern Pacific [Di Lorenzo et al., 2015]. The NPGO is the second EOF of sea-surface heights in the North Pacific [Di Lorenzo et al., 2008]. The RICE $\delta$ D-NPGO correlation displays a significant negative correlation during its matching interval (1950-1978) with the negative IPO phase (Figure 4.18a). The $\delta$ D-NPGO correlation displays a similar breakdown as the $\delta$ D-PDO correlation during the recent positive IPO/PDO phase (1979-1999), but with a later onset in the beginning of the 1980s (Figure 4.18a). Unfortunately, the NPGO index does not extend further back than 1950. The RICE $\delta$ D correlation breakdown with the 
PDO and NPGO Pacific decadal indices, coincide with the period of strongest significant negative SAM correlation between the early 1980s and late 1990s (Figure 4.18a). It is thus possible that $\mathrm{SAM}$ has become a stronger $\delta \mathrm{D}$ modulator due to its positive trend and has reduced the influence from the tropical Pacific ENSO signal on $\delta \mathrm{D}$, during the most recent positive IPO/PDO phase (1979-1999). In fact, the significance with the SAM indices is stronger than for the IPO and ENSO Niño-4 indices during this period (1979-1999; Figure 18d). This provides a compelling explanation as to why the correlation with the central Pacific decadal-variability indices (IPO and Niño-4) is reduced and the correlation with the North Pacific indices (PDO and NPGO) breaks down during the latest positive IPO period. The difference between the decadalscale indices correlation on $\delta \mathrm{D}$ is attributed to that both IPO and $\delta \mathrm{D}$ are highly influenced by central-Pacific decadal-scale ENSO variability (Niño-4), whereas RICE $\delta \mathrm{D}$ is less sensitive to the North Pacific centered components of the PDO (e.g. the Aleutian Low and North Pacific SST "reemergence").

However, our ability to assess the significance of the RICE $\delta$ D-Pacific decadal relationship is hampered by the brevity of the observational records, and the nature of the low-frequency variability that requires extended datasets to assess significance. RICE $\delta \mathrm{D}$ can potentially be employed for decadal-scale SST reconstruction in the central-equatorial Pacific (Niño-4) and South Pacific (Area 3; Figure 4.17). Future research can involve comparisons of RICE $\delta D$ with existing palaeo-SST reconstructions [e.g., Linsley et al., 2008; Tierney et al., 2015]. 
Table 4.4. States of climate modes during IPO/PDO positive and negative states and their relation to RICE $\delta D^{\mathrm{a}}$

\begin{tabular}{ccc}
\hline & IPO+ & IPO- \\
\hline Periods & 1979-1999 & 1945-1979, 2000-2012 \\
State & PSA1+ (El Niño) & PSA1- (La Niña) \\
& PSA2+ & PSA2- \\
& SAM- & SAM+ \\
& weak ASL & deep ASL \\
& RS and AS & \\
& anticyclones & RS and AS cyclones \\
& PFJ- & PFJ+ \\
$\delta$ D-ENSO corr & pos. significant & pos. significant \\
$\delta D-S A M$ corr & neg. significant & breakdown \\
RICE $\delta$ D anomaly & $\delta D-$ & $\delta$ D + \\
\hline
\end{tabular}

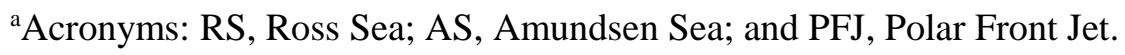

Table 4.5. RICE $\delta D$ averages for PDO polarity phases ${ }^{\mathrm{a}}$

\begin{tabular}{ccc}
\hline IPO period & Polarity & RICE $\delta D(\%)$ \\
\hline $1925-1944$ & pos. & -181.08 \\
$1945-1978$ & neg. & -176.45 \\
$1979-1999$ & pos. & -180.61 \\
\hline
\end{tabular}

${ }^{\mathrm{a}}$ The IPO polarity averages can be compared to the RICE $\delta$ D mean of $-178.9 \%$ (1900-2009).

\subsubsection{SAM Breakdown Hypothesis}

During the negative state of the IPO, La Niña becomes more frequent, the polar front jet strengthens (partly driven by an increase frequency of PSA1 and PSA2 cyclones) SAM tend to appears in its positive state and importantly the ASL is anomalous deep (Table 4.4). It therefore appears that the variability in SAM has little effect on $\delta \mathrm{D}$ during an anomalously positive state of SAM. These conditions prevail during a negative IPO/PDO phase. We hypothesize that this can be due to the deep state of the ASL, associated with a positive SAM state that results in an eastward longitudinal-circulation migration [e.g., Turner et al., 2013] and enhanced air mass advection over AP and Ellsworth Land. Thus, during a prevailing anomalous deep ASL state (caused by SAM-variability), a weakening of the ASL (also related to SAM variability), appears to not result in an increase in blocking, only a weakening of the low. Therefore, air mass advection into RICE does not appear to display any significant correlation with the variability in SAM. As easterly-located ABS cyclones, whether weak or vigorous, does not appear to be 
associated with moisture transport to RICE, as it would imply that flow across the WA interior prior to reaching RICE would be associated with precipitation (Chapter 3).

In contrast, the positive state of the IPO is associated with increased frequency of El Niño, a weaker SAM, a shallower ASL, and frequent ABS blocking [e.g., Turner, 2004; Trenberth et $a l ., 2014]$. These conditions are associated with northerly moisture transport into RICE. SAM variability appears to play an active role for RICE during IPO+ conditions, and increasingly so due to its positive trend. SAM appears to actively impact blocking frequencies during a positive state of the IPO. Additionally, during a shallower ASL, cyclones tend to be located further west, conditions under which Amundsen Sea cyclones can bring in moisture to RICE, however, with a depleted $\delta \mathrm{D}$ signature due to transport over western Marie Byrd Land orography. Circumstantial evidence for the hypothesize comes from: the breakdown of the $\delta \mathrm{D}-\mathrm{SAM}$ indices' correlation during the 1945-1978 negative IPO coincides with an enriched isotopic period and the highest broad peak in $\delta \mathrm{D}$ in the mid-1960s (Figures 4.18b and 4.18d; Also importantly with positive SST anomalies in the Niño-4 region and negative SST anomalies south of Australia, Figure 4.19). Furthermore, the recent strong negative $\delta$ D-SAM (1979-1999, PDO+) and the negative $\delta D-S A M$ correlation interval in the beginning of the twentieth-century ( 1915-1930, IPO+/neutral IPO) both coincide with a depleted $\delta \mathrm{D}$ signals (Figure $4.18 \mathrm{~b}$ and Table 4.5).

\subsubsection{West Antarctic $\delta D$ Pacific Decadal-scale Variability}

ITASE 2000-5 displays notable similarities with the RICE decadal-scale correlations (Figure 4.20), which is consistent with its western Marie Byrd Land location, and with previous studies that have indicated that this core preserves a climate signal [Küttel et al., 2012]. However, in contrast to RICE, ITASE 2000-5 $\delta$ D correlation with IPO is weaker during most of the correlation (Figure 4.20). ITASE 2000-1 (located on the WAIS-Divide) $\delta$ D correlation with IPO is weak throughout most of the correlation interval (Figure 4.20). The ITASE 2001-5 (Ellsworth Land) $\delta$ D correlation with IPO is typically strong but is associated with frequent switches in sign of the correlation with IPO (Figure 4.20). Among the examined cores, the preservation of IPO variability appears to be unique for RICE (Figure 4.20). RICE appears to be exclusive in that it preserves the polarity of PSA1 and thus the ENSO correlation remains significant throughout both IPO phases. 


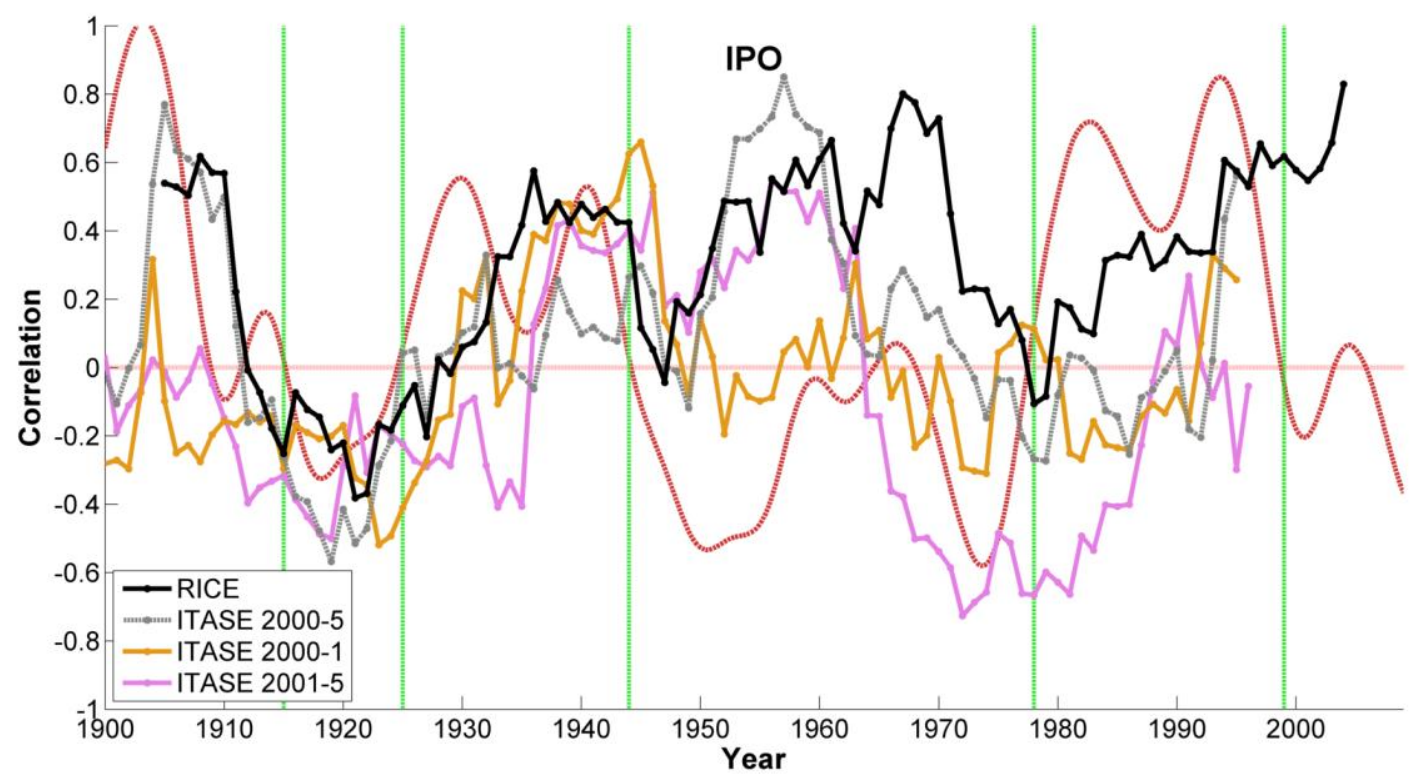

Figure 4.20. Eleven-year moving-window correlation of Interdecadal Pacific Oscillation (IPO) index with $\delta$ D ratios from several ice cores (RICE, ITASE 2000-5, ITASE 2000-1, and ITASE 2001-5).

\subsubsection{Modern RICE Snow Accumulation and $\delta D$ Trends}

There are no long-term significant trends in the RICE snow accumulation and $\delta \mathrm{D}$ records (Figure 4.2, 1900-2009). Neither is there a significant trend over the satellite-era interval $\left(-2.07 \%\right.$ o decade $\left.{ }^{-1}, p=0.39,1979-2009\right)$. However, from 1965 and onwards, the records show a significant decrease in snow accumulation $\left(-1.88 \mathrm{~cm}\right.$ w.e. decade $\left.^{-1}, p<0.01,1965-2009\right)$ and $\delta \mathrm{D}\left(-3.11 \%\right.$ decade $\left.{ }^{-1}, p<0.05,1965-2009\right)$. These recent trends do not appear to be outside of the range of records natural variability (Figure 4.2). The trend in the RICE $\delta \mathrm{D}$ record is a consequence of elevated isotope ratios between 1963 and 1974 (Figure 4.2b;-169.3\%o) and anomalously low ratios in the mid to late 2000s (-189.4\%o, 1993-2000). Anomalously high $\delta^{18} \mathrm{O}$ ratios between mid-1960 and the mid-1970s have also been reported from an array of firn cores from the Ross Ice Shelf [Clausen et al., 1979].

The significant trend in $\delta \mathrm{D}$ and snow accumulation since the mid-1960s is attributed to changes in the drivers of low-frequency $\delta \mathrm{D}$ variability, related to the transition from a negative IPO state to a positive IPO state. RICE $\delta$ D was in an anomalously enriched state during the 1945-1978 negative IPO regime, which we attribute to the congruent breakdown of the correlation with SAM. In contrast, the recent positive IPO state has been associated with a strong 
SAM influence, due to an active negative $\delta \mathrm{D}-\mathrm{SAM}$ correlation and a concurrent strengthening of SAM. For RICE $\delta \mathrm{D}$, one can think of the strength of the ENSO influence as being modulated by SAM, through periods of active influence from SAM (associated with weaker ENSO signal and relatively depleted $\delta \mathrm{D}$ ) and through periods associated with a breakdown of the correlation with SAM (strong correlation with ENSO and enriched $\delta \mathrm{D}$ ). Where the $\delta \mathrm{D}-\mathrm{SAM}$ active and breakdown phases largely corresponded to IPO phases and where SAM appears to have become a stronger modulator during positive IPO phases, due to its increasing trend since the mid-1960s.

During recent decades low-frequency ENSO variability [Power et al., 1999; Wang et al., 2008], has caused a suppression of positive central-eastern equatorial SST anomalies (Figure 4.8a) and thus a decline in El Niño and an increase in frequency of La Niña events [England et al., 2014; Trenberth et al., 2014; Schneider et al., 2015]. In addition to eastern tropical Pacific SST trends (Figure 4.8a; [e.g., Meehl et al., 2016]), SST south of Australia associated with PSA2 wave train initiation (Figure 4.6e), are closely linked to the conditions in the ASL region [Ding et al., 2011, 2012]. SST in this region display a significant positive trend $\left(0.113^{\circ} \mathrm{C}\right.$ decade $^{-1}, p<$ $0.01,1979-2014$, Figure $\left.4.8 \mathrm{a} ; 0.105^{\circ} \mathrm{C}_{\text {decade }^{-1}, p}<0.01,1900-2014\right)$. The PSA2 associated positive SST trend therefore provides an additional modulator of the depth of the ASL, specifically to negative seasonal z500 trends in the Ross Sea region $\left(\sim 150^{\circ} \mathrm{W}\right.$, Figures $4.8 \mathrm{~b}-$ $4.8 \mathrm{e})$. The reported positive SST trends in the western tropical and western-central subtropical Pacific (Figure 4.8a) [Deser et al., 2010b; Schneider et al., 2011, 2015; Simpkins et al., 2014], can thus potentially be linked to reduced geopotential heights in the Amundsen Sea (Figures 4.4a and $4.5 \mathrm{a})$ and strengthening of $850-\mathrm{hPa}$ zonal westerly winds $\left(\sim 60^{\circ} \mathrm{S}\right)$ around Antarctica. This is in agreement with the reported strengthening of the SAM [Thompson and Solomon, 2002; Marshall et al., 2004; Ding et al., 2012; Schneider et al., 2015] and observed deepening of the ASL (Figures 4.8b-4.8e) [Burgener et al., 2013; Turner et al., 2013]. The trend in $\delta D$ coincide with positive summer and fall trends in the SAM [Marshall, 2003] index (DJF, 0.67 decade $^{-1}, p$ $<0.001,1965-2009$; MAM, 0.36 decade $\left.^{-1}, p<0.01,1965-2009\right)$ and a decline in stratospheric ozone since the early 1960s [Thompson and Solomon, 2002; Gillett and Thompson, 2003; Son et al., 2008; Thompson et al., 2011]. A warmer climate has been suggested to be associated with an increase in the positive-phase of the SAM [Fyfe et al., 1999; Cai et al., 2003; Marshall et al., 2004; Miller et al., 2006]. A recent study by Schneider et al. [2015] indicates that both stratospheric ozone depletion and tropical Pacific SST have a significant role in the 
strengthening of the $\mathrm{SH}$ westerlies around Antarctica $\left(\sim 60^{\circ} \mathrm{S}, \mathrm{SAM}\right)$. Combined these factors provide a compelling explanation to why the SAM influence on $\delta \mathrm{D}$ has become stronger during the most recent positive IPO phase (Figure 4.18d). Thus, the recent trend in $\delta \mathrm{D}$ is likely caused by a natural IPO cycle, where however, its depleted signature during the IPO positive/active SAM is anomalously low due to the positive trend in SAM. Where the strengthening of SAM can partly by anthropogenically induced from ozone and through positive secular SST trends.

\subsection{Conclusions}

In this study, we characterize and interpret the water-isotope $(\delta \mathrm{D})$ data of the RICE ice core. The RICE isotope record provides a proxy record that captures the CP-ENSO variability (SST in the Niño-4 region). RICE $\delta$ D correlation with SST displays a significant correlation pattern over the CTP, which contains the Niño-4 region. SST anomalies in the Niño-4 region are commonly regarded to be forcing CP-ENSO variability. Amundsen Sea anticyclones are associated with El Niño [Turner, 2004] and positive PSA1 [Kidson, 1988; Mo, 2000]. Amundsen Sea anticyclones impede zonal westerly winds and convey the blocked westerly flow towards western Marie Byrd Land (Chapter 3). These conditions are associated with increased precipitation and an enriched $\delta$ D-signal at RICE. Vice versa for La Niña and Amundsen Sea cyclones, which are linked to a depleted $\delta \mathrm{D}$. Thus, owing to the marked difference in the response of RICE $\delta \mathrm{D}$ to the CP-ENSO polarities (CP-El Niño and CP-La Niña), RICE $\delta \mathrm{D}$ preserves CP-ENSO variability.

Recent studies have shown that the nature of the CP-El Niño has changed over recent decades, imposing changes to the ENSO teleconnections and climate in countries surrounding the Pacific Ocean and Antarctica [Seager et al., 2010; Thompson et al., 2011; Furtado et al., 2012]. Thus, establishing the intrinsic natural CP-ENSO variability is an important step for determining whether recent increasing trends in CP-El Niño occurrence frequencies are within the range of natural variability and to constrain future climate predictions. RICE $\delta \mathrm{D}$ preserves low-frequency Pacific ENSO-like variability. RICE $\delta$ D appears to be characterized by anomalously high values during IPO negative periods (1945-1978), and low anomalies for the opposing, IPO positive state (1922-1944 and 1979-2000). ENSO appears to provide a “constant" signal, away from IPO transitions, and the low-frequency tropical Pacific influence on the RICE $\delta \mathrm{D}$ record appears to be weakened/modulated by an active and non-active influence 
from SAM during IPO+ and IPO- conditions, respectively. If the correlation with SAM is strong during the IPO+ phase, the RICE $\delta$ D correlation with IPO and Niño-4 is reduced. The influence from SAM during IPO+ has increased congruent with the positive trend in SAM. To our knowledge, the RICE isotopic record is the first ice core record where interannual and decadalscale ENSO variability appears to be preserved throughout both negative and positive IPO states.

An IPO proxy reconstruction can potentially establish natural-variability boundaries and determine which tropical Pacific SST forcing cycle (CP-El Niño or CP-La Niña) has prevailed in the past, i.e. the polarity of IPO. This will be a highly relevant record as CP SST have a large influence on tropical, as well as mid-latitude and high-latitude, climate variability [Deser et al., 2004; Ding et al., 2011, 2012; Schneider et al., 2011; Okumura et al., 2012; Bromwich et al., 2013; Henley et al., 2015]. A proxy reconstruction using the RICE $\delta$ D can provide a record longer than currently available observational data sets, allowing us to examine the intrinsic lowfrequency variability of Pacific climate. However, our ability to evaluate the significance of the RICE $\delta$ D-Pacific decadal relationship is hampered, by the brevity of the observational records and the nature of the low-frequency variability, that require longer datasets to assess significance, compared to the interannual correlations. Thus, these findings warrants further investigation using the full extent of the RICE record.

As Rodrigues et al. [2015], we also argue that CP-El Niño is linked to PSA2. However, we argue that PSA2 mainly is forced by SST anomalies south and southeast of Australia. This is consistent with earlier studies that have linked this region as a source of Rossby wave train generation [Ding et al., 2011, 2012]. The interaction and interference between PSA1 and PSA2 wave trains varies seasonally and spatially. The PSA2 wave train is strong in austral summer (DJF) and fall (MAM) and the high-latitude influence from PSA1 increases throughout the year, with a peak in spring. The PSA seesaw patterns coincide over vast regions of the Pacific sector: the central high-latitudes $\left(\sim 45^{\circ}-60^{\circ} \mathrm{S}, 100^{\circ}-170^{\circ} \mathrm{W}\right)$, and the subtropical Pacific $\left(30^{\circ} \mathrm{S}\right.$, particularly in DJF). The destructive (dampening effect from PSA pattern with SST of opposing signs) interference from PSA2 on the PSA1-ENSO signal is reduced during the latter part of the year (JJA and SON). Mainly because the polar front jet, associated with PSA2, becomes weak in comparison to the subtropical jet (associated with PSA1), as the subtropical jet strengthens during the latter part of the year. The SST influence from PSA2 thus becomes small in 
comparison to PSA1, i.e. it appears to lose its ability to cancel-out SST anomalies linked to PSA1. Therefore, a relatively unperturbed PSA1-ENSO signal can propagate southward to the extratropics and Antarctica in spring (SON), which is the most mature ENSO season out of JJA and SON. In addition to a weaker DJF ENSO signal caused by a weak subtropical jet, the strength of the ENSO (PSA1) signal is reduced further by a seasonally pronounced high-latitude destructive interaction (dampening of SST) caused by interference between the PSA patterns. Thus, providing a compelling explanation to the weak ENSO (PSA1) signal in the extratropics and Antarctica in austral summer, compared to spring.

Acknowledgements. We are grateful to the ECMWF institute for providing the ERA-Interim reanalysis data sets and we thank the Hadley Centre for providing the HadISST data sets. We would also like to thank the United States National Snow and Ice Data Center for making ITASE isotope data available (https://nsidc.org/). The funding for the project was provided by the New Zealand Government through GNS Science (Global Change through Time Programme, GNS540GCT12 and GNS-540GCT32) and Victoria University of Wellington (RDF-VUW-1103). This work is a contribution to the Roosevelt Island Climate Evolution (RICE) Program, funded by national contributions from New Zealand, Australia, Denmark, Germany, Italy, People's Republic of China, Sweden, United Kingdom and the United States of America. The main logistic support was provided by Antarctica New Zealand (K049) and the US Antarctic Program. 


\subsection{References}

Alexander, M. A., I. Bladé, M. Newman, J. R. Lanzante, N.-C. Lau, and J. D. Scott (2002), The Atmospheric Bridge: The Influence of ENSO Teleconnections on Air-Sea Interaction over the Global Oceans, J. Clim., 15(16), 2205-2231, doi:10.1175/1520-

0442(2002)015<2205:TABTIO>2.0.CO;2.

Ashok, K., S. K. Behera, S. A. Rao, H. Weng, and T. Yamagata (2007), El Niño Modoki and its possible teleconnection, J. Geophys. Res. Ocean., 112(C11), n/a-n/a, doi:10.1029/2006JC003798.

Bertler, N. A. N., T. R. Naish, P. A. Mayewski, and P. J. Barrett (2006a), Opposing oceanic and atmospheric ENSO influences on the Ross Sea Region, Antarctica, Adv. Geosci., 6, 83-86, doi:10.5194/adgeo-6-83-2006.

Bertler, N. A. N., T. R. Naish, H. Oerter, S. Kipfstuhl, P. J. Barrett, P. A. Mayewski, and K. Kreutz (2006b), The effects of joint ENSO\&\#8211;Antarctic Oscillation forcing on the McMurdo Dry Valleys, Antarctica, Antarct. Sci., 18(04), 507-514.

Bracegirdle, T. J., and G. J. Marshall (2012), The Reliability of Antarctic Tropospheric Pressure and Temperature in the Latest Global Reanalyses, J. Clim., 25(20), 7138-7146, doi:10.1175/JCLI-D-11-00685.1.

Bromwich, D. H., and C. J. Weaver (1983), Latitudinal displacement from main moisture source controls $\delta 180$ of snow in coastal Antarctica, Nature, 301(5896), 145-147.

Bromwich, D. H., R. L. Fogt, K. I. Hodges, and J. E. Walsh (2007), A tropospheric assessment of the ERA-40, NCEP, and JRA-25 global reanalyses in the polar regions, J. Geophys. Res. Atmos., 112(D10), 1-21, doi:10.1029/2006JD007859.

Bromwich, D. H., J. P. Nicolas, A. J. Monaghan, M. A. Lazzara, L. M. Keller, G. A. Weidner, and A. B. Wilson (2013), Central West Antarctica among the most rapidly warming regions on Earth, Nat. Geosci, 6(2), 139-145.

Burgener, L. et al. (2013), An observed negative trend in West Antarctic accumulation rates from 1975 to 2010: Evidence from new observed and simulated records, J. Geophys. Res. Atmos., 118(10), 4205-4216, doi:10.1002/jgrd.50362.

Cai, W., P. H. Whetton, and D. J. Karoly (2003), The Response of the Antarctic Oscillation to Increasing and Stabilized Atmospheric CO2, J. Clim., 16(10), 1525-1538, doi:10.1175/1520-0442-16.10.1525.

Cazes-Boezio, G., A. W. Robertson, and C. R. Mechoso (2003), Seasonal Dependence of ENSO Teleconnections over South America and Relationships with Precipitation in Uruguay, $J$. Clim., 16(8), 1159-1176, doi:10.1175/1520-0442(2003)16<1159:SDOETO>2.0.CO;2.

Chen, B., S. R. Smith, and D. H. Bromwich (1996), Evolution of the Tropospheric Split Jet over the South Pacific Ocean during the 1986-89 ENSO Cycle, Mon. Weather Rev., 124(8), 1711-1731, doi:10.1175/1520-0493(1996)124<1711:EOTTSJ>2.0.CO;2.

Chen, X., and J. M. Wallace (2015), ENSO-Like Variability: 1900-2013, J. Clim., 28(24), 96239641, doi:10.1175/JCLI-D-15-0322.1. 
Ciasto, L. M., G. R. Simpkins, and M. H. England (2014), Teleconnections between Tropical Pacific SST Anomalies and Extratropical Southern Hemisphere Climate, J. Clim., 28(1), 56-65, doi:10.1175/JCLI-D-14-00438.1.

Clausen, H. B., W. Dansgaard, J. O. Nielsen, and J. W. Clough (1979), Surface accumulation on Ross Ice Shelf, Antarct. J. United States, 14(5), 68-74.

Cohen, L. (2013), Atmospheric variability and precipitation in the Ross Sea region, Victoria University of Wellington.

Connolley, W. M. (1997), Variability in annual mean circulation in southern high latitudes, Clim. Dyn., 13, 745-756, doi:10.1007/s003820050195.

Cullather, R. I., D. H. Bromwich, and M. L. Van Woert (1996), Interannual variations in Antarctic precipitation related to El Niño-Southern Oscillation, J. Geophys. Res. Atmos., 101(D14), 19109-19118, doi:10.1029/96JD01769.

Dansgaard, W. (1964), Stable isotopes in precipitation, Tellus, 16(4), 436-468, doi:10.1111/j.2153-3490.1964.tb00181.x.

Dee, D. P. et al. (2011), The ERA-Interim reanalysis: configuration and performance of the data assimilation system, Q. J. R. Meteorol. Soc., 137(656), 553-597, doi:10.1002/qj.828.

Deser, C., A. S. Phillips, and J. W. Hurrell (2004), Pacific Interdecadal Climate Variability: Linkages between the Tropics and the North Pacific during Boreal Winter since 1900, $J$. Clim., 17(16), 3109-3124, doi:10.1175/1520-0442(2004)017<3109:PICVLB>2.0.CO;2.

Deser, C., M. A. Alexander, S.-P. Xie, and A. S. Phillips (2010a), Sea surface temperature variability: Patterns and mechanisms, Ann. Rev. Mar. Sci., 2, 115-143.

Deser, C., A. S. Phillips, and M. A. Alexander (2010b), Twentieth century tropical sea surface temperature trends revisited, Geophys. Res. Lett., 37(10), n/a-n/a, doi:10.1029/2010GL043321.

Ding, Q., E. J. Steig, D. S. Battisti, and M. Kuttel (2011), Winter warming in West Antarctica caused by central tropical Pacific warming, Nat. Geosci, 4(6), 398-403.

Ding, Q., E. J. Steig, D. S. Battisti, and J. M. Wallace (2012), Influence of the Tropics on the Southern Annular Mode, J. Clim., 25(18), 6330-6348, doi:10.1175/JCLI-D-11-00523.1.

Emanuelsson, B. D., W. T. Baisden, N. A. N. Bertler, E. D. Keller, and V. Gkinis (2015), Highresolution continuous-flow analysis setup for water isotopic measurement from ice cores using laser spectroscopy, Atmos. Meas. Tech., 8(7), 2869-2883, doi:10.5194/amt-8-28692015.

England, M. H., S. McGregor, P. Spence, G. A. Meehl, A. Timmermann, W. Cai, A. Sen Gupta, M. J. McPhaden, A. Purich, and A. Santoso (2014), Recent intensification of wind-driven circulation in the Pacific and the ongoing warming hiatus, Nat. Clim. Chang., 4(3), 222227.

Fan, T., C. Deser, and D. P. Schneider (2014), Recent Antarctic sea ice trends in the context of Southern Ocean surface climate variations since 1950, Geophys. Res. Lett., 41(7), 24192426, doi:10.1002/2014GL059239. 
Fogt, R. L., and D. H. Bromwich (2006), Decadal variability of the ENSO teleconnection to the high-latitude south pacific governed by coupling with the Southern Annular mode, J. Clim., 19, 979-997, doi:10.1175/JCLI3671.1.

Fogt, R. L., J. Perlwitz, A. J. Monaghan, D. H. Bromwich, J. M. Jones, and G. J. Marshall (2009), Historical SAM Variability. Part II: Twentieth-Century Variability and Trends from Reconstructions, Observations, and the IPCC AR4 Models, J. Clim., 22(20), 5346-5365, doi:10.1175/2009JCLI2786.1.

Folland, C. K., J. A. Renwick, M. J. Salinger, and A. B. Mullan (2002), Relative influences of the interdecadal Pacific oscillation and ENSO on the South Pacific convergence zone, Geophys. Res. Lett., 29(13).

Furtado, J. C., E. Di Lorenzo, B. T. Anderson, and N. Schneider (2012), Linkages between the North Pacific Oscillation and central tropical Pacific SSTs at low frequencies, Clim. Dyn., 39(12), 2833-2846, doi:10.1007/s00382-011-1245-4.

Fyfe, J. C., G. J. Boer, and G. M. Flato (1999), The Arctic and Antarctic oscillations and their projected changes under global warming, Geophys. Res. Lett., 26(11), 1601-1604, doi:10.1029/1999GL900317.

Genthon, C., G. Krinner, and M. Sacchettini (2003), Interannual Antarctic tropospheric circulation and precipitation variability, Clim. Dyn., 21(3), 289-307, doi:10.1007/s00382003-0329-1.

Gill, A. E. (1980), Some simple solutions for heat-induced tropical circulation, Q. J. R. Meteorol. Soc., 106(449), 447-462, doi:10.1002/qj.49710644905.

Gillett, N. P., and D. W. J. Thompson (2003), Simulation of Recent Southern Hemisphere Climate Change, Science (80-. )., 302(5643), 273-275.

Gonfiantini, R. (1978), Standards for stable isotope measurements in natural compounds, Nature, 271(5645), 534-536.

Henley, B. J., J. Gergis, D. J. Karoly, S. Power, J. Kennedy, and C. K. Folland (2015), A Tripole Index for the Interdecadal Pacific Oscillation, Clim. Dyn., 45(11), 3077-3090, doi:10.1007/s00382-015-2525-1.

Hosking, J. S., A. Orr, G. J. Marshall, J. Turner, and T. Phillips (2013), The Influence of the Amundsen-Bellingshausen Seas Low on the Climate of West Antarctica and Its Representation in Coupled Climate Model Simulations, J. Clim., 26(17), 6633-6648, doi:10.1175/JCLI-D-12-00813.1.

Hoskins, B. J., and D. J. Karoly (1981), The Steady Linear Response of a Spherical Atmosphere to Thermal and Orographic Forcing, J. Atmos. Sci., 38(6), 1179-1196, doi:10.1175/15200469(1981)038<1179:TSLROA>2.0.CO;2.

$\mathrm{Hu}$, X., S. Yang, and M. Cai (2016), Contrasting the eastern Pacific El Niño and the central Pacific El Niño: process-based feedback attribution, Clim. Dyn., 1-12, doi:10.1007/s00382015-2971-9.

Jacobel, R. W., B. C. Welch, E. J. Steig, and D. P. Schneider (2005), Glaciological and climatic significance of Hercules Dome, Antarctica: An optimal site for deep ice core drilling, $J$. 
Geophys. Res. Earth Surf., 110(F1), n/a-n/a, doi:10.1029/2004JF000188.

Jin, D., and B. P. Kirtman (2009), Why the Southern Hemisphere ENSO responses lead ENSO, J. Geophys. Res. Atmos., 114(D23), n/a-n/a, doi:10.1029/2009JD012657.

Jin, D., and B. P. Kirtman (2010), How the annual cycle affects the extratropical response to ENSO, J. Geophys. Res. Atmos., 115(D6), n/a-n/a, doi:10.1029/2009JD012660.

Johnsen, S. J., H. B. Clausen, K. M. Cuffey, G. Hoffmann, J. Schwander, and T. Creyts (2000), Diffusion of stable isotopes in polar firn and ice: the isotope effect in firn diffusion, Phys. ice core Rec., 159, 121-140.

Jones, R. W., I. A. Renfrew, A. Orr, B. G. M. Webber, D. M. Holland, and M. A. Lazzara (2016), Evaluation of four global reanalysis products using in-situ observations in the Amundsen Sea Embayment, Antarctica, J. Geophys. Res. Atmos., n/a-n/a, doi:10.1002/2015JD024680.

Kao, H.-Y., and J.-Y. Yu (2009), Contrasting Eastern-Pacific and Central-Pacific Types of ENSO, J. Clim., 22(3), 615-632, doi:10.1175/2008JCLI2309.1.

Karoly, D. J. (1989), Southern Hemisphere Circulation Features Associated with El NiñoSouthern Oscillation Events, J. Clim., 2(11), 1239-1252, doi:10.1175/15200442(1989)002<1239:SHCFAW >2.0.CO;2.

Khider, D., L. D. Stott, J. Emile-Geay, R. Thunell, and D. E. Hammond (2011), Assessing El Niño Southern Oscillation variability during the past millennium, Paleoceanography, 26(3), n/a-n/a, doi:10.1029/2011PA002139.

Kidson, J. W. (1988), Interannual Variations in the Southern Hemisphere Circulation, J. Clim., I(12), 939-953, doi:10.1175/1520-0442(1988)001<1177:IVITSH>2.0.CO;2.

Kim, W., S.-W. Yeh, J.-H. Kim, J.-S. Kug, and M. Kwon (2011), The unique 2009-2010 El Niño event: A fast phase transition of warm pool El Niño to La Niña, Geophys. Res. Lett., 38(15), n/a-n/a, doi:10.1029/2011GL048521.

Kug, J.-S., F.-F. Jin, and S.-I. An (2009), Two Types of El Niño Events: Cold Tongue El Niño and Warm Pool El Niño, J. Clim., 22(6), 1499-1515, doi:10.1175/2008JCLI2624.1.

Küttel, M., E. J. Steig, Q. Ding, A. J. Monaghan, and D. S. Battisti (2012), Seasonal climate information preserved in West Antarctic ice core water isotopes: relationships to temperature, large-scale circulation, and sea ice, Clim. Dyn., 39(7), 1841-1857, doi:10.1007/s00382-012-1460-7.

L'Heureux, M. L., and D. W. J. Thompson (2006), Observed Relationships between the El Niño-Southern Oscillation and the Extratropical Zonal-Mean Circulation, J. Clim., 19(2), 276-287, doi:10.1175/JCLI3617.1.

Lachlan-Cope, T., and W. Connolley (2006), Teleconnections between the tropical Pacific and the Amundsen-Bellinghausens Sea: Role of the El Niño/Southern Oscillation, J. Geophys. Res. Atmos., 111(D23), n/a-n/a, doi:10.1029/2005JD006386.

Larkin, N. K., and D. E. Harrison (2005), Global seasonal temperature and precipitation anomalies during El Niño autumn and winter, Geophys. Res. Lett., 32(16), n/a-n/a, 
doi:10.1029/2005GL022860.

Latif, M., and N. S. Keenlyside (2009), El Niño/Southern Oscillation response to global warming, Proc. Natl. Acad. Sci. , 106 (49 ), 20578-20583.

Lee, S.-K., C. Wang, and B. E. Mapes (2009), A Simple Atmospheric Model of the Local and Teleconnection Responses to Tropical Heating Anomalies, J. Clim., 22(2), 272-284, doi:10.1175/2008JCLI2303.1.

Lee, T., and M. J. McPhaden (2010), Increasing intensity of El Niño in the central-equatorial Pacific, Geophys. Res. Lett., 37(14), n/a-n/a, doi:10.1029/2010GL044007.

Linsley, B. K., P. Zhang, A. Kaplan, S. S. Howe, and G. M. Wellington (2008), Interdecadaldecadal climate variability from multicoral oxygen isotope records in the South Pacific Convergence Zone region since 1650 A.D., Paleoceanography, 23(2), n/a-n/a, doi:10.1029/2007PA001539.

Di Lorenzo, E. et al. (2008), North Pacific Gyre Oscillation links ocean climate and ecosystem change, Geophys. Res. Lett., 35(8), n/a-n/a, doi:10.1029/2007GL032838.

Di Lorenzo, E., G. Liguori, N. Schneider, J. C. Furtado, B. T. Anderson, and M. A. Alexander (2015), ENSO and meridional modes: A null hypothesis for Pacific climate variability, Geophys. Res. Lett., 42(21), 9440-9448, doi:10.1002/2015GL066281.

Mantua, N. J., S. R. Hare, Y. Zhang, J. M. Wallace, and R. C. Francis (1997), A Pacific Interdecadal Climate Oscillation with Impacts on Salmon Production, Bull. Am. Meteorol. Soc., 78(6), 1069-1079, doi:10.1175/1520-0477(1997)078<1069:APICOW>2.0.CO;2.

Marshall, G. J. (2003), Trends in the Southern Annular Mode from Observations and Reanalyses, J. Clim., 16(24), 4134-4143, doi:10.1175/1520-0442(2003)016<4134:TITSAM>2.0.CO;2.

Marshall, G. J., and D. W. J. Thompson (2016), The signatures of large-scale patterns of atmospheric variability in Antarctic surface temperatures, J. Geophys. Res. Atmos., 121(7), 3276-3289, doi:10.1002/2015JD024665.

Marshall, G. J., P. A. Stott, J. Turner, W. M. Connolley, J. C. King, and T. A. Lachlan-Cope (2004), Causes of exceptional atmospheric circulation changes in the Southern Hemisphere, Geophys. Res. Lett., 31(14), n/a-n/a, doi:10.1029/2004GL019952.

Mayewski, P. A. (2005), The International Trans-Antarctic Scientific Expedition (ITASE): An overview, Ann. Glaciol., 41, 180-185.

Meehl, G. A., J. M. Arblaster, C. M. Bitz, C. T. Y. Chung, and H. Teng (2016), Antarctic sea-ice expansion between 2000 and 2014 driven by tropical Pacific decadal climate variability, Nat. Geosci, advance on.

Miller, R. L., G. A. Schmidt, and D. T. Shindell (2006), Forced annular variations in the 20th century Intergovernmental Panel on Climate Change Fourth Assessment Report models, $J$. Geophys. Res. Atmos., 111(D18), n/a-n/a, doi:10.1029/2005JD006323.

Mo, K. C. (2000), Relationships between Low-Frequency Variability in the Southern Hemisphere and Sea Surface Temperature Anomalies, J. Clim., 13(20), 3599-3610, doi:10.1175/1520-0442(2000)013<3599:RBLFVI>2.0.CO;2. 
Mo, K. C., and M. Ghil (1987), Statistics and Dynamics of Persistent Anomalies, J. Atmos. Sci., 44(5), 877-902, doi:10.1175/1520-0469(1987)044<0877:SADOPA>2.0.CO;2.

Mo, K. C., and R. W. Higgins (1998), The Pacific-South American Modes and Tropical Convection during the Southern Hemisphere Winter, Mon. Weather Rev., 126(6), 15811596, doi:10.1175/1520-0493(1998)126<1581:TPSAMA>2.0.CO;2.

Mo, K. C., and J. N. Paegle (2001), The Pacific-South American modes and their downstream effects, Int. J. Climatol., 21(10), 1211-1229, doi:10.1002/joc.685.

Mulvaney, R., N. J. Abram, R. C. a. Hindmarsh, C. Arrowsmith, L. Fleet, J. Triest, L. Sime, O. Alemany, and S. Foord (2012), Recent Antarctic Peninsula warming relative to Holocene climate and ice shelf history, Nature, 488(7414), 141-144, doi:10.1038/nature11391.

Newman, M., G. P. Compo, and M. A. Alexander (2003), ENSO-Forced Variability of the Pacific Decadal Oscillation, J. Clim., 16(23), 3853-3857, doi:10.1175/15200442(2003)016<3853:EVOTPD>2.0.CO;2.

Newman, M. et al. (2016), The Pacific Decadal Oscillation, Revisited, J. Clim., 29(12), 43994427, doi:10.1175/JCLI-D-15-0508.1.

Noone, D., and I. Simmonds (2002), Annular variations in moisture transport mechanisms and the abundance of $\delta 180$ in Antarctic snow, J. Geophys. Res. Atmos., 107(D24), ACL 3-1ACL 3-11, doi:10.1029/2002JD002262.

Nye, J. F. (1963), Correction factor for accumulation measured by the thickness of the annual layers in an ice sheet, J. Glaciol., 4(36), 785-788.

Okumura, Y. M., D. Schneider, C. Deser, and R. Wilson (2012), Decadal-Interdecadal Climate Variability over Antarctica and Linkages to the Tropics: Analysis of Ice Core, Instrumental, and Tropical Proxy Data, J. Clim., 25(21), 7421-7441, doi:10.1175/JCLI-D-12-00050.1.

Pierce, D. W. (2002), The role of sea surface temperatures in interactions between ENSO and the North Pacific Oscillation, J. Clim., 15(11), 1295-1308.

Power, S., T. Casey, C. Folland, A. Colman, and V. Mehta (1999), Inter-decadal modulation of the impact of ENSO on Australia, Clim. Dyn., 15(5), 319-324, doi:10.1007/s003820050284.

Raphael, M. N. (2004), A zonal wave 3 index for the Southern Hemisphere, Geophys. Res. Lett., 31(December), 1-4, doi:10.1029/2004GL020365.

Raphael, M. N., G. J. Marshall, J. Turner, R. Fogt, D. Schneider, D. a. Dixon, J. S. Hosking, J. M. Jones, and W. R. Hobbs (2015), The Amundsen Sea Low: Variability, Change and Impact on Antarctic Climate, Bull. Am. Meteorol. Soc., 150331122920005, doi:10.1175/BAMS-D-14-00018.1.

Rasmusson, E. M., and T. H. Carpenter (1982), Variations in Tropical Sea Surface Temperature and Surface Wind Fields Associated with the Southern Oscillation/El Niño, Mon. Weather Rev., 110(5), 354-384, doi:10.1175/1520-0493(1982)110<0354:VITSST>2.0.CO;2.

Rayner, N. A., D. E. Parker, E. B. Horton, C. K. Folland, L. V Alexander, D. P. Rowell, E. C. Kent, and A. Kaplan (2003), Global analyses of sea surface temperature, sea ice, and night 
marine air temperature since the late nineteenth century, J. Geophys. Res. Atmos., 108(D14), 1-37, doi:10.1029/2002JD002670.

Renwick, J. A. (2005), Persistent Positive Anomalies in the Southern Hemisphere Circulation, Mon. Weather Rev., 133(4), 977-988, doi:10.1175/MWR2900.1.

Rodrigues, R. R., E. J. D. Campos, and R. Haarsma (2015), The Impact of ENSO on the South Atlantic Subtropical Dipole Mode, J. Clim., 28(7), 2691-2705, doi:10.1175/JCLI-D-1400483.1.

Rogers, J. C., and H. van Loon (1982), Spatial Variability of Sea Level Pressure and $500 \mathrm{mb}$ Height Anomalies over the Southern Hemisphere, Mon. Weather Rev., 110(10), 1375-1392, doi:10.1175/1520-0493(1982)110<1375:SVOSLP>2.0.CO;2.

Salinger, M. J., J. A. Renwick, and A. B. Mullan (2001), Interdecadal Pacific Oscillation and South Pacific climate, Int. J. Climatol., 21(14), 1705-1721, doi:10.1002/joc.691.

Santer, B. D., T. M. L. Wigley, J. S. Boyle, D. J. Gaffen, J. J. Hnilo, D. Nychka, D. E. Parker, and K. E. Taylor (2000), Statistical significance of trends and trend differences in layeraverage atmospheric temperature time series, J. Geophys. Res. Atmos., 105(D6), 73377356, doi:10.1029/1999JD901105.

Schneider, D. P., and D. C. Noone (2007), Spatial covariance of water isotope records in a global network of ice cores spanning twentieth-century climate change, J. Geophys. Res. Atmos., 112(D18), n/a-n/a, doi:10.1029/2007JD008652.

Schneider, D. P., E. J. Steig, and T. Van Ommen (2005), High-resolution ice-core stable-isotopic records from Antarctica: Towards interannual climate reconstruction, Ann. Glaciol., 41, 6370, doi:10.3189/172756405781813357.

Schneider, D. P., C. Deser, and Y. Okumura (2011), An assessment and interpretation of the observed warming of West Antarctica in the austral spring, Clim. Dyn., 38(1), 323-347, doi:10.1007/s00382-010-0985-x.

Schneider, D. P., Y. Okumura, and C. Deser (2012), Observed Antarctic Interannual Climate Variability and Tropical Linkages, J. Clim., 25(12), 4048-4066, doi:10.1175/JCLI-D-1100273.1.

Schneider, D. P., C. Deser, and T. Fan (2015), Comparing the Impacts of Tropical SST Variability and Polar Stratospheric Ozone Loss on the Southern Ocean Westerly Winds, J. Clim., 28(23), 9350-9372, doi:10.1175/JCLI-D-15-0090.1.

Seager, R., N. Harnik, W. A. Robinson, Y. Kushnir, M. Ting, H.-P. Huang, and J. Velez (2005), Mechanisms of ENSO-forcing of hemispherically symmetric precipitation variability, $Q$. $J$. R. Meteorol. Soc., 131(608), 1501-1527, doi:10.1256/qj.04.96.

Seager, R., N. Naik, W. Baethgen, A. Robertson, Y. Kushnir, J. Nakamura, and S. Jurburg (2010), Tropical Oceanic Causes of Interannual to Multidecadal Precipitation Variability in Southeast South America over the Past Century, J. Clim., 23(20), 5517-5539, doi:10.1175/2010JCLI3578.1.

Simpkins, G. R., S. McGregor, A. S. Taschetto, L. M. Ciasto, and M. H. England (2014), Tropical Connections to Climatic Change in the Extratropical Southern Hemisphere: The 
Role of Atlantic SST Trends, J. Clim., 27(13), 4923-4936, doi:10.1175/JCLI-D-1300615.1.

Son, S.-W., L. M. Polvani, D. W. Waugh, H. Akiyoshi, R. Garcia, D. Kinnison, S. Pawson, E. Rozanov, T. G. Shepherd, and K. Shibata (2008), The Impact of Stratospheric Ozone Recovery on the Southern Hemisphere Westerly Jet, Science (80-. )., 320(5882), 14861489.

Steig, E. J. et al. (2005), High-resolution ice cores from USITASE (West Antarctica): development and validation of chronologies and determination of precision and accuracy, Ann. Glaciol. Vol 41, 2005, 41, 77-84.

Steig, E. J., Q. Ding, D. S. Battisti, and A. Jenkins (2012), Tropical forcing of circumpolar deep water inflow and outlet glacier thinning in the amundsen sea embayment, west antarctica, Ann. Glaciol., 53(60), 19-28, doi:10.3189/2012AoG60A110.

Steig, E. J. et al. (2013), Recent climate and ice-sheet changes in West Antarctica compared with the past 2,000 years, Nat. Geosci, 6(5), 372-375.

Su, H., and J. H. Jiang (2013), Tropical Clouds and Circulation Changes during the 2006/07 and 2009/10 El Niños, J. Clim., 26(2), 399-413, doi:10.1175/JCLI-D-12-00152.1.

Thomas, E. R., T. J. Bracegirdle, J. Turner, and E. W. Wolff (2013), A 308 year record of climate variability in West Antarctica, Geophys. Res. Lett., 40(20), 5492-5496, doi:10.1002/2013GL057782.

Thompson, D. W. J., and S. Solomon (2002), Interpretation of Recent Southern Hemisphere Climate Change, Science (80-. )., 296(5569), 895-899.

Thompson, D. W. J., and J. M. Wallace (2000), Annular Modes in the Extratropical Circulation. Part I: Month-to-Month Variability*, J. Clim., 13(5), 1000-1016, doi:10.1175/15200442(2000)013<1000:AMITEC>2.0.CO;2.

Thompson, D. W. J., S. Solomon, P. J. Kushner, M. H. England, K. M. Grise, and D. J. Karoly (2011), Signatures of the Antarctic ozone hole in Southern Hemisphere surface climate change, Nat. Geosci, 4(11), 741-749.

Tierney, J. E., N. J. Abram, K. J. Anchukaitis, M. N. Evans, C. Giry, K. H. Kilbourne, C. P. Saenger, H. C. Wu, and J. Zinke (2015), Tropical sea surface temperatures for the past four centuries reconstructed from coral archives, Paleoceanography, 30(3), 226-252, doi:10.1002/2014PA002717.

Trenberth, K. E. (1997), The Definition of El Niño, Bull. Am. Meteorol. Soc., 78(12), 27712777, doi:10.1175/1520-0477(1997)078<2771:TDOENO>2.0.CO;2.

Trenberth, K. E., G. W. Branstator, D. Karoly, A. Kumar, N.-C. Lau, and C. Ropelewski (1998), Progress during TOGA in understanding and modeling global teleconnections associated with tropical sea surface temperatures, J. Geophys. Res. Ocean., 103(C7), 14291-14324, doi:10.1029/97JC01444.

Trenberth, K. E., J. T. Fasullo, G. Branstator, and A. S. Phillips (2014), Seasonal aspects of the recent pause in surface warming, Nat. Clim. Chang., 4(10), 911-916. 
Turner, J. (2004), The El Niño-southern oscillation and Antarctica, Int. J. Climatol., 24(1), 1-31, doi:10.1002/joc.965.

Turner, J., T. Phillips, J. S. Hosking, G. J. Marshall, and A. Orr (2013), The Amundsen Sea low, Int. J. Climatol., 33(7), 1818-1829, doi:10.1002/joc.3558.

Vance, T. R., T. D. Van Ommen, M. a J. Curran, C. T. Plummer, and A. D. Moy (2013), A millennial proxy record of ENSO and eastern Australian rainfall from the law dome ice core, east Antarctica, J. Clim., 26, 710-725, doi:10.1175/JCLI-D-12-00003.1.

Wang, C., C. Deser, J.-Y. Yu, P. DiNezio, and A. Clement (2012), El Nino and southern oscillation (ENSO): a review, Coral Reefs East. Pacific, 3-19.

Wang, L., W. Chen, and R. Huang (2008), Interdecadal modulation of PDO on the impact of ENSO on the east Asian winter monsoon, Geophys. Res. Lett., 35(20), n/a-n/a, doi:10.1029/2008GL035287.

Woollings, T., C. Franzke, D. L. R. Hodson, B. Dong, E. A. Barnes, C. C. Raible, and J. G. Pinto (2014), Contrasting interannual and multidecadal NAO variability, Clim. Dyn., 45(1), 539556, doi:10.1007/s00382-014-2237-y.

Yeh, S.-W., J.-S. Kug, B. Dewitte, M.-H. Kwon, B. P. Kirtman, and F.-F. Jin (2009), El Nino in a changing climate, Nature, 461(7263), 511-514.

Yeo, S.-R., and K.-Y. Kim (2015), Decadal changes in the Southern Hemisphere sea surface temperature in association with El Niño-Southern Oscillation and Southern Annular Mode, Clim. Dyn., 45(11), 3227-3242, doi:10.1007/s00382-015-2535-z.

Yuan, X., and C. Li (2008), Climate modes in southern high latitudes and their impacts on Antarctic sea ice, J. Geophys. Res. Ocean., 113(C6), 1-13, doi:10.1029/2006JC004067. 


\subsection{Supplementary Material}

\section{Supplementary Figures}

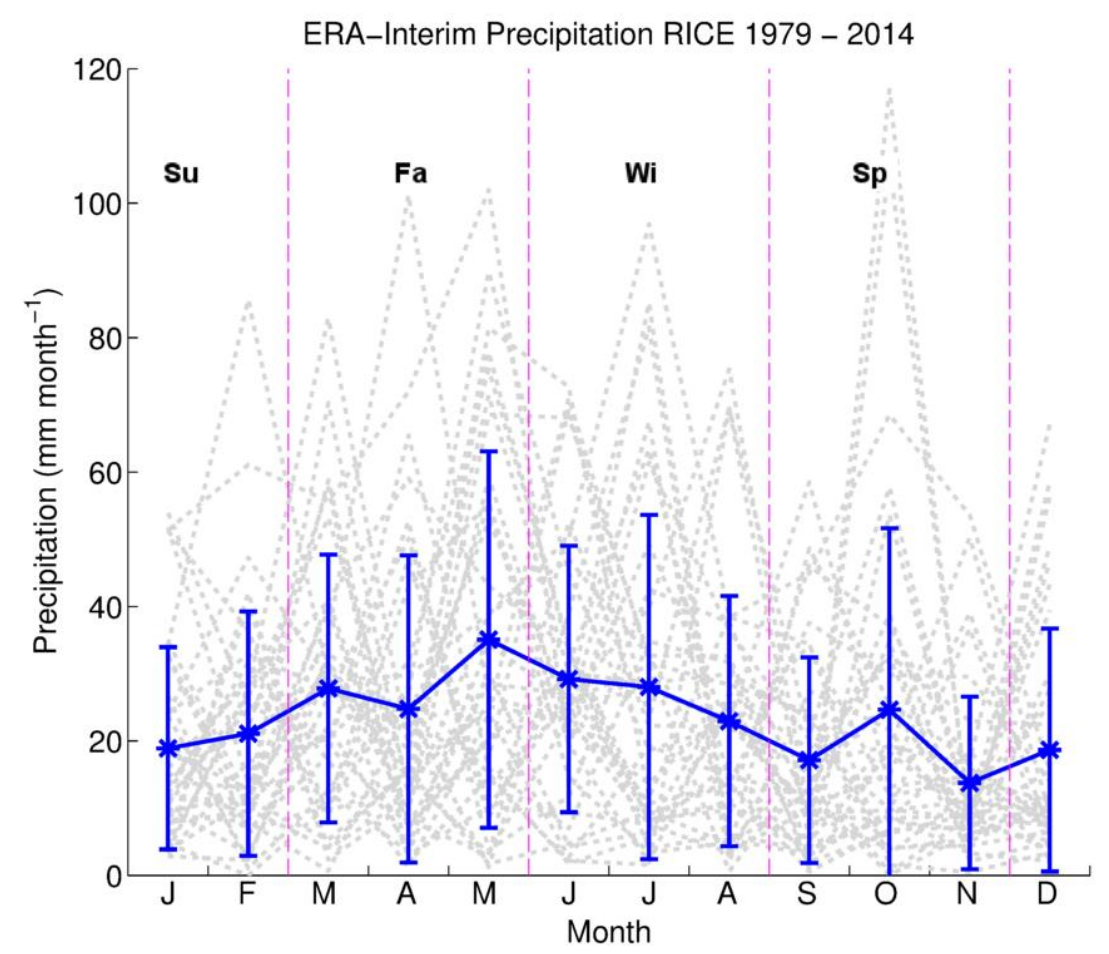

Figure S4.1. Mean monthly RICE ERA-Interim precipitation values (blue asterisks). Vertical bars represent the standard deviations of the mean monthly values and monthly precipitation time series for individual years (gray dashed lines, 1979-2014). 

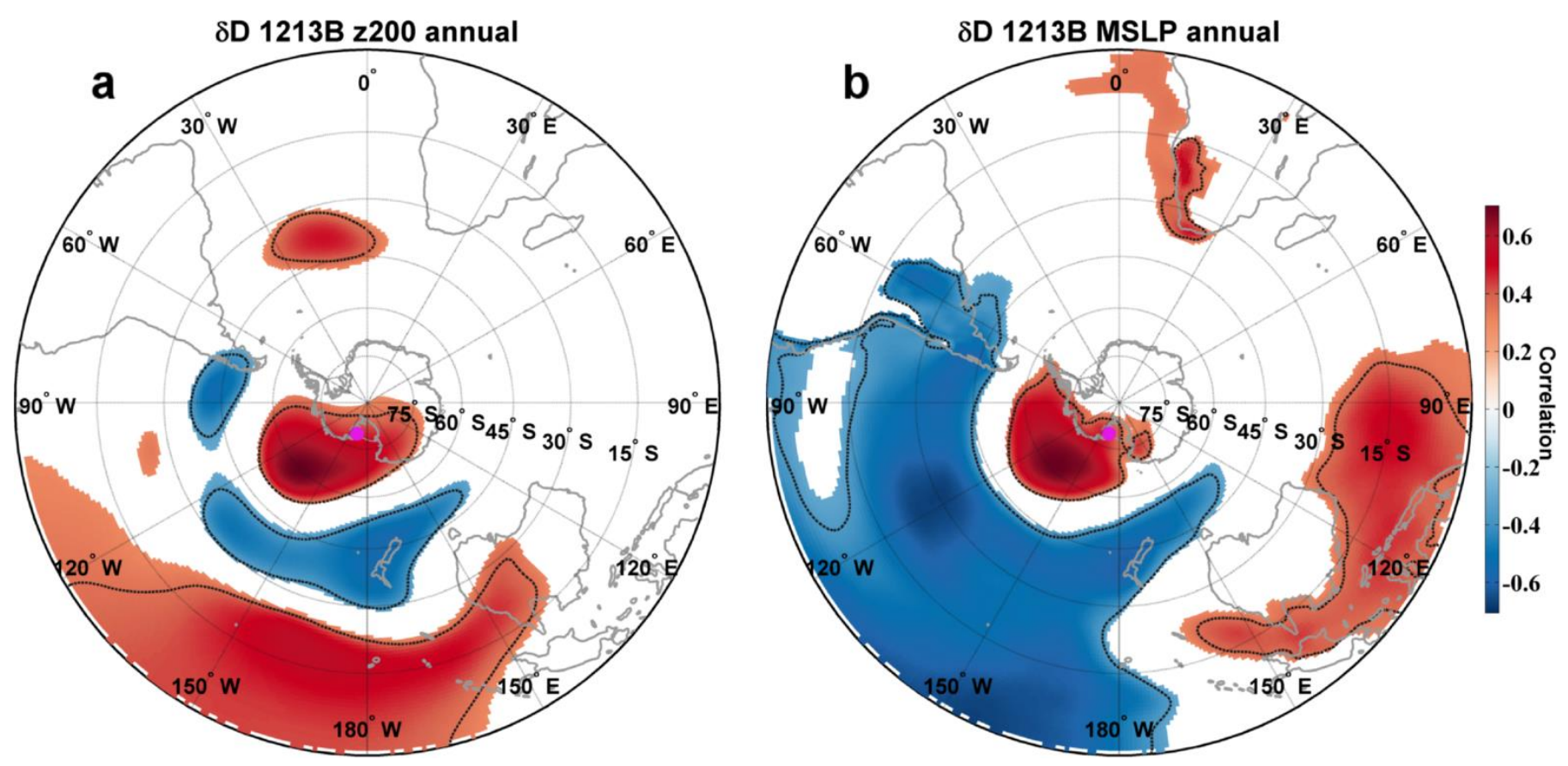

Figure S4.2. Interannual correlation of RICE $\delta D$ (1979-2009) with ERA-Interim (a) 200-hPa geopotential height, and (b) Mean Sea-Level Pressure (MSLP).

Table S4.1. Trends in the three first PC indices: PC1 SAM, PC2 PSA1, and PC3 PSA2 (a) 1980-2014, and (b) 1998-2014

\begin{tabular}{|c|c|c|c|c|c|c|c|}
\hline & & PC1 SAM & & PC2 PSA1 & & PC3 PSA2 & \\
\hline & Range & $\begin{array}{c}\mathrm{r} \\
\left(\text { s.d. decade }{ }^{-1}\right)\end{array}$ & $\mathrm{p}$ & $\begin{array}{c}\mathrm{r} \\
\left(\text { s.d. decade }{ }^{-1}\right)\end{array}$ & $\mathrm{p}$ & $\begin{array}{c}\mathrm{r} \\
(\text { s.d. decade } \\
-1\end{array}$ & $\mathrm{p}$ \\
\hline Annual & $1980-2015$ & 0.15 & $<0.05$ & 0.00 & 0.96 & -0.02 & 0.66 \\
\hline DJF & $1980-2015$ & 0.26 & $<0.05$ & 0.14 & 0.11 & -0.20 & $<0.05$ \\
\hline MAM & $1980-2015$ & 0.28 & $<0.05$ & -0.07 & 0.44 & 0.07 & 0.50 \\
\hline JJA & $1980-2015$ & 0.15 & 0.27 & 0.00 & 1.00 & 0.05 & 0.68 \\
\hline SON & $1980-2015$ & -0.04 & 0.69 & -0.08 & 0.48 & -0.03 & 0.80 \\
\hline
\end{tabular}




\section{Chapter 5: $\quad$ Summary and Conclusions}

\subsubsection{Continuous-Flow Analysis Water Stable Isotope Setup}

A first practical step of this $\mathrm{PhD}$ project was the development of a continuous-flow analysis (CFA) setup for isotope measurements which enabled real time measurement of water isotopes from a continuous sample stream using a laser absorption spectroscopy analyzer. The customized CFA setup enabled us to obtain the fundamental high-resolution RICE $\delta \mathrm{D}$ record. Information is provided on how a commercially available water standard evaporation unit can be modified to facilitate sample introduction, improve temporal resolution, comply with a rigorous (two-point) calibration regime and be integrated with other simultaneous continuous flow analytical methods (e.g. methane). Additionally, it is demonstrated, how this setup can be employed and integrated with other continuous simultaneous analysis equipment during major ice core processing campaigns, e.g. discreet samples for chemical impurities, and the continuous analysis of methane concentration, black carbon, dust particles, $\mathrm{pH}$ and conductivity.

Results are presented that characterize the performance of the laser spectroscopy setup during testing and continuous measurement of water isotopes from the RICE ice core during the ice core processing campaigns. The customized setup is the first continuous flow laser spectroscopy system that is using Off-Axis Integrated Cavity Output Spectroscopy technology (OA-ICOS; analyzer from LGR [Baer et al., 2002]) in combination with an evaporation unit to continuously analyze sample from an ice core. Response time tests and stability tests, demonstrated that the custom setups are more responsive (shorter response time, $\sim 54 \mathrm{~s}$ and $18 \mathrm{~s}$ for the 2013 and 2014 custom setups, respectively), while the cavity ring-down spectroscopy (CRDS) University of Copenhagen (UC) setup is more stable. For the custom 2013 setup $\delta^{18} \mathrm{O}$ is drift sensitive compared to $\delta \mathrm{D}$, with corresponding Allan deviation values of 0.30 and $0.21 \%$ for $\delta^{18} \mathrm{O}$ and $\delta \mathrm{D}$, respectively, after $10^{4} \mathrm{~s}(2.78 \mathrm{~h})$. When calculating secondary parameters, such as d-excess and ${ }^{17} \mathrm{O}$-excess, a system that is optimized for stability, such as the UC setup, has an advantage the customized setup. 


\subsubsection{The Role of Anticyclonic Activity for WA Air Mass Intrusions}

Persistent positive anomalies in 500-hPa geopotential height fields from the ECMWF ERAInterim reanalysis are used to quantify Amundsen-Bellingshausen Sea anticyclonic and cyclonic event occurrences associated with subsequent WA precipitation. Intermittent, low-frequency anticyclones are shown to play a key role in the ABS in providing enhanced non-zonal transport, associated with heat and moisture advection into WA, affecting surface climate, precipitation rates and isotopic signatures.

RICE is sensitive to one predominant circulation center in the Amundsen Sea, and shows a significant correlation with ASL and SAM as RICE predominantly receives high accumulation and enriched isotopes when the ASL is anomalously weak. RICE is sheltered from direct moisture input from Amundsen Sea cyclonic conditions by prominent Marie Byrd Land topography. In contrast, for the majority of WA sites high accumulation amounts and enriched isotopic signatures can be received when the ASL is either anomalously high or low. This makes the climate signal for these regions more complex, and explains the lack of, or intermittent correlation with ENSO indices. The RICE accumulation and $\delta \mathrm{D}$ records' significant correlation with climate variables, therefore, helps to unravel air mass intrusion mechanisms that apply for all of WA. Even so, the correlation pattern often is masked at WA sites.

\subsubsection{Tropical Pacific Forcings Impact on RICE Isotopic Signature}

In this thesis, the drivers behind the RICE water-isotope $(\delta \mathrm{D})$ data have been characterized. RICE $\delta$ D correlation with SST displays a significant pattern over the central-tropical Pacific, which contains the Niño-4 SST region. SST anomalies in the Niño-4 region are commonly regarded to force CP-ENSO variability. Amundsen Sea anticyclones are associated with El Niño and a positive PSA1 pattern. Amundsen Sea anticyclones impede zonal westerly winds and convey the blocked westerly flow towards western Marie Byrd Land/eastern Ross Sea. These conditions cause increased precipitation and an enriched $\delta$ D-signal at RICE. During La Niña and Amundsen Sea cyclones, $\delta \mathrm{D}$ is depleted. Thus, RICE $\delta \mathrm{D}$ preserves ENSO variability. RICE $\delta \mathrm{D}$ appears to preserve interdecadal tropical Pacific El Niño-like and Pacific-wide Interdecadal Pacific Oscillation (IPO) variability. However, these two indices appear to be similar as they are strongly correlated [Newman et al., 2016]. On decadal-scales RICE $\delta$ D is modulated by ENSO 
and SAM; if the correlation with SAM is active, $\delta \mathrm{D}$ appears to be in a depleted state (during positive IPO polarity) and when the influence with SAM breaks down (negative IPO), $\delta \mathrm{D}$ appears to be in a relatively enriched state. SAM appears to have become a stronger RICE $\delta \mathrm{D}$ modulator (during positive IPO phases) due to its positive trend.

The interaction and interference between PSA1 and PSA2 wave trains vary seasonally and spatially. The PSA2 wave train is strong in austral summer (DJF) and fall (MAM) and the highlatitude influence from PSA1 increases throughout the year, with a peak in spring. The PSA seesaw patterns coincide over vast regions of the Pacific sector: the central high-latitudes and the subtropical Pacific $\left(30^{\circ} \mathrm{S}\right.$, particularly in DJF). The destructive (dampening effect from PSA pattern with SST of opposing signs) interference from PSA2 on the PSA1-ENSO signal is reduced during the latter part of the year (JJA and SON). This is because the polar front jet, associated with PSA2, becomes weak in comparison to the subtropical jet (associated with PSA1), as the subtropical jet strengthens during the latter part of the year. PSA2, thus, appears to lose its ability to cancel-out SST anomalies linked to PSA1. Therefore, a relatively unperturbed PSA1-ENSO signal can propagate southward to the extratropics and Antarctica in spring (SON), which is the most mature ENSO season out of JJA and SON. In addition to a weaker DJF ENSO signal caused by a weak subtropical jet [Jin and Kirtman, 2009; Ding et al., 2012; Schneider et al., 2012; Ciasto et al., 2014], the strength of the ENSO (PSA1) signal appears to be reduced further by a seasonally pronounced high-latitude destructive interaction (dampening of SST) caused by interference between the PSA patterns. Thus, combined, these effects provide a compelling explanation to the weak ENSO (PSA1) signal in the extratropics and Antarctica in austral summer, compared to spring.

A RICE $\delta \mathrm{D}$ proxy reconstruction provides a record longer than currently available from observational datasets, potentially allowing for examination of intrinsic decadal-scale tropical Pacific climate variability and its extratropical impact. However, our ability to evaluate the significance of the RICE $\delta$ D-Pacific decadal relationship is hampered, by the brevity of the observational records and the nature of the low-frequency variability, which requires extended datasets to assess significance. Thus, these findings warrant further investigation. 


\subsection{Outlook}

Studies have demonstrated that tropical Pacific ENSO-like SH high-latitude teleconnections in addition to interannual variability are associated with intrinsic decadal climate variability [Bromwich et al., 2000; Fogt and Bromwich, 2006] that likely influence Antarctic climate through similar mechanisms as on interannual timescales [Garreaud and Battisti, 1999; Mo, 2000; Salinger et al., 2001; Okumura et al., 2012]. However, low-frequency variability influences on SH high latitudes are not well understood, mainly due to paucity of long Antarctic observational records. Future work could involve using the RICE water stable isotope record as a proxy to reconstruct the CTP SST influence on Antarctic climate variability through time. The RICE $\delta \mathrm{D}$ can provide a longer record, than is currently available from the reanalysis satellite-era datasets (36 years), which allow us to examine the nature of the low-frequency (on interdecadal and longer time scale) tropical Pacific ENSO-like climate variabilities impact on Antarctic climate.

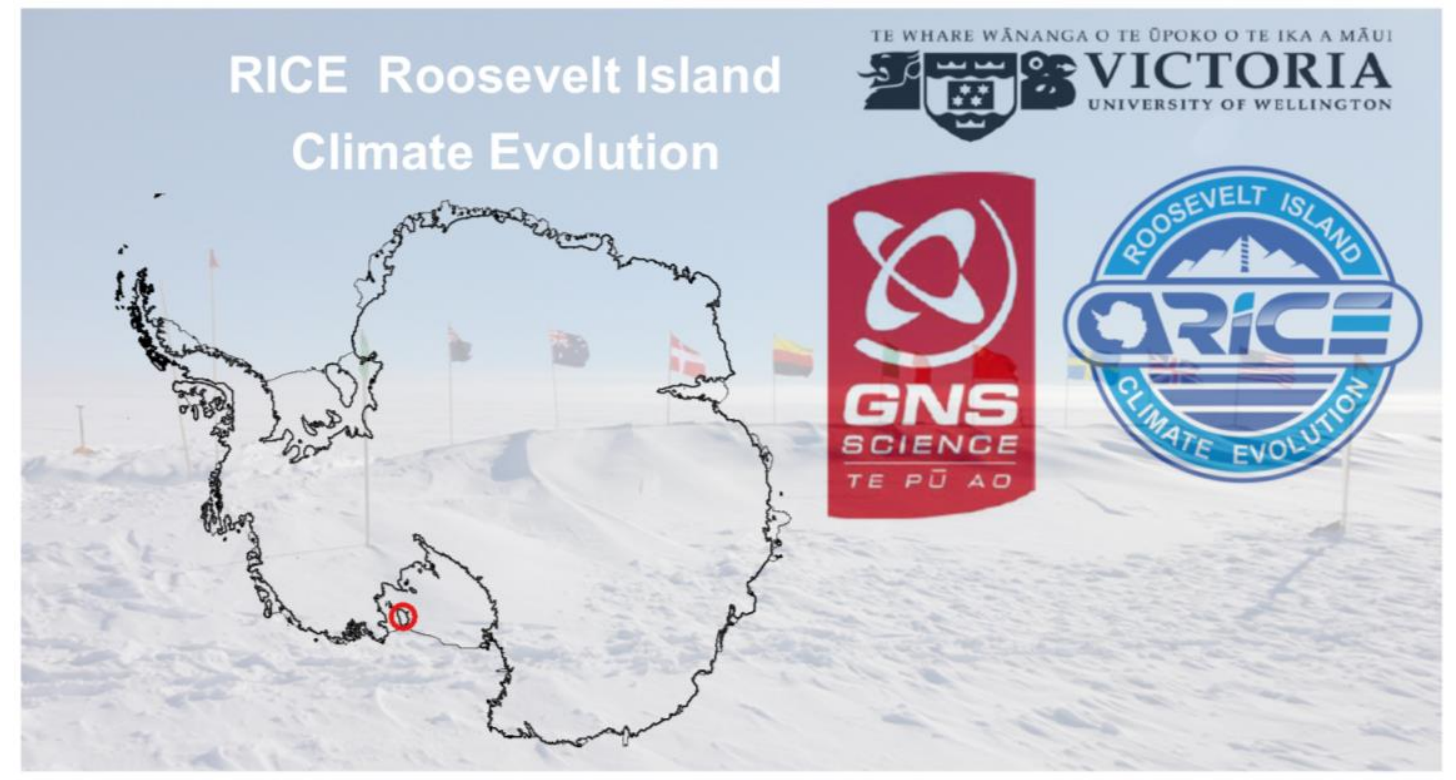




\subsection{References}

Baer, D. S., J. B. Paul, M. Gupta, and a. O’Keefe (2002), Sensitive absorption measurements in the near-infrared region using off-axis integrated-cavity-output spectroscopy, Appl. Phys. B Lasers Opt., 75, 261-265, doi:10.1007/s00340-002-0971-z.

Bromwich, D. H., A. N. Rogers, P. Kållberg, R. I. Cullather, J. W. C. White, and K. J. Kreutz (2000), ECMWF Analyses and Reanalyses Depiction of ENSO Signal in Antarctic Precipitation*, J. Clim., 13(8), 1406-1420, doi:10.1175/15200442(2000)013<1406:EAARDO>2.0.CO;2.

Ciasto, L. M., G. R. Simpkins, and M. H. England (2014), Teleconnections between Tropical Pacific SST Anomalies and Extratropical Southern Hemisphere Climate, J. Clim., 28(1), 56-65, doi:10.1175/JCLI-D-14-00438.1.

Deser, C., M. A. Alexander, S.-P. Xie, and A. S. Phillips (2010), Sea surface temperature variability: Patterns and mechanisms, Ann. Rev. Mar. Sci., 2, 115-143.

Ding, Q., E. J. Steig, D. S. Battisti, and J. M. Wallace (2012), Influence of the Tropics on the Southern Annular Mode, J. Clim., 25(18), 6330-6348, doi:10.1175/JCLI-D-11-00523.1.

Fogt, R. L., and D. H. Bromwich (2006), Decadal variability of the ENSO teleconnection to the high-latitude south pacific governed by coupling with the Southern Annular mode, J. Clim., 19, 979-997, doi:10.1175/JCLI3671.1.

Garreaud, R., and D. S. Battisti (1999), Interannual (ENSO) and Interdecadal (ENSO-like) Variability in the Southern Hemisphere Tropospheric Circulation*, J. Clim., 12(7), 21132123, doi:10.1175/1520-0442(1999)012<2113:IEAIEL>2.0.CO;2.

Gregory, S., and D. Noone (2008), Variability in the teleconnection between the El NiñoSouthern Oscillation and West Antarctic climate deduced from West Antarctic ice core isotope records, J. Geophys. Res. Atmos., 113(D17), n/a-n/a, doi:10.1029/2007JD009107.

Jin, D., and B. P. Kirtman (2009), Why the Southern Hemisphere ENSO responses lead ENSO, J. Geophys. Res. Atmos., 114(D23), n/a-n/a, doi:10.1029/2009JD012657.

Kidson, J. W. (1988), Interannual Variations in the Southern Hemisphere Circulation, J. Clim., 1(12), 939-953, doi:10.1175/1520-0442(1988)001<1177:IVITSH>2.0.CO;2.

Mo, K. C. (2000), Relationships between Low-Frequency Variability in the Southern Hemisphere and Sea Surface Temperature Anomalies, J. Clim., 13(20), 3599-3610, doi:10.1175/1520-0442(2000)013<3599:RBLFVI>2.0.CO;2.

Newman, M. et al. (2016), The Pacific Decadal Oscillation, Revisited, J. Clim., 29(12), 43994427, doi:10.1175/JCLI-D-15-0508.1.

Okumura, Y. M., D. Schneider, C. Deser, and R. Wilson (2012), Decadal-Interdecadal Climate Variability over Antarctica and Linkages to the Tropics: Analysis of Ice Core, Instrumental, and Tropical Proxy Data, J. Clim., 25(21), 7421-7441, doi:10.1175/JCLI-D-12-00050.1.

Salinger, M. J., J. A. Renwick, and A. B. Mullan (2001), Interdecadal Pacific Oscillation and South Pacific climate, Int. J. Climatol., 21(14), 1705-1721, doi:10.1002/joc.691. 
Schneider, D. P., Y. Okumura, and C. Deser (2012), Observed Antarctic Interannual Climate Variability and Tropical Linkages, J. Clim., 25(12), 4048-4066, doi:10.1175/JCLI-D-1100273.1.

Trenberth, K. E., G. W. Branstator, D. Karoly, A. Kumar, N.-C. Lau, and C. Ropelewski (1998), Progress during TOGA in understanding and modeling global teleconnections associated with tropical sea surface temperatures, J. Geophys. Res. Ocean., 103(C7), 14291-14324, doi:10.1029/97JC01444.

Turner, J. (2004), The El Niño-southern oscillation and Antarctica, Int. J. Climatol., 24(1), 1-31, doi:10.1002/joc.965. 